\title{
Análise de Desempenho de Algoritmos Paralelos Utilizando Plataformas de Portabilidade
}

\author{
Adriana Molina Centurion
}

Orientador: Prof ${ }^{\mathrm{a}}$. Dr ${ }^{\mathrm{a}}$. Regina Helena Carlucci Santana

Dissertação apresentada ao Instituto de Ciências Matemáticas e d Computação da Universidade de São Paulo - ICMC/USP, como parte do requisitos para a obtenção do título de Mestre em Ciências - Área: Ciências de Computação e Matemática Computacional.

USP - São Carlos

Dezembro de 1998 
Dedico este trabalho a meus pais, Evani e Emilio, que sempre me cercam de amizade e companheirismo. Sem o carinho, a confiança e o apoio a mim dedicados, nada disso seria possivel. 


\section{Agradecimentos}

À Profa. Dra. Regina Helena Carlucci Santana, pela paciência, pela orientação, tanto acadêmica como pessoal, e principalmente pela amizade.

Ao Prof. Dr. Marcos José Santana, pelo incentivo, amizade e companheirismo.

Aos amigos Paulo Sérgio, Márcio e Luciano pelo apoio e pelas contribuições feitas a este trabalho.

Aos amigos que fiz durante o mestrado, sobretudo às pessoas do grupo de Sistemas Distribuídos e Programação Concorrente, pelos momentos descontraídos que passamos juntos.

A todos os funcionários, que direta ou indiretamente, colaboraram para a realização deste trabalho. Um agradecimento especial à Adriana e à Sandra, da seção de bolsas, pela assistência e ao Rogério, do Centro de Informática de São Carlos - CISC, pela colaboração e paciência.

Ao CNPQ e à FAPESP, pelo apoio financeiro.

E principalmente, aos meus pais, que me apoiaram e me incentivaram nos momentos mais difíceis. 


\section{Resumo}

Este trabalho apresenta uma avaliação de desempenho das plataformas de portabilidade PVM e MPI quando executadas em um sistema computacional distribuído e na máquina paralela.IBM SP2. Essa análise é feita através do desenvolvimento de vários algoritmos paralelos de ordenação. São utilizadas quatro implementações do MPI e do PVM: IBM MPI, IBM PVMe (ambas executadas no SP2); MPICH e PVM (ambas executadas no sistema computacional distribuído).

Os algoritmos paralelos foram desenvolvidos e os resultados obtidos são usados para estabelecer uma comparação entre os diferentes ambientes e entre os diversos algoritmos de ordenação implementados. Os algoritmos seqüenciais foram também avaliados, permitindo analisar o "speedup" para a execução das aplicações paralelas implementadas em cada plataforma.

Os resultados globais obtidos tornam possivel verificar-se e demonstrar-se (para o ambiente particular considerado) que o PVM apresenta melhor desempenho em ambientes computacionais distribuídos e o MPI se comporta mais adequadamente em arquiteturas paralelas. 


\section{Abstract}

This work presents a performance evaluation of the portability platforms PVM and MPI when running on both a distributed computing system and a parallel architecture the IBM SP2. The evaluation is performed on the implementation of a number of sorting parallel algorithms. Four implementation of MPI and PVM are considered: the IBM MPI and the IBM PVMe (both running in the SP2); the MPICH and the PVM (both running in a distributed computing system).

The parallel algorithms were developed and the results obtained are used to establish a comparison between the different environments and between the several sorting algorithms implemented. The sequential algorithms were also analysed allowing the speedup evaluation for the execution in each environment.

The global results obtained make possible to verify and to demonstrate (for the particular environment considered) that the PVM presents better performance in distributed computing environment and the MPI behaves more adequately in parallel architectures. 


\section{Sumário}

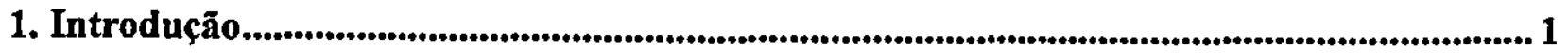

2. Programação Concorrente...............................................................................................5

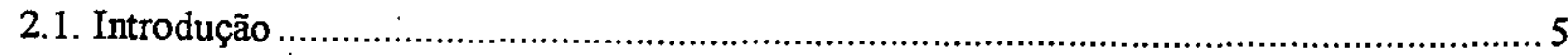

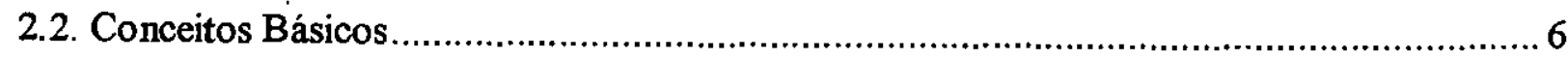

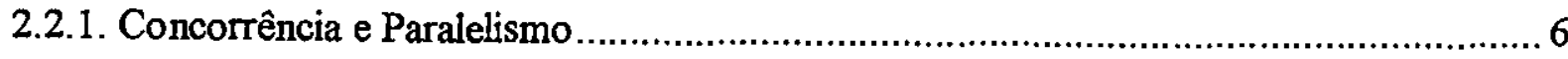

2.2.2. Granulação

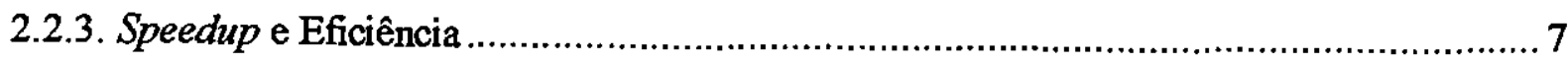

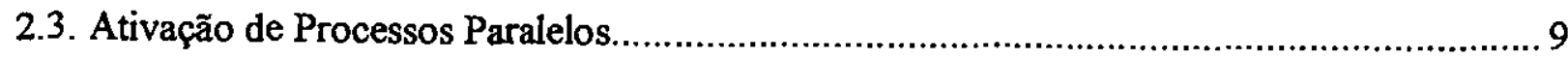

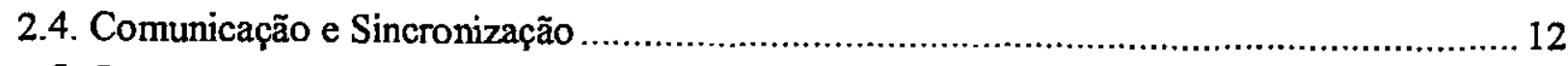

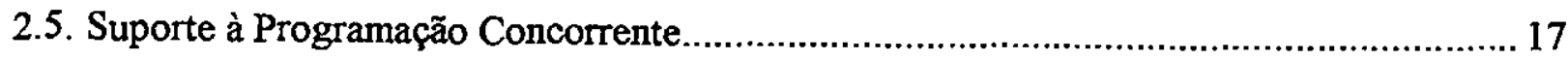

2.6. Plataformas de Portabilidade

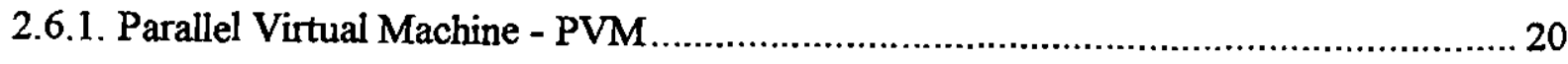

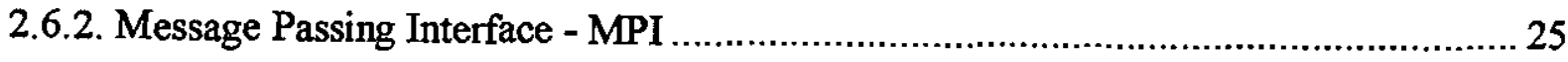

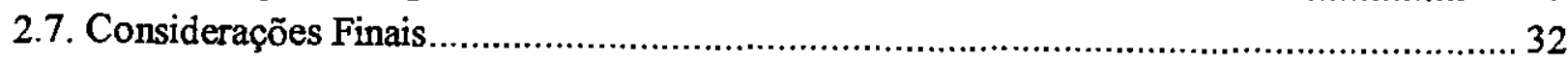

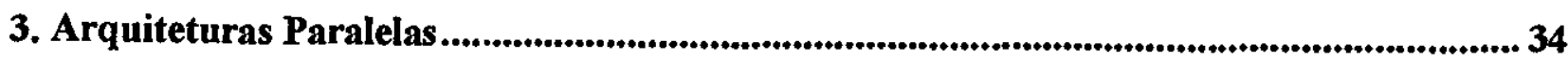

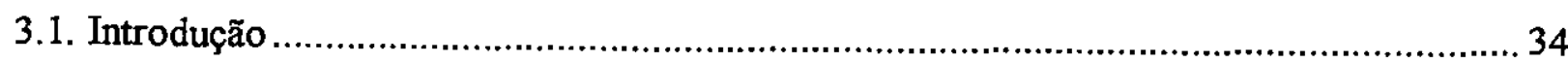

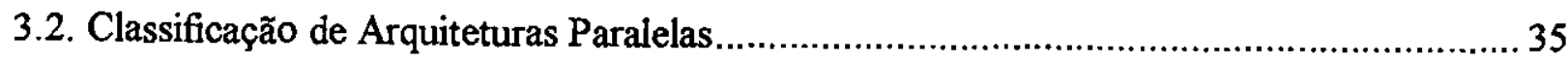

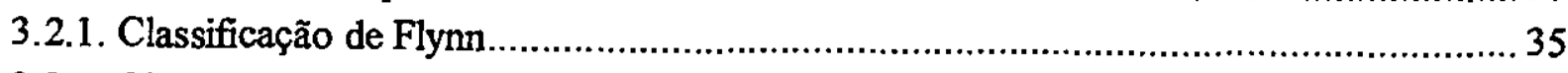

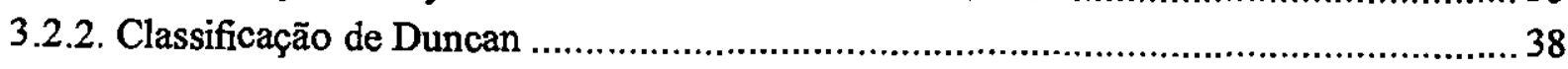

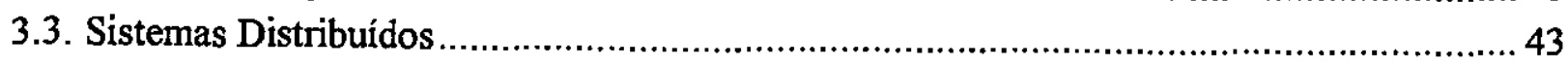

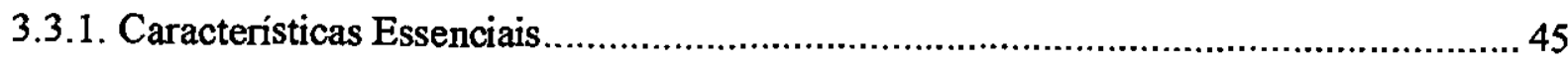

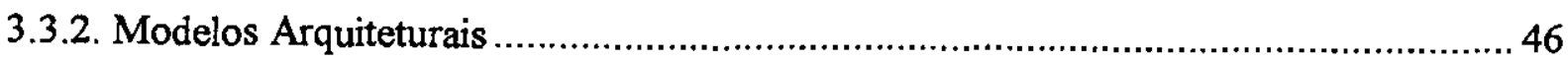

3.3.3. Programação Paralela em Sistemas Distribuídos........................................................ 49

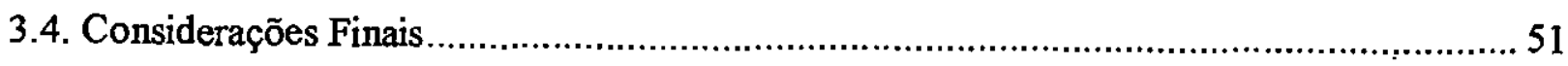

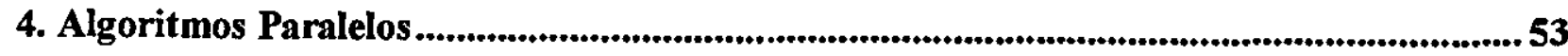

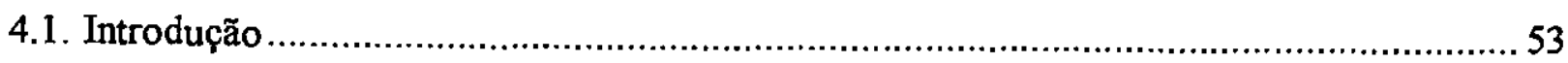

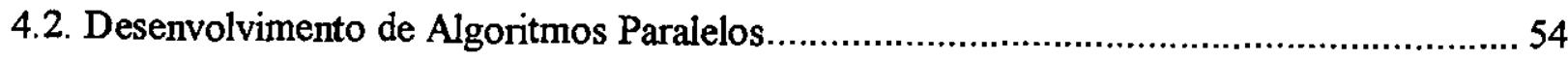

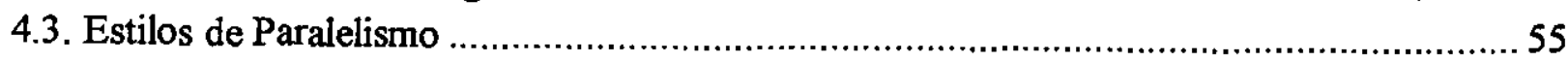

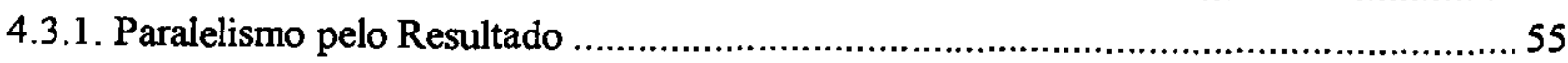

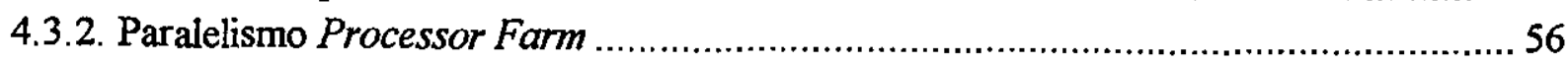

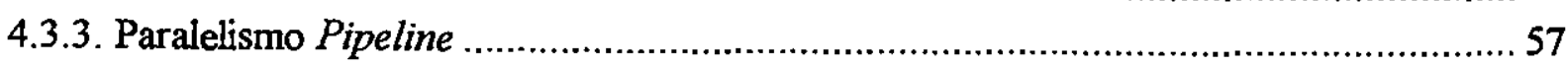

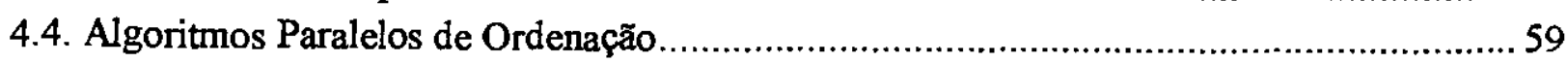

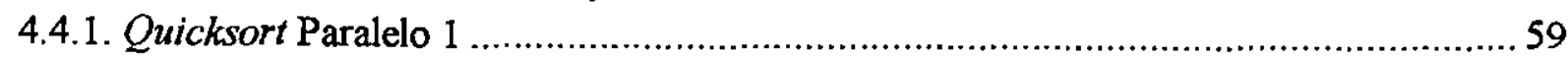

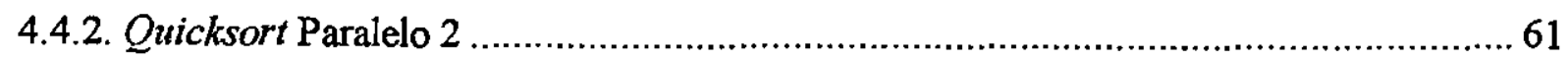


4.4.3. Select Sort

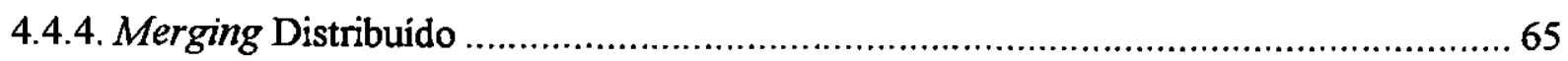

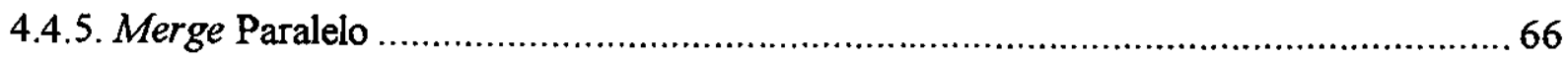

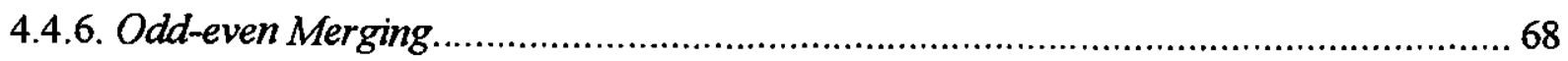

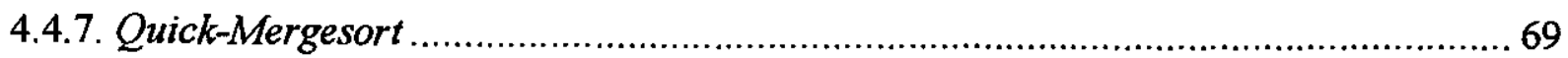

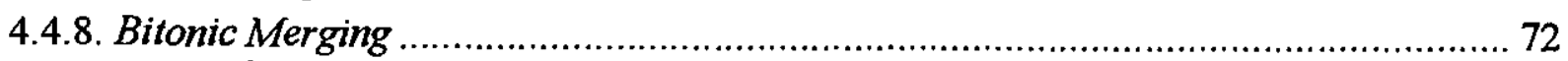

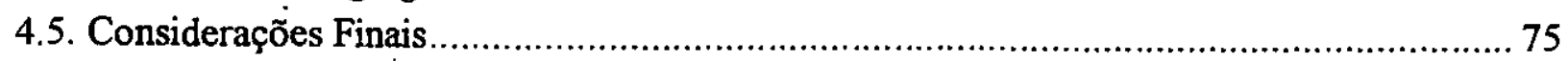

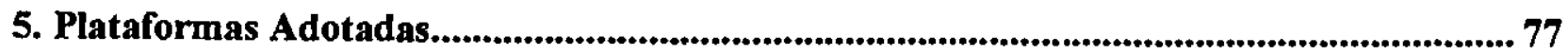

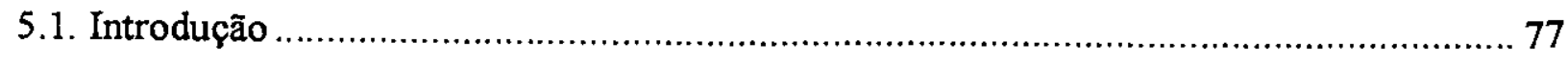

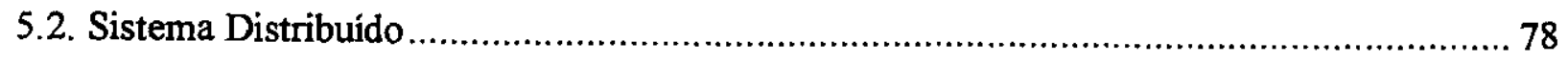

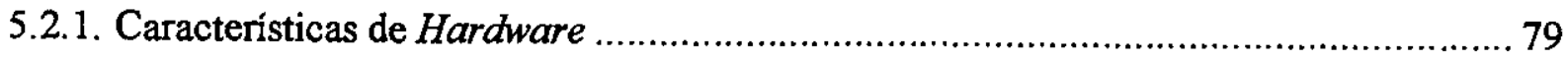

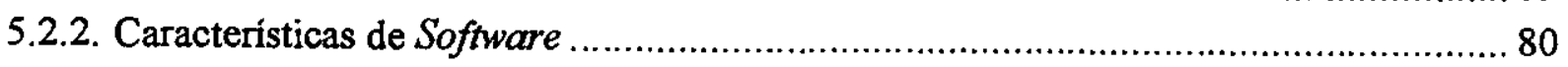

5.3. SP2 - Scalable POWERparallel System 2 …..................................................... 90

5.3.1. Arquitetura do Processador POWER2 …..................................................... 91

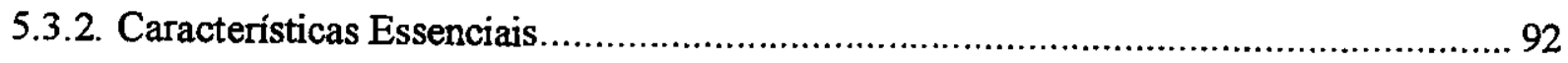

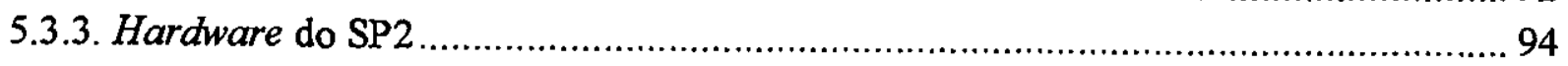

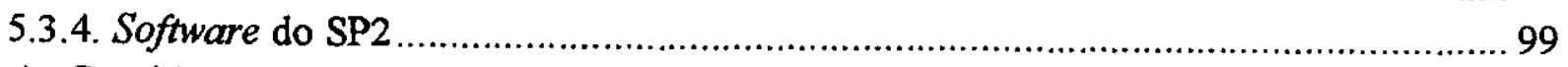

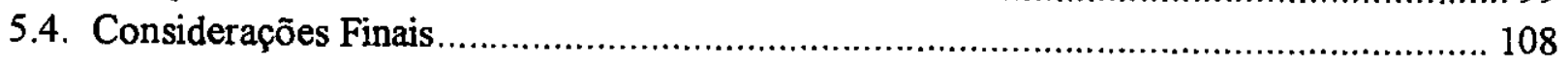

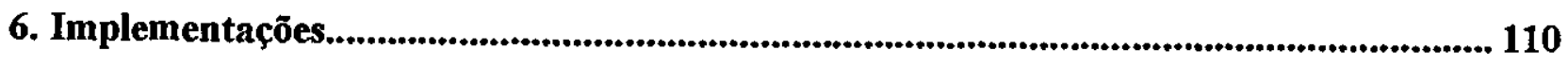

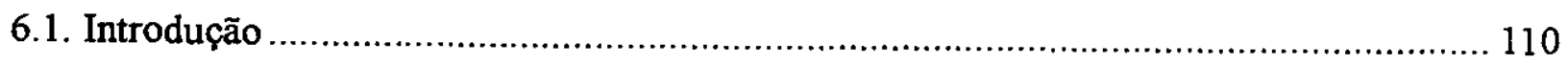

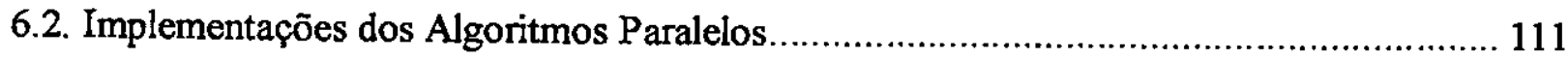

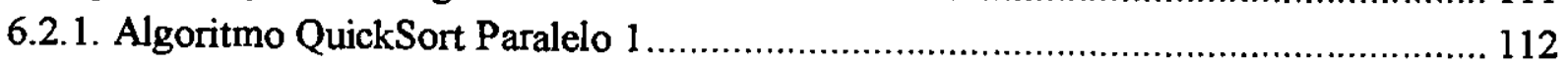

6.2.2. Algoritmo QuickSort Paralelo 2 ................................................................. 114

6.2.3. Algoritmo QuickSort Paralelo 2.1 ............................................................. 116

6.2.4. Algoritmo Merge Paralelo ....................................................................... 117

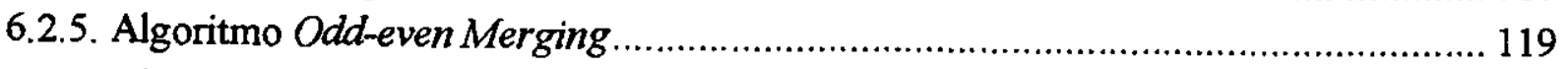

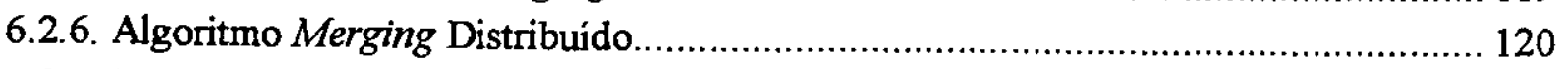

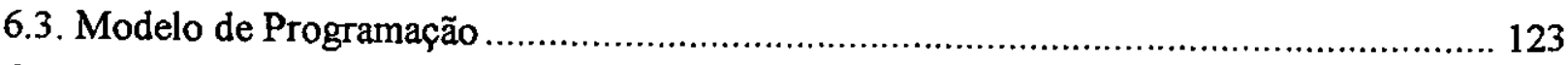

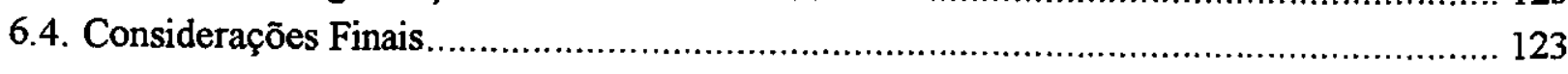

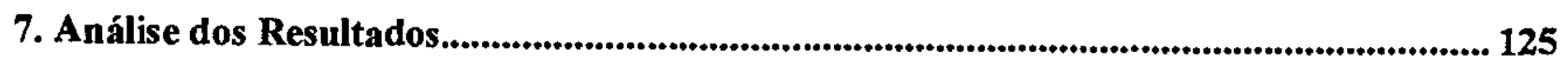

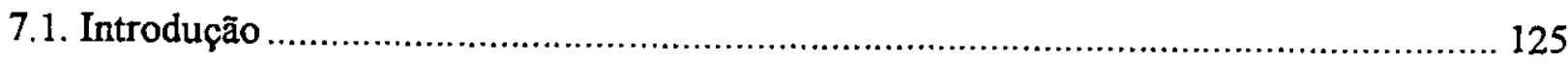

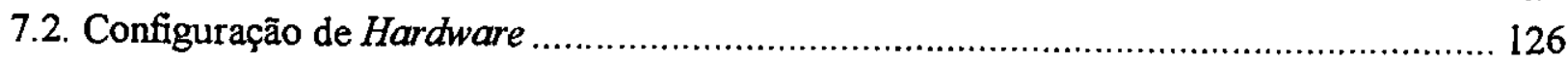

7.3. Medida de Avaliação de Desempenho ................................................................. 129

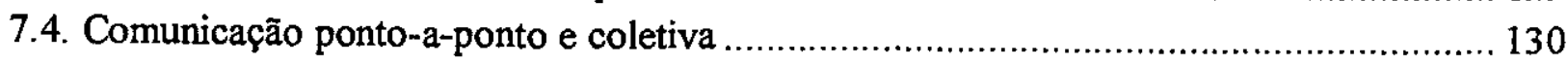

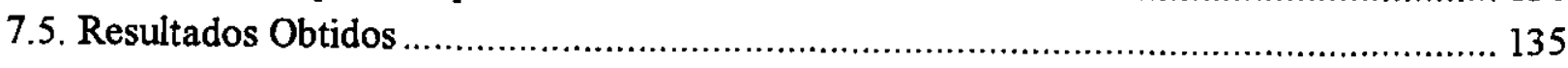

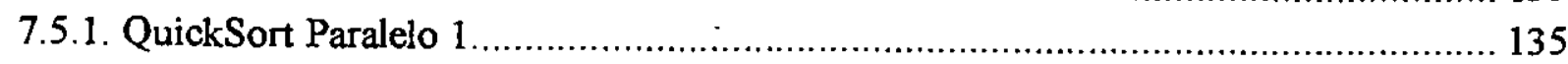

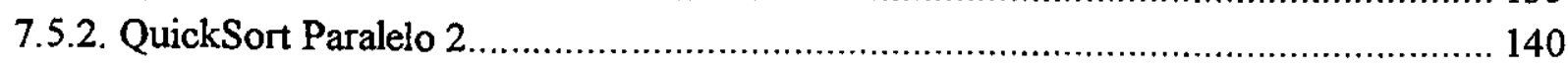

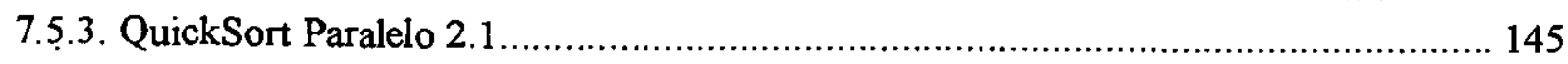


7.5.4. Merge Paralelo

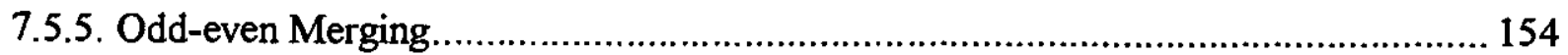

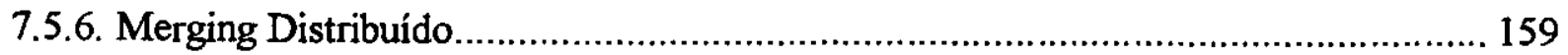

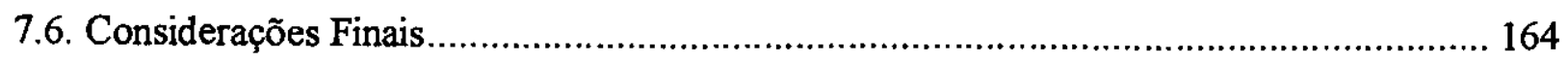

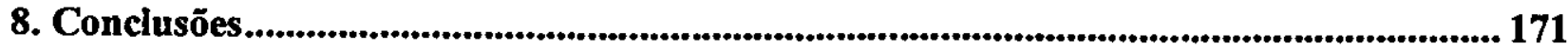

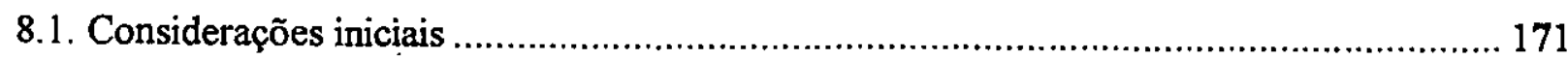

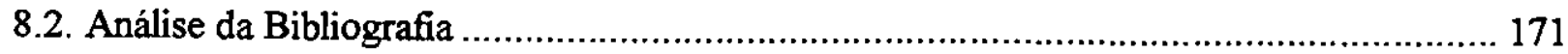

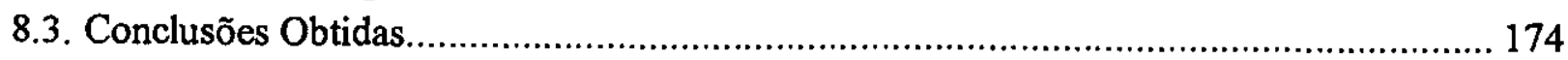

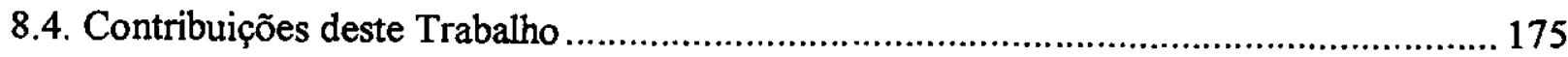

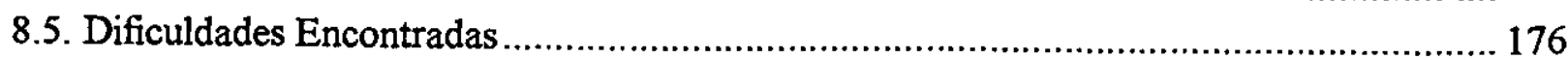

8.6. Sugestões para Trabalhos Futuros.......................................................................... 177

Referências Bibliográficas ................................................................................................ 179 


\section{Índice de Figuras}

Figura 2.1 - Exemplo da Utilização de Co-rotinas. ............................................................ 9

Figura 2.2 - Exemplo da Utilização de Cobegin/Coend ................................................... 10

Figura 2.3 - Exemplo da Utilização dos comandos Fork/Join. ........................................... 11

Figura 2.4 - Exemplo da Utilização de Doall. ........................................................... 12

Figura 2.5 - Send/Receive. (a) Bloqueante (b) Não Bloqueante ....................................... 15

Figura 2.6 - Mecanismos de Comunicação. (a) Ponto-a-Ponto (b) Rendezvous.................... 15

Figura 2.7 - Mecanismo de Comunicação RPC............................................................ 16

Figura 2.8 - PVM - Modelo Computacional ............................................................. 22

Figura 2.9 - Exemplo da Rotina broadcast( ) ............................................................. 30

Figura 2.10 - Exemplo da Rotina reduce () .................................................................. 31

Figura 2.11 - Exemplo da Rotinas scatter() e gather() .................................................. 32

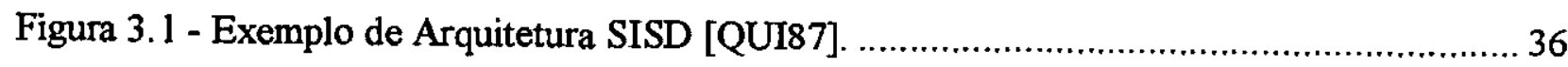

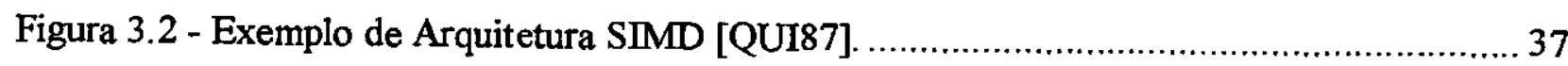

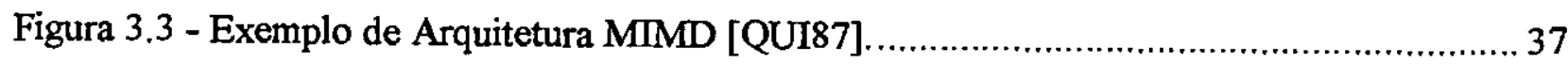

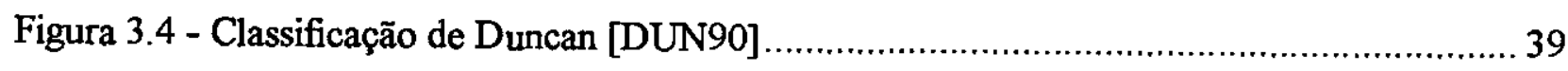

Figura 3.5 - Arquitetura MIMD. (a) Mem. Compartilhada (b) Mem. Distribuída .................... 41

Figura 3.6 - Modelo Arquitetural Estação de Trabalho/Servidor [COU88] ............................. 47

Figura 3.7 - Modelo Arquitetural Banco de Processadores [COU88] ...................................... 47

Figura 3.8 - Modelo Arquitetural Híbrido [COU88] ...................................................... 48

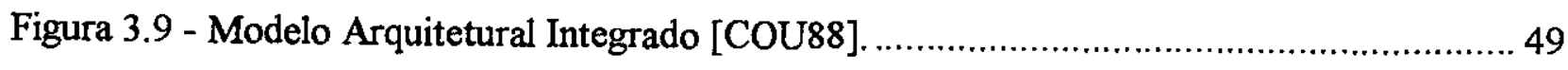

Figura 4.1. - Paralelismo pelo Resultado - pintura de uma casa ........................................... 56

Figura 4.2. - Paralelismo Processor Farm - construção de uma casa ..................................... 57

Figura 4.3. - Paralelismo Pipeline - projeto de uma casa ..................................................... 58

Figura 4.4. - Execução do Algoritmo Quicksort Paralelo 1 ...................................................6 60

Figura 4.5 - Execução do Algoritmo Quicksort Paralelo 2 ...................................................62

Figura 4.6 - Execução do Algoritmo Merging Distribuido .................................................66

Figura 4.7 - Execução do Algoritmo Merge Paralelo ........................................................... 67

Figura 4.8 - Execução do Algoritmo Odd-even Merging …..................................................69

Figura 4.9 - Um Hipercubo Tridimensional................................................................... 70

Figura 4.10 - Distribuição dos Dados em um Hipercubo Tridimensional ................................... 71 
Figura 4.11 - Intercalação das Sublistas Ordenadas em um Hipercubo ..................................... 71

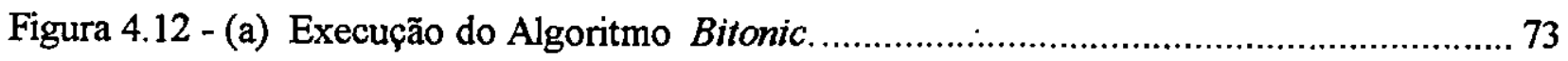

Figura 4.12 - (b) Classificação Bitonic para um Hipercubo Tridimensional …........................ 73

Figura 4.13 - Execução do Algoritmo Bitonic Merging..................................................... 74

Figura 5.1 - Os pvmds executando em todos os hosts da máquina virtual................................. 84

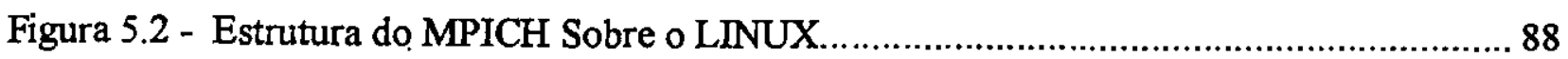

Figura 5.3 - Estrutura do MPICH Sobre o Dispositivo ch_p4 ................................................. 89

Figura 5.4 - Arquitetura de Processadores POWER2 …..................................................... 93

Figura 5.5 - Visão Geral do Sistema SP2 [IBM95] ............................................................... 94

Figura 5.6 - Modelos de Nós de Processamento do SP2 …..................................................... 95

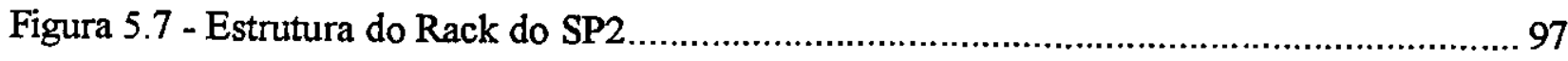

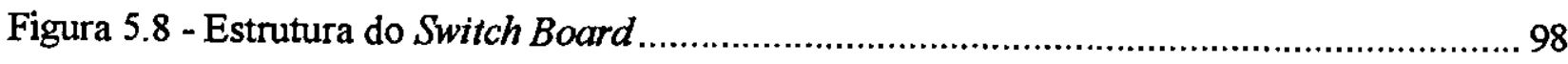

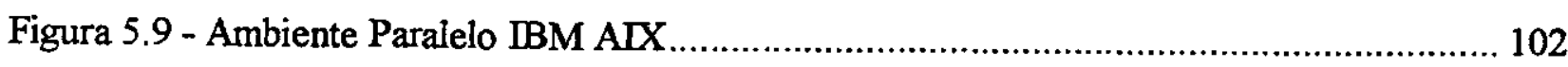

Figura 6.1 - Comunicações envolvidas no Algoritmo Quicksort Paralelo 1 ............................ 113

Figura 6.2 - Comunicações envolvidas no Algoritmo Quicksort Paralelo 2 ............................. 115

Figura 6.3 - Comunicações envolvidas no Algoritmo Merge Paralelo ..................................... 118

Figura 6.4 - Comunicą̧ões envolvidas no Algoritmo Odd-even Merging................................ 120

Figura 6.5 - Comunicações envolvidas no Algoritmo Merging Distribuído .............................. 122

Figura 7.1 - Configuração da máquina paralela virtual ..................................................... 127

Figura 7.2 - Modelos de comunicação: a) Ping. b) Ping-pong.............................................. 131 


\section{Índice de Tabelas}

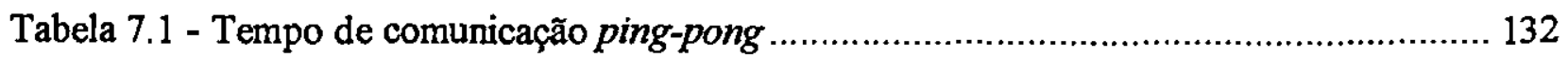

Tabela 7.2 - Tempo de comunicação coletiva (broadcast) .................................................. 134

Tabela 7.3 - Tempos das execuções do algoritmo quicksort paralelo 1................................. 136

Tabela 7.4 - Tempos das execuções do algoritmo quicksort 1 serial e paralelo......................... 137

Tabela 7.5 - Speedup das execuções do algoritmo quicksort paralelo 1.................................. 139

Tabela 7.6 - Tempos das execuções do algoritmo quicksort paralelo 2................................... 141

Tabela 7.7 - Tempos das execuções do algoritmo quicksort 2 serial e paralelo.......................... 143

Tabela 7.8 - Speedup das execuçōes do algoritmo quicksort paralelo 2 ............................... 145

Tabela 7.9 - Tempos das execuções do algoritmo quicksort paralelo 2.1............................... 146

Tabela 7.10 - Tempos das execuções do algoritmo quicksort 2.1 serial e paralelo.................... 147

Tabela 7.11 - Speedup das execuções do algoritmo quicksort paralelo 2.1 ............................ 149

Tabela 7.12 - Tempos das execuções do algoritmo merge paralelo ....................................... 151

Tabela 7.13 - Tempos das execuções do algoritmo merge serial e paralelo ............................ 152

Tabela 7.14 - Speedup das execuçōes do algoritmo merge paralelo....................................... 154

Tabela 7.15 - Tempos das execuções do algoritmo odd-even merging ................................... 156

Tabela 7.16 - Tempos das execuções do algoritmo odd-even merging serial e paralelo ........... 157

Tabela 7.17 - Speedup das execuções do algoritmo odd-even merging ….............................. 159

Tabela 7.18 - Tempos das execuções do algoritmo merging distribuido …............................ 160

Tabela 7.19 - Tempos das execuções do merging distribuido serial e paralelo ........................ 162

Tabela 7.20 - Speedup das execuções do algoritmo merging distribuido................................. 163 


\section{Índice de Gráficos}

Gráfico 7.1 - Tempos das execuçōes do algoritmo quicksort paralelo 1 ...............................136

Gráfico 7.2 - Tempos das execuções do algoritmo quicksort 1 serial e paralelo ....................... 138

Gráfico 7.3 - Speedups das execuçð̃es do algoritmo quicksort paralelo 1 ............................. 139

Gráfico 7.4 - Tempos das execuções do algoritmo quicksort paralelo 2 …............................. 141

Gráfico 7.5 - Tempos das execuç̃̃es do algoritmo quicksort 1 serial e paralelo ........................ 143

Gráfico 7.6 - Speedup das execuções do algoritmo quicksort paralelo 2................................ 145

Gráfico 7.7 - Tempos das execuções do algoritmo quicksort paralelo 2.1 ............................. 146

Gráfico 7.8 - Tempos das execuçōes do algoritmo quicksort 2.1 serial e paralelo..................... 148

Gráfico 7.9 - Speedup das execuções do algoritmo quicksort paralelo 2.1 ............................ 149

Gráfico 7.10 - Tempos das execuçōes do algoritmo merge paralelo ....................................... 151

Gráfico 7.12 - Speedup das execuções do algoritmo merge paralelo ...................................... 154

Gráfico 7.13 - Tempos das execuçōes do algoritmo odd-even merging................................... 156

Gráfico 7.14 - Tempos das execuções do algoritmo oddeven merging serial e paralelo............ 157

Gráfico 7.15 - Speedup das execuçðes do algoritmo odd-even merging.................................. 159

Gráfico 7.16 - Tempos das execuçōes do algoritmo merging distribuído ................................ 161

Gráfico 7.17 - Tempos das execuções do merging distribuido serial e paralelo........................ 162

Gráfico 7.18 - Speedup das execuções do algoritmo merging distribuido ................................ 164

Gráfico 7.19 - Tempo das execuçðes dos algoritmos utilizando as plataformas do SP2 2........... 167

Gráfico 7.20 - Tempo das execuções dos algoritmos utilizando as plataformas do S.D. ........... 168 


\section{Capítulo 1}

\section{Introdução}

Os últimos anos tem apresentado um grande aumento na aceitação e adoção do processamento paralelo, tanto para computação científica de alto desempenho como para aplicações de propósito geral. Essa aceitação tem sido favorecida principalmente pelo desenvolvimento dos ambientes com processamento maciçamente paralelo (MPP Massively Parallel Processing) e da computação distribuída [ALM94] [MCB94].

A computação paralela e a computação distribuída surgiram por motivos diferentes. A necessidade de se compartilhar recursos motivou o uso de sistemas distribuídos, enquanto a busca por maior desempenho no processo computacional motivou a utilização do processamento paralelo [SOU95]. Atualmente, as duas áreas têm convergido, de maneira que a combinação entre os dois enfoques computacionais oferece benefícios para ambos os lados. A utilização de sistemas distribuídos para computação paralela oferece flexibilidade e uma maneira eficiente de se explorar hardware interligado já disponível [ZAL91].

Um ponto comum entre sistemas distribuídos e ambientes MPPs é a noção de passagem de mensagem, que permite a comunicação entre processos paralelos. Um ambiente de passagem de mensagem consiste basicamente de uma biblioteca de comunicação que, atuando como uma extensão das linguagens seqüenciais (como $\mathrm{C}$ e Fortran), permite a elaboração de aplicações paralelas. Para a maioria desses sistemas, ambientes para passagem de mensagem portáteis têm sido desenvolvidos, dos quais dois representantes merecem destaque no cenário computacional atual: o PVM (Parallel Virtual Machine) [GEI94] [SUN94] e o MPI (Message Passing Interface) [MCB94] [DON95] [SNI96]. 
O PVM destaca-se por ser considerado por alguns autores um padrão de fato para plataformas de portabilidade, enquanto o MPI é uma tentativa de padronização de direito, levada a cabo por diversas organizações mundiais [MCB94].

O PVM tem mostrado as vantagens da programação paralela portátil. Entre os principais motivos do sucesso do PVM destacam-se: seu domínio público, sua simplicidade, a portabilidade de suas aplicações e sua emulação de uma máquina paralela virtual. O PVM não foi projetado para sistemas paralelos fortemente acoplados, sendo melhor utilizado em computação distribuída[BOD96] [GEI96].

O objetivo principal do MPI é garantir eficiência em qualquer plataforma paralela (arquiteturas paralelas ou sistemas distribuídos) e segundo Geist [GEI96], o MPI implementado em máquinas paralelas apresenta melhor desempenho do que em sistemas distribuídos. Algumas implementações do MPI já estão disponíveis em domínio público, para diversas plataformas.

Assim, o objetivo deste trabalho é verificar as afirmações discutidas nos parágrafos anteriores, ou seja, segundo Geist [GEI96] o MPI é mais adequado para arquiteturas paralelas, enquanto o PVM se adapta melhor em sistemas distribuídos [BOD96] [GEI96]. Para tanto, visa-se analisar e comparar o desempenho do PVM e do MPI, implementados tanto em sistemas distribuídos como em máquinas paralelas.

Esta análise é realizada através do desenvolvimento de vários algoritmos paralelos de ordenação, utilizando tanto PVM quanto MPI e da execução desses algoritmos em um sistema distribuido (baseado em computadores do tipo PC) e em uma máquina paralela SP2 (Scalable POWERparallel System 2) da IBM.

A análise a ser efetuada considera diferentes algoritmos paralelos de ordenação (em linguagem $\mathrm{C}$ ), com diferentes granulações (média e grossa), modelos de programação (SPMD ou MPMD) e comunicações (considerando número e tamanho das mensagens).

Através dos dados obtidos para se analisar os ambientes e as plataformas, pode-se adicionalmente comparar diversos algoritmos de ordenação. 
Os testes foram realizados em quatro implementações. No sistema distribuído utilizou-se as plataformas de portabilidade PVM versão 3.3.10 e MPICH versão 1.0.12 (uma implementação da especificação MPI). Enquanto que na máquina paralela SP2 adotou-se duas implementações proprietárias da IBM, sendo IBM PVMe e IBM MPI.

Foram realizados também testes comparativos com os algoritmos seqüenciais correspondentes, a fim de se verificar os speedups alcançados com a execução dos algoritmos paralelos de ordenação utilizando cada plataforma. Além disso, foi incluído um estudo das comunicações ponto-a-ponto e coletivas do PVM e do MPI, que foram utilizados para uma melhor avaliação dos resultados obtidos.

Esta dissertação está dividida em 8 capitulos. No capítulo 2, são apresentados os tópicos básicos relacionados a programação concorrente, abordando os principais métodos para a ativação e coordenação (comunicação e sincronismo) de processos, ferramentas que dão suporte a programação concorrente, como também uma descrição das plataformas de portabilidade PVM e MPI. No capitulo 3, é apresentada uma visão geral de arquiteturas paralelas, incluindo as classificações de arquiteturas paralelas e os sistemas distribuídos.

No capítulo 4, é discutido o desenvolvimento de algoritmos paralelos, ilustrando três estilos de paralelismo existentes para o projeto de algoritmos, paralelismo pelo resultado, paralelismo processor farm e paralelismo pipeline. Neste capitulo encontramse também análises e descrições de algoritmos paralelos de ordenação implementados em diferentes arquiteturas paralelas.

O capítulo 5 apresentada os ambientes computacionais utilizados neste trabalho, abordando as características de hardware e software das arquiteturas adotadas (o sistema distribuído e a máquina paralela SP2). Neste capitulo encontram-se as descrições das plataformas de portabilidade (IBM MPI, IBM PVMe, MPICH e PVM) analisadas neste trabalho.

No capítulo 6, são descritas as implementações dos algoritmos paralelos de ordenação utilizadas para a análise de desempenho das plataformas de portabilidade. No 
capítulo 7, são apresentados os resultados obtidos com a execução dos algoritmos paralelos de ordenação utilizando as plataformas de portabilidade e a análise desses resultados.

Finalmente, no capítulo 8 são apresentadas a análise da bibliografia, as principais conclusões obtidas, as contribuições oferecidas, algumas dificuldades encontradas no decorrer desse trabalho, como também sugestões de trabalhos futuros. 


\section{Capítulo 2}

\section{Programação Concorrente}

O objetivo deste capítulo é descrever tópicos relevantes da área de programação concorrente através das seguintes seções: conceitos básicos, ativação de processos paralelos, comunicação e sincronismo, suporte à programação concorrente e plataformas de portabilidade (PVM e MPI).

\subsection{Introdução}

O modelo arquitetural proposto por von Neumman assume que o processador possui a capacidade de executar seqüências de instruções [FOS95]. Uma instrução pode especificar, além de várias operaçбes aritméticas, o endereço de dados a serem lidos ou escritos na memória e/ou o endereço da próxima instrução a ser executada. A programação seqüencial utiliza esses recursos, disponiveis através de uma linguagem de máquina, ou de uma maneira mais usual, através de linguagens de alto nível como $C$, Pascal e Fortran, que permitem o uso de abstrações (por exemplo if, else, while) que são traduzidas automaticamente em código executável.

A programação paralela necessita de recursos não disponiveis nas linguagens para programação seqüencial. Essa necessidade é gerada pela inclusão de recursos que devem ser explorados. São necessários métodos para definir quais tarefas serão executadas paralelamente, métodos para a ativação e finalização da execução dessas tarefas, bem como meios para coordenar a interação entre elas [ALM94].

O objetivo da programação concorrente é suprir essas necessidades, fornecendo ferramentas para a construção de programas paralelos que utilizam o hardware disponível, seja esse paralelo ou não [ALM94] [ FOS95]. 
Para a especificação da execução concorrente algumas notações foram idealizadas, cada uma apresentando detalhes e finalidades diferentes [ALM94]. As construções, Corotinas, Cobegin/Coend, Fork/Join e Doall são exemplos dessas notações, permitindo especificar a ativação, finalização e coordenação de programas concoirentes. Um detalhamento dessas ferramentas é apresentado na seção 2.3 (Ativação de Processos Paralelos).

A utilização de mecanismos para coordenar a execução dos processos é outro tópico que deve ser considerado no estudo da programação paralela. A comunicação e a sincronização, discutidas na seção 2.4 , tratam especificamente dessa necessidade.

Alguns conceitos básicos são necessários para o estudo de programação paralela. Estes conceitos são apresentados na próxima seção.

\subsection{Conceitos Básicos}

Esta seção discute alguns conceitos básicos utilizados na computação paralela, tais como: nomenclatura utilizada (concorrência e paralelismo), granulação, speedup e eficiência.

\subsubsection{Concorrência e Paralelismo}

O termo paralelismo, na literatura, é normalmente utilizado para designar paralelismo físico, ou seja, tem-se múltiplos elementos de processamento para executar os processos, sendo que todos eles podem estar ativos simultaneamente. É importante então, ressaltar a diferença entre paralelismo e concorrência.

A concorrência implica em mais de um processo iniciado e não ainda terminado. Não existe uma relação com o número de elementos de processamento utilizados. Obter paralelismo na execução desses processos só é possivel quando existe mais de um 
elemento de processamento, de modo que os processos possam estar em execução em um determinado instante.

Quando existe apenas um elemento de processamento e vários processos estão sendo executados de maneira concorrente existe um pseudo-paralelismo. $\mathrm{O}$ usuário tem a falsa impressão que os processos estão sendo executados ao mesmo tempo, mas o que realmente acontece é o compartilhamento do elemento de processamento entre os processos em execução. Isto é, em um determinado instante de tempo, apenas um processo está em execução, enquanto os demais estão aguardando a liberação do processador.

\subsubsection{Granulação}

Granulação, ou nível de paralelismo, relaciona o tamanho das unidades de trabalho submetidas aos processadores. Diversas definições de granulação podem ser encontradas na literatura [HWA84] [NAV89] [KIR91] [ALM94]. Mas, de maneira simples, a granulação pode ser dividida em três níveis: fina, média e grossa.

Granulação grossa relaciona o paralelismo a nível de processos e programas, e geralmente se aplica a plataformas com poucos processadores grandes e complexos.

Granulação fina, por outro lado, relaciona paralelismo a nível de instruções ou operações. e implica em grande número de processadores pequenos e simples. A granulação média situa-se em um patamar entre as duas anteriores, implicando em procedimentos sendo executados em paralelo.

\subsubsection{Speedup e Eficiência}

Uma característica fundamental da computação paralela trata-se do aumento de velocidade de processamento através da utilização do paralelismo. Para se calcular o 
aumento obtido, dois parâmetros são abordados na literatura: speedup e eficiência [KIR91] [ALM94].

Speedup (Sp) é uma medida utilizada para determinar o aumento de velocidade obtido durante a execução de um programa utilizando p processadores, em relação a sua execução seqüencial.

$$
\mathrm{Sp}=\mathrm{T}_{\mathrm{seq}} / \mathrm{T}_{\mathrm{par}}
$$

Onde: $\mathbf{T}_{\text {seq }}$ é o tempo de execução em um único processador.

$\mathrm{T}_{\mathrm{par}}$ é o tempo de execução em p processadores.

$\mathrm{O}$ caso ideal é quando o $\mathbf{S p}=\mathbf{p}$, isto é, a velocidade de processamento torna-se proporcional à quantidade de processadores utilizada. Mas existem fatores principais que degradam essa situação ideal: a sobrecarga de comunicação, algoritmos que são dificilmente paralelizáveis, a dificuldade de balanceamento da carga entre os processadores e os casos onde a granulação é inadequada para o tipo de arquitetura utilizada [ALM94]. Existem também casos em que o speedup alcançado é maior que o previsto, isto é, $\mathrm{Sp}>\mathbf{p}$. Esse fenômeno é chamado de anomalia de speedup ou speedup super linear [FOS95].

Outra medida amplamente utilizada é a eficiência, representada por Ep:

$$
\mathbf{E p}=\mathbf{S p} / \mathbf{p}
$$

Onde: Sp é o speedup obtido

p é o número de processadores utilizados.

A eficiência quantifica a utilização do processador. Variando entre 0 e 1 , o caso ideal é verificado quando $\mathbf{E p}=1$, indicando uma eficiência de $100 \%$. 


\subsection{Ativação de Processos Paralelos}

Várias construções têm sido propostas para a ativação de processos concorrentes, sendo que as principais [ALM94] são: Co-rotinas, Cobegin/Coend, Fork/Join e Doall.

Co-rotinas : Co-rotinas são como as subrotinas normais. A diferença reside na transferência de controle, que é feita de modo não hierárquico. Para controlar a transferência, o comando resume é utilizado. Sempre que uma co-rotina é ativada, ela começa a executar a partir do ponto onde foi executado o último comando resume (Figura 2.1). Cada co-rotina pode ser vista como implementando um processo, e elas são executadas intercaladamente. Sempre existe apenas uma co-rotina ativa em cada instante, o que implica na adequação desta estrutura para a organização de programas concorrentes que compartilhem uma única CPU.

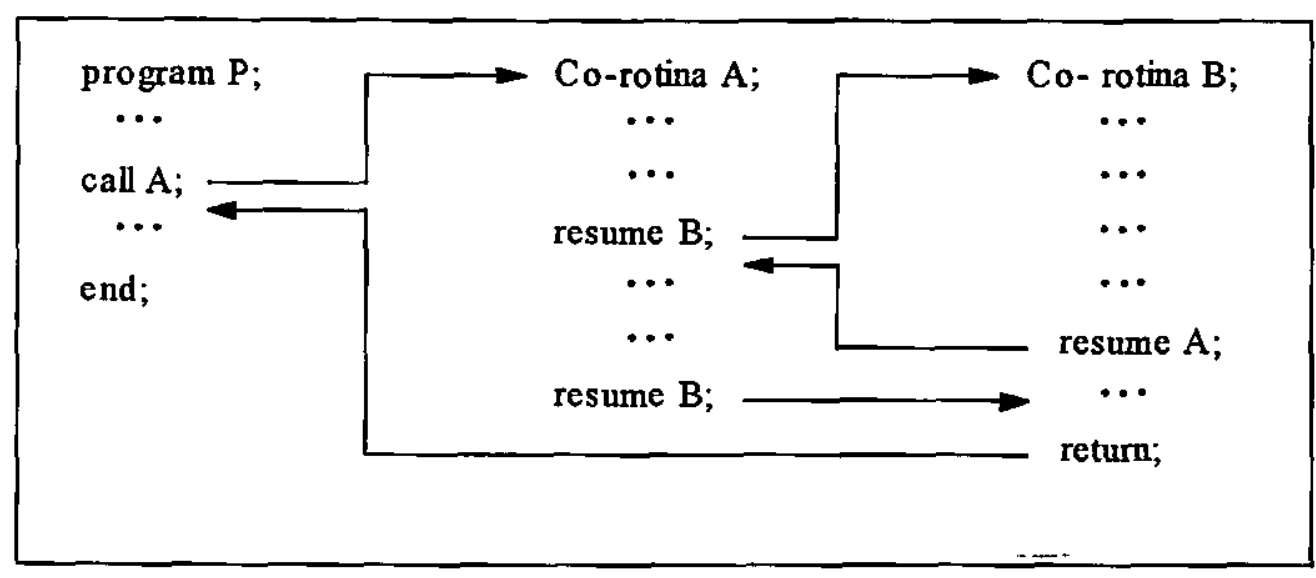

Figura 2.1 - Exemplo da Utilização de Co-rotinas.

Cobegin/Coend: Também chamados de parbegin/parend, fornecem uma maneira altamente estruturada para a ativação de processos (ou um grupo de instruções) concorrentes. Os processos definidos entre comandos cobegin/coend devem ser executados concorrentemente, isto é, todos os processos ativados entre estes dois 
comandos devem ser disparados ao mesmo tempo e os processos que os seguem só serão iniciados após o término de todos os processos que fazem parte do cobegin/coend (Figura 2.2).

A estrutura Cobegin/Coend oferece uma forma estruturada de ativar os processos concorrentes, sendo fácil a identificação de quais processos são seqüenciais e quais processos são concorrentes. No entanto, cobegin/coend é pouco flexível, pois todos os processos ativados em paralelo devem terminar para que seja possível a execução de outros processos.

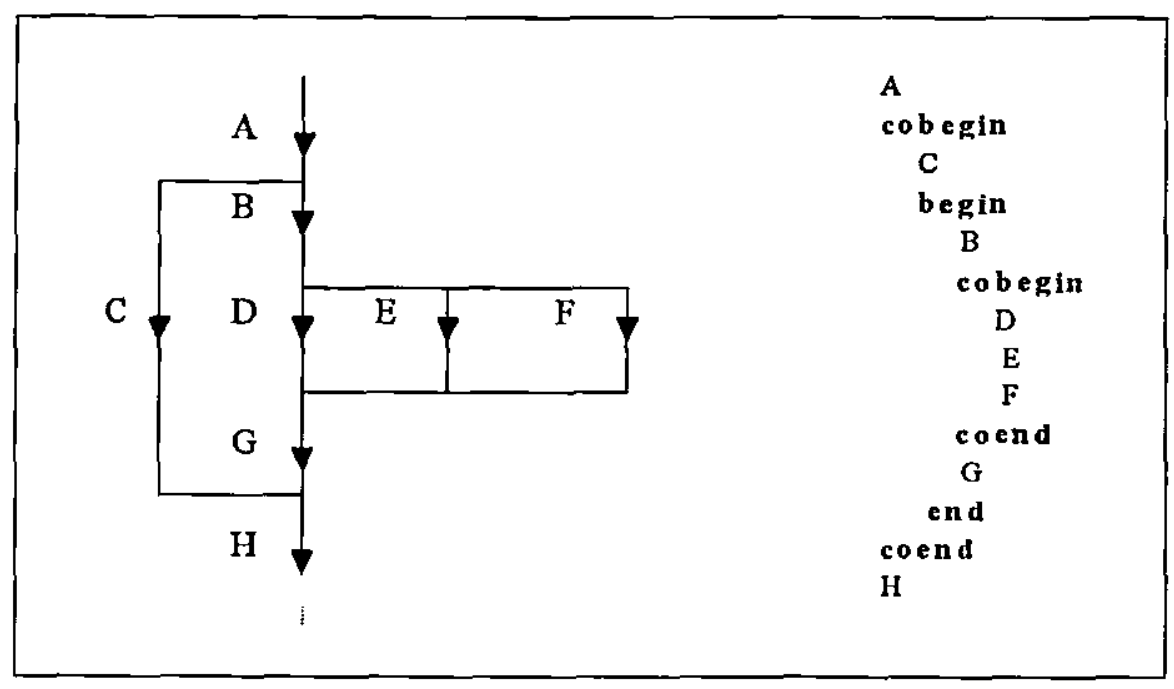

Figura 2.2 - Exemplo da Utilização de Cobegin/Coend.

Fork/Join: A declaração fork determina o início da execução de um conjunto de instruções (processo filho), concorrentemente com o processo que está sendo executado (processo pai). O comando join é utilizado para a sincronização do processo pai com os processos filhos gerados (Figura 2.3). As sintaxes dos comandos fork/join são :

Fork endereço : executa o processo que está em endereço concorrentemente com os demais processos; 
Join var, endereco1, endereco2 - Decrementa a variável var, que contém o número de processos que devem sincronizar-se. Se var $=0$, considera a execução a partir de endereçol. Caso contrário, transfere a execução para o endereço2.

A principal vantagem dos comandos fork/join é a flexibilidade. Com o uso desses comandos, pode-se representar qualquer tipo de execução concorrente. Em contrapartida, a falta de estruturação representa uma desvantagem desse método.

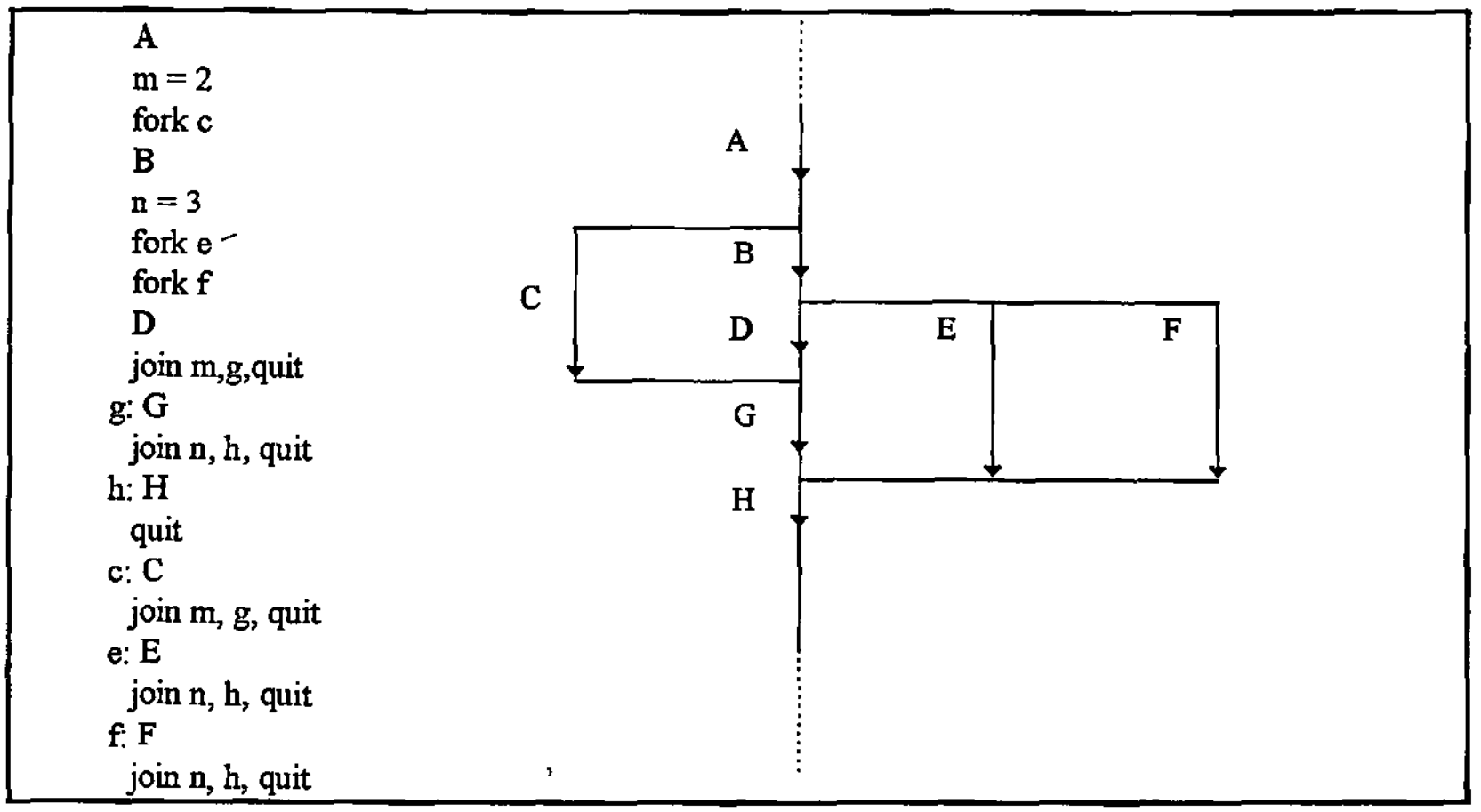

Figura 2.3 - Exemplo da Utilização dos comandos Fork/Join.

Doall: O comando Doall executa instruções em paralelo que formam as várias instâncias de um bloco de comandos situado dentro de um laço de repetição (Figura 2.4). Alguns comandos de função semelhante são: forall, pardo e doacross.

A escolha do método de ativação de processos concorrentes deve ser feita de acordo com os objetivos do programador. Co-rotinas são utilizadas para ativação de processos concorrentes, fork/join e cobegin/coend para a ativação de processos paralelos e doall para a ativação paralela de instâncias de loops. Em relação ao contraste flexibilidade/estruturação, fork/join oferece um mecanismo flexível porém 
desestruturado, enquanto cobegin/coend e doall apresentam maior estruturação, o que diminui a flexibilidade.

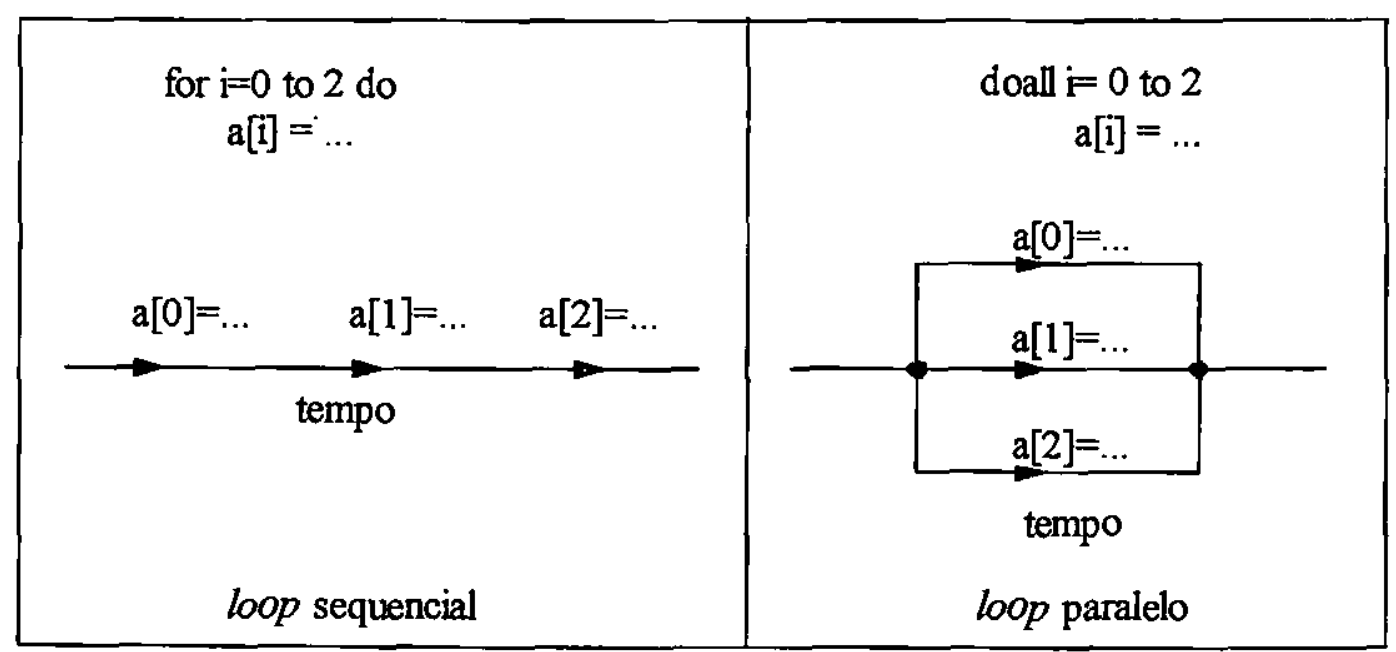

Figura 2.4 - Exemplo da Utilização de Doall.

\subsection{Comunicação e Sincronização}

A comunicação é necessária para que processos interagindo na resolução de determinada aplicação troquem informações e se sincronizem. Quando há comunicação, devem existir operações de sincronização, para fornecer controle de acesso e controle de seqüência. De forma semelhante, quando processos devem ser sincronizados é necessário que exista uma forma de comunicação.

O controle de seqüência é utilizado quando existe a necessidade de estabelecer uma determinada ordem na execução dos processos. Já o controle de acesso é utilizado quando é importante o acesso organizado aos recursos do sistema que são compartilhados pelos processos concorrentes [ALM94].

$\mathrm{Na}$ análise de linguagens concorrentes, um dos aspectos de grande importância é a forma de comunicação entre os processos. A comunicação entre processos pode ser efetuada com o uso de variáveis compartilhadas ou através de um mecanismo de 
passagem de mensagens. Cada uma dessas formas de comunicação é mais aplicada para um determinado tipo de arquitetura: com memória centralizada e com memória distribuída

\section{Comunicacão e Sincronizacão em Memória Centralizada}

A comunicação e o sincronismo em memória centralizada são implementados através da utilização de variáveis compartilhadas entre os diversos processos concorrentes. $\mathrm{O}$ acesso a essas variáveis é geralmente implementado com exclusão mútua. Para o controle de acesso e controle de seqüência em memória centralizada, os mecanismos utilizados são busy-waiting, semáforos e monitores [QUI87] [KIR89] [SNO92] [ALM94].

Busy-waiting: Utilizando-se uma variável compartilhada cujo valor pode ser manipulado (modificado e testado/test-and-set) através de uma primitiva indivisível, criase um modo simples para a sincronização de processos concorrentes. Um processo querendo entrar em uma região crítica deve executar esta primitiva continuamente até conseguir permissão de entrada. São gastos ciclos de CPU enquanto se está testando a variável, caracterizando este método de sincronização como um exemplo de busy-waiting, ou espera ocupada.

Semáforos: Um semáforo é uma variável compartilhada inteira e não negativa com duas operações atômicas (indivisíveis) associadas: p e v (também chamados de down e up, respectivamente). Dado um semáforo $s$, implementa-se p e v como:

\begin{tabular}{|c|c|}
\hline $\mathrm{p}(\mathrm{s}): \operatorname{Se}(s=0)$ & $\mathrm{v}(\mathrm{s}): \mathrm{s}=\mathrm{s}+1$ \\
então bloqueia-se o processo & \\
senão $s=s-1$ & \\
\hline
\end{tabular}

Semáforos oferecem um meio de sincronização de nível mais elevado do que busywaiting, além de evitar o desperdício de CPU. Um exemplo de sua utilização, trata-se da 
implementação de exclusão mútua. Seja o semáforo $\mathrm{s}$, iniciado com o valor 1 . Então, a seqüência:

$$
\mathbf{p}(\mathbf{s}) \text {; região crítica; } \mathbf{v ( s ) ;}
$$

garante que apenas um único processo esteja executando esta região crítica em um determinado instante.

Monitores: Um monitor consiste de variáveis representando o estado de algum recurso compartilhado e procedimentos que implementam operações sobre esse recurso. Essas variáveis podem ser acessadas somente pelos procedimentos internos a cada monitor, e a execução desses procedimentos é feita de maneira mutuamente exclusiva.

\section{Comunicacão e Sincronizacão em Memória Distribuída}

A comunicação e o sincronismo em memória distribuída são possíveis através do uso de troca de mensagens [TAN92] [ALM94]. Uma operação de comunicação via troca de mensagens, de maneira genérica, é realizada pela utilização das primitivas send/receive (envia/recebe), cujas sintaxes, por exemplo, podem ser:

\section{send mensagem to destino \\ receive mensagem from origem}

A comunicação pode ser bloqueante ou não bloqueante. Na comunicação bloqueante o comando send (receive) aguarda que o comando receive (send) seja executado, permitindo assim que a mensagem seja enviada (Figura 2.5a). Na comunicação não bloqueante, o comando send (receive) não necessita esperar o comando receive (send), utilizando um buffer temporário para a comunicação (Figura $2.5 \mathrm{~b}$ ).

As primitivas send/receive fornecem subsídios para a construção de diferentes formas de comunicação: Comunicação Ponto-a-Ponto, Rendezvouz e RPC [BIR84] [WIL87] [TAN92] [ALM94]. 


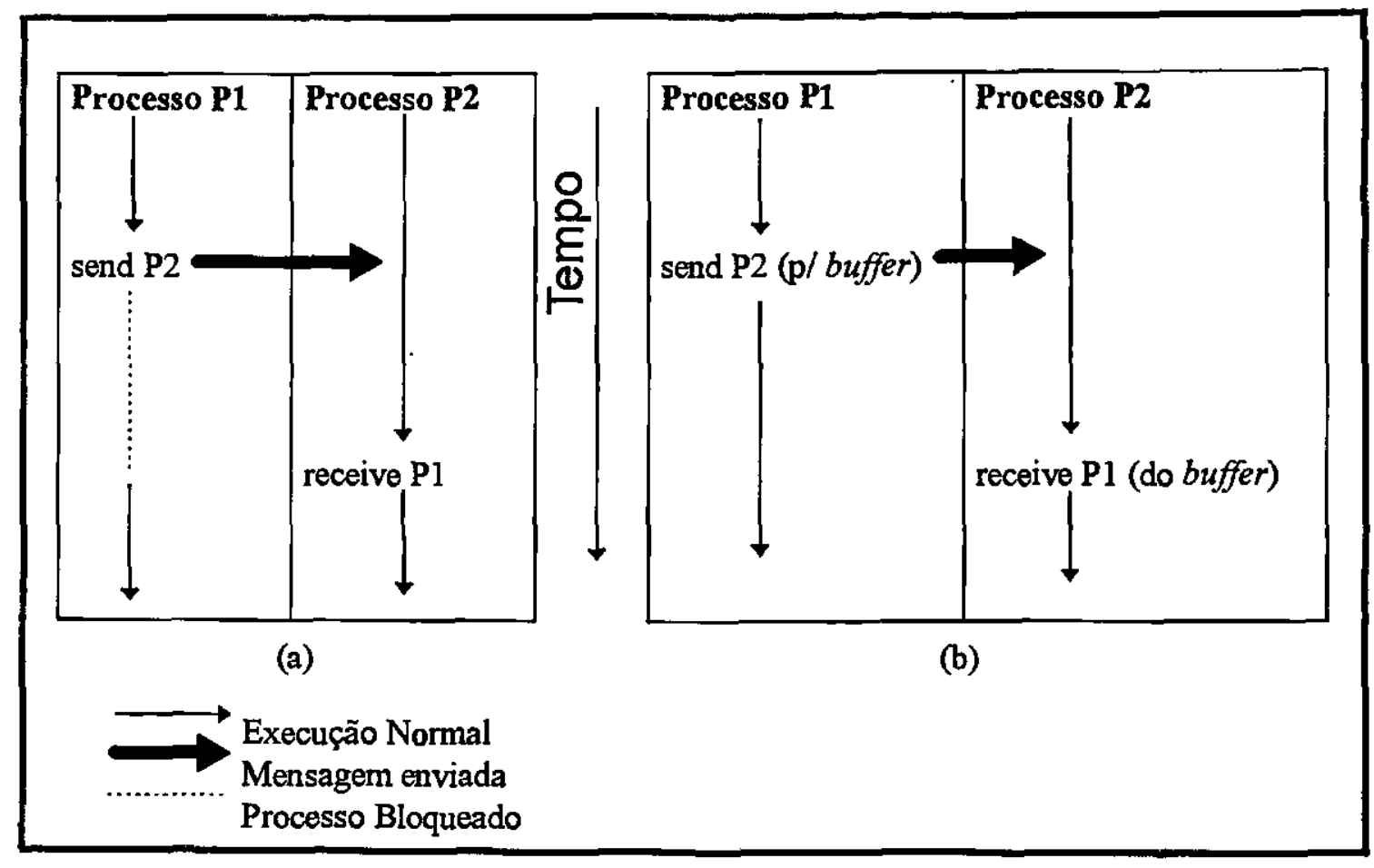

Figura 2.5 - Send/Receive. (a) Bloqueante (b) Não Bloqueante

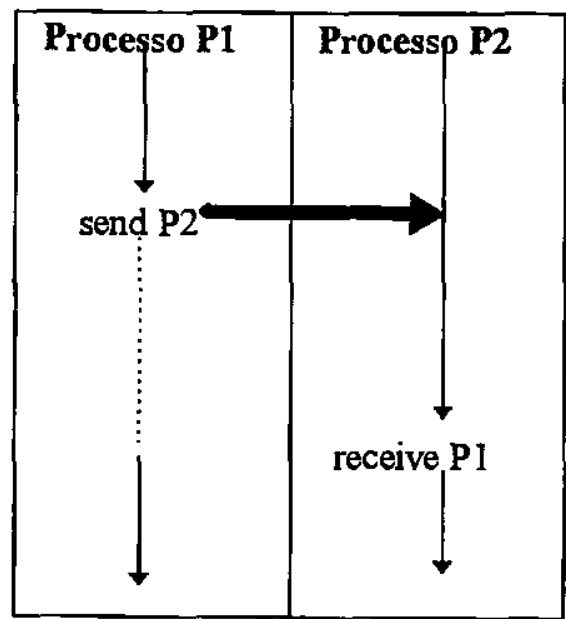

(a)

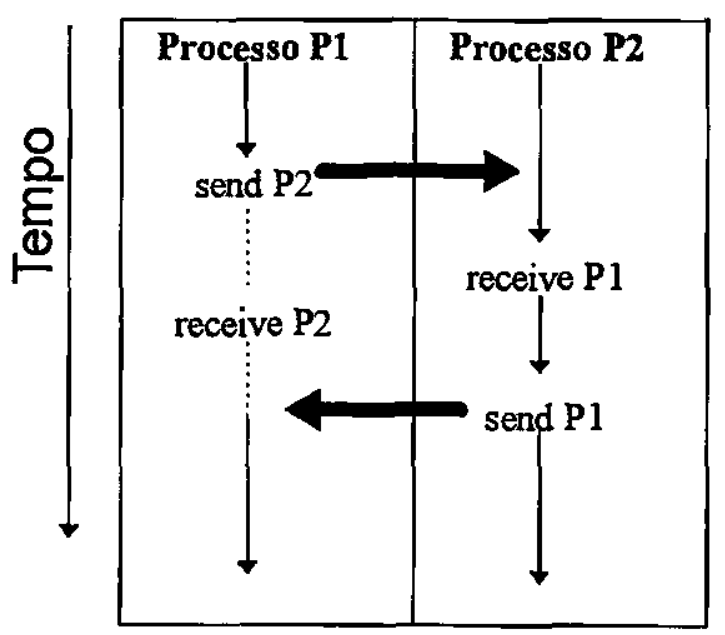

(b)

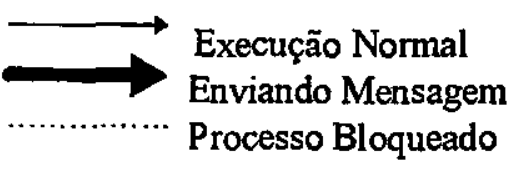

Figura 2.6 - Mecanismos de Comunicação. (a) Ponto-a-Ponto (b) Rendezvous. 
Na Comunicação Ponto-a-Ponto existe o uso de uma operação send/receive bloqueante (Figura 2.6 (a)). Esta comunicação unidirecional permite a sincronização entre dois processos.

A estrutura Rendezvouz implementa uma comunicação bidirecional. Esse mecanismo permite, por exemplo, que um processo solicite a execução de um trecho de programa ou uma subrotina que faz parte de um outro processo. Isso é conseguido através do uso de dois conjuntos de operações send/receive bloqueantes (Figura 2.6 (b)).

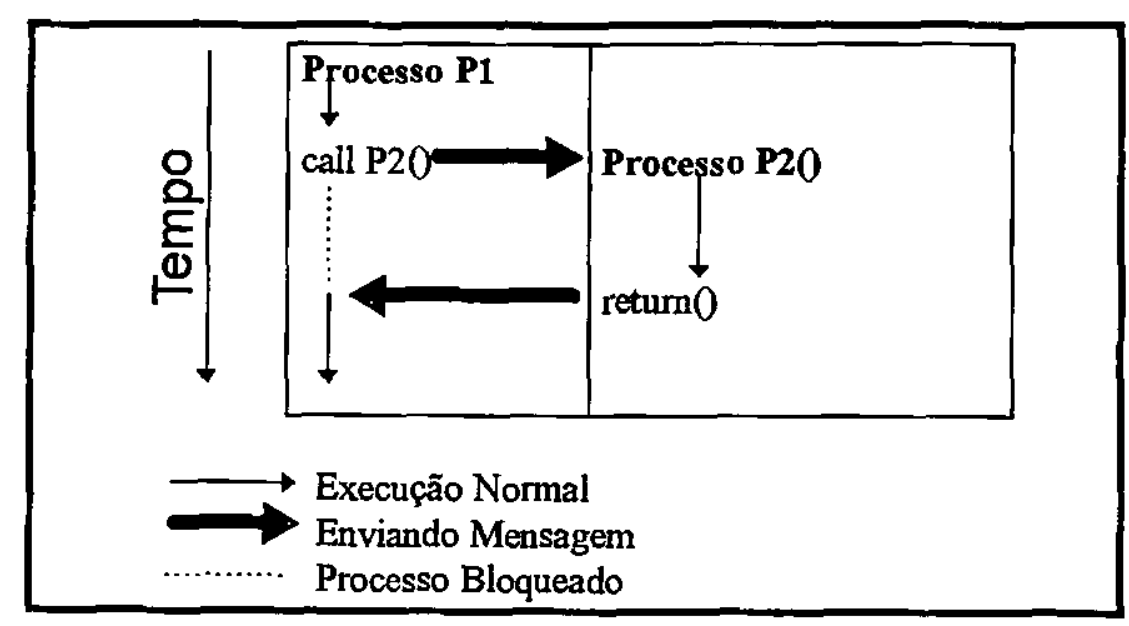

Figura 2.7 - Mecanismo de Comunicação RPC.

$\mathrm{Na}$ chamada de procedimento remoto (RPC), um processo pode solicitar a execução de um outro processo remotamente, usando a mesma sintaxe das chamadas de procedimentos locais. $\mathrm{O}$ processo fonte fica bloqueado até que o procedimento remoto seja executado fazendo, portanto, uma comunicação síncrona. Normalmente, o procedimento remoto retorna valores, tornando a comunicação bidirecional (Figura 2.7). 


\subsection{Suporte à Programação Concorrente}

As linguagens para programação concorrente vêm surgindo no sentido de oferecer ferramentas eficientes e de fácil utilização para a ativação de processos concorrentes e cooperação (comunicação e sincronização) entre os processos.

A escolha do tipo de ferramenta (que implemente esses mecanismos) que será utilizada para o desenvolvimento de um programa paralelo, é uma decisão extremamente importante e que se deve levar em consideração vários fatores. Entre eles, o tipo de aplicação, o tipo de usuário que utilizará a ferramenta e a arquitetura que executará os códigos gerados. Baseado no tipo de aplicação e na arquitetura, define-se a granulação desejada, que deve ser considerada também no processo de escolha. Segundo Almasi [ALM94], deve-se avaliar dois aspectos principais: o trabalho requerido pelo programador (incluindo o tempo de aprendizado da ferramenta) e o desempenho obtido.

Atualmente, existem alguns tipos de ferramentas para construção de programas paralelos, entre os quais podemos citar: ambientes de paralelização automática, extensões paralelas para linguagens seriais e linguagens concorrentes.

Compiladores paralelizadores, que caracterizam ambientes de paralelização automática, são responsáveis por gerarem automaticamente programas paralelos através de sua versão serial. Tais compiladores exigem o mínimo de trabalho do usuário, não sendo preciso modificar o programa, nem aprender uma nova linguagem. Entretanto, o desempenho obtido geralmente é modesto. Além disso, nem sempre esses compiladores estão disponíveis, principalmente para sistemas de memória distribuída.

Extensões paralelas são bibliotecas que contêm um conjunto de instruções que complementam linguagens seriais já existentes. Estes ambientes requerem mais trabalho do programador, mas ainda evitam a necessidade de aprendizagem de uma nova linguagem e a completa reescrita do código fonte (o usuário deve aprender uma extensão para uma linguagem já conhecida). Geralmente, o desempenho obtido é superior ao obtido pelos compiladores paralelizadores. Exemplos de extensões paralelas são: Express, 
PARMACS, P4, Linda, PVM, MPI, entre outros [SUN94]. Vale destacar os dois ambientes de passagem de mensagens mais utilizados na atualidade, PVM e MPI, que são ambientes de programação paralela portáteis para memória distribuída, que permitem o transporte de programas paralelos entre diferentes arquiteturas (e sistemas distribuídos) de maneira transparente. Estes ambientes são discutidos na próxima seção.

O terceiro tipo de ferramenta relaciona as linguagens criadas especialmente para processamento concorrente, o que implica em tempo de aprendizagem de uma linguagem totalmente nova e rescrita total do código fonte. Essas ferramentas tendem a fornecer melhores desempenhos, de maneira que se compense a sobrecarga sobre o programador. Outra vantagem destas linguagens é que geralmente elas possibilitam a construção de códigos bem estruturados, tornando fácil a identificação dos processos que estão executando em paralelo e a comunicação entre eles. Exemplos dessas linguagens são: Occam e Ada.

De maneira sucinta, a escolha de uma ferramenta para programação paralela, deve ser feita de acordo com os objetivos do programador. Compiladores paralelizadores oferecem speedup limitado, porém com sobrecarga nula sobre o programador. Por outro lado, linguagens concorrentes oferecem melhor desempenho, mas oferecem uma sobrecarga considerável sobre o programador. Num patamar intermediário de desempenho e sobrecarga sobre o programador, situam-se as extensões paralelas.

\subsection{Plataformas de Portabilidade}

A computação paralela tem sido alvo de intensa pesquisa na comunidade acadêmica mundial, e um fator que contribuiu para sua expansão foi a possibilidade de utilização de sistemas distribuídos como plataformas de execução de programas paralelos.

Para a realização da computação paralela sobre sistemas distribuídos são utilizados os ambientes de passagem de mensagens. Um ambiente de passagem de mensagem consiste basicamente de uma biblioteca de comunicação que, atuando como uma extensão 
das linguagens seqüenciais (como C e Fortran), permite a elaboração de aplicações paralelas.

Os ambientes de passagem de mensagem foram desenvolvidos inicialmente para máquinas com processamento maciçamente paralelo (Massively Parallel Processing MPP) onde, devido à ausência de um padrão, cada fabricante desenvolveu seu próprio ambiente, sem se preocupar com a portabilidade do software gerado.

Com o objetivo de acabar com o problema de portabilidade, vários grupos de pesquisa desenvolveram ambientes de passagem de mensagens independentes da máquina a ser utilizada. Esses ambientes foram chamados de plataformas de portabilidade, que são ambientes de programação portáteis implementados em várias arquiteturas paralelas e sistemas distribuídos [MCB94] [KIT95].

O intuito foi definir um conjunto de funções, independente da máquina que está sendo utilizada, e implementá-las em várias plataformas de hardware. Desta forma, as aplicações puderam ganhar a portabilidade perdida e serem executadas em todos os equipamentos para os quais o ambiente foi desenvolvido. Estes ambientes podem ser utilizados em sistemas heterogêneos, onde duas ou mais máquinas distintas cooperam entre si para resolver um problema. Com isso, ganhou-se popularidade e aceitação, já que disponibilizam um ambiente paralelo com custo relativamente baixo quando comparado às máquinas paralelas.

Dentre as plataformas de portabilidade, pode-se citar dois representantes que merecem destaque no cenário computacional atual: o MPI (Message Passing Interface) [MCB94] [DON95] [SNI96] e o PVM (Parallel Virtual Machine)[GEI94] [SUN94].

O PVM destaca-se por ser considerado, por alguns autores, um padrão de fato para plataformas de portabilidade, enquanto o MPI é uma tentativa de padronização de direito, levada a cabo por diversas organizações mundiais [MCB94]. Essas duas plataformas de portabilidade, PVM e MPI serão descritas nas seções 2.6.1 e 2.6.2. 


\subsubsection{Parallel Virtual Machine - PVM}

PVM (Parallel Virtual Machine) é um conjunto integrado de bibliotecas e de ferramentas de software, cuja finalidade é emular um sistema computacional concorrente heterogêneo, flexível e de propósito geral [GEI94].

Diferente de outros ambientes portáteis desenvolvidos inicialmente para máquinas com multiprocessadores, o PVM nasceu com o objetivo de permitir que um grupo de computadores interconectados, possivelmente com diferentes arquiteturas, possa trabalhar cooperativamente formando uma máquina paralela virtual [GEI94].

O projeto PVM teve início em 1989 no Oak Ridge National Laboratory - ORNL nos EUA, e atualmente envolve diversos institutos de pesquisa e universidades. A versão 1.0 (protótipo), foi implementada por Vaidy Sunderam e Al Geist (ORNL) sendo direcionada ao uso do laboratório. Em 1991, Bob Mancheck (University of Tenessee) juntou-se à pesquisa e implementou uma nova versão do projeto PVM (PVM 2.0). Esta versão deu início à distribuição gratuita do PVM. Depois de várias revisões (PVM 2.1 2.4), o PVM foi completamente rescrito, gerando a versão 3.0 (1993).

Os princípios básicos nos quais o PVM está baseado são [GEI94]:

- Host pool: as aplicações são executadas em um conjunto de máquinas que podem ser configuradas pelo próprio usuário. Fazem parte deste conjunto máquinas com um único processador e multiprocessadores ( com memória compartilhada e distribuída). O host pool também pode ser alterado durante a execução.

- Acesso transparente ao hardware: As aplicações podem tratar o hardware como uma coleção de elementos de processamento em uma máquina paralela virtual, ou podem explorar as características individuais de cada arquitetura.

- Computação baseada em tarefas (tasks): a unidade de paralelismo no PVM é a tarefa ( análoga a um processo UNIX). 
- Modelo para passagem de mensagens: No PVM, conjunto de tarefas, cada uma executando uma parte de uma aplicação, efetuam comunicação e sincronização através de troca de mensagens. $O$ tamanho das mensagens é limitado apenas pela quantidade de memória disponível na máquina hospedeira. Aplicações escritas em $\mathrm{C}, \mathrm{C}+\mathrm{e}$ Fortran podem ser paralelizadas utilizando troca de mensagens.

Suporte a heterogeneidade: PVM suporta heterogeneidade em termos de máquina, rede e aplicações. Em outras palavras, PVM manipula todas as conversões de dados necessárias quando dois computadores utilizam diferentes representações de dados. Para isso, o PVM codifica a mensagem no padrão XDR (External Data Representation)*, possibilitando que os dados transmitidos sejam decodificados no padrão compativel com o host destino.

\section{O Modelo computacional}

O modelo computacional do PVM é baseado na idéia de que uma aplicą̧ão é constituída por diversas tasks, cada uma responsável por executar uma parte da aplicação.

Uma aplicação pode ser paralelizada por dois métodos: o paralelismo funcional e o paralelismo de dados. No paralelismo funcional (também conhecido como paradigma mestre-escravo) a aplicação é dividida através das suas funções, isto é, cada tarefa desempenha uma função distinta (como por exemplo entrada, processamento e saída) e diferentes máquinas executam diferentes tarefas (possivelmente sobre os mesmos dados).

\footnotetext{
* A Representação de Dados Externa ou XDR (Exxternal Data Representation), é um padrão de representação de dados desenvolvido pela SUN Microsystems, Inc., para a troca de mensagens entre clientes e servidores quando estes não são do mesmo tipo [COU94].
} 


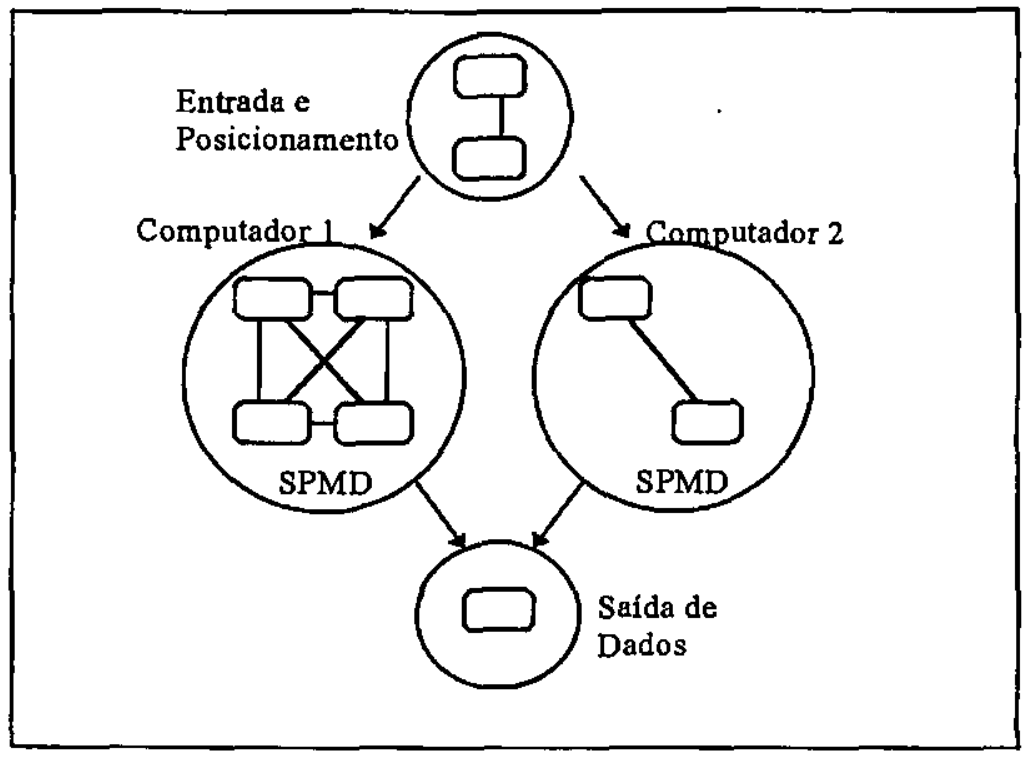

Figura 2.8 - PVM - Modelo Computacional

No paralelismo de dados todas as tarefas são idênticas, porém trabalham com dados distintos, que são particionados e distribuídos entre as mesmas. Os programas são executados sobre cada conjunto de dados e informações são trocadas entre as tasks até que o problema seja resolvido. Esse modelo de paralelismo refere-se ao paradigma SPMD (Single Program Multiple Data) e se popularizou em sistemas MIMD com memória distribuída pela sua simplicidade. Muitos algoritmos matriciais e relacionados a algebra linear tem sido desenvolvidos utilizando esse método de paralelismo [GEI94] [SUN94].

O PVM permite a utilização de SPMD, de MPMD (Multiple Program Multiple Data e também de métodos híbridos (combinação dos dois - Figura 2.8).

\section{Componentes do PVM}

O sistema PVM é composto por duas partes [GEI94]:

-Daemon: denominado pvmd3 (ou simplesmente $p v m d$ ), é executado em todos os hosts e possibilita a formação da máquina virtual. O pvmd foi projetado para ser instalado na máquina por qualquer usuário com um login válido. Quando um usuário deseja executar uma aplicação PVM, ele primeiro deve executar o pvmd e especificar uma lista de hosts 
que vão constituir a máquina virtual. O primeiro pvmd, iniciado pelo usuário, é designado como mestre, enquanto os outros são designados como escravos. Durante a maioria das operaçðes os pvmds não possuem diferença, a não ser quando há necessidade de operações de gerenciamento, como criar novos pvmds escravos e adicioná-los à máquina virtual. As aplicaçðes no PVM, que podem ser iniciadas em qualquer host que compõe o sistema, fazem requisições e recebem serviços do pvmd. $\mathrm{O}$ pvmd não realiza nenhum processamento, mas atua como roteador e controlador de mensagens, funcionando como um ponto de contato entre os hosts.

- Rotinas de interface PVM - Libpvm: esta biblioteca contém um conjunto de primitivas que atuam como elo de ligação entre uma tarefa e a máquina virtual (pvmd e as outras tarefas). Essas primitivas são ativadas pelo usuário para efetuar troca de mensagens, gerar processos, coordenar tarefas (sincronização), e modificar a máquina virtual. A biblioteca Libpvm foi desenvolvida com o intuito de torná-la tão pequena quanto possivel, visto que compartilha o espaço de endereçamento com o código desenvolvido pelo usuário. Possui 82 funções disponíveis para o usuário. Os programas de aplicação devem ser ligados a esta biblioteca para utilizar o PVM. O sistema PVM permite que sejam escritas aplicą̧ões nas linguagens Fortran, $\mathrm{C}$ e $\mathrm{C}++$. A escolha por esse conjunto de linguagens deve-se ao fato de que a maioria das aplicações passíveis de paralelização estão escritas nessas linguagens.

\section{O modelo de comunicação}

O PVM possui rotinas para o "empacotamento" e o envio de mensagens entre tarefas. $O$ modelo assume que qualquer tarefa pode enviar uma mensagem para outra $e$ que não há limites para o tamanho ou número de tais mensagens (apenas a quantidade de memória disponível em cada host). 
Enviar uma mensagem compreende três passos no PVM. Primeiro, um buffer deve ser criado para que as mensagens enviadas sejam depositadas temporariamente. Segundo, a mensagem deve ser "empacotada" dentro do buffer. Terceiro, a mensagem inteira (o conteúdo do buffer) é enviada para outra tarefa ou grupo de tarefas.

A mensagem é recebida por uma função bloqueante ou não bloqueante e então "desempacotada" retirando do buffer (no host receptor da mensagem) os dados enviados. As rotinas de recepção podem aceitar quaisquer mensagens, qualquer mensagem de um host específico, qualquer mensagem com um identificador específico (número de mensagem), ou somente mensagens de um host específico com um identificador específico.

A comunicação no PVM pode ser utilizada nos seguintes modos:

- send bloqueante assíncrono;

- receive bloqueante assíncrono;

- receive não bloqueantes.

Rotina send: O send bloqueante retorna tão logo o buffer de transmissão esteja livre para ser novamente utilizado e o send assíncrono não depende do receptor executar um receive para poder retornar. $\mathrm{O}$ send só bloqueia quando a mensagem exceder o tamanho do buffer e precisar ser dividida. Nesse caso o send fica bloqueado até o receptor executar um receive e liberar o buffer para continuar o envio da mensagem.

Rotina Receive: Um receive não bloqueante retorna imediatamente após ter verificado o buffer no host receptor. No caso da mensagem não estar disponivel, é retornado um código indicando que o buffer não continha a mensagem. Um receive bloqueante não retorna enquanto a mensagem esperada não for recebida e inserida no buffer [GEI94] [SUN94].

O PVM oferece comunicação ponto-a-ponto, broadcasting (para um grupo de tarefas definido pelo usuário) e multicasting (para um conjunto de tarefas). 
Mensagens entre dois nós de um multiprocessador utilizam suas próprias rotinas para a troca de mensagens. Já as mensagens destinadas a um host externo são roteadas através dos daemons.

\section{Grupos Dinâmicos de Tarefas}

Há aplicações onde é natural o agrupamento de tarefas em grupos e há casos onde o usuário gostaria de identificar suas tarefas por números (de 0 até p-1), onde p é o número de tarefas. Para essas aplicações, o PVM inclui o conceito de grupos dinâmicos, criados pelo usuário em tempo de execução. Quando uma tarefa une-se a um grupo, ela recebe um número único para aquele grupo, sendo que esses números começam no 0 (zero) e aumentam gradativamente.

As funções de manipulação dos grupos são projetadas para serem transparentes para o usuário. Uma tarefa pode unir-se e deixar qualquer grupo, em qualquer instante, sem precisar comunicar outra tarefa dos grupos afetados.

Uma biblioteca separada (libgpvm3.a) deve ser montada com as aplicações que fazem uso de qualquer função para grupos de tarefas. $O$ pvmd não possui nenhuma função para grupos. Essa tarefa é manipulada por um servidor de grupos iniciado automaticamente quando a primeira função para grupos for solicitada [GEI94] [SUN94].

\subsubsection{Message Passing Interface - MPI}

O grande número de plataformas portáteis propostas ao longo dos últimos anos levaram ao surgimento de problemas semelhantes aos dos ambientes de passagem de mensagens propostos inicialmente. A maioria das plataformas portáteis existentes possui apenas um subconjunto das características necessárias para os mais diversos 
equipamentos fabricados [MCB94], dificultando a tarefa de implementação em diferentes máquinas.

Devido a esses problemas foi criado o Comitê MPI (em 1992), para definir um padrão para os ambientes de passagem de mensagens denominado MPI (Message Passing Interface).

O MPI é uma tentativa de padronização de uma interface de passagem de mensagens para aplicações que utilizam arquiteturas paralelas de memória distribuída ou sistemas distribuídos.

David Walker [WAL95] relaciona, de maneira mais geral, uma série de motivos que explicam a necessidade de um padrão para este tipo de sistema:

- Portabilidade e facilidade de uso: À medida que aumente a utilização do MPI, será possível portar transparentemente aplicações entre um grande número de plataformas paralelas;

- Fornecer uma especificação precisa: Fabricantes de hardware podem implementar eficientemente em suas máquinas um conjunto bem definido de rotinas;

- Crescimento da indústria de software paralelo: A existência de um padrão torna a criação de software paralelo (ferramentas, bibliotecas, aplicativos, etc.) por empresas uma opção comercialmente viável;

- Incentivar uma maior utilização de arquiteturas paralelas: $O$ crescimento da indústria de software paralelo implica em maior difusão do uso de computadores paralelos.

O processo de desenvolvimento do MPI iniciou em abril de 1992, sendo que, em novembro do mesmo ano, uma primeira versão foi apresentada (MPI1) [WAL94] [DOS95].

A partir do MPI1, decidiu-se colocar o processo de padronização em bases mais formais, de maneira mais organizada. Foram então criados subcomitês, um para cada 
componente do MPI, e também foram criadas mailing-lists para cada um desses subcomitês. $O$ grupo de desenvolvimento passaria a se encontrar a cada seis semanas, e o conjunto dessas reuniōes e mailing-lists se definiu como o Fórum MPI.

Em novembro de 1993 foi apresentada a especificação do padrão MPI, sendo esta publicada em abril de 1994.

O processo de padronização envolveu cerca de 80 pessoas, provenientes de 40 organizações, principalmente americanas e européias. A maioria dos principais fabricantes de computadores paralelos participaram do desenvolvimento do MPI, além de universidades e laboratórios ligados ao governo. Os principais objetivos que guiaram o processo de padronização foram [DON95]:

- Lançar uma versão inicial em um tempo predefinido, de maneira que não se perdesse o controle sobre o padrão;

- Prover portabilidade real;

- Prover implementação eficiente em plataformas paralelas distintas;

- Possuir uma aparência compatível com a atualidade, visto que uma interface totalmente nova dificultaria a sua aceitação.

Levando-se em consideração o limite de tempo imposto à formulação do padrão, definiu-se um conjunto básico de rotinas relacionadas à comunicação ponto-a-ponto e coletiva, deixando para uma próxima versão uma maior abrangência de operações.

O MPI define um conjunto de 129 rotinas, que oferecem os seguintes serviços [DON95]: suporte para grupos de processos, suporte para contextos de comunicação, comunicação ponto-a-ponto e comunicação coletiva [WAL94] [DON95] [MAL96].

\section{Suporte para Grupos de Processos}

O MPI relaciona os processos em grupos, e estes processos são identificados pela sua classificação dentro desse grupo. Por exemplo, suponha um grupo contendo $\mathbf{n}$ 
processos: estes processos serão identificados utilizando-se números entre 0 e n-1. Essa classificação dentro do grupo é denominada rank. O MPI apresenta primitivas de crią̧ão e destruição de grupos de processos. Assim, um processo no MPI é identificado por um grupo e por um rank dentro deste grupo [DON95].

No MPI, os grupos são projetados para serem estáticos, pois todos eles derivam de um grupo inicial e novos processos não podem ser criados durante a execução do programa [MAL96].

\section{Suporte para Contextos de Comunicação}

Contextos podem ser definidos como escopos que relacionam um determinado grupo de processos. Estes tipos de instâncias são implementadas com o intuito de garantir que não hajam mensagens que sejam recebidas ambiguamente por grupos de processos não relacionados. Isto é, um grupo de processos ligados por um contexto não consegue comunicar-se com um grupo que esteja definido em outro contexto. Apesar do usuário definir os grupos, este tipo de estrutura não é visível nem controlável pelo usuário, e o seu gerenciamento fica a cargo do sistema.

Um novo conceito muito importante introduzido pelo MPI é o communicator. Um communicator é um objeto manuseado pelo programador e relaciona um grupo (ou grupos) de processos com um determinado contexto. Se existem, por exemplo, aplicações paralelas distintas executando em um mesmo ambiente, para cada uma delas será criado um communicator. Isso criará contextos distintos que relacionarão os grupos de processos de cada aplicação e evitará que os processos interfiram entre si.

\section{Comunicação Ponto-a-Ponto}

As rotinas de comunicação ponto-a-ponto são responsáveis pela ação básica de uma biblioteca de troca de mensagens, que trata da transferência de uma mensagem. Uma 
comunicação ponto-a-ponto envolve dois processos: um processo enviando e outro processo recebendo uma mensagem. Estas operações são feitas pela utilização de duas rotinas: send() que é responsável pela transmissão e receive() que é responsável pela recepção de uma mensagem.

Todo procedimento de comunicação ponto-a-ponto no MPI possui uma versão bloqueante e uma não bloqueante.

Rotina send(): A maneira eficiente de implementação de uma rotina send(), depende de certa maneira do protocolo e da plataforma paralela sobre o qual o MPI está executando. Para garantir a eficiência em qualquer plataforma, o MPI define vários modos de comunicação, que definem diferentes semânticas para a rotina. Os modos disponíveis, que apresentam versões bloqueantes e não bloqueantes, são [DON95]:

- Síncrono: o transmissor, ao enviar uma mensagem, espera uma confirmação de recep̧̧ão da mensagem;

- Padrão: envia uma mensagem, sem se preocupar se o receive() correspondente foi executado, e sem que a mensagem seja explicitamente bufferizada pelo MPI;

- bufferizado: similar ao modo padrão, diferindo no fato de existirem buffers criados explicitamente pelo programador;

- ready: similar ao modo padrão, excetuando-se que o receive() correspondente deve ter sido obrigatoriamente iniciado.

Rotina Receive(): Uma mensagem é selecionada para recebimento pelo rank do processo que a enviou e pelo seu identificador (tag), dentro de um determinado contexto. Esses dois valores podem ser wild-cards, isto é, pode-se utilizar rotinas que recebam de qualquer processo mensagens de qualquer tag. A rotina receive() é implementada apenas no modo padrão, bloqueante ou não bloqueante. 


\section{Comunicação coletiva}

As rotinas coletivas caracterizam-se pela participação de dois ou mais processos em cada operação de comunicação [MAL96]. Estas funções podem ser construídas a partir de rotinas de comunicação ponto-a-ponto.

Algumas das operações coletivas disponiveis no MPI são:

- Rotina de sincronização - barrier(): A função desta rotina é retornar depois de ter sido chamado por todos processos relacionados com o communicator que foi passado como um argumento para o barrier(). Uma chamada barrier (barreira) não tem efeito na memória local dos processos.

- broadcast(): Um broadcast envia uma mesma mensagem de um processo (raiz), para todos os outros processos relacionados a um communicator (o processo raiz deve também pertencer a este communicator). A figura 2.9 ilustra um broadcast, onde um processo $P_{1}$ (raiz) envia a mesma mensagem (a) para os processos $P_{2}, P_{3}, P_{4}, P_{5}$ pertencentes ao mesmo communicator.

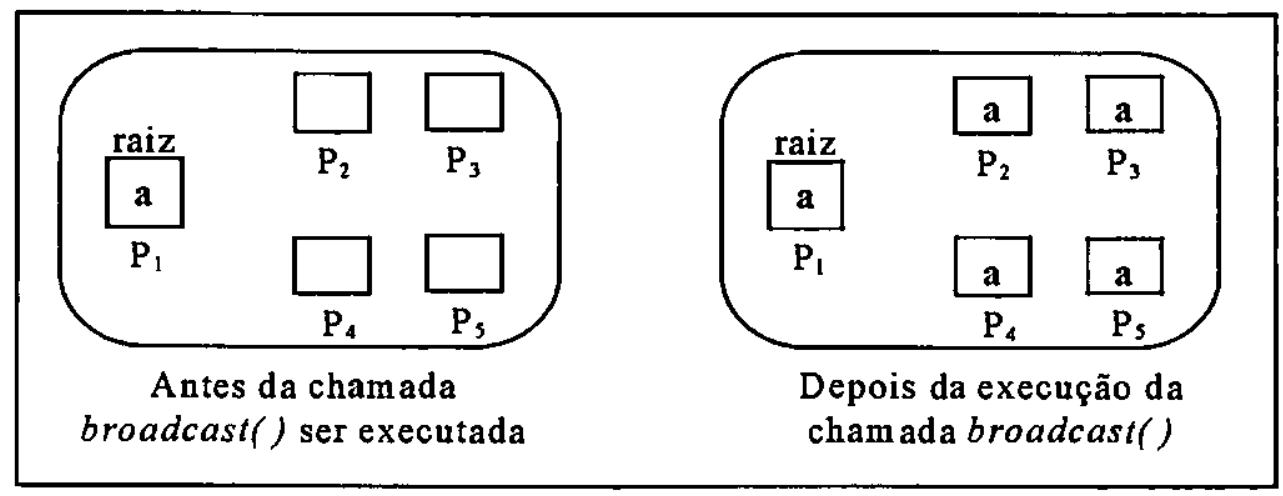

Figura 2.9 - Exemplo da Rotina broadcast()

- Rotina aritmética global - reduce(): Um processo raiz é responsável por receber os operandos de cada um dos processos relacionados com o communicator e calcular o resultado desejado, executando uma determinada operação (como soma, produto, entre 
outras). A seqüência resultante é armazenada na seqüência de saída do processo raiz, como pode ser visto na figura 2.10 .

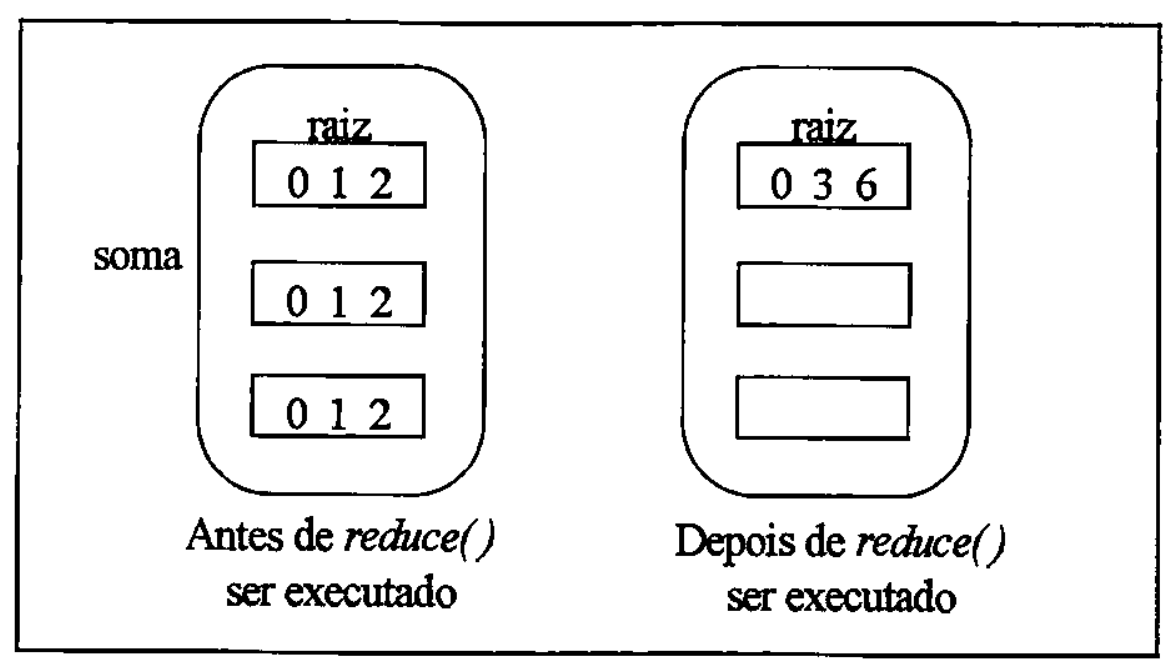

Figura 2.10 - Exemplo da Rotina reduce()

- Rotinas scatter () e gather(): Na operação scatter, um processo raiz envia diferentes mensagens (do mesmo tipo de dados) para cada um dos processos relacionados com o argumento communicator (em comparação, o broadcast envia a mesma mensagem para todos os processos). Na operação gather, o processo raiz recebe e concatena mensagens distintas de todos os processos associados com o argumento communicator. A fiomra 2.11 ilustra as rotinas scatter e gather

A grande variedade de funções coletivas disponíveis no virı vasam garantir operações coletivas eficientes em todas as plataformas paralelas [DON95]. Todas as operações coletivas no MPI são bloqueantes e executam no modo padrão (exceto as rotinas de sincronização que operam -...-dn síncrono). 


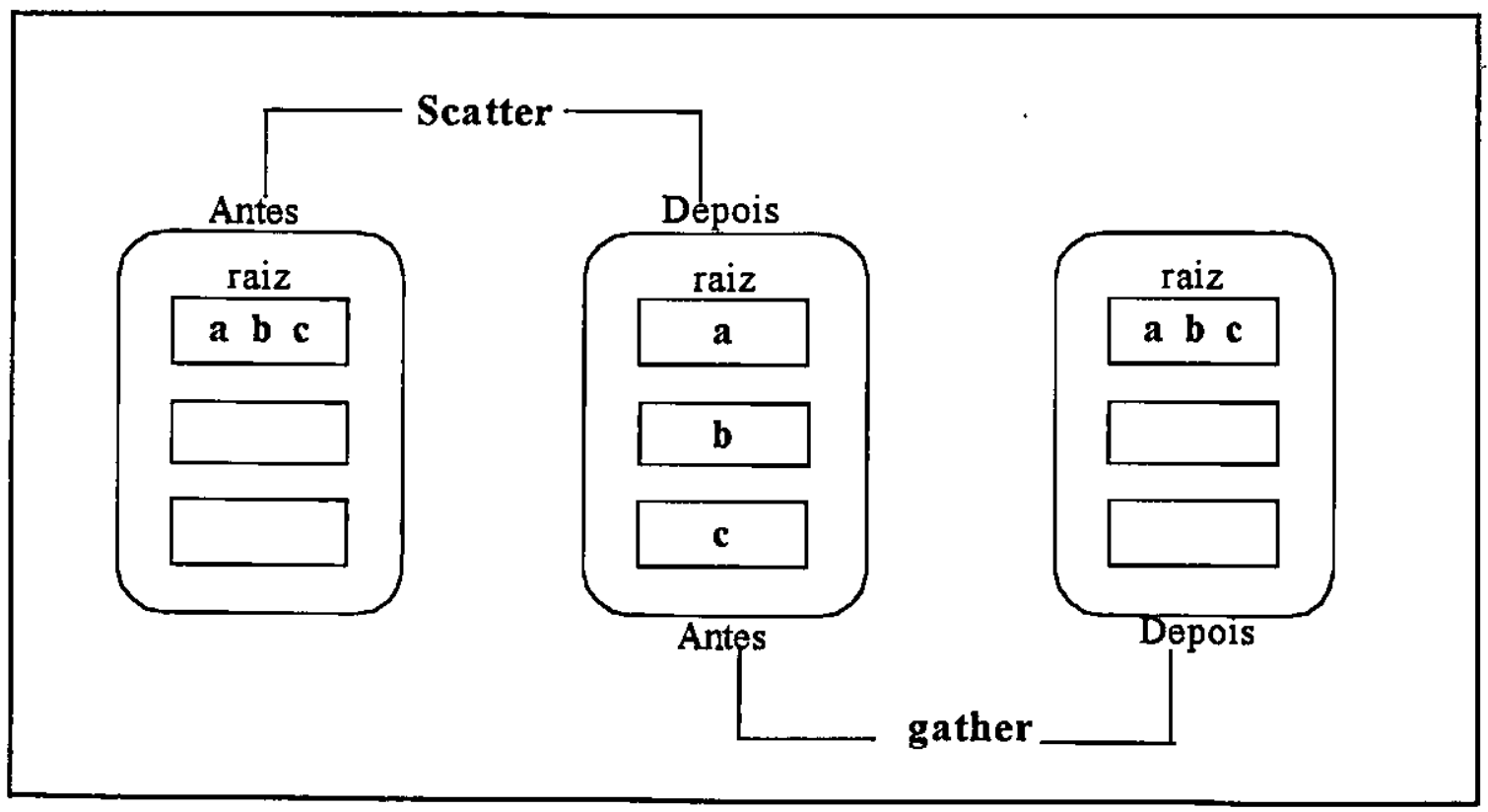

Figura 2.11 - Exemplo da Rotinas scatter() e gather()

\subsection{Considerações Finais}

A computação paralela surgiu principalmente para suprir a necessidade de se aumentar a potência computacional. Como o aumento do desempenho nas arquiteturas de von Neumann apresenta limitações tecnológicas, a computação paralela se torna uma alternativa mais apropriada, principalmente para problemas intrinsicamente paralelos.

O processamento paralelo vem se tornando uma realidade dentro da comunidade empresarial, sendo que isto se deve principalmente à sua ótima relação custo/desempenho, confiabilidade e produtividade [KIR91] [ALM94].

Muita experiência já foi adquirida em relação ao hardware para computação paralela, mas em relação ao software existem muitas lacunas a serem preenchidas e muito ainda a ser pesquisado [NAV89]. Segundo Zaluska [ZAL91], as características fundamentais que um software paralelo deve possuir englobam: ser facilmente transportado entre arquiteturas diferentes, ser facilmente ampliado para acomodar grandes problemas sem dificuldade e ser de uso fácil. 
No cenário atual existem três tipos de ferramentas que dão suporte à programação paralela: ambientes de paralelização automática, extensões paralelas para linguagens seriais (ambientes de passagem de mensagens) e linguagens concorrentes [ALM94].

Os ambientes de passagem de mensagem foram desenvolvidos com três objetos principais:

- Utilizar o potencial dos sistemas distribuídos para o desenvolvimento de aplicações paralelas;

- Permitir a união de plataformas heterogêneas;

- Permitir a portabilidade das aplicações paralelas desenvolvidas.

Visando tornar essas aplicações independentes da arquitetura utilizada, formulou-se a idéia de plataformas de portabilidade. Vários ambientes de passagem de mensagem, como o MPI e PVM, foram desenvolvidos seguindo essa idéia e os demais objetivos da computação paralela distribuída.

Esses ambientes, caracterizados pela busca de simplicidade e eficiência, permitem que aplicações paralelas sejam desenvolvidas, utilizando hardware relativamente barato (se comparado às máquinas paralelas) e com software familiar à equipe de desenvolvimento [MCB94]. 


\section{Capítulo 3}

\section{Arquiteturas Paralelas}

Este capítulo apresenta uma revisão sobre plataformas para computação paralela, através das seguintes seções: classificação de arquiteturas paralelas e sistemas distribuídos (como uma plataforma paralela).

\subsection{Introdução}

O processamento paralelo surgiu da necessidade de um melhor desempenho para aplicações que necessitam de uma grande potência computacional. Essa potência não encontra-se ainda, mesmo com o avanço tecnológico, nas arquiteturas seqüenciais de von Neumman. Uma vantagem adicional da utilização de arquiteturas paralelas é nos problemas intrinsecamente paralelos, que neste caso apresentam uma solução mais natural [ALM94].

Apesar do $I L L L A C I V$, máquina construída na década de 60 na Universidade de Illinois e composta de 64 processadores, ser considerado o marco inicial do surgimento de máquinas paralelas, em 1940 von Neumman já possuía artigos publicados propondo o uso de processamento paralelo em um método para a resolução de equações diferenciais [NAV89]: Isso demonstra que a idéia da utilização de elementos de processamento que interagem entre si para a resolução de problemas é quase tão antiga quanto a idéia da própria computação. Mesmo assim, a filosofia de von Neumman ainda representa um grande obstáculo que a computação paralela necessita remover.

Um computador paralelo é um conjunto de processadores capaz de trabalhar cooperativamente para resolver um problema computacional rapidamente. Esta definição é suficiente para incluir supercomputadores com centenas e milhares de processadores, redes de computadores e estações multiprocessadoras [FOS95]. 


\subsection{Classificação de Arquiteturas Paralelas}

Com o avanço do processamento paralelo, observa-se que foram propostas inúmeras arquiteturas, cada uma apresentando características diferentes. Portanto, para que se possa visualizar melhor todo o conjunto de possíveis opções de arquiteturas paralelas, é interessante classificá-las.

Para acompanhar o desenvolvimento das arquiteturas e para agrupar equipamentos com características comuns, foram propostas algumas classificações. A mais conhecida pela comunidade computacional é a classificação de Flynn [FLY72], embora muito antiga, é amplamente utilizada e baseia-se no fluxo de instruções e no fiuxo de dados. Duncan [DUN90] propõe uma classificação mais completa, com o objetivo de acrescentar novas arquiteturas surgidas, permitindo apresentar uma visão geral dos estilos de organização para computadores paralelos da atualidade.

\subsubsection{Classificação de Flynn}

Flynn [FLY72], em 1966, propôs uma classificação das arquiteturas em quatro categorias de máquinas conforme a multiplicidade do fluxo de dados e de instruções. A palavra fluxo é empregada para descrever uma seqüência de instruções, ou dados, executados pela máquina. Portanto, um fluxo de instruções é uma seqüência de instruções executadas por um processador, enquanto um fluxo de dados é uma seqüência de dados, de entrada, de resultados parciais ou intermediários, utilizados pelo fluxo de instruções [HWA87].

Usando um modelo baseado em fluxos, pode-se representar os diferentes tipos de paralelismo disponíveis. Desta forma, Flynn combina quatro categorias de arquiteturas paralelas [FLY72][QUI87][NAV89][FLY96]: SISD (Single Instruction Stream, Single Data Stream), SIMD (Single Instruction Stream, Multiple Data Stream), MISD (Multiple 
Instruction Stream, Single Data Stream) e MIMD (Multiple Instruction Stream, Multiple

Data Stream). Cada uma destas combinações caracterizam uma classe de arquitetura e um tipo correspondente de paralelismo.

- SISD: Esta categoria possui apenas um fluxo de instruções e um fluxo de dados. São as máquinas baseadas no princípio de Von Neumann. As instruções são executadas seqüencialmente sobre um único fluxo de dados, mas podem ser sobrepostas nos seus estágios de execução (pipeline) ${ }^{*}$. Os computadores SISD podem ter mais de uma unidade funcional porém todos sob a supervisão de uma unidade de controle. A figura 3.1 ilustra uma máquina SISD.

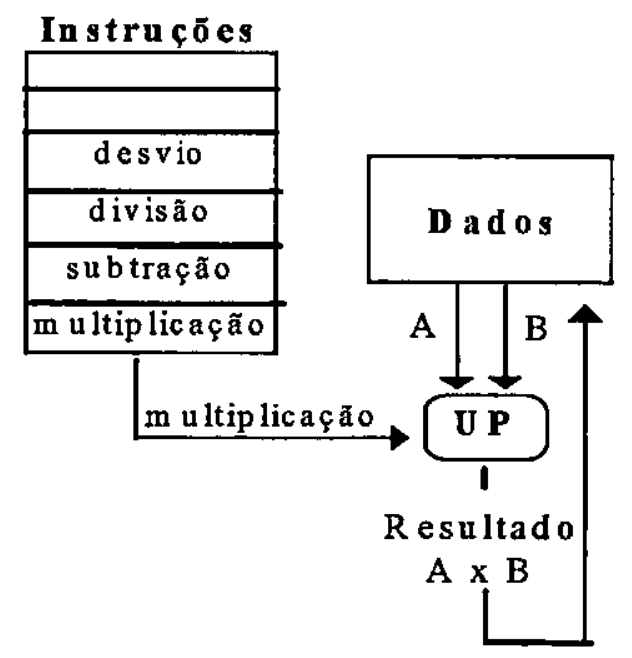

UP - Unidade de Processamento

Figura 3.1 - Exemplo de Arquitetura SISD [QUI87].

- SIMD: A categoria SIMD, único fluxo de instruções com múltiplos fluxos de dados, possui várias unidades de processamento supervisionados por uma mesma unidade de controle (Figura 3.2). Isso faz com que todos os processadores executem as mesmas instruções sobre dados diferentes. A memória utilizada pode ser compartilhada por

\footnotetext{
"Pipeline implica na execução de eventos sobrepostos no tempo. Uma determinada tarefa é subdividida em uma sequência de subtarefas, sendo cada uma delas executada por um estágio especializado de hardware e software que opera concorrentemente com os outros estágios do pipeline [HWA84].
} 
todas as unidades de processamento ou pode estar dividida em módulos, vinculados a cada unidade de processamento. Processadores matriciais são exemplos desta categoria [QUI87] [NAV89].

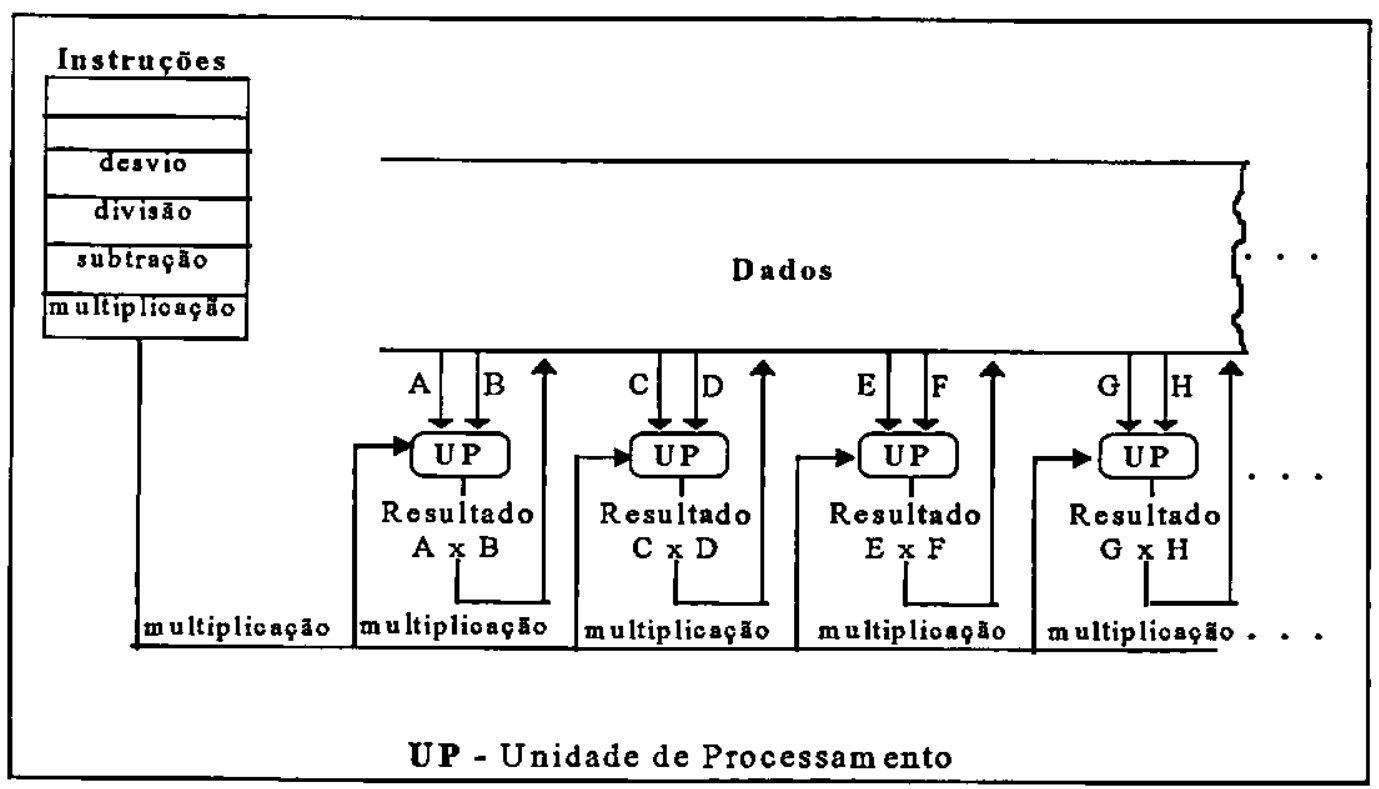

Figura 3.2 - Exemplo de Arquitetura SIMD [QUI87].

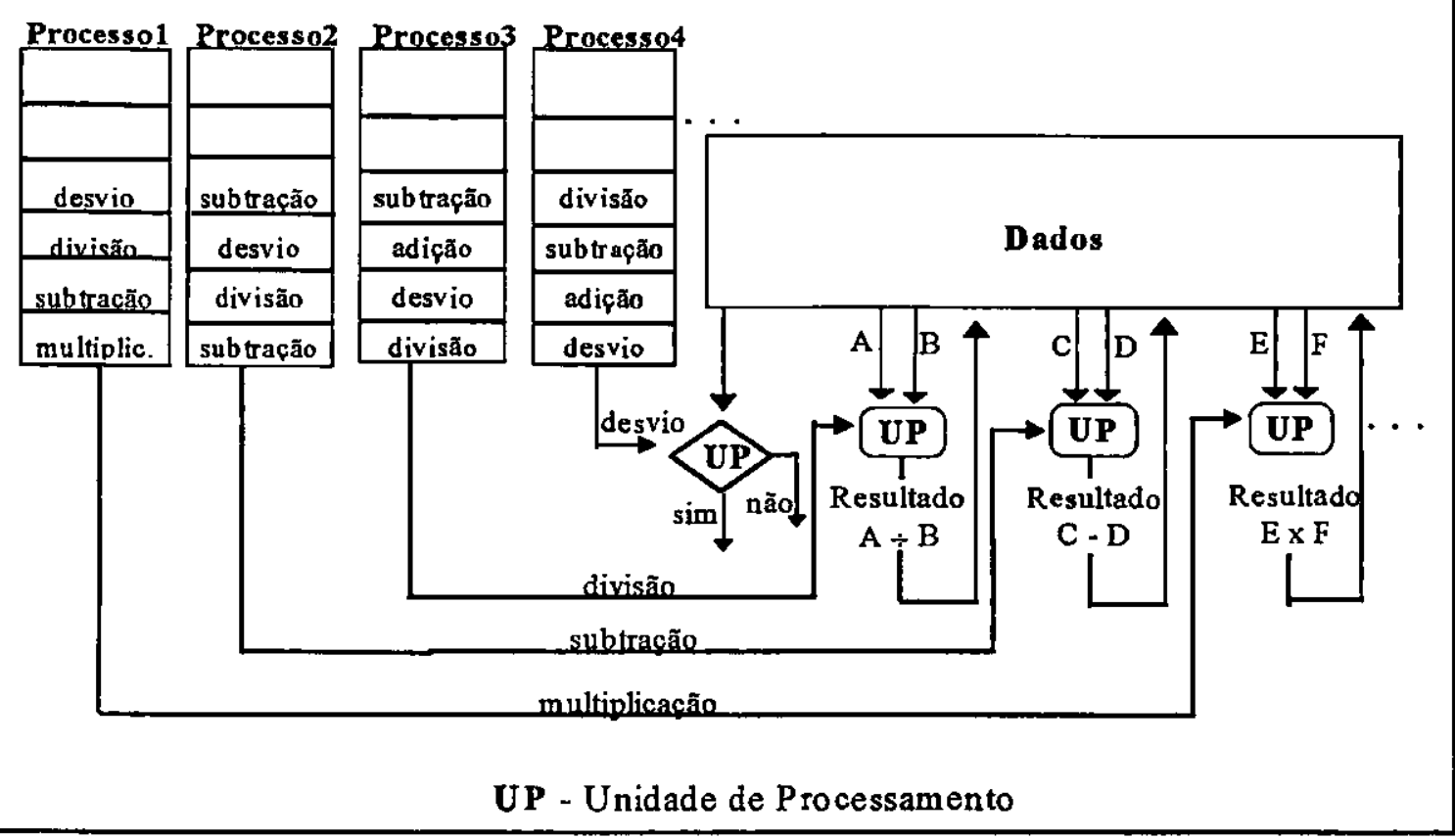

Figura 3.3 - Exemplo de Arquitetura MIMD [QUI87]. 
-MISD: A categoria MISD, múltiplo fluxo de instruções e único fluxo de dados, corresponderia a uma máquina que tivesse várias unidades de processamento recebendo instruções distintas das unidades de controle, porém processando o mesmo fluxo de dados. Não há, na literatura disponivel, exemplos de máquinas MISD. Contudo, alguns autores [NAV89] [FLY96] citam a possibilidade de encaixar o pipeline como representante dessa categoria.

-MIMD: A categoria MIMD, múltiplo fluxo de instruções e de dados é a mais difundida e a classificação básica de um computador paralelo [FLY96]. Cada unidade de processamento, possui sua unidade de controle executando instruções sobre conjuntos de dados (Figura 3.3). A comunicação entre os diversos processadores é feita através da memória. Máquinas MIMD podem ser fracamente ou fortemente acoplados, dependendo do grau de interação existente entre os processadores. Os multiprocessadores e os multicomputadores são representantes desta categoria.

\subsubsection{Classificação de Duncan}

Para Duncan [DUN90], o primeiro passo para fornecer uma classificação satisfatória é definir uma arquitetura paralela. A definição incluiria computadores apropriados que a classificação de Flynn não pôde abranger, e excluir arquiteturas que incorporam apenas paralelismo de baixo nível. A classificação de Duncan mostra várias alternativas de arquiteturas paralelas, como ilustrado na figura 3.4.

\section{Arquiteturas Síncronas}

Arquiteturas paralelas síncronas, coordenam suas operações concorrentes sincronamente em todos os processadores através de relógios globais, unidades de controle únicas ou controladores de unidades vetorias [DUN90]. Fazem parte desta categoria: 
- Processadores Vetoriais: Um processador vetorial contém um hardware específico, que permite que sejam executadas seqüências de operações idênticas sobre vetores de forma mais rápida do que uma seqüência de operações escalares [ALM94]. Essas arquiteturas foram desenvolvidas com o intuito de prover mecanismos eficientes para o suporte de cálculos pesados em matrizes e vetores. Os processadores vetoriais utilizam pipeline para agilizar a execução das operações. Esquematicamente, a organização básica de um processador vetorial apresenta um processador escalar (para a execução do código não vetorizável do programa), uma unidade de processamento vetorial e um processador de instruções (que define quais instruções serão executadas em qual processador).

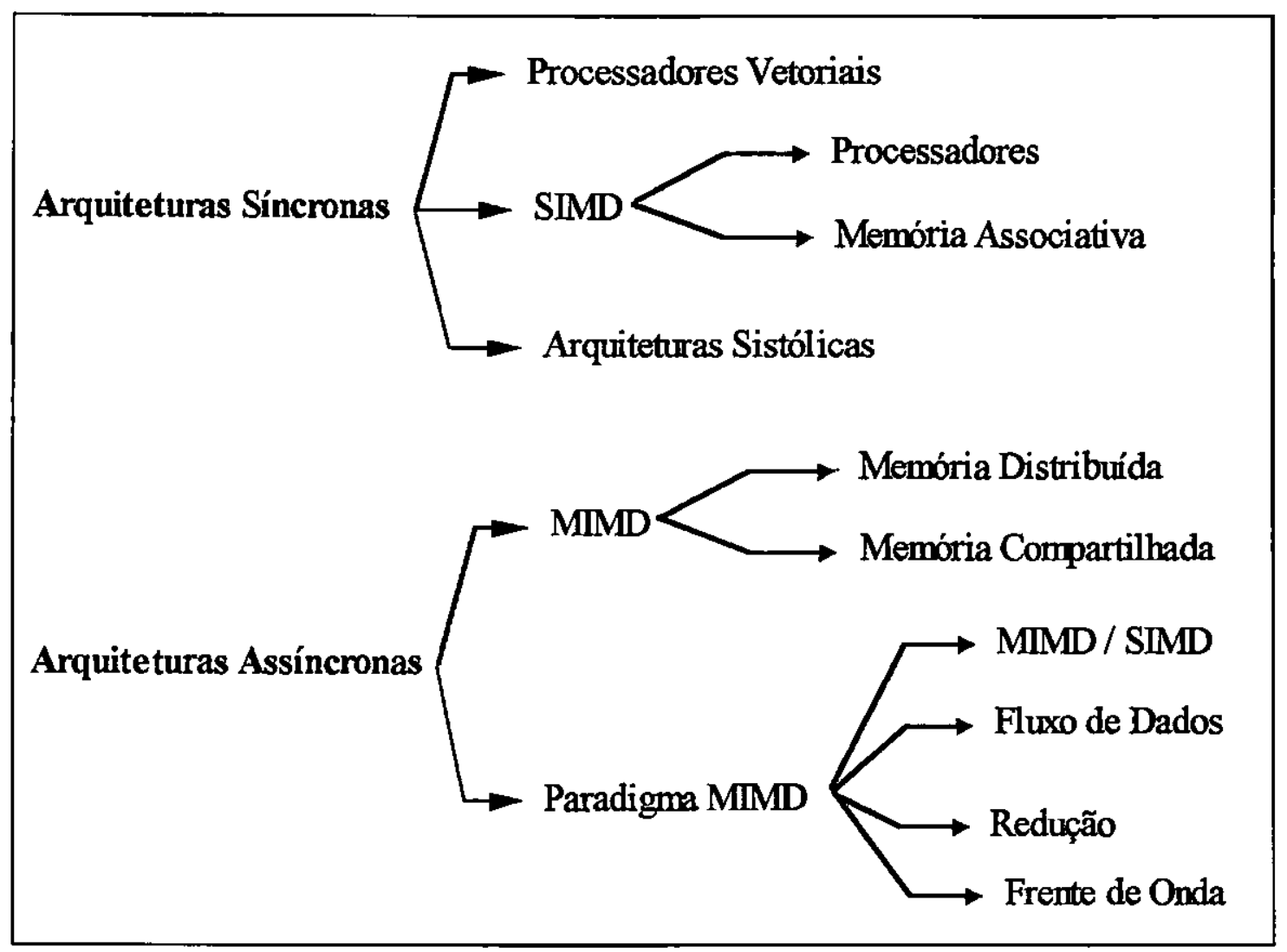

Figura 3.4 - Classificação de Duncan [DUN90]

- Arquiteturas SIMD: As arquiteturas SIMD, como já descrito anteriormente, apresentam vários processadores sobre a supervisão de uma unidade de controle central. 
Os processadores executam a mesma instrução sincronamente em conjuntos de dados distintos. Os processadores matriciais e processadores com memória associativa são representantes desta categoria.

Os processadores matriciais foram projetados especialmente para cálculos científicos (como processamento de imagens) e cálculo sobre matrizes. Esta arquitetura fornece acesso à memória via endereço. A máquina Illiac IV, desenvolvida no fim da década de 60, é um exemplo desta arquitetura [DUN90] [ALM94].

Os processadores com memória associativa constituem um tipo de arquitetura SIMD que utiliza uma comparação lógica para acessar os dados armazenados na memória, de acordo com seu conteúdo. Ao invés de ter uma memória de acesso randômico, um processador associativo é construído em torno de uma memória associativa que permite pesquisas simultâneas à memória de acordo com um certo padrão de dados. Exemplos desse tipo de arquitetura são: Goodyer Aerospace STARAN e PEPE (Parallel Element Processing Esemble) [NAV89].

- Arquiteturas Sistólicas: Essas arquiteturas foram propostas no início da década de 80, por H. T. Kung na Universidade de Carnegie Mellon, para resolver os problemas de sistemas que necessitem de computação intensiva com grande quantidade de operações de E/S. Arquiteturas sistólicas são multiprocessadores pipelined, cuja informação trafega de maneira rítmica e sincronizada por vários processadores, através de um relógio global, antes de retornar à memória. Desta forma, a comunicação entre os processadores não necessita de armazenamento temporário dos dados em memória.

\section{Arquiteturas Assíncronas}

As arquiteturas assincronas se caracterizam por ter um controle descentralizado, onde múltiplos processadores podem executar diferentes fluxos de instruções, utilizando dados locais, de maneira independente. Essas arquiteturas são compostas basicamente por máquinas MIMD, convencionais ou não. A categoria MIMD, proposta por Flynn, é um 
computador assíncrono, sendo caracterizado pelo controle descentralizado de hardware, onde cada processador opera de maneira altamente autônoma [DUN90].

- Arquitetura MIMD: A comunicação e o sincronismo entre os vários processadores dessa arquitetura, são realizados de acordo com a organização da memória. A memória pode ser compartilhada (comum a todos os processadores) ou distribuída (cada processador possui sua própria memória local).

Nas arquiteturas MIMD com memória compartilhada, têm-se um único espaço de endereçamento para todos os processadores. Essas máquinas também são chamadas de multiprocessadores e são fortemente acoplados devido à grande quantidade de troca de informação existente entre os processadores. A comunicação entre os processadores é feita através do compartilhamento de posições de memória. Para garantir que acessos concorrentes não tornem as informações inconsistentes, são necessários mecanismos de hardware e software adicionais. Geralmente, arquiteturas de memória compartilhada implementam mecanismo de cache, para evitar que a memória se torne um gargalo. A figura 3.5(a) ilustra uma arquitetura MIMD com memória compartilhada.

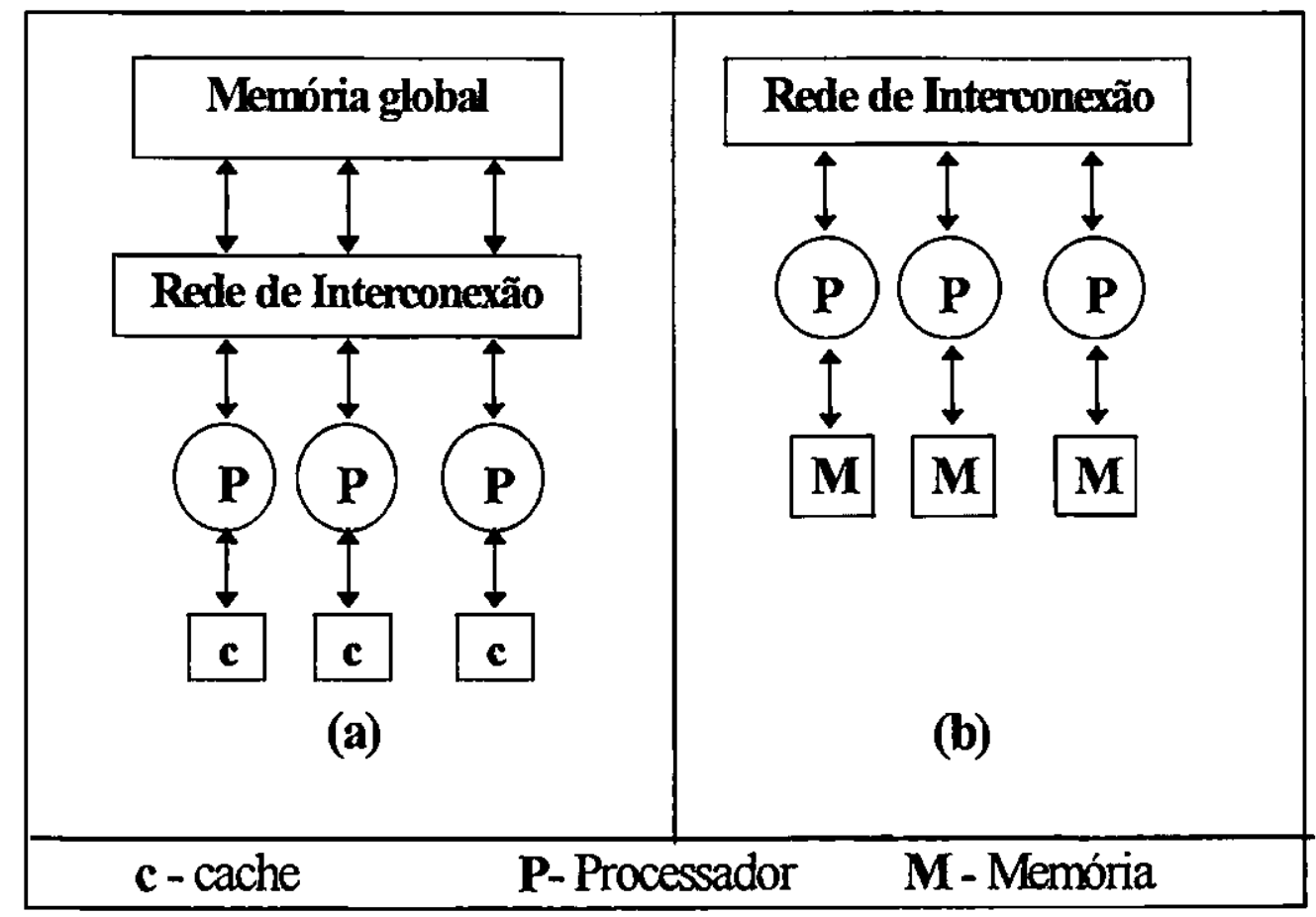

Figura 3.5 - Arquitetura MIMD. (a) Mem. Compartilhada (b) Mem. Distribuída 
As arquiteturas MIMD com memória distribuida possuem processadores autônomos com suas próprias memórias locais, e desta forma o espaço de endereçamento é distinto para cada processador, como mostra a figura 3.5(b). Pelo fato de não haver compartilhamento de memória, a comunicação e o sincronismo ocorrem via troca de mensagens (transferência explicita de dados entre os processadores), através da rede de interconexão. Essas máquinas, também denominadas de multicomputadores, são fracamente acoplados, onde as aplicações procuram evitar grande quantidade de troca de informações, devido ao tempo de latência existente na troca de mensagens.

- Paradigma MIMD: Esta categoria engloba as arquiteturas que não se encaixam em nenhuma das categorias anteriores. Máquinas híbridas - MIMD/SIMD, a fluxo de dados, redução e de frente de onda são exemplos dessas arquiteturas. Elas apresentam aspectos MIMD, pois são assíncronas e com múltiplos fluxos de instruções e de dados, mas possuem suas próprias características, dificultando sua classificação como puramente MIMD. Por esta razão, essas máquinas são denominadas paradigmas MIMD.

As arquiteturas híbridas - MIMD/SIMD caracterizam-se por apresentarem controle SIMD para determinadas partes de uma arquitetura MIMD. A flexibilidade que essas arquiteturas possuem, as tornam candidatas atrativas para pesquisas futuras. Elas podem suportar aplicações como processamento de imagens e sistemas especialistas.

A característica fundamental de arquiteturas de fluxo de dados é que uma instrução é executada assim que todos os seus operandos estejam disponíveis [DUN90]. A seqüência de instruções executadas é baseada na dependência dos dados, permitindo a essas arquiteturas explorarem concorrência à nível de tarefa, rotina e instruções (granulação fina). Desta forma, a execução de um programa é controlada de maneira não centralizada, com os dados fluindo de instrução a instrução, de maneira que se consiga paralelismo em alta escala.

As arquiteturas de Redução ou arquiteturas dirigidas por demanda, implementam um paradigma de execução na qual uma instrução é ativada para ser executada quando os 
seus resultados são requeridos como operandos por outra instrução já ativada para execução [DUN90]. Essas arquiteturas são baseadas no conceito de redução, que implica que partes do código fonte original sejam reduzidas aos seus resultados em tempo de execução [KIR91]. Assim, os processadores só executam os comandos quando as expressões necessitam do seu cálculo.

As arquiteturas de Frente de Onda combinam as estruturas pipeline sistólicas com o paradigma assíncrono de execução baseada no fluxo de dados. Essas arquiteturas foram construídas com os mesmos objetivos de balanceamento entre computação e E/S das arquiteturas sistólicas. Tanto as arquiteturas de frente de onda, como arquiteturas sistólicas, possuem uma rede de conexão regular interligando os processadores. Porém, as arquiteturas de frente de onda substituem o relógio global e os atrasos explícitos, usados para sincronização das estruturas pipeline, por protocolos assíncronos, para coordenar os movimentos dos dados entre os processadores [DUN90].

Como pode ser observado nesta seção, a classificação de Duncan envolve a maioria das arquiteturas existentes, nos quais a classificação de Flynn falha. Além disso, uma característica importante da classificação proposta por Duncan é a presença dos termos MIMD e SIMD, propostos por Flynn e largamente aceitos.

As arquiteturas MIMD (principalmente o modelo de memória distribuída), são as arquiteturas que mais se destacam, devido à sua flexibilidade e por representar uma boa opção para o desenvolvimento de algoritmos paralelos de granulação média e grossa [ZAL91] [BLE94].

\subsection{Sistemas Distribuídos}

Há pouco mais de uma década, os sistemas computacionais eram em sua maioria sistemas centralizados (sistema de único processador). Isto é, grande mainfraimes, computadores de grande porte e alto preço, eram compartilhados entre diversos usuários. 
A maioria das organizações possuiam poucos computadores, e por falta de meios de interconexão estes operavam separadamente [TAN95].

Com o avanço tecnológico, poderosos microprocessadores foram desenvolvidos, alguns com poder computacional comparável a mainfraimes, a custo mais acessível. Além disso, houve uma grande evolução na tecnologia de interconexão de computadores. Estes dois avanços tecnológicos, permitiu a difusão do uso de redes de computadores.

O surgimento de redes locais de computadores, no início da década de 70 , possibilitou a construção de sistemas compostos por um grande número de processadores ligados através de redes de alta velocidade. Tais sistemas são denominados sistemas distribuídos, em contraste aos sistemas centralizados anteriormente citados [TAN95].

Dessa forma, com a disponibilidade de computadores pessoais e estações de trabalho de alto desempenho, vários projetos foram desenvolvidos tornando os sistemas distribuídos mais eficazes e mais difundidos [COU94].

A definição de sistemas distribuídos não é única. Pode-se dizer que não há ainda entre os especialistas da área uma definição de sistemas distribuídos que seja consensual. Segundo Tanenbaum [TAN88] [TAN95], esses sistemas podem ser definidos como: "Um sistema distribuído é aquele que roda em um conjunto de máquinas sem memória compartilhada, máquinas estas independentes que aparecem aos usuários do sistema como um único computador."

Coulouris [COU94], apresenta uma definição um pouco mais extensa: "Um sistema distribuído consiste de uma coleção de computadores autônomos ligados por uma rede de computadores e equipados com software de sistema distribuído. Usuários de um sistema distribuído bem projetado devem perceber um sistema computacional único e integrado mesmo que ele possa estar implementado por muitos computadores em diferentes localizações."

Cada autor descreve um conjunto de características que um sistema deve possuir para que ele possa ser considerado um sistema distribuído. Embora, essas características variem de autor para autor, uma característica muito importante e que destaca-se como 
um conceito comum a todos eles, é a transparência [MÜL93] [COU94] [TAN95]. Isto

é, apesar de existirem vários computadores ligados trabalhando em conjunto, é interessante que esta distribuição fique transparente ao usuário, de maneira que este enxergue todo o ambiente como um sistema único.

Um sistema distribuído deve possuir algumas características básicas que todos projetistas de sistemas buscam alcançar. Essas características, que são discutidas a seguir, demonstram a potencialidade e utilidade que esses sistemas têm a oferecer.

\subsubsection{Características Essenciais}

Coulouris [COU94] apresenta seis características que todo sistema distribuído bem projetado deve oferecer: compartilhamento de recursos, abertura, concorrência, "escalabilidade", tolerância a falhas e transparência [COU94].

Compartilhamento de recursos significa a disponibilidade para que qualquer usuário possa acessar os recursos do sistema, não importando sua localização física. $O$ termo recurso engloba tanto os componentes de hardware (como discos e impressoras) como de software (como arquivos, banco de dados, entre outros).

Abertura é a característica que determina se um sistema pode ser expandido, sempre que necessário. Um sistema pode ser aberto ou fechado. Ele é aberto quando pode ser expandido em termos de hardware (como adicionar novos periféricos, memórias, discos e interfaces de comunicação) e de software (como adicionar novas características do sistema operacional, protocolos de comunicação e serviços de compartilhamento de recursos).

Concorrência existe quando diversos processos estão disputando por algum recurso, ou seja se há $N$ processos e $M$ processadores, sendo $N>M$, os processos são executados concorrentemente. Por outro lado, se existem $\mathrm{N}$ processos e $\mathrm{N}$ processadores, os processos podem ser executados simultaneamente, ou seja, eles são 
executados em paralelo. Em sistemas distribuídos existem vários computadores com um ou mais processadores, cada qual executando uma ou várias tarefas.

"Escalabilidade" é a capacidade de se expandir o sistema sem interferir em suas características (por exemplo, a perda de desempenho com o aumento do número de estações de trabalho).

Tolerância a falhas é uma característica que todo sistema distribuído deve ter. Ela implica na recuperação de possíveis falhas provenientes tanto do hardware como do software. O projeto de mecanismos visando a tolerância a falhas do sistema é feito considerando-se dois aspectos fundamentais: a redundância de hardware (com a replicação de componentes essenciais - como um servidor de arquivos) e a recuperação de software (com o projeto de programas que recuperam dados em face de uma falha.).

Transparência é uma das características mais importantes em sistemas distribuídos, sendo a responsável por fazer com que um conjunto de máquinas seja visto por seus usuários como um sistema único, isto é, o uso de múltiplas unidades de processamento deve ser invisível ao usuário.

\subsubsection{Modelos Arquiteturais}

Vários modelos arquiteturais foram propostos na década de 80, visando alcançar as características essenciais de sistemas distribuídos, considerando-se também os objetivos e recursos disponíveis do sistema. Os modelos propostos são: estação de trabalho/servidor, banco de processadores, modelo híbrido e modelo integrado [COU94].

Estação de trabalho/Servidor: Este modelo consiste de uma coleção de estações interligadas através de uma rede de comunicação, como mostra a figura 3.6. A maioria dos sistemas distribuídos existentes são baseados neste modelo. As estações com uma melhor configuração (como maior potência de processamento, mais memória, presença de discos entre outros) geralmente desempenham a função de servidoras. As estações com menos recursos são utilizadas apenas para executar as aplicações dos usuários. 


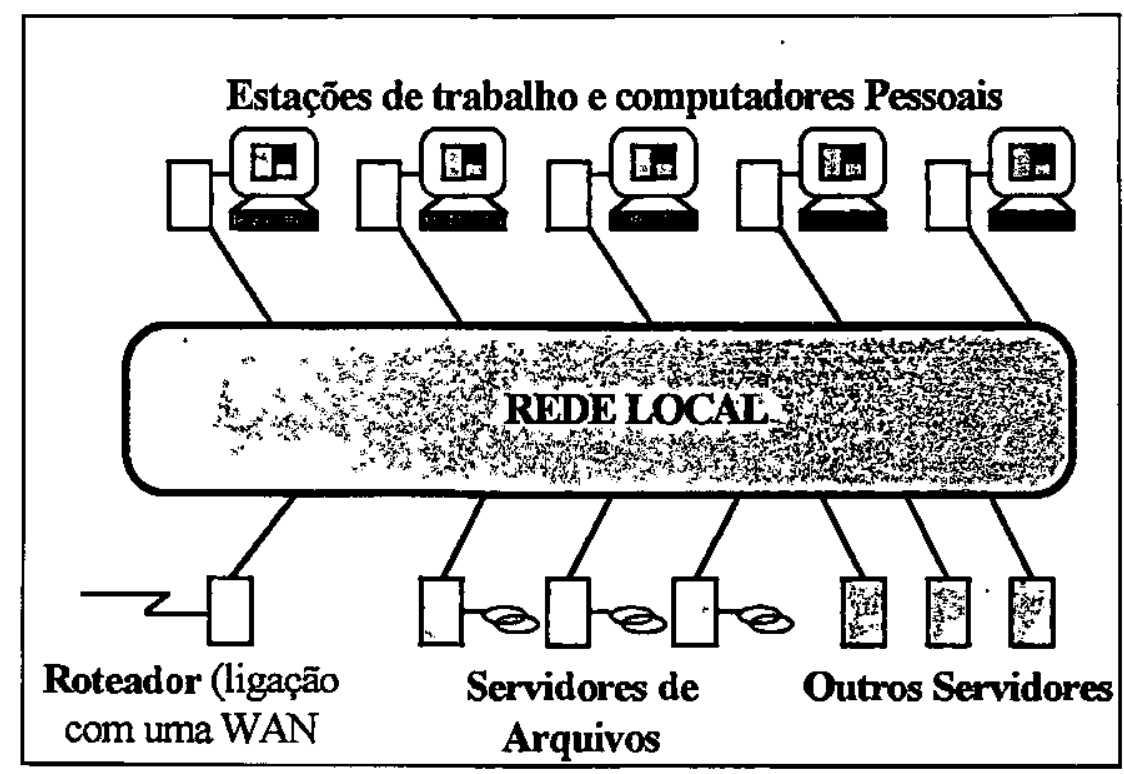

Figura 3.6 - Modelo Arquitetural Estação de Trabalho/Servidor [COU88].

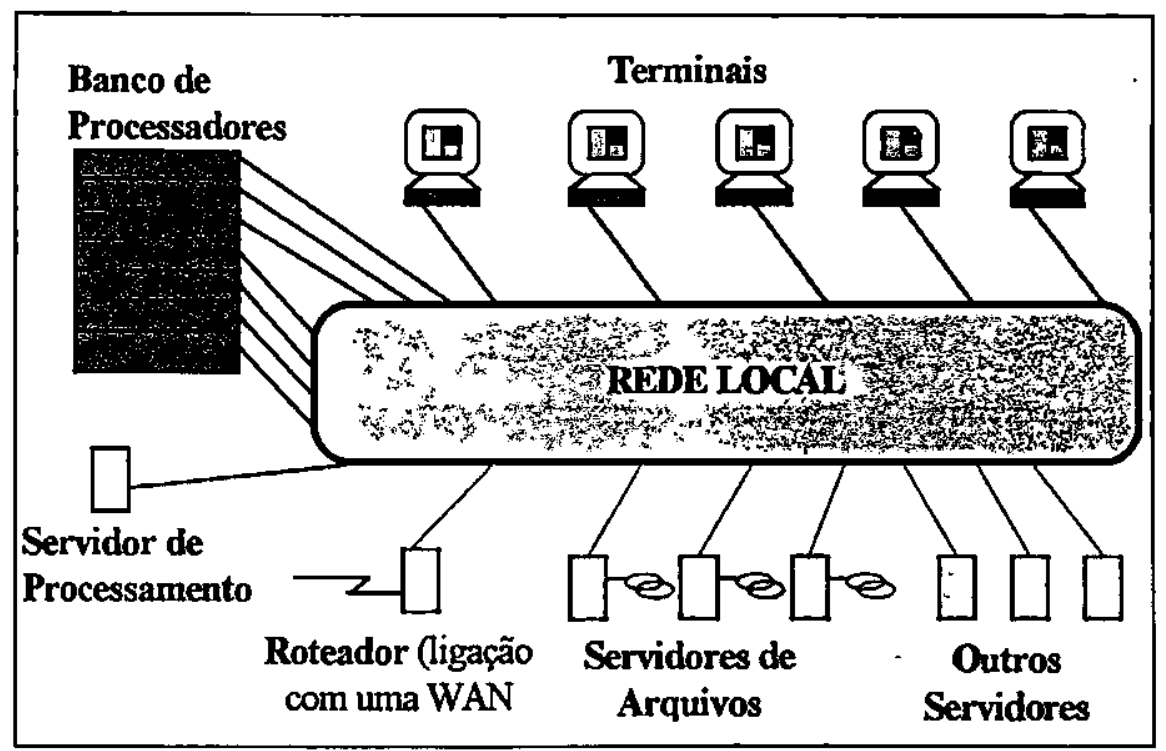

Figura 3.7 - Modelo Arquitetural Banco de Processadores [COU88].

Banco de Processadores: Este modelo consiste basicamente de um conjunto de terminais e um banco de processadores. Um banco de processadores possui uma coleção de processadores, sendo que cada um possui uma conexão de rede independente. Existe a necessidade de um servidor de processamento, responsável pela alocação e liberação dos 
elementos de processamento disponíveis no banco de processadores para os terminais remotos. A figura 3.7 ilustra um modelo de banco de processadores.

Modelo Híbrido: Esse modelo é a união do modelo estação de trabalho/ servidor e do modelo banco de processadores (Figura 3.8). Neste modelo, é possível alocar dinamicamente as tarefas que necessitam de vários computadores concorrentemente, além de possibilitar aos usuários o uso de estações de trabalho para a execução de aplicações interativas [COU88].

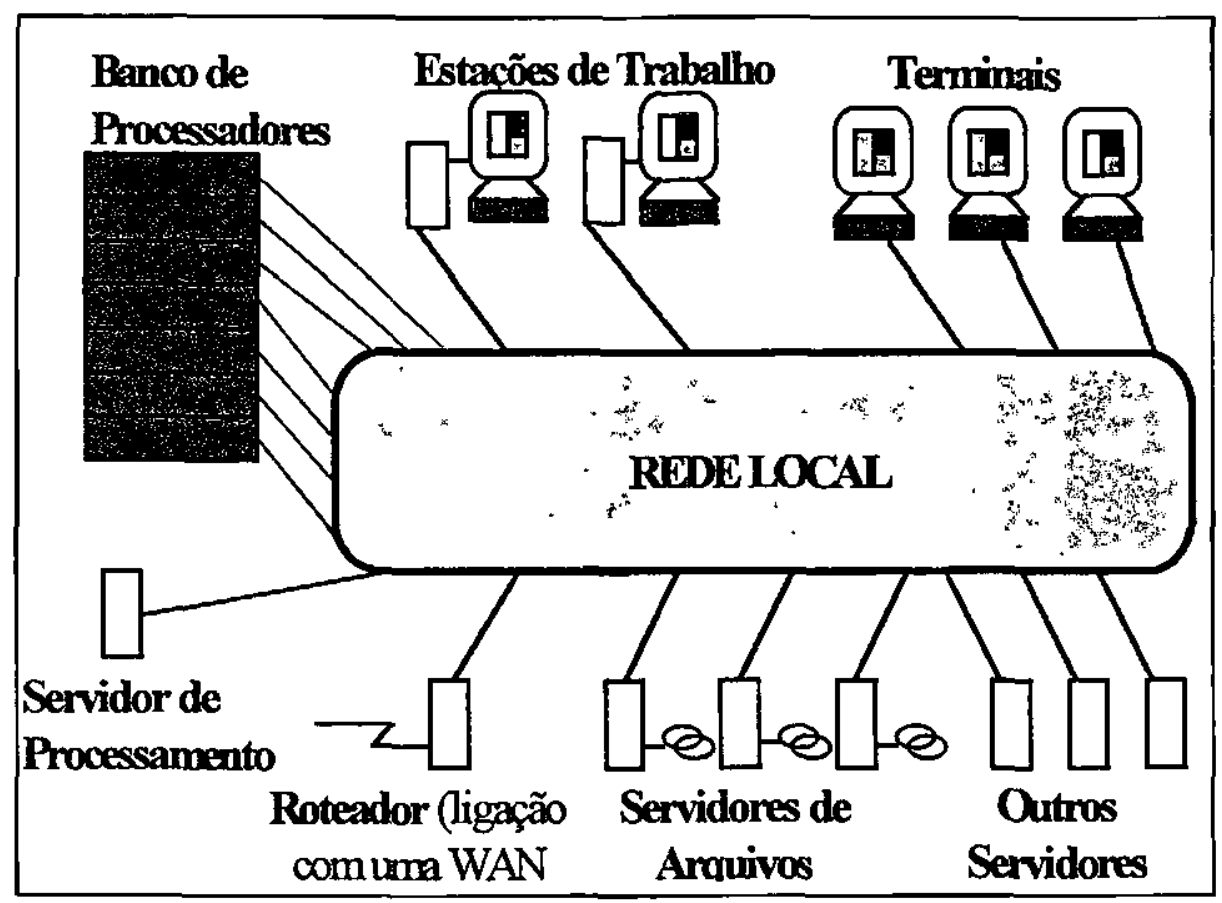

Figura 3.8 - Modelo Arquitetural Híbrido [COU88].

Modelo Integrado: Este modelo arquitetural caracteriza-se pela interligação de minicomputadores com estações de trabalho e terminais, através de uma rede de comunicação (Figura 3.9). Cada máquina está equipada com um software apropriado para desempenhar tanto as funções de servidor como também a função de executar aplicações de usuário [COU88]. 


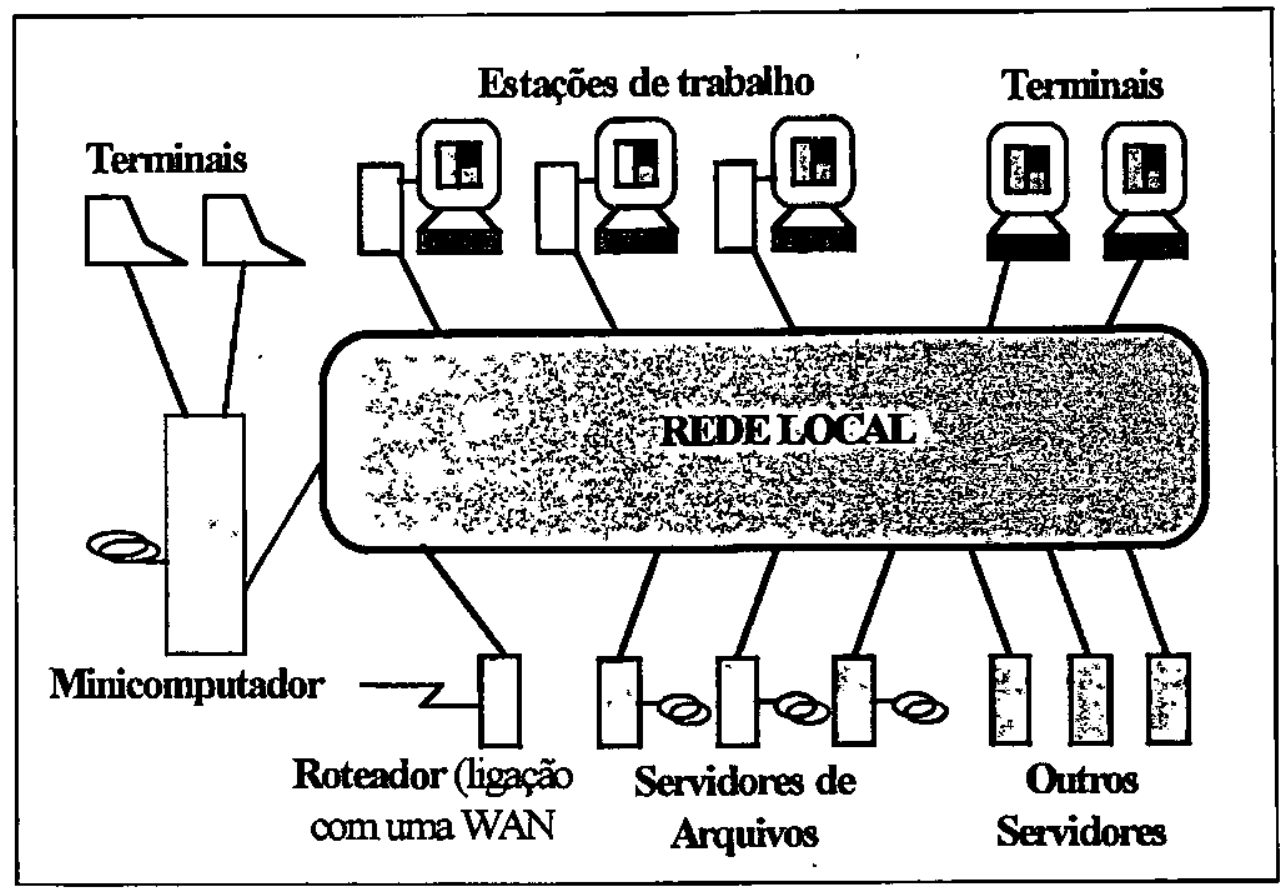

Figura 3.9 - Modelo Arquitetural Integrado [COU88].

\subsubsection{Programação Paralela em Sistemas Distribuídos}

Segundo Geist [GE194], dois fatores foram importantes para o desenvolvimento da computação paralela: os processadores maciçamente paralelos (MPP) e a difusão da computação distribuída.

Sistemas distribuídos podem ser utilizados como plataformas de memória distribuída para a execução de programas paralelos, formando as chamadas máquinas paralelas virtuais.

A utilização de redes de computadores para computação paralela, apresenta vantagens e algumas desvantagens, quando comparado à uma arquitetura paralela. Uma característica que pode ser vista como uma vantagem ou uma desvantagem, quando se utiliza uma rede de computadores, trata-se da heterogeneidade de componentes [SOU95]. Em arquiteturas maciçamente paralelas (MPP's) todos processadores são normalmente iguais em capacidade, recursos, software e velocidade de comunicação. Em contraste, os 
componentes de uma rede de computadores podem possuir várias diferenças, em termo de arquiteturas, formato de dados, potência computacional, carga de trabalho em cada máquina e na rede. Sendo assim, esta característica pode ser encarada como uma vantagem, uma vez fornece alta flexibilidade, ou como uma desvantagem, pois com a existência de diferentes computadores, cada um possuindo seu próprio formato de dados, a comunicação entre os vários componentes se torna uma tarefa mais dificil [SOU96].

Um outro problema que pode ocorrer é a diferença de velocidades entre os diversos computadores interligados, sendo que os computadores mais rápidos não devem ficar ociosos esperando dados de computadores mais lentos. Isto é, deve existir balanceamento de carga de trabalho nas diferentes máquinas.

Apesar dos problemas gerados pela heterogeneidade de componentes, a computação paralela sobre sistemas distribuídos oferece muitas vantagens:

- Arquiteturas paralelas geralmente são muito caras e de uso específico. Com a utilização de um sistema distribuído, pode-se ter uma plataforma de programação com um custo normalmente mais baixo, que pode ser usado tanto para este fim como para compartilhamento de recursos e informações [GEI94].

- Com a existência de redes de computadores de alta performance ligando várias estações de trabalho de propósito geral, é possível obter um poder computacional que pode exceder o poder de um computador paralelo de alto desempenho.

- Possibilita explorar a heterogeneidade natural de certas aplicações, permitindo acesso a bancos de dados diferentes e a processadores especiais para determinadas partes do problema;

- Os componentes da máquina virtual podem evoluir gradativamente, de modo a acompanhar os avanços tecnológicos;

- A produtividade do programador é maior devido a utilização de ambientes (editores, compiladores, debuggers) familiares; 
- A computação distribuída pode facilitar o trabalho corporativo.

Todos esses benefícios, contribuem para um. maior aceitação de sistemas distribuídos como plataformas de programação paralela, expandindo o uso da computação paralela para uma comunidade maior de usuários.

As plataformas de portabilidade PVM e MPI, apresentadas no capítulo 2, são as principais ferramentas utilizadas para a execução de programas paralelos em sistemas distribuídos.

\subsection{Considerações Finais}

Nas primeiras décadas de existência da computação, a arquitetura de von Neumann representou uma alternativa suficiente, onde tanto a memória como o processador eram recursos caros e preciosos. Entretanto, atualmente esses recursos vêem se tornado cada vez mais baratos, e a construção de computadores com vários processadores já não é uma opção economicamente inviável [KIR91].

As diversas áreas computacionais necessitam cada vez mais de poder computacional, e a computação paralela surgiu principalmente para suprir esta necessidade. Como o aumento do desempenho nas arquiteturas de von Neumann apresenta limitação tecnológica, a computação paralela compõe uma alternativa mais barata e mais elegante, principalmente para problemas intrinsecamente paralelos.

Dentre as plataformas de execução de programas paralelos, destaca-se as arquiteturas MIMD com memória distribuída, devido à sua flexibilidade e facilidade de ampliação. Os módulos independentes de processamento podem ser dispostos de várias maneiras, adequando-se ao problema desejado e realizando paralelismo em vários níveis (normalmente granulação média ou grossa). A máquina paralela SP2 (Scalable POWERparallel System 2 - IBM), descrita no capítulo 5, é uma implementação moderna de uma arquitetura MIMD com memória distribuída. 
Segundo Blech [BLE94], a computação paralela tem-se dirigido à utilização do modelo computacional MIMD, baseado em sistemas distribuídos formados por microprocessadores cada vez mais poderosos interligados por redes de computadores mais rápidas e confiáveis. Os sistemas distribuídos, com conceitos também usados pela computação paralela (como concorrência, tolerância a falhas e aumento da potência computacional), representa uma solução de custo acessível, em comparação às arquiteturas paralelas de alto custo. 


\section{Capítulo 4}

\section{Algoritmos Paralelos}

Neste capítulo serão abordados alguns tópicos fundamentais para o projeto de algoritmos paralelos, compreendendo as seguintes seções: etapas para o desenvolvimento de algoritmos paralelos, estilos de paralelismo e alguns exemplos de algoritmos paralelos de ordenação.

\subsection{Introdução}

O desenvolvimento de algoritmos paralelos é um item de grande importância na computação paralela [HWA87]. Na construção de um algoritmo paralelo os programadores devem considerar alguns pontos importantes, como a escolha da abordagem a ser seguida, o custo de comunicação entre os diversos processadores e a arquitetura paralela utilizada.

Três abordagens diferentes são possíveis no projeto de algoritmos paralelos [NAV89]. A primeira op̧̧ão é a conversão de um algoritmo seqüencial existente numa versão paralela. Nem sempre esta solução é adequada, pois a conversão pode gerar um algoritmo ineficiente, com baixo speedup. Isto é, nem sempre o melhor algoritmo para resolver um problema seqüencialmente é o mais paralelizável. A segunda situação é o projeto de um novo algoritmo paralelo. Esta abordagem permite a obtenção de algoritmos eficientes, porém o problema em questão deve ser detalhadamente analisado. $O$ desenvolvimento de um algoritmo paralelo seguindo esta abordagem apresenta maior complexidade. Por último, a abordagem mais prática é uma espécie de combinação dos dois primeiros, inicia-se com um algoritmo paralelo para um problema semelhante $\mathrm{e}$ modificações sucessivas são efetuadas para atender o problema em questão. Nesta solução têm-se um bom desempenho, exigindo menor trabalho do programador em 
relação a construção completa do algoritmo. A escolha da abordagem deve ser feita de maneira cuidadosa, para que se consiga a melhor eficiência, levando em consideração o tempo de escrita do algoritmo e o desempenho obtido.

A comunicação necessária, é outro aspecto importante na construção de um algoritmo eficiente [QUT87]. Deve-se pesar o custo da comunicação entre processos em relação ao tempo de execução efetiva, visto que operações de comunicação geram uma sobrecarga que pode degradar o desempenho, tornando o algoritmo menos eficiente que o seqüencial. Além disso, a arquitetura na qual se executará o algoritmo, também deve ser considerada, visto que a eficiência do algoritmo pode variar de acordo com o tipo de arquitetura.

\subsection{Desenvolvimento de Algoritmos Paralelos}

No desenvolvimento de algoritmos paralelos, várias etapas, não utilizadas na programação seqüencial, devem ser seguidas. De modo geral, o processo de desenvolvimento de algoritmos paralelos envolvem 4 etapas básicas:

- Identificação do paralelismo inerente ao problema, que consiste no estudo do problema a fim de se determinar possíveis eventos paralelizáveis;

- Organização do trabalho, englobando a escolha do estilo de paralelismo que será utilizado (descrito na próxima seção) e a divisão de tarefas entre os diversos processadores a fim de maximizar o desempenho e o balanceamento de carga;

- Desenvolvimento do algoritmo, utilizando ferramentas para expressar o paralelismo e para possibilitar a comunicação e sincronismo entre os processos. A escolha do tipo de ferramenta a ser utilizada foi um dos tópicos abordados no capítulo 2 (seção 2.5, Suporte à Programação Concorrente) ; 
- Implementação através da utilização de um método de programação adequado. Esta etapa engloba a escolha de uma linguagem de programação adequada, tratamento de possíveis deadlocks e mapeamento de tarefas.

\subsection{Estilos de Paralelismo}

Um algoritmo paralelo pode ser organizado de várias maneiras, de acordo com o tipo de arquitetura a ser utilizada, do problema a ser resolvido, etc, que são: paralelismo pelo resultado, paralelismo processor farming e paralelismo pipeline.

Durante o desenvolvimento de algoritmo paralelo, deve-se procurar escolher o estilo de paralelismo mais natural ao problema. Desenvolvido o algoritmo utilizando o método de programação mais natural ao estilo, pode-se conseguir resultados não satisfatórios em relação ao desempenho. Deve-se então transpor o algoritmo para um estilo de paralelismo mais eficiente. Pode-se utilizar métodos definidos na literatura para facilitar essa transição entre estilos de paralelismo [CAR89].

\subsubsection{Paralelismo pelo Resultado}

Também chamado de paralelismo de dados (Data Parallel) ou paralelismo geométrico, caracteriza-se pela divisão do conjunto de dados a serem executados igualmente entre todos os processadores. Cada processador possui uma cópia completa do código principal, executando sobre um subconjunto de dados. Este estilo de paralelismo é considerado o modo mais fácil de desenvolvimento de algoritmos paralelos e é intensamente utilizado em computadores maciçamente paralelos. Para exemplificar este estilo de paralelismo, considere a pintura de uma casa, sendo que cada pintor é um processador [CAR89]. A casa é dividida em partes iguais e cada uma das partes são distribuídas para um trabalhador. Todos eles começam simultaneamente, e trabalham em paralelo. Desta forma, cada trabalhador (processador) é designado para produzir um pedaço do produto final (Figura 4.1). 
Este paralelismo tem como vantagem a facilidade de implementação e o melhor ajuste dos processadores [DUA96]. A eficiência dependerá do sincronismo entre os processos e o balanceamento de carga de trabalho, de modo que as tarefas sejam divididas igualmente entre os processadores.

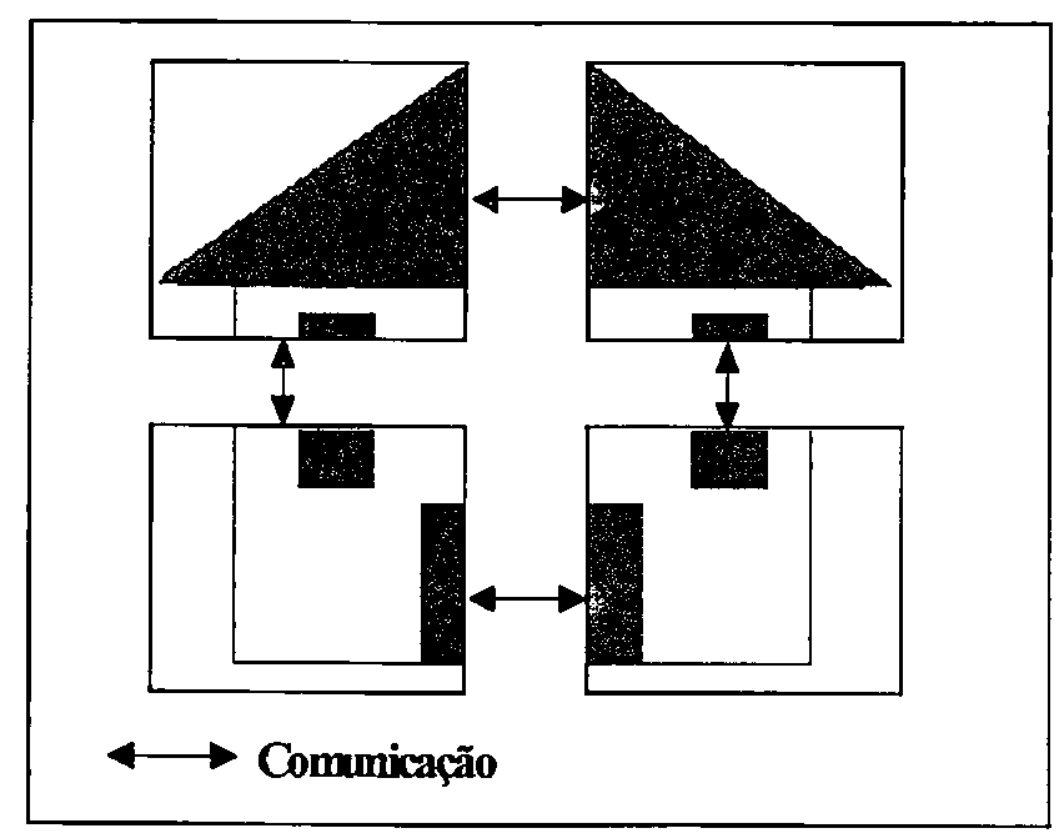

Figura 4.1. - Paralelismo pelo Resultado - pintura de uma casa

\subsubsection{Paralelismo Processor Farm}

O paralelismo processor farm caracteriza-se pela existência de um processador "mestre" que supervisiona um grupo de processadores "escravos", cada um processando assincronamente tarefas enviadas a eles pelo processador "mestre". Este modelo também é conhecido como paralelismo pela pauta, visto que, é definido um conjunto de tarefas (pauta) e a partir daí são distribuídas as tarefas pelo processador mestre.

No exemplo de uma casa sendo construída, uma construção baseada em "processor farm" pode ser organizada criando-se tarefas básicas: construir o alicerce, construir paredes, construir telhado e assim por diante [CAR89]. Essas tarefas são 
submetidas a cada um dos operários pelo mestre de obras (processador mestre), que ao finalizarem, estarão disponível para novas tarefas ordenadas pelo mestre (figura 4.2).

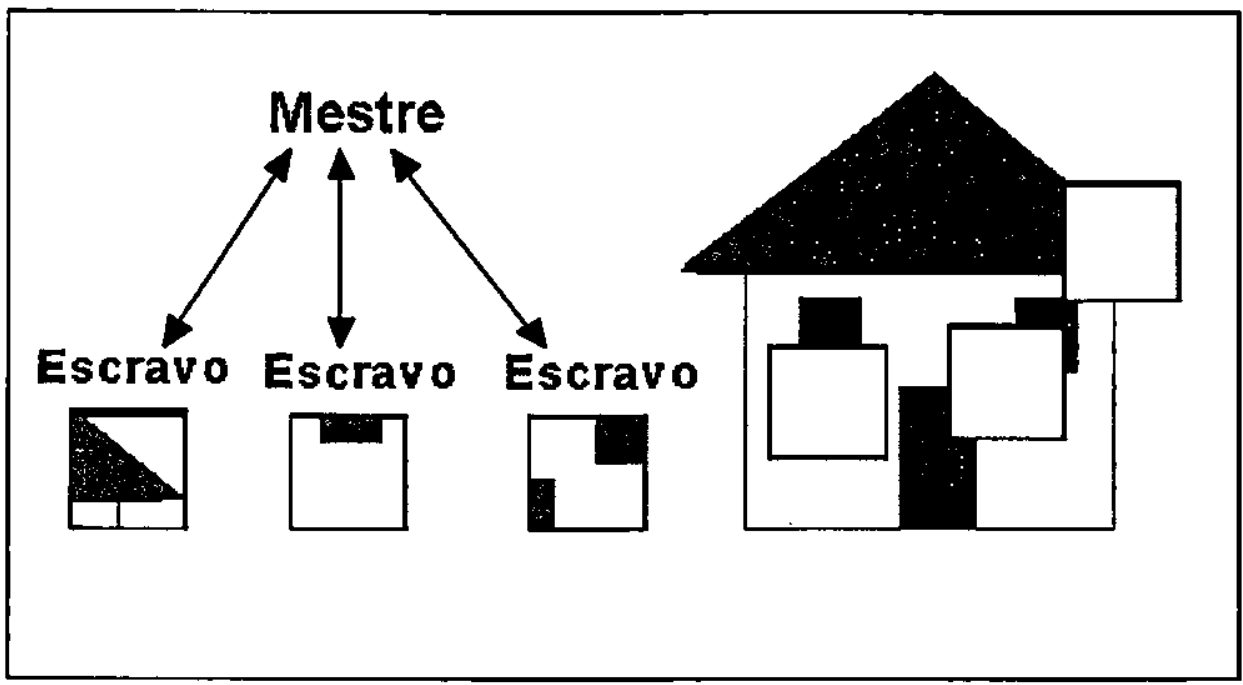

Figura 4.2. - Paralelismo Processor Farm - construção de uma casa

Caso o sistema seja homogêneo, o fator mais relevante deste paralelismo é o balanceamento de carga, visto que as tarefas vão sendo submetidas aos processadores de acordo com a disponibilidade. Outra vantagem é a facilidade de ampliação do sistema, permitindo o acréscimo de novos processadores. Como desvantagens, tem-se a sobrecarga de comunicação e a possibilidade de gargalo no processador mestre.

\subsubsection{Paralelismo Pipeline}

Também conhecido por paralelismo especialista ou algorítmico, caracteriza-se pela divisão de uma aplicação em várias tarefas especificas, que são distribuídas sobre os processadores em forma de pipeline. Nesse caso, quando apenas uma unidade de dados atravessa o pipeline não há paralelismo. 
Considerando o exemplo do projeto de uma casa, neste paralelismo, cada trabalhador seria especialista em determinada tarefa, como engenheiro, arquiteto, decorador, entre outros. Eles todos começam simultaneamente, mas inicialmente, a maioria dos trabalhadores devem esperar, pelo fato de depender do término de alguma(s) atividade(s), por exemplo a planta da casa não pode ser feita antes de projetá-la. Se forem construídas várias casas, o engenheiro pode trabalhar em uma casa enquanto o arquiteto trabalharia em uma outra, e assim por diante. Em resumo, cada trabalhador é responsável por um tipo especial de trabalho, e todos eles trabalham em paralelo até que ocorram restrições naturais impostas pelo problema (Figura 4.3) [CAR89].

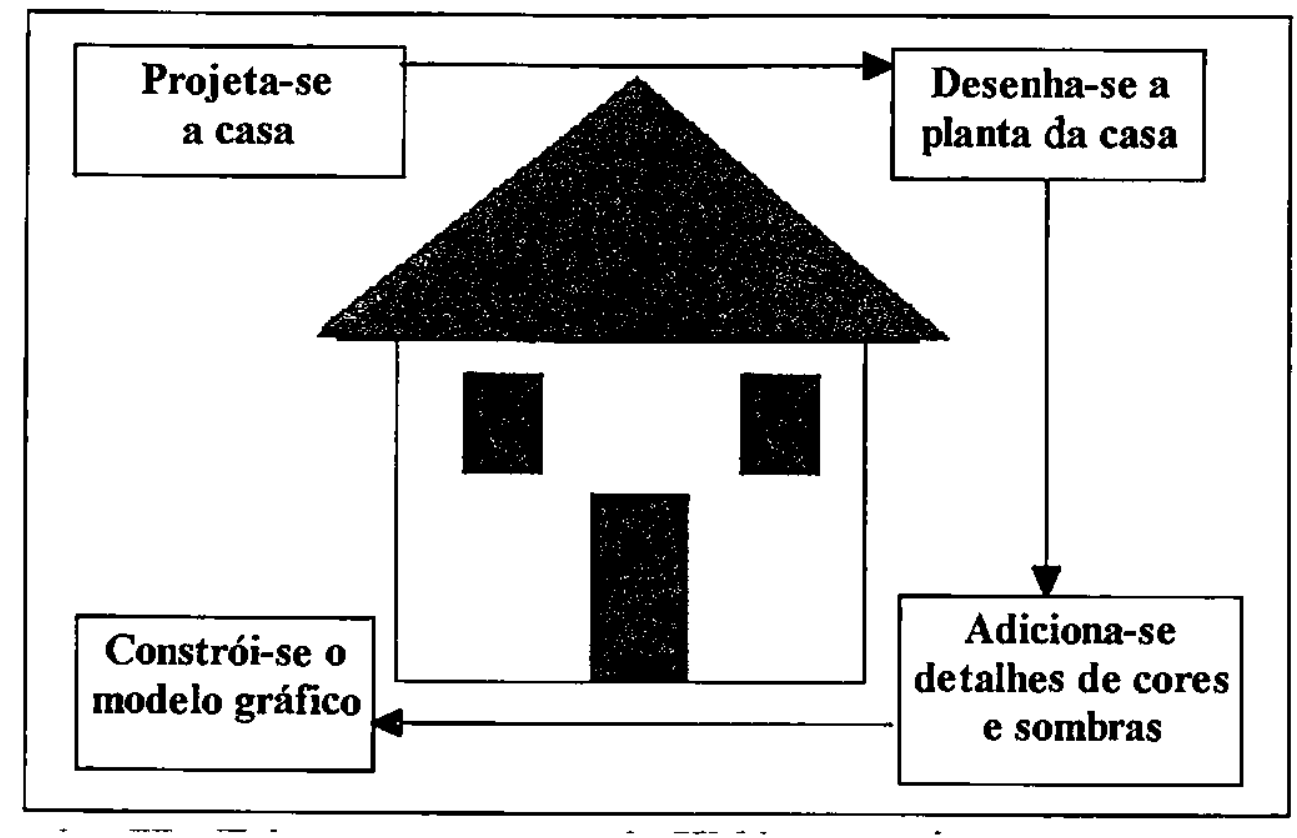

Figura 4.3. - Paralelismo Pipeline - projeto de uma casa

Muitas vezes, este é o estilo mais natural para desenvolver paralelismo a partir de um programa seqüencial, sendo até possível a sua deteç̧ão por compiladores e analisadores de código-fonte. Porém, algumas desvantagens que podem ser citadas são: pouca flexibilidade, visto que modificações no algoritmo podem requerer mudanças drásticas na rede de processadores; balanceamento de carga deve ser feito de maneira cuidadosa, a fim de que subtarefas lentas não tornem a execução de todo pipeline lenta; a 
relação entre comunicação e execução deve ser baixo, a fim de que a sobrecarga de comunicação não torne o algoritmo ineficiente.

\subsection{Algoritmos Paralelos de Ordenação}

A classificação de uma seqüência de números em uma ordem crescente ou decrescente, para facilitar o acesso a um determinado item em um arquivo de dados, constitui um dos assuntos mais conhecidos dos sistemas de programação. De modo geral, um conjunto de itens é ordenado para produzir um relatório ou para tornar mais eficiente o acesso aos dados. Muitas das técnicas seriais utilizadas, como classificação por troca de partição (quicksort), classificação por intercalação (merge sort), classificação por transposição de par-ímpar (odd-even transposition sort), entre outras, tem sido restruturadas para tornar possível que essas técnicas sejam paralelizadas [MOD88] [WEN96].

Em uma máquina serial, cada etapa de ordenação deve ser realizada seqüencialmente. Os algoritmos paralelos podem executar várias comparações e trocas simultaneamente. A construção de algoritmos paralelos de ordenação tem como objetivo minimizar o tempo de execução e o número de passos necessários para classificar um conjunto de dados. Por esta razão, novas técnicas para ordenação de dados têm sido propostas em busca de melhores desempenhos.

A seguir serão descritos alguns algoritmos paralelos de ordenação, que podem ser implementados tanto em multiprocessadores com memória compartilhada, como em multicomputadores de memória distribuída.

\subsubsection{Quicksort Paralelo 1}

Este algoritmo tem como objetivo ordenar $\mathbf{N}$ elementos em $\mathbf{P}$ processadores, sendo que cada processador é responsável pela ordenação de N/P elementos [GRE91]. Neste método, um dos processadores é nomeado mestre, enquanto os demais são referenciados 
como escravos. $O$ processador mestre gerencia a execução dos processadores escravos e distribui uma sublista de elementos a ser ordenada para cada um deles (o mestre também pode executar o algoritmo de ordenação sobre uma das sublistas). Para que essas sublistas sejam classificadas, cada processador executa em paralelo o algoritmo quicksort seqüencial e o resultado enviado ao processador mestre, para que este produza a lista final ordenada, através do algoritmo de intercalação (merge sort). A intercalação é um processo que combina dois ou mais arquivos classificados num terceiro arquivo classificado.

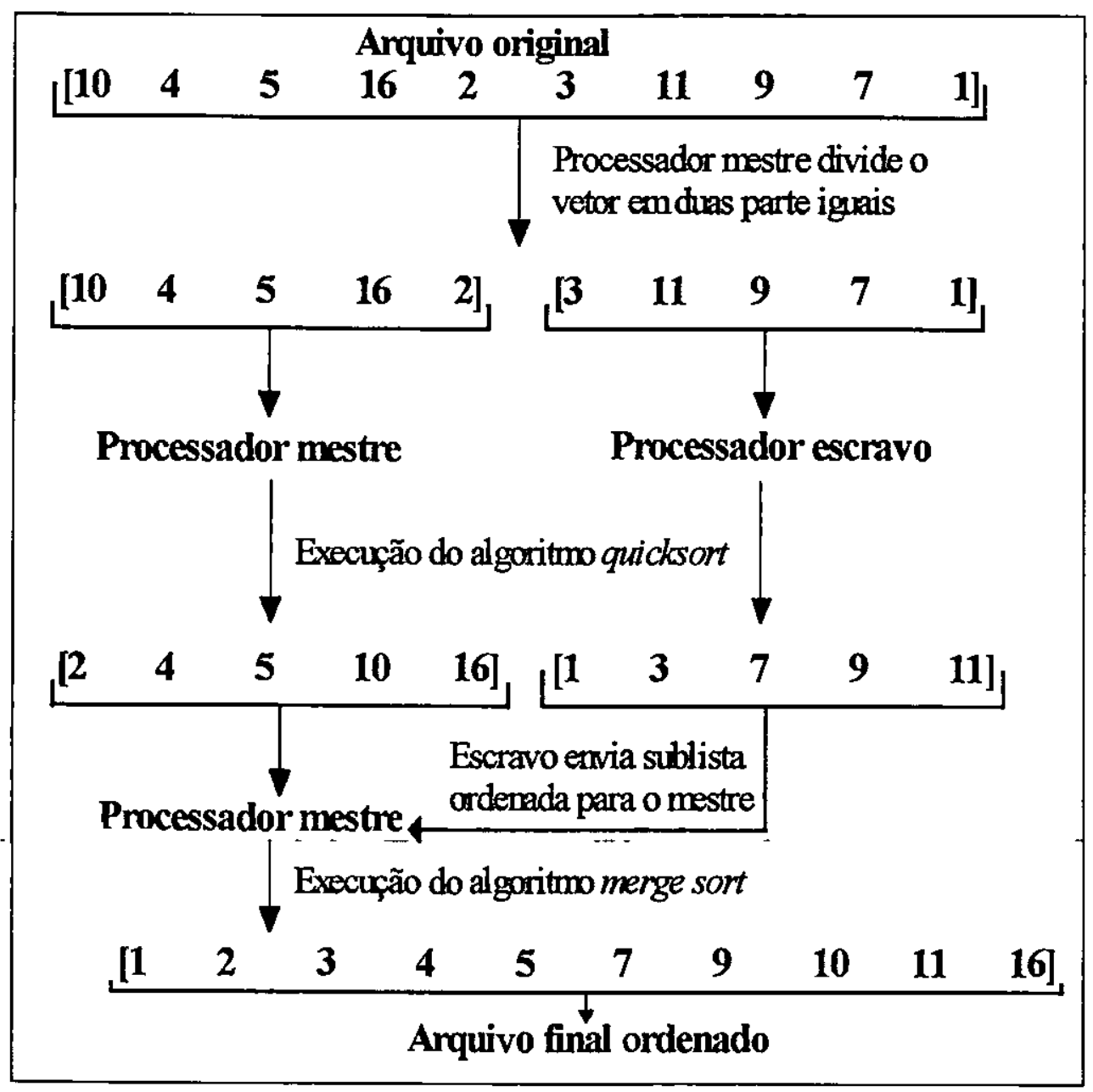

Figura 4.4. - Execução do Algoritmo Quicksort Paralelo 1

Considere, por exemplo, um vetor de 10 elementos $(10,4,5,16,2,3,11,9,7,1)$, para ser ordenado por 2 processadores (mestre e escravo), ilustrado na figura 4.4. Desta forma, o processador mestre distribui N/P elementos (sendo que N/P elementos ficam 
com o próprio mestre). Com a execução do algoritmo quicksort seqüencial, tanto o mestre como o escravo geram as sublistas ordenadas, de modo que o processador mestre ao receber o resultado obtido do escravo, inicia a execução do algoritmo de intercalação para produzir a lista final ordenada.

Se os processadores utilizados forem homogêneos, este algoritmo tem como vantagem o balanceamento de carga entre os processadores, uma vez todos eles recebem do processador mestre a mesma quantidade de elementos para serem ordenados [DUA96]. Entretanto, com a necessidade de um algoritmo de intercalação entre as sublistas ordenadas, há um aumento na comunicação e sincronismo entre os processadores, acarretando mais sobrecarga.

\subsubsection{Quicksort Paralelo 2}

Em contraste com o algoritmo de ordenação anterior, neste método os elementos de uma lista são distribuídos entre os vários processadores de maneira não balanceada, sendo que cada processador receberá uma sublista gerada a partir de alguns pivôs [DUA96].

Neste algoritmo, como no anterior, um dos processadores é definido como mestre e os outros como escravos. O mestre é encarregado em definir um vetor com P - 1 elementos (o processo de escolha dos elementos é feito de maneira aleatória), onde cada elemento é um pivô. Este vetor é ordenado e as sublistas distribuídas para os processadores escravos. A idéia básica deste algoritmo, é que o processador $P_{1}$ receba os elementos menores ou iguais ao pivô $1, \circ \mathrm{P}_{2}$ receba todos os elementos maiores que o pivô1, porém menores ou iguais que o pivô 2 , e assim sucessivamente.

Todos os processadores, em paralelo, ordenam suas sublistas, através da execução do algoritmo seqüencial quicksort. Ao terminarem, enviam para o mestre sua respectiva sublista ordenada. Por sua vez, o mestre gera a lista final ordenada, simplesmente 
concatenando todas as sublistas, respeitando a ordem estipulada pelo vetor de pivôs, ou seja, concatenando-se os elementos de $P_{1}, P_{2}, \ldots ., P p$.

A figura 4.5 ilustra os passos deste algoritmo para classificar um vetor com 20 elementos em dois processadores (no caso o processador mestre e processador escravo).

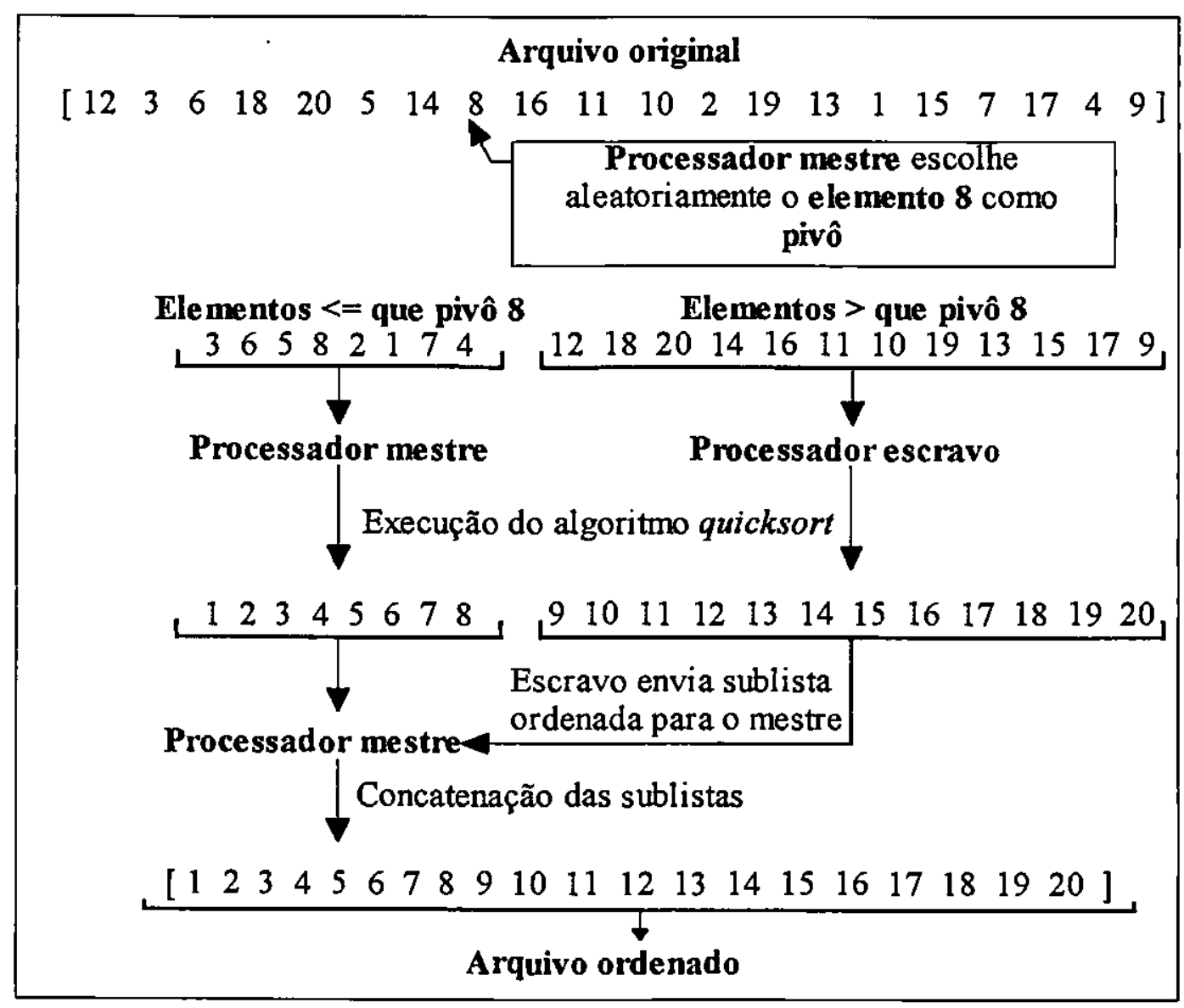

Figura 4.5 - Execução do Algoritmo Quicksort Paralelo 2

Uma vantagem deste algoritmo é que o processador mestre não necessita intercalar as sublistas ordenadas, através da execução do algoritmo merge sort, como é feito no algoritmo quicksort 1 . Ao invés, ele simplesmente concatena as sublistas ordenadas, de modo que torna o processo mais rápido que no anterior. Entretanto, não há nenhum balanceamento de carga, visto que com a escolha aleatória dos elementos pivôs, as sublistas não são igualmente distribuição para cada processador. Caso esteja utilizando-se um sistema homogêneo, esta carga não balanceada pode tornar o algoritmo inefíciente. 


\subsubsection{Select Sort}

O algoritmo select sort [HUA90] caracteriza-se pela classificação de $\mathbf{N}$ elementos distintos em $\mathbf{P}$ processadores, assumindo que N/P elementos serão ordenados em cada processador. Neste método, como nos anteriores, um dos processadores é designado como mestre, e os demais como escravos. Cabe ao mestre gerenciar a execução e a distribuição dos N/P elementos aos processadores. Cada processador escravo executa, em paralelo, um algoritmo serial de ordenação (por exemplo o quicksort) sobre seu conjunto de dados. $O$ processador mestre, ao detectar que todos os processadores finalizaram o processo de ordenação, inicia o processo de intercalação das sublistas ordenadas.

$\mathrm{Na}$ técnica select sort, devem ser gerados $\mathrm{P}-1$ elementos pivôs, de modo a possibilitar que o processador $\mathrm{P}_{1}$ contenha os primeiros N/P elementos do conjunto, $\mathrm{P}_{2}$ contenha os $(\mathrm{N} / \mathrm{P})+1$ a $2^{*}(\mathrm{~N} / \mathrm{P})$ próximos elementos, e assim por diante. Para conhecer quem serão os elementos pivôs, primeiramente deve-se encontrar os índices N/P, $2^{*}(\mathrm{~N} / \mathrm{P}), 3^{*}(\mathrm{~N} / \mathrm{P}), \ldots,(\mathrm{P}-1)^{*}(\mathrm{~N} / \mathrm{P})$, pois estes serão os índices de cada um dos pivôs a serem calculados. A abordagem utilizada neste algoritmo para encontrar os elementos pivôs é uma combinação dos algoritmos de contagem e pesquisa binária.

No algoritmo de contagem, se um processador $\mathrm{P}_{\mathrm{i}}$ deseja encontrar o índice geral de uma determinada chave $\mathbf{x}$ contida em sua lista local, ele envia o valor desta chave para os demais processadores. Todos os processadores, exceto $P_{i}$, verificam quantos elementos em suas listas locais são menores que este valor e enviam este número para $\mathrm{P}_{\mathrm{i}}$. $\mathrm{O}$ índice geral de $\mathbf{x}$ é obtido com a soma destes números com o índice local da chave $\mathbf{x}$. A pesquisa binária é utilizada, se o índice geral calculado for maior ou menor que o índice desejado. Se for maior, a nova chave deverá estar entre os índices 1 e x, caso contrário estará entre $\mathrm{x}$ e o último índice da lista local de $\mathrm{P}_{\mathrm{j}}$.

Após os elementos pivôs serem encontrados, uma nova distribuição das chaves é necessária, de modo que o processador $P_{1}$ receba todas as chaves menores que o pivô com indice N/P, $P_{2}$ receba as chaves maiores que o pivô do índice N/P, porém menores 
que o pivô do índice $2^{*}(\mathrm{~N} / \mathrm{P})$, e assim sucessivamente. Com, isso a lista final ordenada é obtida pela concatenação das listas contidas em $\mathrm{P}_{1}, \mathrm{P}_{2}, \ldots, \mathrm{P}_{\mathrm{p}}$.

Considere por exemplo, um vetor de 20 elementos [DUA96]:

\section{$\begin{array}{llllllllllllllllllll}12 & 3 & 6 & 18 & 20 & 5 & 14 & 8 & 16 & 11 & 10 & 2 & 19 & 13 & 1 & 15 & 7 & 17 & 4 & 9 ;\end{array}$}

utilizando-se 2 processadores (mestre e escravo). $\mathrm{O}$ mestre distribui $\mathrm{N} / \mathrm{P}$ elementos (no caso 10 elementos) para o processador escravo e para si próprio.

Mestre : $\quad \begin{array}{llllllllll}12 & 3 & 6 & 18 & 20 & 5 & 14 & 8 & 16 & 11\end{array}$

Escravo : $\quad \begin{array}{llllllllll}10 & 2 & 19 & 13 & 1 & 15 & 7 & 17 & 4 & 9\end{array}$

Deste modo, eles executam um algoritmo seqüencial de ordenação, em paralelo, obtendo as sublistas ordenadas:

Mestre : $\begin{array}{lllllllllll}3 & 5 & 6 & 8 & 11 & 12 & 14 & 16 & 18 & 20\end{array}$

$\begin{array}{lllllllllll}\text { Escravo : } & 1 & 2 & 4 & 7 & 9 & 10 & 13 & 15 & 17 & 19\end{array}$

Tendo-se as sublistas ordenadas, o algoritmo para calcular o elemento pivô é executado. $O$ processador escravo envia o elemento do índice $\mathrm{N} / \mathrm{P}$ da sua sublista (que corresponde ao elemento 10) para o mestre. Desta forma, o mestre verifica quantos elementos da sua sublista são menores que o elemento 10 e envia este número ao processador escravo (no exemplo são 4 elementos). O escravo então soma este número com o índice do elemento 10 (no caso, o vetor é numerado de 1 a $\mathrm{N}$, correspondendo ao índice 6). Assim, o elemento pivô corresponde ao elemento 10 (se a soma fosse maior ou menor que 10 , a pesquisa binária seria utilizada). O processador mestre, então, envia todos os elementos maiores que 10 para o processador escravo, e este, por sua vez, envia todos elementos menores que pivô 10. O mestre passa a conter a sublista 123456789 10, enquanto o escravo, mantém 11121314151617181920 . Desta forma, a lista final ordenada é obtida concatenando-se as duas sublistas ordenadas.

Este algoritmo tem como vantagem a distribuição balanceada de carga de trabalho entre os vários processadores. Entretanto, necessita de muita comunicação para se 
calcular os elementos pivôs, e que de certa forma, dependendo da arquitetura utilizada, pode tornar o algoritmo ineficiente.

\subsubsection{Merging Distribuído}

Este algoritmo é um algoritmo distribuído que consiste em intercalar $\mathrm{k}$ listas ordenadas, contendo cada uma $\mathrm{N} / \mathrm{k}$ elementos, utilizando-se $\mathrm{k}+1$ processadores. $\mathrm{O}$ motivo de se ter $\mathrm{k}+1$ processadores é que um deles é designado para armazenar a lista final ordenada, enquanto os outros possuem cada uma das listas a serem intercaladas. Esse algoritmo pode ser decomposto em ciclos, de forma que para cada ciclo, é determinado o maior elemento contido em cada processador [KLE86].

O processo inicia-se com a escolha de um processador que deverá inicializar o ciclo, de modo que este difunda pela rede seu valor corrente, e todos os outros processadores ao perceberem que seu valor corrente é maior do que aquele que está na rede, transmitem seu valor para o próximo processador, e assim sucessivamente (mostrado na figura 4.6). Os valores que estão na rede são empilhados pelo processador de saída $\left(\mathrm{P}_{\mathrm{k}+1}\right)$, sendo que o último elemento (valor contido em topo na pilha), em cada ciclo, é o maior valor dentre todos os outros. Esse processo se repete até que todas as listas de cada processador estejam vazias, sendo que em cada ciclo o processador escolhido como inicializador é aquele que possui seu valor contido em topo-1 na pilha do processador de saída.

No exemplo da figura 4.6 , existem 4 listas ordenadas com 2 elementos $(\mathrm{N} / \mathrm{K})$, utilizando-se 5 processadores. Quando todas as listas (de cada processador) estiverem vazias, a lista final ordenada estará armazena no "processador de saída", no exemplo o $\mathrm{P}_{5}$ (isto ocorre no ciclo 8).

Esse algoritmo pode apresentar alta eficiência, se a plataforma paralela utilizada, possuir uma rede de interconexão de alto desempenho, visto que a taxa de comunicação entre os processadores para gerar a lista final ordenada é muito intensa [DUA96]. 


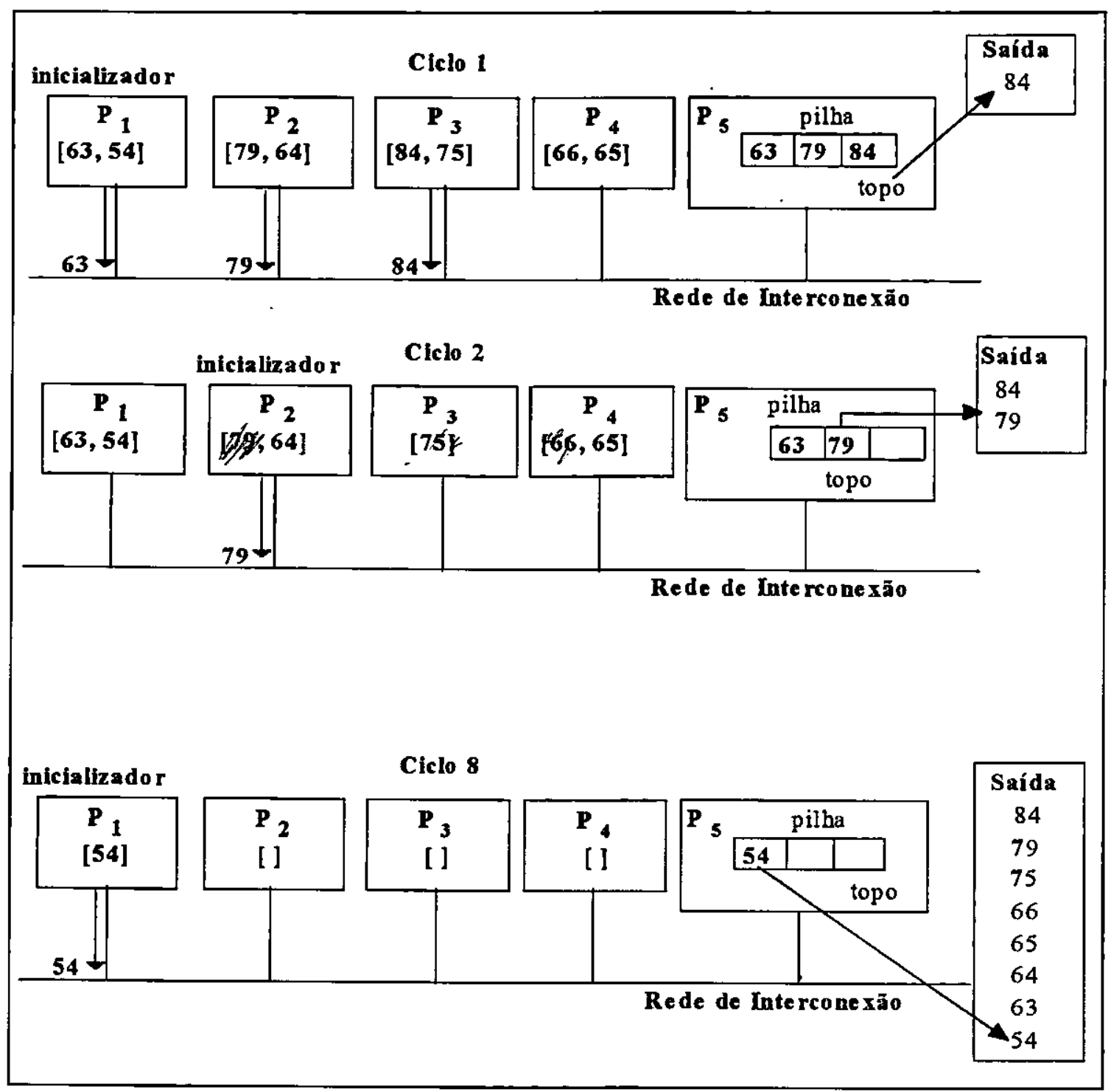

Figura 4.6 - Execução do Algoritmo Merging Distribuído

\subsubsection{Merge Paralelo}

Este algoritmo tem como objetivo ordenar $\mathbf{N}$ elementos em $\mathbf{P}$ processadores numerados de 1 a $\mathrm{P}$ (sendo $\mathrm{P}_{1}$ o processador mestre), onde cada um deles é responsável pela ordenação de seu subvetor, através de algumas etapas de intercalação. 


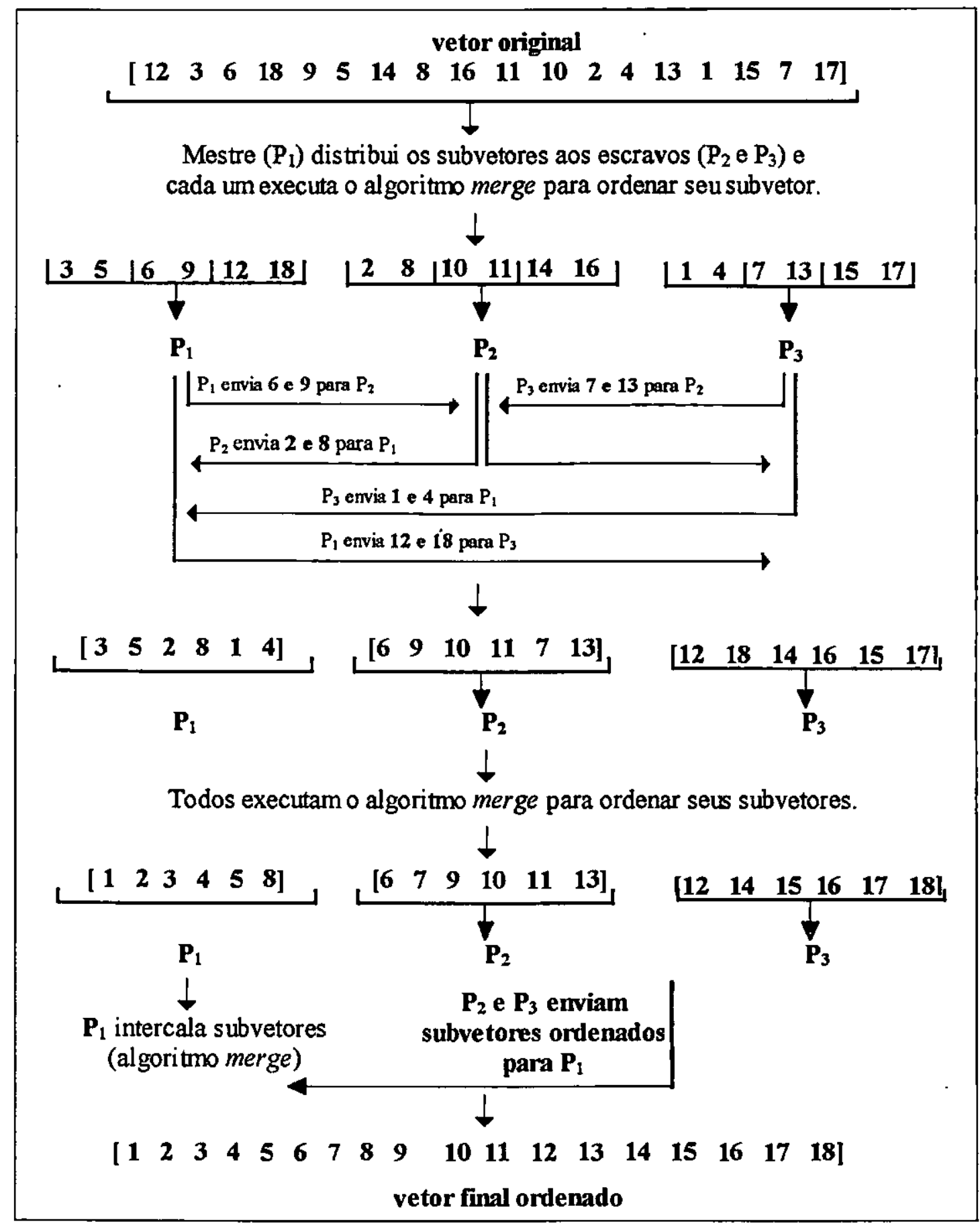

Figura 4.7 - Execução do Algoritmo Merge Paralelo

$O$ processador mestre $\left(\mathrm{P}_{1}\right)$ divide o vetor original em relação à quantidade de processadores que serão utilizados. Desta forma, o mestre $\left(\mathrm{P}_{1}\right)$ é responsável pela distribuição dos subvetores aos processadores escravos $\left(\mathrm{P}_{2}\right.$ a $\left.\mathrm{P}_{\mathrm{p}}\right)$, retendo um dos 
subvetores consigo. Para que esses subvetores sejam classificados, cada processador executa em paralelo o algoritmo merge sort seqüencial.

Após a ordenação dos elementos em cada processador, todos eles (mestre e escravos) fazem uma nova divisão dos seus subvetores em relação ao número de processadores utilizados, iniciando assim, a troca de elementos entre si. Nesta etapa são transferidas as partes referentes ao número do processador, ou seja, a primeiras partes dos subvetores dos escravos $\left(\mathrm{P}_{2}\right.$ a $\left.\mathrm{P}_{\mathrm{p}}\right)$ são enviadas ao mestre $\left(\mathrm{P}_{1}\right)$, a segunda parte do subvetor de cada processador é enviada ao processador $\mathrm{P}_{2}$ (escravo), a terceira é enviada ao processador $\mathrm{P}_{3}$, e assim sucessivamente. Considere por exemplo a utilização de três processadores $\left(\mathrm{P}_{1}, \mathrm{P}_{2}\right.$ e $\left.\mathrm{P}_{3}\right)$, como mostra a figura 4.7. A troca de elementos é feita através do envio das primeiras partes do subvetor dos processadores escravos $\left(\mathrm{P}_{2}\right.$ e $\left.\mathrm{P}_{3}\right)$ ao mestre $\left(\mathrm{P}_{1}\right)$, este por sua vez, envia a segunda e a terceira parte de seu subvetor ao processador $P_{2}$ e $P_{3}$ respectivamente, e finalmente, o processador $P_{2}$ transfere a terceira parte para $P_{3}$ e este transfere a segunda parte de seu subvetor para $\mathrm{P}_{2}$.

Feita a troca de elementos entre os processadores, é necessário que cada um execute novamente o algoritmo merge sort seqüencial, para que seus subvetores sejam ordenados. Desta forma, os processadores escravos enviam seus subvetores ao processador mestre $\left(\mathrm{P}_{1}\right)$, para que este produza o vetor final ordenado, através da intercalação de todos os subvetores (merge sort).

\subsubsection{Odd-even Merging}

O método por intercalação de par-ímpar (odd-even merging) [UML94] [NAR96] é baseado na classificação por comparações e trocas. Considere que $\mathbf{N}$ elementos são distribuídos igualmente para $\mathbf{P}$ processadores, numerados de 0 a $\mathrm{P}-1$, sendo que cada processador é responsável pela ordenação de sua sublista, através de um algoritmo de ordenação seqüencial. 
O processo de intercalação inicia-se com o passo ímpar, isto é, todos os processadores com índice $\mathrm{i}$ ímpar (sendo $0<\mathrm{i}<\mathrm{P}-1$ ) tornam-se ativos e obtêm uma cópia da sublista ordenada dos seus sucessores $\left(\mathrm{P}_{\mathrm{i}+1}\right)$. Com isso, os elementos da sublista de $\mathrm{P}_{\mathrm{i}} \mathrm{e}$ da sublista de $\mathrm{P}_{\mathrm{i}+1}$ são intercalados (através do algoritmo merge sort), gerando uma única lista ordenada. Esta lista, então é dividida em duas partes, sendo que a parte com os menores elementos permanecem em $P_{i}$ e a outra parte é transferida para $P_{i+1}$. O próximo estágio, é realizado o passo par, que é semelhante ao anterior, só que neste passo é utilizado um índice $\mathbf{j}$ par (sendo $0<=j<P-1$ ), onde os elementos dos processadores $P_{j}$ são intercalados com os dos seus sucessores $\mathrm{P}_{\mathrm{j}+1}$.

Estes passos (ímpar e par) são executados até que todos os elementos dos processadores $P_{i}$ forem menores ou iguais aos elementos de $P_{j}($ para $i<j$ ). Obtendo-se a lista final ordenada nos processadores $\mathrm{P}_{0}, \mathrm{P}_{1}, \mathrm{P}_{2}, \mathrm{P}_{3}, \ldots . ., \mathrm{P}_{\mathrm{N}-1}$, nesta ordem. A figura 4.8, ilustra os passos para ordenar um vetor com os elementos $3,4,1,2,5,6,7$ (para simplificar a ilustração temos 7 processadores, cada qual contendo um único elemento).

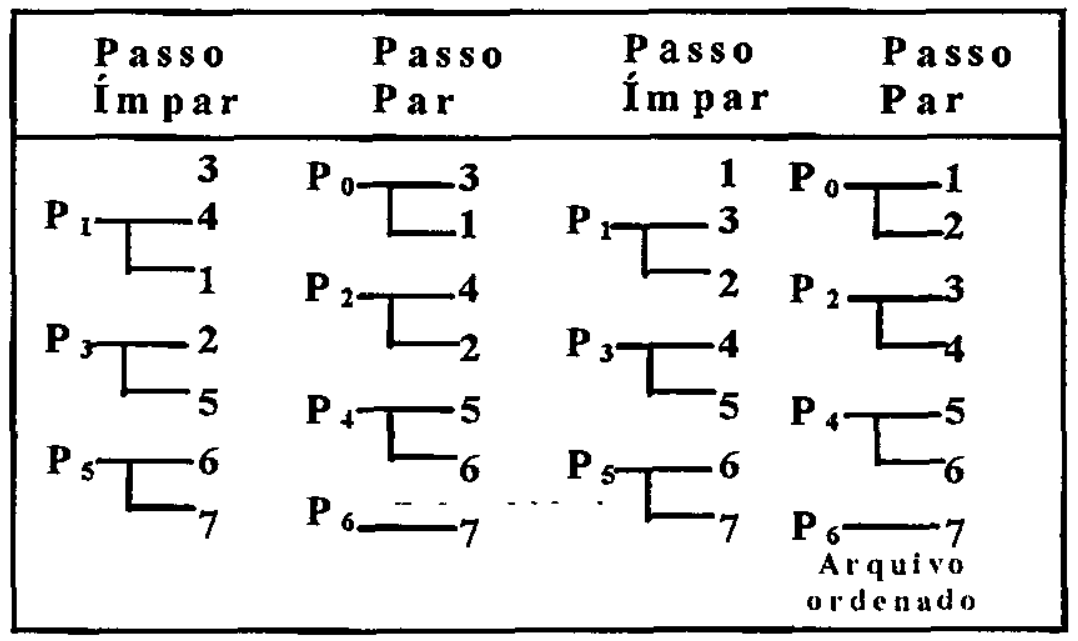

Figura 4.8 - Execução do Algoritmo Odd-even Merging

\subsubsection{Quick-Mergesort}

Este algoritmo caracteriza-se pela combinação dos algoritmos de ordenação quicksort e merge sort. A plataforma utilizada para a implementação deste algoritmo é 
uma arquitetura paralela com topologia hipercubo de dimensão $K$ [LOO92]. Nesta topologia existem $2^{k}$ processadores $(\mathbf{P})$. Considerando-se uma rede hipercubo constituída de processadores numerados em $0,1,2, \ldots, \mathrm{P}-1$, dois processadores são vizinhos se a representação binária de seus números diferem em exatamente um bit de posição (Figura 4.9).

No algoritmo quick-mergesort, para ordenar uma lista de $\mathrm{N}$ elementos, cada processador recebe N/P elementos, sendo que o processador P0 é o responsável pela lista original e pela distribuição dos dados desordenados para os demais processadores.

$O$ processo de distribuição consiste em várias etapas. No primeiro passo o processador P0 envia N/2 elementos da lista para o processador $\mathrm{P} 4$. No segundo passo, $\mathrm{P} 0$ envia N/4 elementos para o processador P2 e P4 transmite N/4 para P6. Durante o terceiro passo, N/8 elementos são enviados de $\mathrm{P} 0$ para $\mathrm{P} 1$, de $\mathrm{P} 2$ para $\mathrm{P} 3$, de $\mathrm{P} 4$ para $\mathrm{P} 5$ e de P6 para P7 (Figura 4.10). De modo geral, a todo passo $i$, o processador $j$ (para todo $j$ $\bmod 2 d=0$ e $j>P$, onde $d=P / 2 i)$ transmite $N / 2 i$ elementos para o processador $j+d$. No final de todos os passos, cada processador conterá exatamente N/P elementos da lista original.

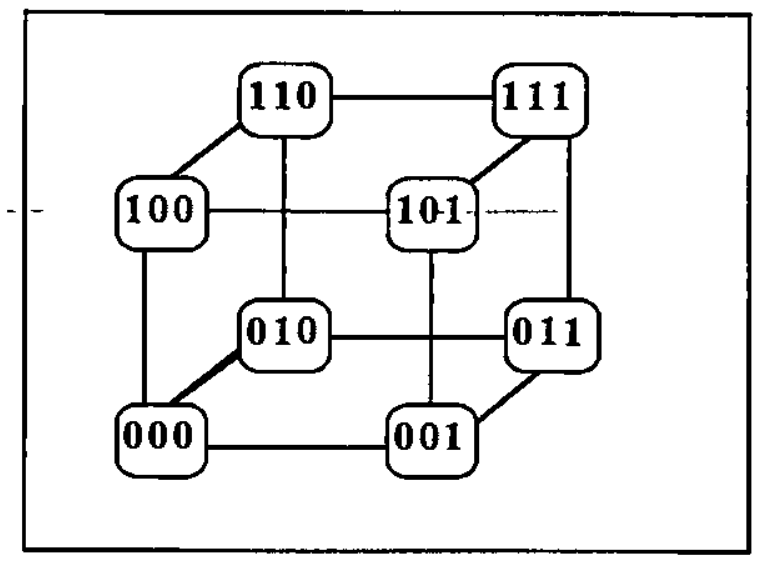

Figura 4.9 - Um Hipercubo Tridimensional 


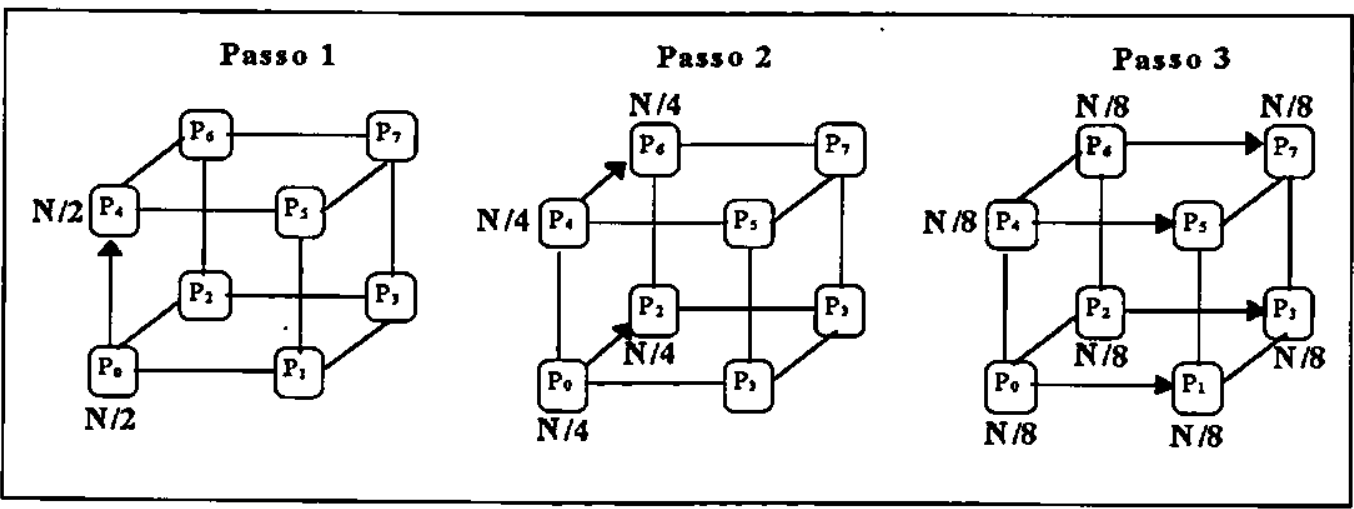

Figura 4.10 - Distribuição dos Dados em um Hipercubo Tridimensional

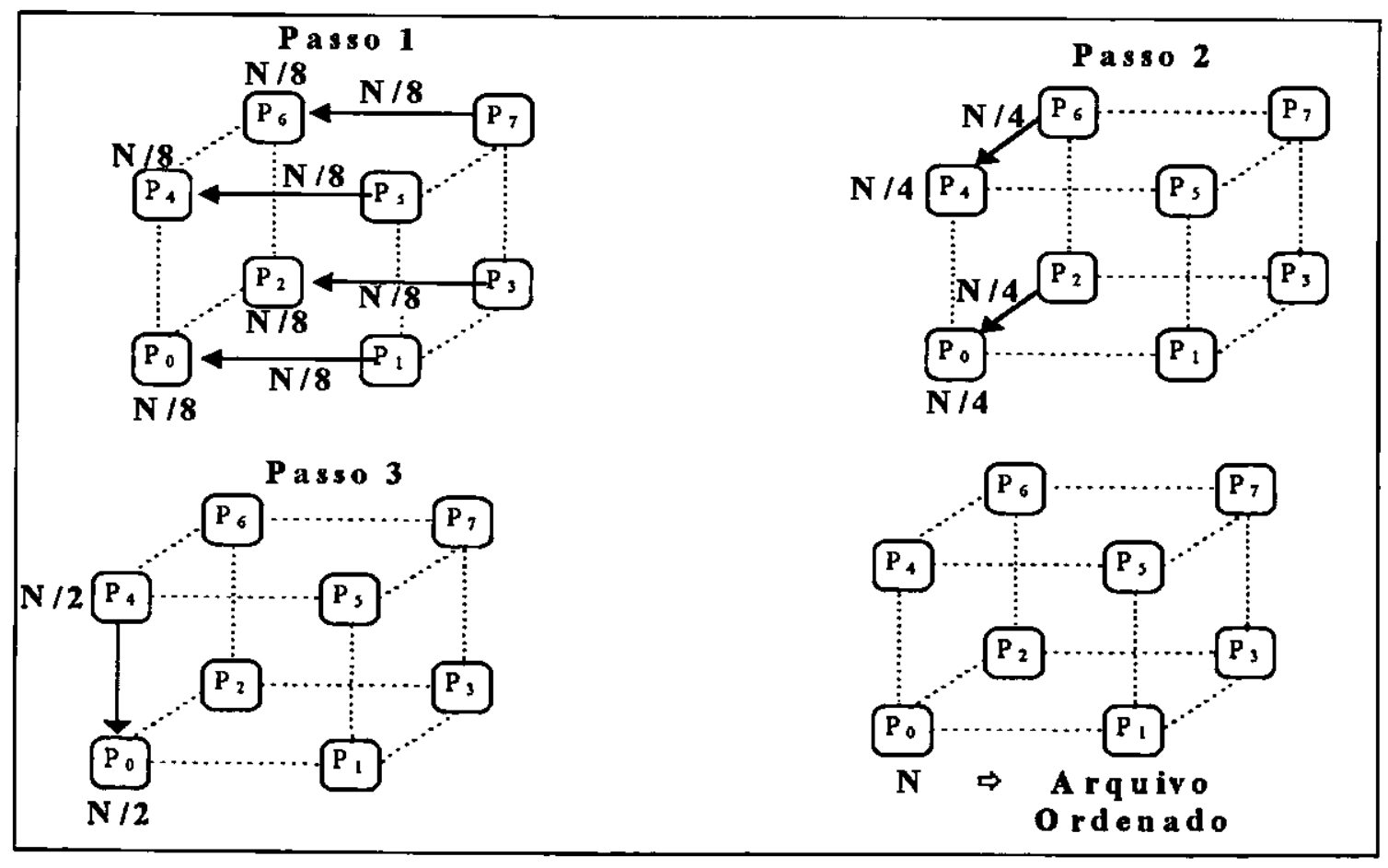

Figura 4.11 - Intercalação das Sublistas Ordenadas em um Hipercubo

Feita distribuição dos elementos, cada processador inicia o processo de ordenação de sua sublista local, através do algoritmo quicksort. Com isso, as sublistas ordenadas de cada processador são transmitidas utilizando os mesmos caminhos para a distribuição dos dados, só que agora ocorre em direções opostas (figura 4.11). Assim, cada processador ao receber uma sublista, inicia o processo de intercalação da lista recebida com sua sublista local, de forma que a todo passo $\mathbf{i}$ o processador $\mathbf{j}+\mathbf{d}$ (sendo $\mathrm{j} \bmod 2 \mathrm{~d}=0 \mathrm{e} j<P$, onde 
$\mathrm{d}=2^{\mathrm{i}+\mathrm{1}}$ ) envia a sua lista de comprimento $\mathrm{N} / 2^{\mathrm{k}-\mathrm{i}+1}$ para o processador $\mathrm{j}$, e estas são intercaladas. Assim, a lista final ordenada é obtida no processador $\mathrm{P}_{0}$.

\subsubsection{Bitonic Merging}

$\mathrm{O}$ algoritmo bitonic merging, como no merge-quicksort, é apropriado para uma arquitetura hipercubo de dimensão $\mathrm{K}$. O método é baseado no algoritmo de ordenação bitonic e faz uso das chamadas seqüenciais bitonic [AKL85] [NAR96].

No algoritmo bitonic, uma seqüência de elementos $\left(a_{1}, a_{2}, a_{3}, \ldots, a_{n}\right)$ é chamada bitonic, se a lista consistir de uma seqüência de elementos na ordem crescente seguida por outra na ordem decrescente (p.ex. $3,5,6,6,4,2,1$ ). Neste algoritmo, em um único passo de ordenação, uma seqüência de elementos bitonic é dividida em duas seqüências bitonic [QU187] [MOD88] [LOO92] [UML94].

Considere uma lista de $\mathbf{N}$ elementos de tamanho par, sendo $\mathrm{N}=2^{\mathrm{k}}$ (para $\mathrm{K}>0$ ), de modo que $\left(a_{0}<=a_{1}<=\ldots<=a_{N / 2-1}\right)$ e $\left(a_{N / 2}>=a_{N / 2+1}>=\ldots>=a_{N-1},\right)$. A cada passo de ordenação são executados $\mathbf{N}$ comparações e trocas, para obter:

$$
\begin{aligned}
& \min \left(a_{0}, a_{n / 2}\right), \min \left(a_{1}, a_{n / 2+1}\right), \min \left(a_{2}, a_{n / 2+2}\right), \ldots, \min \left(a_{n / 2}, a_{n-1}\right) \\
& \text { e } \\
& \max \left(a_{0}, a_{n / 2}\right), \max \left(a_{1}, a_{n / 2+1}\right), \max \left(a_{2}, a_{n / 2+2}\right), \ldots, \max \left(a_{n / 2}, a_{n-1}\right) .
\end{aligned}
$$

Para exemplificar este algoritmo, a figura 4.12(a) ilustra os passos de ordenação de uma seqüência de elementos $3,4,7,9,6,4,2,0$, para $k=3$. Cada linha horizontal indica a posição de cada elemento (na figura 4.12(b) cada processador de um hipercubo tridimensional, corresponderia a uma linha horizontal) e as flechas verticais indicam os pares de elementos que estão sendo comparados e se necessário, trocados de posição. Como pode ser observado, o algoritmo gasta 3 passos paralelos $(\mathrm{K})$ para ordenar a seqüência de elementos. 
Este algoritmo pode ser facilmente modificado para um algoritmo bitonic merging [UML94]. Considere um hipercubo com $P$ processadores $\left(P=2^{k}\right)$ e uma uma seqüência de elementos bitonic de comprimento $\mathrm{N}$ onde cada processador recebe uma sublista de N/P elementos. $O$ processo de distribuição dos dados para os processadores é o mesmo utilizado no método quick-mergesort, sendo que cada processador recebe uma lista de dados de seu predecessor, mantendo uma sublista consigo mesmo e enviando o restante para seus sucessores. Cada processador então ordena sua sublista local e, ao invés de se comparar dois elementos, como mostrado na figura 4.12 , cada sublista será intercalada de modo semelhante ao algoritmo odd-even merging.

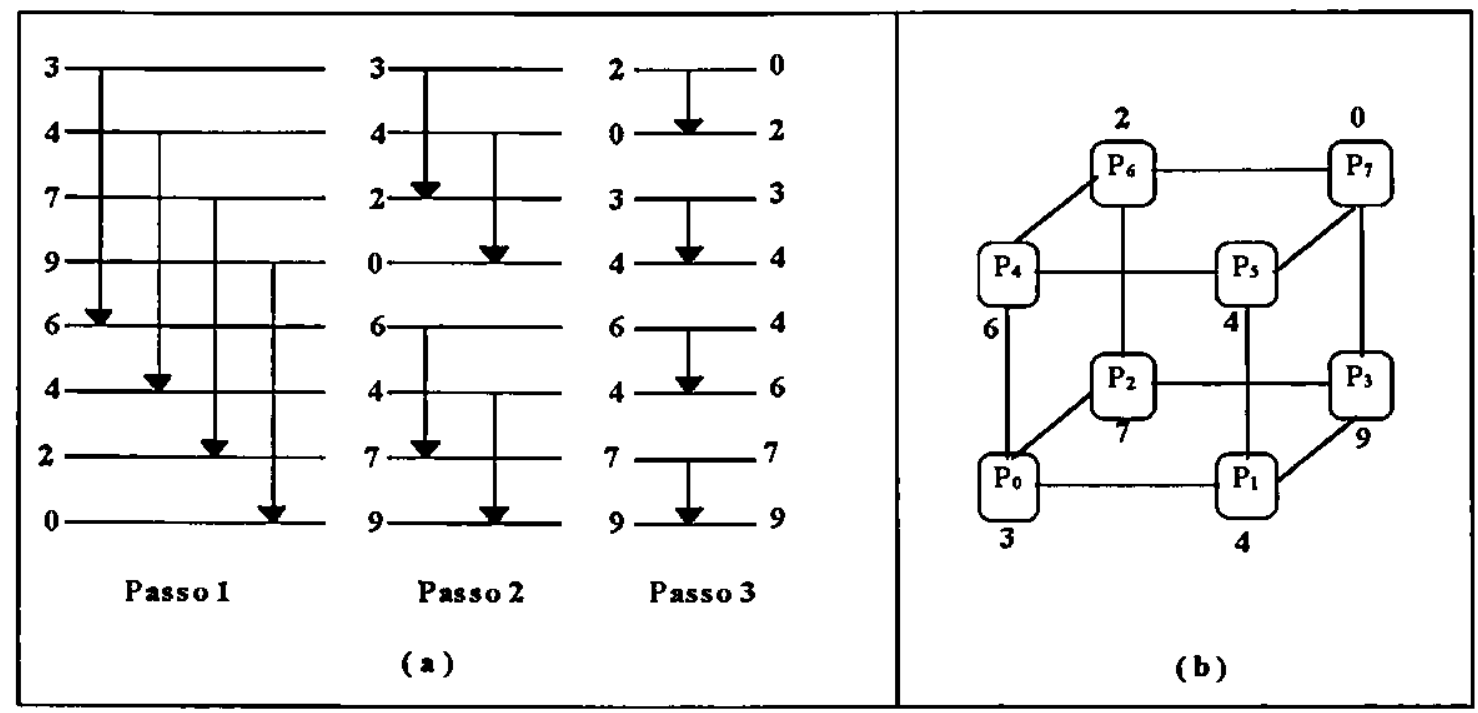

Figura 4.12 - (a) Execução do Algoritmo Bitonic.

(b) Classificação Bitonic para um Hipercubo Tridimensional

Para exemplificar, como este processo de intercalação ocorre, considere que cada processador de um hipercubo tridimensional mantêm uma sublista de N/P elementos.

No primeiro passo, o processo de intercalação das sublistas ocorrem entre os processadores $\mathrm{P}_{0}$ e $\mathrm{P}_{4}, \mathrm{P}_{1}$ e $\mathrm{P}_{5}, \mathrm{P}_{2}$ e $\mathrm{P}_{6}, \mathrm{P}_{3}$ e $\mathrm{P}_{7}$ (comunicação vertical), de modo que os memores elementos da sublista intercalada ficam no processador predecessor e os maiores em seu sucessor. Este mesmo processo é repetido, no segundo passo, entre os pares $P_{0}$ e $P_{2}, P_{1}$ e $P_{3}, P_{4}$ e $P_{6}, P_{5}$ e $P_{7}$. No último passo, a intercalação é realizada entre $P_{0}$ 
e $P_{1}, P_{2}$ e $P_{3}, P_{4}$ e $P_{5}, P_{6}$ e $P_{7}$, de modo que a lista final ordenada é obtida pela concatenação das sublistas ordenadas, na ordem dos processadores $\mathrm{P}_{0}, \mathrm{P}_{2}, \ldots, \mathrm{P}_{7}$. A figura 4.13, ilustra os processos necessários para a ordenação de uma seqüência bitonic com 16 elementos $(2,4,7,8,11,15,17,18,20,20,13,12,10,9,3,1)$, de modo que cada processador recebe 2 elementos para serem ordenados e intercalados. Como pode ser observado, após o passo 3, a lista final ordenada pode ser obtida através da concatenação das sublistas de todos os processadores (em ordem).

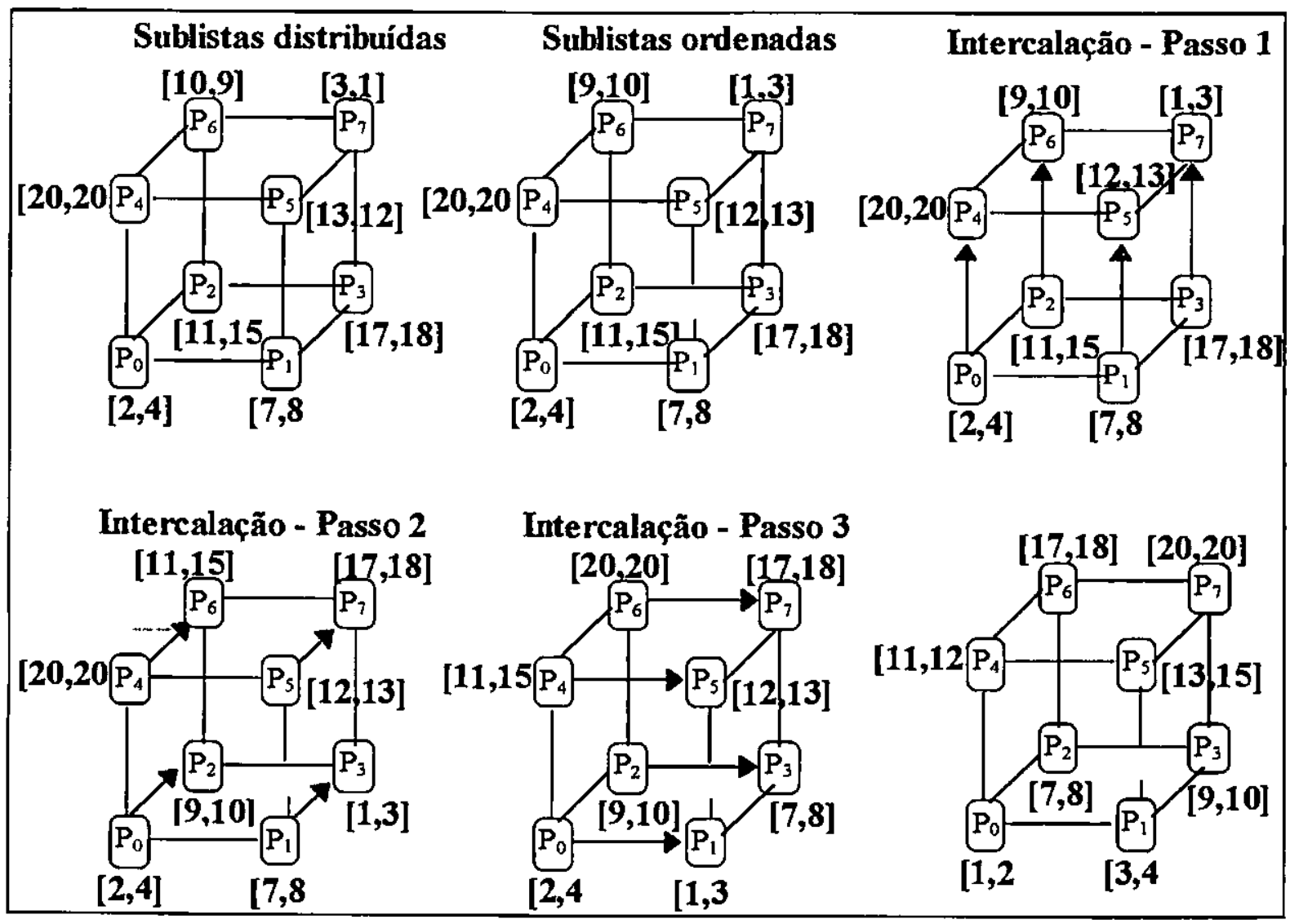

Figura 4.13 - Execução do Algoritmo Bitonic Merging. 


\subsection{Considerações Finais}

Vários fatores explicam a necessidade do processamento paralelo. $\mathrm{O}$ principal deles trata-se da busca por maior desempenho [ALM94]. As diversas áreas nas quais a computação se aplica, sejam cientificas, industriais ou militares, requer cada vez mais poder computacional, em virtude dos complexos algoritmos que são utilizados e do tamanho do conjunto de dados a ser processado [KIR91].

No projeto de um algoritmo paralelo devem ser avaliados vários fatores, não considerados na programação seqüencial, como a escolha da abordagem a ser utilizada, 0 tipo de arquitetura aonde o algoritmo será executado e o tempo de comunicação e sincronismo imposto pelo problema.

Existem três estilos de paralelismo para o desenvolvimento de algoritmos paralelos. O paralelismo pelo resultado enfoca a realização do problema partindo do produto final; paralelismo processor farm trabalha com uma lista de tarefas que devem ser gerenciadas por um processador mestre e realizadas por processadores escravos; e paralelismo pipeline, enfoca a realização do problema particionando-o em objetos que serão realizados em tempos sobrepostos por trabalhadores especialistas em uma determinada tarefa. É importante salientar que a escolha do estilo de paralelismo a ser seguido, deve ser feita atentamente, considerando-se o problema a ser resolvido e principalmente a plataforma a ser utilizada [CAR89].

Ao se tratar de algoritmos paralelos de ordenação, percebe-se uma abrangente literatura enfocando as mais diversas arquiteturas e ambientes de processamento paralelo. Muitos destes algoritmos são desenvolvidos para máquinas paralelas que exploram uma granulação mais fina, sendo que a sobrecarga de comunicação não é tão significativa. Entretanto, os algoritmos implementados para um ambiente que permite a exploração de uma granulação média e grossa (como o modelo MIMD), a comunicação e o sincronismo é um fator que merece destaque, visto que a sobrecarga de comunicação pode tornar o algoritmo ineficiente. Os algoritmos paralelos de ordenação descritos neste capítulo 
podem ser desenvolvidos tanto em multiprocessadores como em multicomputadores, o que pressupõe um granulação entre média e grossa. 


\section{Capítulo 5}

\section{Plataformas Adotadas}

Este capítulo apresenta os ambientes computacionais utilizados neste trabalho, incluindo as características de hardware e software tanto do sistema distribuído como da máquina paralela SP2.

\subsection{Introdução}

Atualmente, os sistemas distribuídos têm sido vastamente utilizados como ambientes para execução de programas paralelos. Isso possibilita o uso do processamento paralelo para uma comunidade maior de usuários, por apresentar uma alternativa de grande versatilidade, menor custo e fácil instalação em relação às arquiteturas paralelas [ZAL91] [ALM94] [SUN94] [MCB94].

Um paradigma muito utilizado para a implementação de programas paralelos em ambientes distribuídos fracamente acoplados, como arquiteturas paralelas de memória distribuída e sistemas distribuídos, trata-se da programação via troca de mensagens. Este paradigma fornece ferramentas para permitir a cooperação (comunicação e sincronização) de processos paralelos trabalhando em conjunto em determinada aplicação, quando não há compartilhamento de memória [MCB94] [KIT95] [QUE94].

Os primeiros ambientes de programação via troca de mensagens eram específicos para as arquiteturas para as quais foram desenvolvidos, de tal maneira que se dificultava a portabilidade de programas paralelos. Em virtude disso, surgiram as chamadas plataformas de portabilidade, que são ambientes de programação portáteis implementados em várias arquiteturas paralelas e sistemas distribuídos. Entre estas plataformas de portabilidade destacam-se o PVM (Parallel Virtual Machine) [GEI94] [SUN94] e o MPI (Message Passing Interface) [MCB94] [DON95] [SNI96]. 
As plataformas de portabilidade PVM e MPI possibilitam que as aplicação paralelas possam ser diretamente transportadas entre diversas arquiteturas diferentes, como sistemas distribuídos e arquiteturas paralelas. Em virtude da larga utilização dessas plataformas, elas foram escolhidas para a implementação dos algoritmos paralelos considerados neste trabalho. O MPI e o PVM serão utilizados em um sistema distribuído em uma arquitetura paralela para que se possa comparar seus desempenhos nesses dois tipos distintos de plataforma.

Este capitulo tem como objetivo apresentar os ambientes computacionais adotados neste trabalho, incluindo o sistema distribuído e a máquina paralela SP2, as plataformas de portabilidade e os ambientes de execução relacionados a essas plataformas.

\subsection{Sistema Distribuído}

Sistemas distribuídos, apresentam-se como uma maneira inteligente para melhorar a relação custo/benefício dos recursos disponíveis no sistema. Interligando um conjunto de computadores por uma rede de comunicação e coordenando-os através de um sistema operacional distribuído, o usuário tem acesso a todos os equipamentos, softwares e dados separados fisicamente, de maneira transparente, ou seja, o usuário enxerga todo o ambiente como um único sistema [COU94] [TAN95].

Sistemas distribuídos podem ser implementados em plataformas com grande variação de tamanhos, desde uma única rede local isolada até a Internet (rede mundial de computadores que agrega milhões de computadores ligados em redes, podem ser exemplos de plataformas de implementação de sistemas distribuídos [COU94].

As aplicações de sistemas distribuídos também apresentam uma grande variação, podendo incluir desde aplicações de propósito geral para grupo de usuários até aplicações comerciais (como automação bancária), aplicações multimídia, etc [COU94]. 
Os sistemas distribuídos oferecem ainda a possibilidade de utilização como uma plataforma de memória distribuída para execução de programas paralelos, substituindo de maneira eficiente arquiteturas paralelas, que apresentam alto custo de aquisição e manutenção. Porém, deve-se ressaltar que tais plataformas são adequadas a programação paralela de granulação grossa e com poucas operações de comunicação entre processos, visto que apresentam maior sobrecarga de comunicação.

\subsubsection{Características de Hardware}

No capítulo 3 (seção 3.3) foram descritas as características de hardware de um sistema distribuído, incluindo os modelos arquiteturas, suas características essenciais e a utilização de sistemas distribuídos como plataformas de programação paralela. Como já apresentado, vários modelos arquiteturais foram propostos para sistemas distribuídos (estação de trabalho/servidor, banco de processadores, híbrido e integrado), sendo que atualmente o modelo estação de trabalho/servidor tem sido o mais utilizado, devido à sua simplicidade, por atender a maioria das necessidades dos usuários e pelo custo relativamente mais baixo [COU94].

A evolução da computação distribuída está intimamente ligada à evolução da tecnologia de interconexão de computadores, visto que a eficiência de sistemas distribuidos baseia-se no fornecimento de altas velocidades de comunicação. Novas tecnologias de interconexão (Ethernet, FDDI, SONET e ATM, por exemplo) ligando computadores cada vez mais poderosos, tendem a fornecer plataformas extremamente eficientes para a utilização da computação distribuída [GEI94].

$\mathrm{O}$ conjunto de computadores disponíveis em um ambiente de rede pode incluir uma grande variedade de arquiteturas que incluem máquinas PC's (386/486/pentium), estações de trabalho de alto desempenho, multiprocessadores com memória compartilhada e sistemas MPPs (Massively Processing Parallel), além de computadores paralelos. 
O ambiente computacional distribuído utilizado neste trabalho, compreende uma rede de computadores pessoais - PC's (Pentium), executando o sistema operacional LINUX (UNLX-like). As máquinas estão conectadas através de uma rede Ethernet de 10 Mbps, utilizando o protocolo de comunicação TCP/IP.

A rede Ethernet, padrão 802.3 (IEEE ISO Standard 802.3) para redes locais, foi desenvolvida pelo Xerox PARC no início de 1970, e atualmente vêm sendo vastamente utilizada em sistemas distribuídos. Ela é baseada em barramento com o controle descentralizado e operando na taxa de transmissão de dados de $10 \mathrm{Mbps}$ ou $100 \mathrm{Mbps}$ [COU94].

A rede de PC's utilizada, está localizada no laboratório do grupo de Sistemas Distribuídos e Programação Concorrente. A utilização exclusiva pelo grupo facilita o trabalho em relação a possibilidade de execução dos algoritmos sem concorrente de outros usuários, permitindo a medição dos tempos de execução de uma forma fiel. Esta exclusividade possibilita também que o controle e configuração esteja a cargo do próprio grupo.

\subsubsection{Características de Software}

Com a disponibilidade de computadores pessoais e estações de trabalho de alto desempenho, vários projetos foram desenvolvidos tornando os sistemas distribuídos mais eficazes e mais difundidos [COU94]. Recentemente, o projeto de sistemas operacionais distribuídos têm sido alvo de muitas pesquisas, a fim de dar suporte ao desenvolvimento de aplicações distribuídas. Um sistema operacional distribuído (UNIX, por exemplo) é uma coleção de componentes de software que facilita a tarefa de programação e suporte a uma variedade de aplicações.

Uma outra área que envolve um grande número de pesquisas no cenário computacional atual é o uso de sistemas distribuídos dentro da computação paralela. Essa alternativa tornou-se possível através das chamadas plataformas de portabilidade, 
que permitem a execução de aplicações paralelas nesses sistemas. Atualmente, as plataformas de portabilidade PVM e MPI são as que mais se destacam e que são de grande importância neste trabalho, visto que serão as plataformas adotadas para a execução das aplicações paralelas.

Uma vez definida as plataformas de portabilidade a serem consideradas no sistema distribuído, PVM e MPI, deve-se definir qual sistema operacional a ser utilizado. Existem duas alternativas de utilização da plataforma PVM, sendo que uma possibilidade é utilizar - PVM para Windows95 desenvolvido pelo grupo de Sistemas Distribuídos e Programação Concorrente [SAN96][SOU95] e outra opção é utilizar o PVM executando no sistema operacional LINUX.

O LINUX [WEL95] foi escolhido devido as seguintes razões: popularidade (é um sistema operacional UNIX-like largamente utilizado na comunidade acadêmica), versatilidade e facilidade de uso. Além disso, a plataforma de portabilidade MPI já estava disponível no ambiente LINUX, o que tornou interessante utilizar o mesmo ambiente de execução para a plataforma de portabilidade PVM.

Nesta seção serão apresentados os softwares utilizados neste trabalho, incluindo o sistema operacional LINUX e as plataformas de portabilidade PVM e MPICH.

\section{O Sistema Operacional LINUX}

O LINUX é um sistema operacional UNIX-like para computadores pessoais distribuído gratuitamente sobre os termos da Licença Pública Geral GNU. Sua implementação iniciou-se com um projeto desenvolvido por Linus Tovards, e tem-se desenvolvido continuamente [WEL95], sendo largamente utilizado na comunidade acadêmica.

O LINUX possui uma filosofia de projeto totalmente aberta, sendo que muitos profissionais experientes do UNIX de diferentes localidades mundiais trabalham e contribuem para o seu crescimento e aperfeiçoamento. A nível de kernel, o núcleo do 
sistema operacional, também existe este trabalho conjunto, supervisionado pelo seu criador, Linus Tovards, que organiza e controla a distribuição de cada nova versão do kernel.

Existem dois tipos diferentes de kernels LINUX: estáveis e de desenvolvimento. Kernels de desenvolvimento são versões com novos módulos e com algumas correções de erros. Estes kernels devem ser utilizados com maior cuidado, pois ainda estão em fase de desenvolvimento e só apenas quando eles se estabilizam, ou seja, apresentam poucos problemas é que são lançados como kernels estáveis. Neste trabalho foi utilizada a versão de kernel 2.0.30, por já estar disponível no ambiente distribuído e por ser uma versão estável.

\section{Plataformas de Portabilidade}

As versões das plataformas de portabilidade utilizadas para a execução das aplicações paralelas no ambiente computacional distribuído foram: PVM 3.3.10 e MPICH 1.0.12 (uma das implementação da especificação MPI). Essas plataformas foram escolhidas pois já encontravam-se disponível e em utilização pelo grupo do laboratório de Sistema Distribuídos e Programação Concorrente. Além disso, segundo um projeto de mestrado desenvolvido no laboratório [SOU96], o MPICH foi considerado uma implementação muito boa (em relação às implementações LAM e UNIFY da especificação MPI) quando executada sobre o sistema operacional LINUX.

O PVM e o MPI encontram-se descritos de forma mais geral no capítulo 2. Nos próximos tópicos serão descritas as versões específicas das plataformas de portabilidade adotadas neste trabalho (PVM 3.3.10 e implementação MPICH 1.0.12). 


\section{PVM versão 3.3.10 (Parallel Virtual Machine)}

O PVM (Parallel Virtual Machine) surgiu em 1989 no Oak Ridge National Laboratory - ORNL nos EUA, e atualmente envolve diversos institutos de pesquisa e universidades. Diferente de outros ambientes portáteis desenvolvidos inicialmente para máquinas com multiprocessadores, o PVM surgiu com o propósito de interligar um grupo de computadores autônomos conectados por uma rede de comunicação, permitindo a concretização do paradigma máquina paralela virtual. O PVM não foi projetado para sistemas paralelos fortemente acoplados, sendo melhor utilizado em computação distribuída[BOD96] [GEI96].

Para muitos programadores de aplicações o PVM tem mostrado as vantagens da programação paralela portátil, sendo que seu domínio público, sua simplicidade, a portabilidade de suas aplicações e sua emulação de uma máquina paralela virtual são os principais motivos do sucesso do PVM [GEI94].

O PVM utiliza a estrutura de daemons (pvmd), que é executado em todos os hosts da máquina paralela virtual. O pvmd foi projetado para ser instalado na máquina por qualquer usuário e atua como roteador e controlador de mensagens, funcionando como um ponto de contato entre os hosts. O primeiro pvmd (iniciado pelo usuário) é referenciado como mestre e os outros pvmds (iniciados pelo mestre) são chamados escravos. Não existe diferenças entre eles, exceto quando há necessidade de operações de gerenciamento, tais como criar novos pvmds escravos e adicioná-los à máquina virtual. Apenas o pvmd mestre pode executar essas tarefas.

Se o.pvmd mestre falhar, toda a máquina virtual pára de executar. Atualmente não há nenhuma implementação para evitar esse problema de tolerância a falhas. Quando um pvmd escravo falha, ele é considerado morto pelo mestre. Isso ocorre porque o pvmd mestre envia uma mensagem para verificar se os pvmds escravos estão ativos.

A figura 5.1 ilustra um sistema com 4 hosts que compõe uma máquina virtual. Neste exemplo, o host 1 (iniciado pelo usuário) roda o pvmd mestre, enquanto os outros hosts executam os pvmds escravos. 


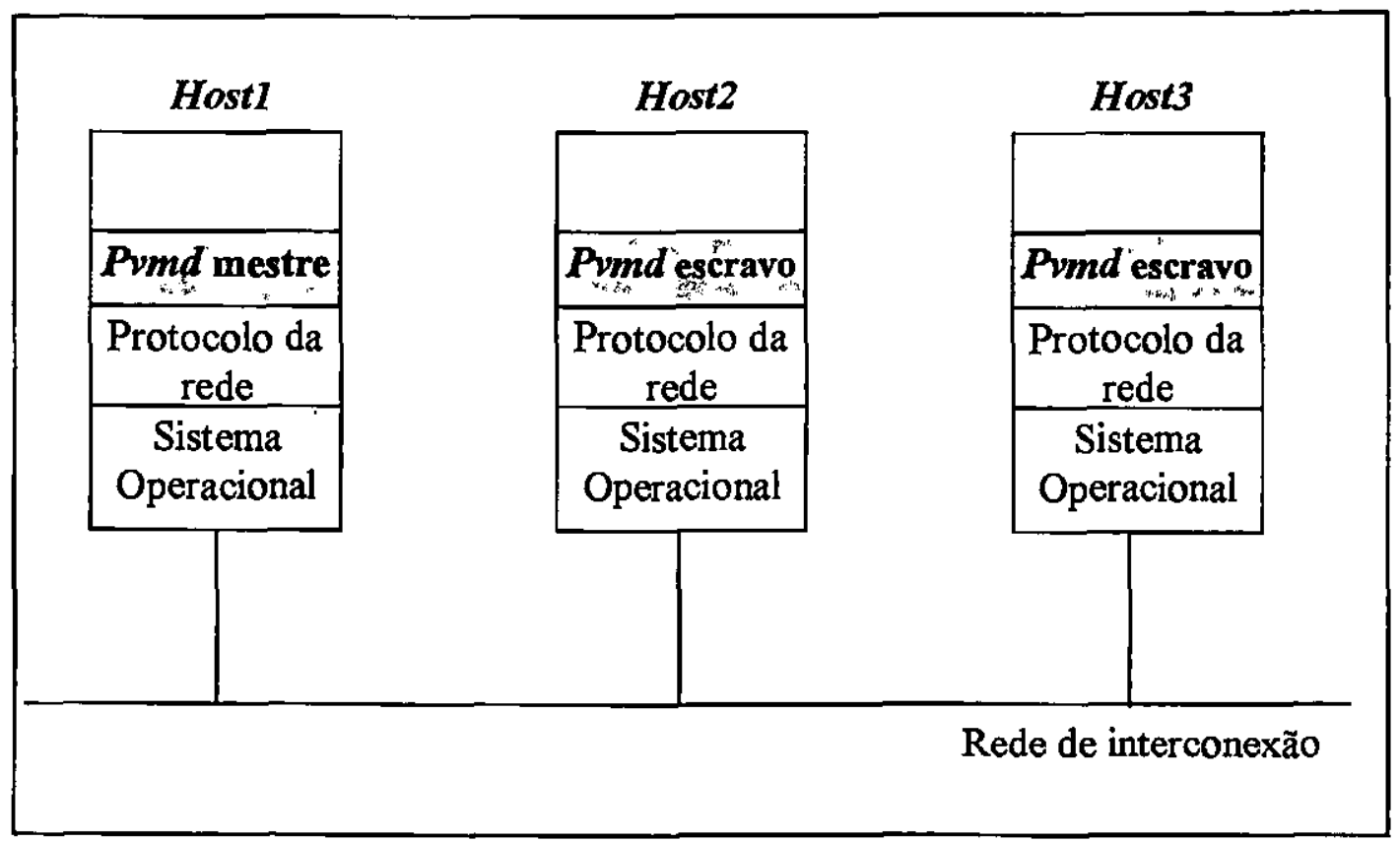

Figura 5.1 - Os pvmds executando em todos os hosts da máquina virtual.

O PVM possui uma biblioteca (Libpvm) que contém um conjunto de 82 funções para efetuar troca de mensagens, gerar processos, coordenar tarefas (sincronização) e modificar a máquina virtual. Os programas de aplicação (que podem ser escritos em $\mathrm{C}$, $\mathrm{C}++$ e Fortran) devem ser ligados a esta biblioteca para utilizar o PVM.

O modelo computacional do PVM é baseado em tarefas (análogo a um processo UNIX), sendo que cada uma delas é responsável por uma parte de trabalho da aplicação. Tarefas são normalmente iniciadas através da função pvm_spawn(), que ativa tarefas "escravas" da tarefa ("mestre") que chamou a função. Além desta função, as tarefas podem ser iniciadas manualmente pelo próprio programador, através do uso da rotina pvm_reg_tasker() que registra um tipo especial de tarefa PVM chamada tasker.

Um conceito muito importante inclúdo no PVM é o conceito de grupos dinâmicos de tarefas, que são criados pelo usuário em tempo de execução. Uma biblioteca separada (libgpvm3.a) deve ser montada com as aplicações que fazem uso de qualquer função para grupos de tarefas. O controle deste grupo é manipulado por um servidor de grupos, o qual é iniciado quando a primeira função para grupos for solicitada [GE194][SUN94]. O PVM 
oferece funções que permitem que uma tarefa se una ou deixe um grupo, além de funções de sincronização e comunicação coletiva (como barrier, multicast, broadcast e reduce).

A comunicação entre duas tarefas PVM pode ser realizada nos seguintes modos: send bloqueante assíncrono, receive bloqueante assíncrono e receive não bloqueante. 0 envio de uma mensagem é efetuada através de três etapas: deve-se criar um buffer, "empacotar" a mensagem dentro do buffer, e finalmente enviar a mensagem inteira (o conteúdo do buffer) para outra tarefa ou grupo de tarefas. A mensagem é recebida por uma função bloqueante ou não bloqueante e então "desempacotada" retirando do buffer (no host receptor da mensagem) os dados enviados. $O$ receptor pode aceitar qualquer mensagem, qualquer mensagem de um determinado host, qualquer mensagem com um determinado identificador (número de mensagem), ou somente mensagens de um determinado host com um identificador específico.

A comunicação realizada pelo PVM é baseada em TCP (Transmission Control Protocol), UDP (User Datagrama Protocol) e sockets (implementação padrão UNIX de comunicação entre os processos [STE90]). [GEI94].

O protocolo UDP é utilizado nas comunicações entre pvmds e por ser um protocolo não confiável o PVM implementa mecanismos de confirmações e retransmissões das mensagens. O principal motivo do protocolo TCP não ser utilizado está relacionado com o número de conexões envolvidas com os pvmds. Um socket UDP aberto pode comunicar-se com qualquer outro socket UDP remoto, enquanto que a cada transmissão aberta com TCP consome um descritor de arquivos no pvmd (alguns sistemas operacionais limitam a quantidade de arquivos abertos), como também gasta tempos extras (overhead) para realizar todas as conexões necessárias.

O protocolo TCP, devido principalmente ao fato de ser um protocolo confiável, foi escolhido para realizar as comunicações entre um pvmd e suas tarefas e entre as tarefas. Como as comunicações não têm o mesmo estilo das feitas entre pvmds, sendo que o tamanho das mensagens e a sua ocorrência dependem da aplicação envolvida, a melhor solução foi a adoção do protocolo TCP. 
Quando a máquina virtual é composta de hosts heterogêneos, os dados transmitidos entre elas podem ser incompativeis. Para solucionar este problema, o PVM codifica a mensagem no padrão XDR possibilitando que os dados transmitidos sejam decodificados no padrão compatível com o host destino. Isso apenas é empregado quando há necessidade, pois impõem naturalmente maiores tempos de transmissão.

A plataforma de portabilidade PVM possui um programa, chamado de console PVM, que permite ao usuário interagir e modificar a máquina virtual, sendo possível chamá-lo e encerrá-lo em qualquer host da máquina virtual sem afetar a execução do PVM ou qualquer outra aplicação em execução. Para executá-lo basta digitar a linha de comando pvm, a qual inicializará o pvmd no host utilizado e será mostrado na tela o prompt pvm>. Com isso, o usuário poderá adicionar novos hosts na máquina virtual (através do comando add <nome do hos $\triangleright$ ), verificar sua configuração (comando conf ), modificá-la (como o comando delete $<$ nome do hos $\triangleright$, que retira hosts da máquina virtual), finalizá-la (comando halt), dentre muitas outras funções disponíveis para o usuário. O PVM também permite que essas funções sejam inseridas nas aplicações, não necessitando portanto a utilização do console PVM.

Neste trabalho, utilizou-se o console PVM ao invés de implementar as funções nas próprias aplicações paralelas, com o objetivo de tornar os algoritmos paralelos menos extensos e mais enxutos, além de permitir maior facilidade na configuração e na modificação da máquina paralela virtual.

\section{MPICH}

O MPICH, uma implementação da especificação MPI versão 1.1, surgiu através de um trabalho conjunto entre as organizações americanas Argonne National Laboratory e Mississippi State University, fornecendo uma primeira amostra para os usuários MPI, à medida que o padrão MPI se desenvolvia. Pelo fato de ser altamente portátil foi nomeado MPI Chameleon ou MPICH [GRO98] [MAL96] [MPI96]. 
O principal objetivo do desenvolvimento do MPICH foi fornecer uma implementação portátil para uma grande variedade de sistemas computacionais paralelos (que utilizassem a computação via troca de mensagens), incluindo tanto arquiteturas paralelas como sistemas distribuídos (plataformas paralelas).

O MPICH implementa todas as rotinas do padrão MPI versão 1.1. Ao contrário de adotar como padrão um ambiente e uma plataforma, incorporou as características de três implementações de plataformas de portabilidade já existentes e estáveis, permitindo que fosse implementado rapidamente. Estas plataformas são: p4 [BUT94], Chameleon [SMI93] e Zipcode [SKJ94][SMI94]. Entretanto, o MPICH vem sendo estendido e otimizado com o intuito de fornecer melhor portabilidade e desempenho, e entre essas otimizações, podem ser citadas: o desenvolvimento do ADI (Abstract Device Interface Interface de Dispositivo Abstrata) que permite que qualquer biblioteca de passagens de mensagens possa ser implementada sobre ela e a elaboração do MPE (Multi-Processing Environment), uma biblioteca que auxilia o desenvolvimento e depuração dos programas paralelos [GRO98] [MEY94].

Com o intuito de facilitar a operação de transporte do código fonte entre diferentes plataformas paralelas, a estrutura do MPICH se divide em dois níveis. No primeiro nível encontra-se todo o código fonte independente de hardware, onde as funções do MPI são implementadas e no segundo nível, situa-se todo o código dependente de hardware. Estes dois níveis comunicam-se através da camada ADI, que fornece rotinas e macros utilizadas na escrita de todas as funções do MPI.

Devido ao fato do MPICH possibilitar fácil transporte do seu código fonte, esta implementação vêm sendo difundida rapidamente, e já executa com eficiência em uma variedade de máquina paralelas e redes de computadores.

A estruturação básica de comunicação do MPICH utiliza o dispositivo ${ }^{1} \mathrm{ch} \_$p4, quando executado sobre o sistema operacional LINUX (como mostra a figura 5.2)

\footnotetext{
${ }^{1}$ Denomina-se dispositivo (device) à uma coleção de softwares que se encontra no segundo nivel de estruturação do MPICH.
} 
[SOU96]. A nomenclatura ch_p4 representa uma implementação mista baseada nas rotinas das plataformas de portabilidade Chameleon [SMI93] e p4 [BUT94]. O dispositivo ch $\_4$ pode ser utilizado em qualquer rede de computadores executando um sistema operacional UNLX-like.

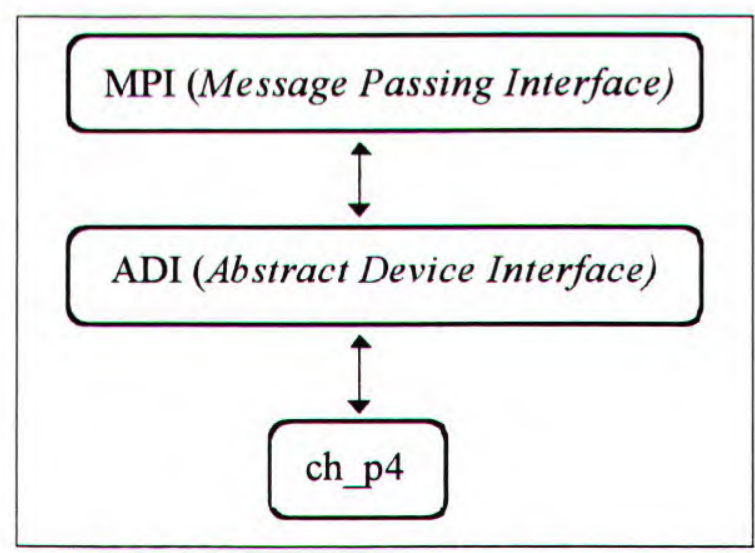

Figura 5.2 - Estrutura do MPICH Sobre o LINUX.

$\mathrm{O}$ ch $\_$p 4 possui organização semelhante à da implementação p4 [BUT94]. No p4 um conjunto de processos de uma aplicação é subdividido em clusters, que são grupos de processos com códigos fontes idênticos executando no mesmo computador. A comunicação entre processos pertencentes ao mesmo cluster é realizada através de memória compartilhada (utilizando-se monitores que implementam controle de acesso e seqüência). Para comunicação entre processos em clusters diferentes, transmitem-se mensagens via sockets TCP [MEY94]. A figura 5.3 apresenta um a estrutura do MPICH sobre o dispositivo ch_p4 [SOU96]. 


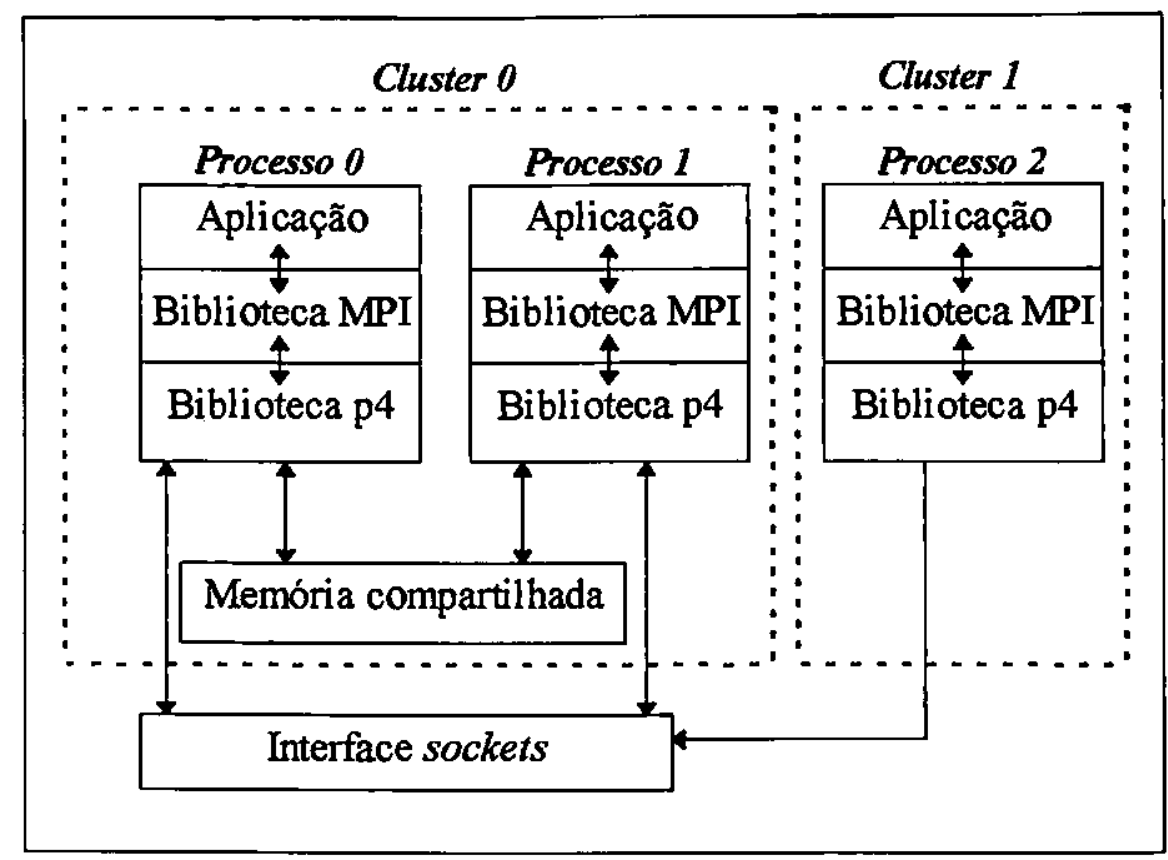

Figura 5.3 - Estrutura do MPICH Sobre o Dispositivo ch_p4.

Diferente da plataforma de portabilidade PVM, o MPICH não utiliza a estrutura de daemons [GRO96]. Uma vantagem disso é que o controle imposto pelo daemon implica em uma certa sobrecarga, principalmente durante a transmissão de mensagens, visto que cada mensagem transmitida é monitorada pelo daemon. Entretanto, a estrutura de daemons permite que as aplicações sejam executadas e encerradas em qualquer componente da máquina virtual, além de facilitar as tarefas de depuração e balanceamento de carga.

Outra característica que o diferencia do PVM é que o MPICH relaciona os processos em grupos, e estes processos são identificados pela sua classificação dentro desse grupo. Os grupos são projetados para serem estáticos, ao invés de dinâmicos como no PVM, pois todos eles derivam de um grupo inicial e novos processos não podem ser criados durante a execução do programa.

O MPICH possui uma especificação longa e relativamente complexa, para se tornar eficiente em diversas arquiteturas computacionais e para fornecer todas as características consideradas importantes para uma biblioteca de passagem de mensagem. Com isso, o MPICH oferece 14 variações para a comunicação ponto-a-ponto (que 
apresentam versões bloqueantes e não bloqueantes). Além das rotina básica send0,são oferecidas as seguintes variantes: síncrono, padrão, bufferizado e ready (apresentados no capitulo 2, seção 2.6.2). A rotina receive() é implementada nos modos bloqueante ou não bloqueante . Além disso, são oferecidas uma variedade de funções para comunicação coletiva, como broadcasting, gather, scatter, alltoall, allgather, entre outras.

Desta forma, o usuário tem um leque muito grande de opções e pode escolher a opção que melhor funcione baseado na sua plataforma paralela e na sua aplicação. $O$ PVM, por outro lado, teve como principal meta de seu projeto ser simples, a fim de facilitar o trabalho do programador [GEI96a].

\subsection{SP2 - Scalable POWERparallel System 2}

Em 1990, a IBM lançou os computadores paralelos da família RISC System/6000 (RS/6000). Essas máquinas envolvem múltiplas unidades funcionais e complexidade de hardware, de forma a permitir que as unidades possam desempenhar suas funções de maneira autônomas. Todos os modelos de processadores RS/6000 (de 20 a $30 \mathrm{MHz}$ ) incluiam 8 Mbytes de cache de instruções, como também cache de dados de 32 a 64 Mbytes. Esses processadores foram as primeiras implementações de arquiteturas POWER (Performance Optimized With Enhanced RISC) realizada pela IBM [IBM95].

Após alguns anos, foram implementadas algumas melhorias adicionais nos processadores POWER, passando a oferecer $62,5 \mathrm{MHz}$ de freqüência e 32 Mbytes de cache de instruções. A partir de 1993, a IBM anunciou a família de computadores Scalable POWERparallel (SP) [IBM94]. As máquinas paralelas SP foram projetadas com o objetivo de obter um processamento paralelo altamente poderoso, possibilitando executar aplicações que necessitam de grande quantidade de operações de $\mathrm{E} / \mathrm{S}$ e computação intensiva. Além do alto desempenho, uma característica intrínseca dessas máquinas é a escalabilidade, sendo possível adicionar-se tantos processadores quanto forem necessários, sem afetar as característica do sistema (como a perda de desempenho). 
O primeiro computador a ser projetado pela IBM, da série Scalable POWER, foi o SP1. Essa máquina possui uma arquitetura de memória distribuída, composta por vários processadores RISC System/6000 POWER [ALM94]. Uma característica do SP1 é que todos os nós de processamento são idênticos (RS/6000 de $62.5 \mathrm{MHz}$ ) e podem suportar até 64 processadores. O desempenho de pico de cada nó pode chegar à 125 MFlOPS.

Posteriormente, a IBM lançou a máquina SP2, visando fornecer o dobro de desempenho obtido com o SP1. O RISC System/6000 Scalable Powerparallel System 2 (SP2) é uma máquina paralela com memória distribuída, composta de diversos processadores (com memória e disco próprio) interligados por interfaces de rede e por um switch de alto desempenho. O sistema pode suportar até 128 nós de processamento, cada um possuindo arquitetura RISC System/6000 POWER2.

A arquitetura paralela utilizada neste trabalho é a máquina paralela SP2, disponível no Centro de Informática de São Carlos (CISC). Devido à sua importância neste trabalho, nas próximas seções serão apresentadas as características básicas de hardware e software do SP2.

\subsubsection{Arquitetura do Processador POWER2}

O processador POWER2 (ilustrado na figura 5.4) é uma implementação multichip da arquitetura POWER, incluindo [IBM97]:

-ICU (Instruction Cache Unit) de 32 KBytes, responsável pela envio de instruções para a FPU (Floating Point Unit) e FXU (Fixed Point Unit), através do barramento de instrução (IBUS - Instruction Dispatching Bus);

- DCU (Data Cache Unit) de 64 a 256 KBytes, contendo 4 chips de cache de dados, dois barramentos para FPU (cada um com capacidade de transmitir 128 bits de uma vez), dois barramentos para FXU (cada um capaz de transferir 32 bits) e um barramento 
para a ICU e para a unidade de E/S. O sistema de memória pode incluir 2,4 ou 8 cartões de memória;

- FXUs (Dual Fixed Point Units), dedicado ao processamento de cálculos de endereços (como pesquisa de diretórios no cache de dados), cálculos aritméticos com inteiros e operações lógicas. Possuem duas unidades de processamento, sendo capaz de processar duas instruções por ciclo;

- FPUs (Dual Floating Point Units), possuem duas unidades de processamento que podem executar todas as operações (exceto instruções que envolvem condições e saltos), permitindo executar duas instruções em ponto-flutuante por ciclo de clock;

- SCU (Storage Control Unit), contém registradores de controle e de configuração para a memória e gerencia todas as comunicações entre a CPU (ICU, FXU, FPU, DCU), memória e o barramento de E/S (SIO Bus - System I/O).

O SP2, sendo organizado com múltiplos processadores super-escalares POWER2, possibilita a execução simultânea de múltiplas instruções.

\subsubsection{Características Essenciais}

Além do alto poder computacional, o SP2 apresenta outras características importantes como:

- Escalabilidade: permite que o sistema cresça, acrescentando-se novos componentes, sem que isto afete o sistema;

- Sistema aberto: suporta muitos protocolos de comunicação, adaptadores e periféricos, tornando o sistema flexível; 


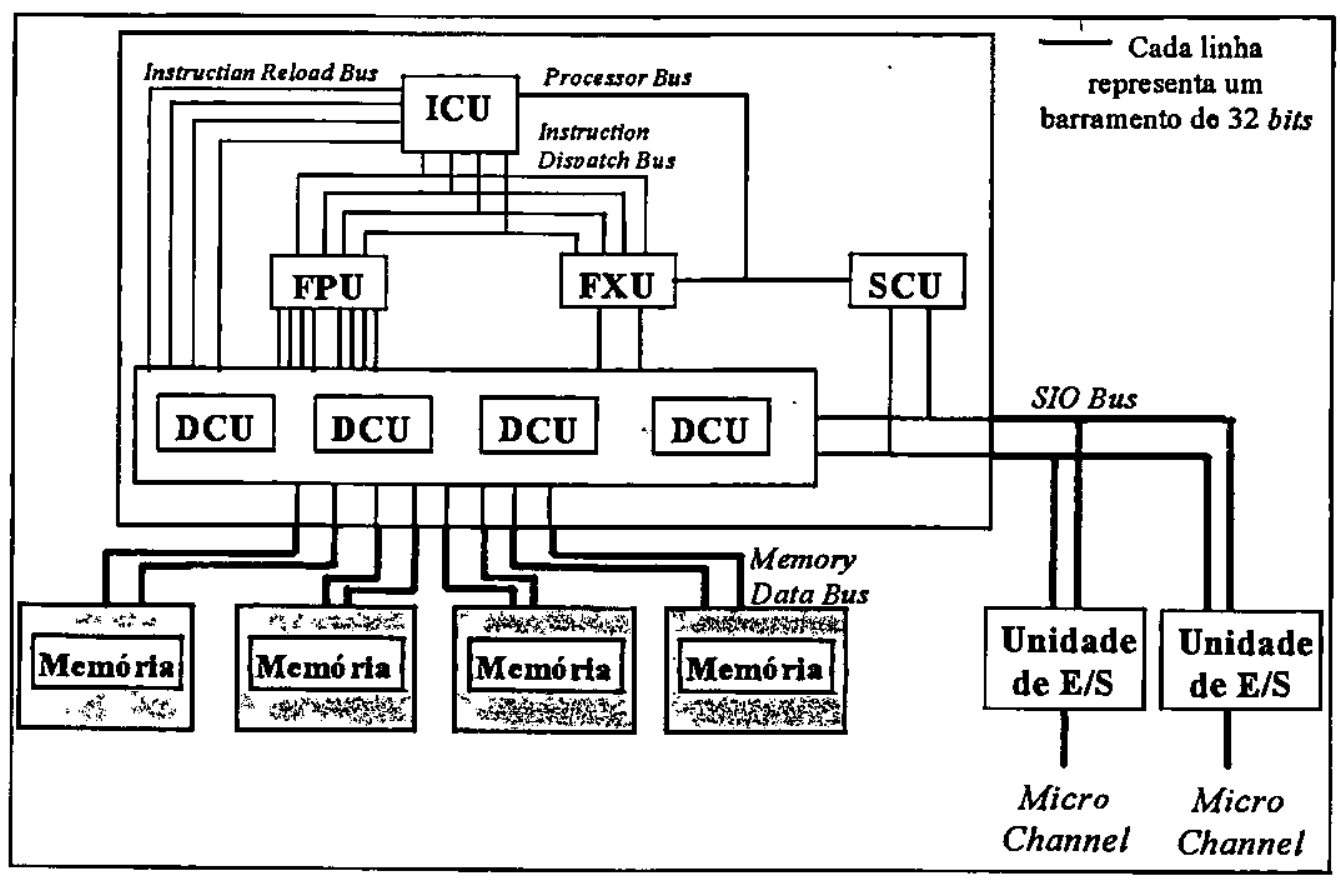

Figura 5.4 - Arquitetura de Processadores POWER2

- Flexibilidade de configuração: fornece vários modelos de nós (descrito na seção 5.3.3) que podem ser misturados no rack do SP2;

- rede de interconexão multi-estágio: suporta comunicação de alto desempenho entre os nós, permitindo que qualquer nó (independentemente de sua localização) possa se comunicar com qualquer outro;

- Único ponto de gerenciamento do sistema: a administração é facilitada, através da utilização de uma estação de controle, que gerencia e monitora o SP2.

- Alta disponibilidade: Com a existência de caminhos redundantes entre os nós de processamento, é possível evitar que o sistema inteiro seja afetado, na ocorrência de uma falha.

- Suporte multi-usuário: Com a utilização de um switch de alto desempenho, é possível ter múltiplos jobs sendo executados ao mesmo tempo. Além disso, o sistema 
operacional AIX/6000 (implementação da IBM e utilizado no SP2) que é instalado em todos nós de processamento, permite comunicação multi-usuário.

\subsubsection{Hardware do SP2}

O hardware do SP2, é composto pelos nós de processamento, pelo rack do SP2, pela switch de alto desempenho e pela estação de controle. Como pode ser observado na figura 5.5, o SP2 conecta todos os nós de processamento através de um subsistema de comunicação chamado de switch de alto desempenho. Cada nó possui vários slots Micro Channel, servindo como uma interface de rede para os adaptadores de comunicação (switch de alto desempenho, Ethernet, FDDI, Token Ring, ATM, são alguns dos adaptadores suportados pelo SP2). Existe também uma estação de controle, responsável pelo gerenciamento e monitoramento do sistema.

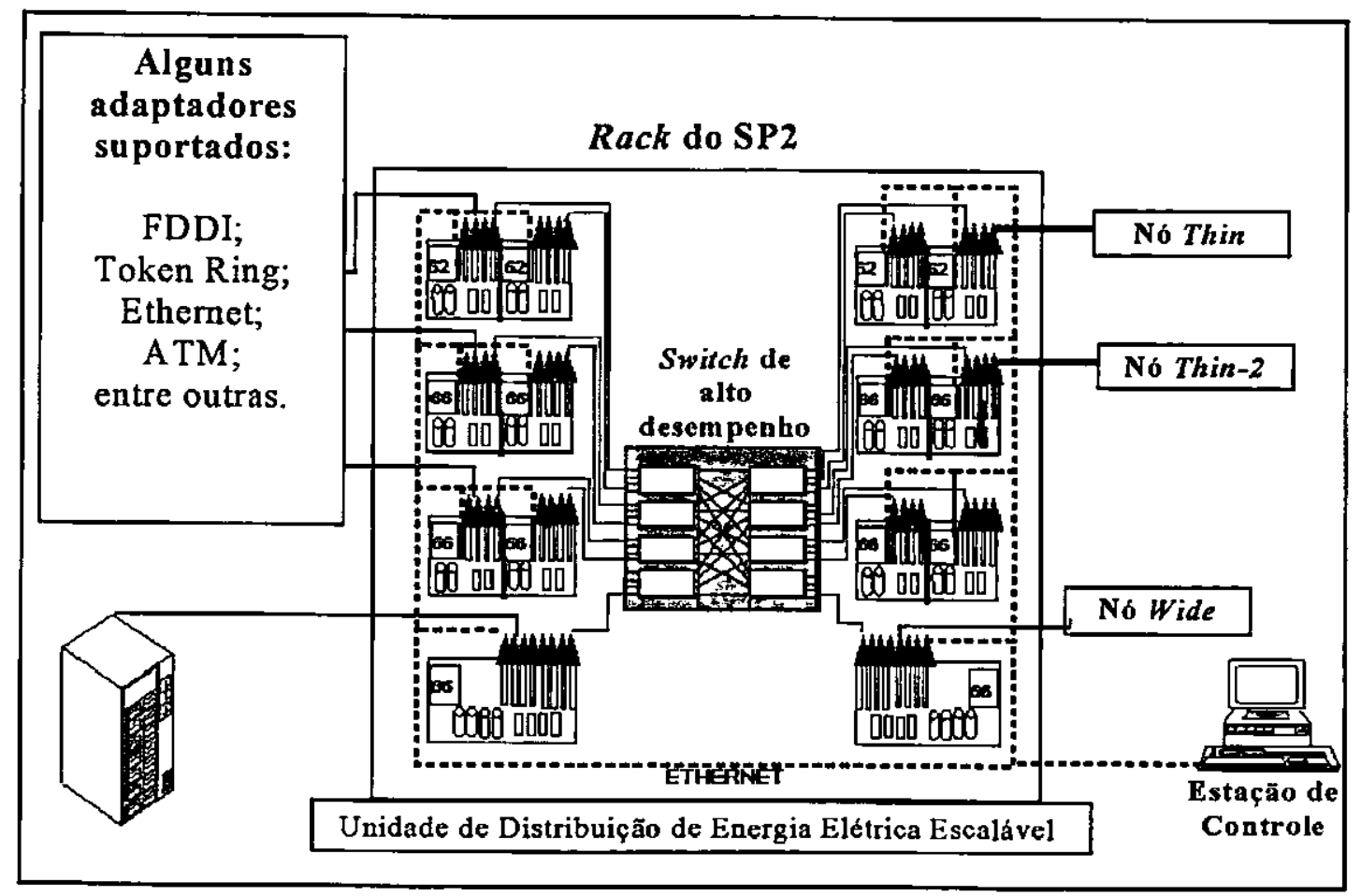

Figura 5.5 - Visão Geral do Sistema SP2 [IBM95] 


\section{Nós de processamento do SP2}

Os nós de processamento para o SP2 são disponíveis em três modelos: nós do tipo Wide, nós do tipo Thin e nós do tipo Thin-2. Cada nó possui sua própria memória, disco e vários slots Micro Channel utilizados para operações de E/S e conectividade. A característica de cada tipo de nó é ilustrada na figura 5.6.

Nós Wide são geralmente configurados para agirem como servidores do sistema. Eles utilizam o processador POWER2, suportam quantidades de memória (tanto secundária, quanto primária e caches) maiores que a suportada pelos nós thin. Além disso, o número de slots disponível é também maior.

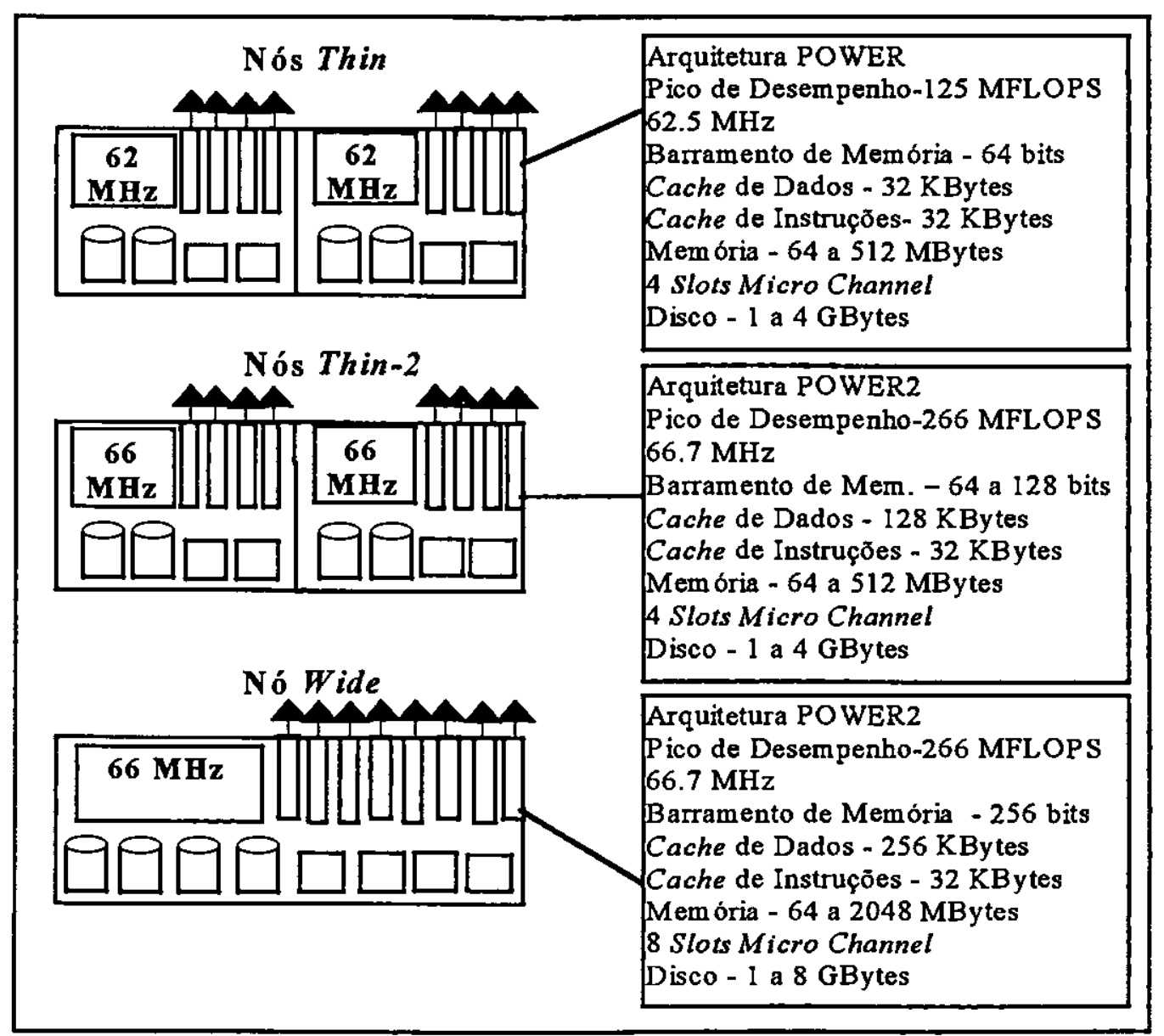

Figura 5.6 - Modelos de Nós de Processamento do SP2

Os nós Thin e Thin-2 são mais adequados para executar os programas do usuário, fornecendo alto poder de processamento. Eles oferecem a flexibilidade de rodar alguma 
combinação de jobs interativos, em batch, seriais e paralelos simultaneamente, podendo ser compartilhados por qualquer um destes jobs ou ser dedicados a rodar uma única aplicação.

A máquina SP2 adotada neste trabalho possui três nós de processamento, sendo um nó do tipo wide e dois nós do tipo thin2. Cada nó thin2 possui processador POWER2 de $66.7 \mathrm{MHz}, 256$ Mbytes de memória, 128 Kbytes de cache de dados e barramento de memória de 128 bits. O nó wide possui processador POWER2 de $66.7 \mathrm{MHz}, 256 \mathrm{Mbytes}$ de memória, 256 Kbytes de cache de dados e barramento de 256 bits. Os nós estão interligados através do switch de alto desempenho que chega a ter um bandwidth de 35 Mbytes/segundo e latência de 50 microsegundos, além de possuir conexões para redes Ethernet, Token Ring e FDDI.

Além dos três nós disponíveis, uma estação de trabalho IBM RISC/6000 3CT é utilizada como nó interativo do SP2. Esse nó interativo possui as mesmas características de hardware dos nós do tipo thin-2, exceto ao barramento de memória que é de 64 bits. Enquanto os nós de processamento do SP2 são destinados ao processamento em batch de programas paralelos, a estação de controle é dedicada ao processamento interativo e a submissão, em batch, de programas de usuários, através do software de gerenciamento LoadLeveler (descrito na seção 5.3.4). O acesso do usuário ao SP2 deve ser efetuado através dessa estação.

\section{Rack do SP2}

O rack do SP2 comporta no máximo 16 nós do tipo thin (ou thin-2) ou 8 nós do tipo wide. É possível também conectar vários racks para se obter a configuração máxima de 128 nós de processamento. Os nós não precisam ser os mesmos, isto é, no SP2 pode-se utilizar nós thin e wide juntos no mesmo rack. Na figura 5.7, mostra um rack composto de 8 nós thin e 4 nós do wide. 
O rack contém fontes de alimentação redundantes, de modo que se um nó falhar, o sistema inteiro não será afetado. Além disso, ele é projetado para possibilitar manutenção concorrente dos nós, ou seja, cada nó de processamento pode ser removido e reparado sem interromper as atividades dos outros nós. Desta forma, o SP2 fornece um sistema altamente confiável para seus usuários.

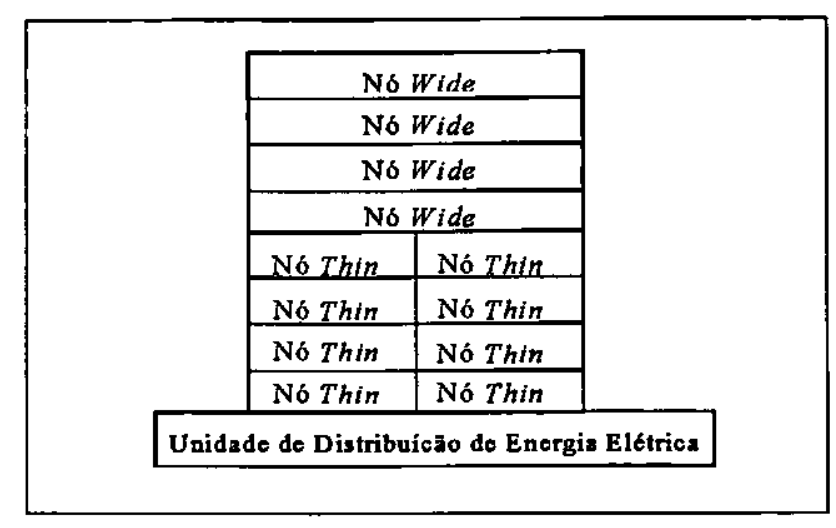

Figura 5.7 - Estrutura do Rack do SP2

\section{Switch de alto desempenho}

O switch de alto desempenho conecta todos os nós de processamento juntos, permitindo que todos eles possam enviar mensagens simultaneamente [IBM95]. Para suportar esta conectividade o hardware consiste de 2 elementos básicos: o switch board $\mathrm{e}$ o adaptador de comunicaçōes. Há um adaptador de comunicações por nó de processamento (ocupando um slot Micro Channel) e um switch board por rack.

O adaptador de comunicações funciona como uma interface dos nós de processamento para o switch. Existem duas versões de adaptador de comunicações para 0 switch, o HPS-1 e HPS-2 (High Performance Switch Adapter 1 e 2).

O switch board é composto por 8 chips lógicos que implementam switch do tipo crossbar $4 \times 4$, ou seja, cada um possui 4 portos de entrada e 4 portos de saída, como 
mostra a figura 5.8. Cada chip lógico pode transferir pacotes (dados) de qualquer porto de entrada para qualquer porto de saída. Além disso, o switch board possui um buffer compartilhado (também chamado de fila central) que aloca dinamicamente pacotes de qualquer porto de entrada.

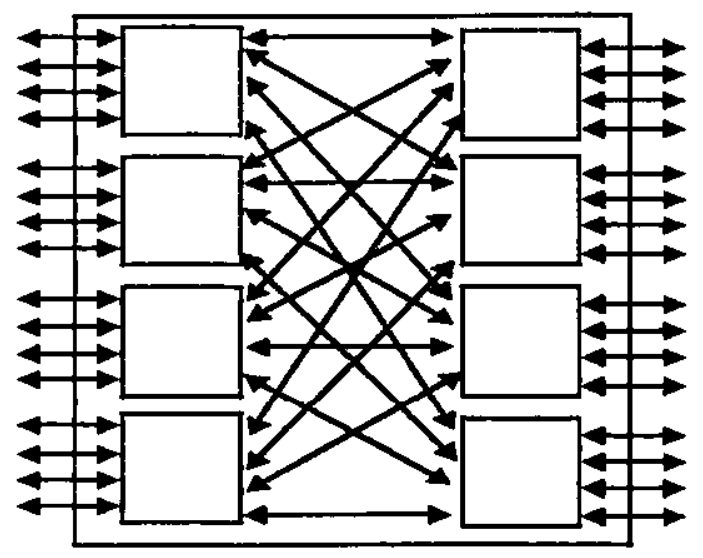

Figura 5.8 - Estrutura do Switch Board

O switch do SP2 é uma rede de comunicação bidirecional, com uma taxa de até $110 \mathrm{Mbytes} / \mathrm{s}$, com interconexão multi-estágio [IBM97]. A rede multi-estágio foi escolhida para que o switch pudesse oferecer uma característica muito importante que é a escalabilidade, com esse tipo de rede é possível o acréscimo de novos nós de processamento, quando há a necessidade de mais poder computacional, sem afetar o desempenho do sistema. Com uma rede multi-estágio, à medida que o sistema cresce, novos switch board podem ser adicionados, garantindo-se que a quantidade de bandwidth disponível para cada processador continue constante.

Outra característica do switch é a existência de caminhos redundantes entre os nós de processamento, permitindo que novas rotas sejam geradas na presença de componentes defeituosos. Isto possibilita que o sistema seja altamente tolerante à falhas.

A confiabilidade é um outro fator de extrema importância, principalmente pelo fato do switch suportar utilização multi-usuário. Uma necessidade para sistemas multiusuários é a distribuição de mensagens livre de erros, e para isso, o sistema fornece proteção nas transmissões de mensagens para detectar erros de transmissão, através do 
uso de códigos de deteç̧ão de erros, chamado CRC (Cyclic Redundancy Code), que são transportados nos pacotes transmitidos e checados no nó de processamento receptor.

Além disso, o switch opera com chaveamento de pacotes. Cada pacote enviado contém um cabeçalho que transporta uma informação de roteamento, sendo que cada chip lógico interpreta esta informação para selecionar o porto de saída apropriado. Se este porto de saída estiver livre, o pacote é transmitido, caso contrário ele será alocado no buffer do switch board, até que o porto de saída esteja desocupado. Desta forma, o switch pode ser compartilhado por múltiplos jobs, garantindo que um único job não monopolize o sistema.

\section{Estação de Controle}

O gerenciamento de sistemas grandes é sempre uma tarefa árdua. No SP2, com a existência de uma única estação de controle, responsável pelo controle, monitoramento, manutenção e administração do sistema, torna esta tarefa mais simples. Geralmente, o administrador do sistema utiliza a estação de controle, juntamente como um software chamado PSSP (Parallel Systems Support Programs) disponivel com o SP2, para realizar tarefas como gerenciamento de contas de usuários, gerenciamento de filas de impressão e filas de submissão de jobs, instalação dos nós de processamento do SP2, etc.

A estação de controle deve ser uma máquina RISC System/6000, que pode ser utilizada também como um servidor de arquivos. O rack do SP2 é interligado com a estação de controle através de uma conexão externa (Ethernet).

\subsubsection{Software do SP2}

O sistema operacional utilizado no SP2 é AIX/6000 que é um sistema similar ao UNIX. Esse sistema operacional é instalado por completo em todos nós de 
processamento, como também no nó interativo (estação de controle). Os seguintes softwares estão disponíveis no SP2:

- Conjunto de utilitários para administração do sistema (como o software PSSP, citado na seção anterior) ;

- Ambiente de programação paralela, consistindo de Bibliotecas de Passagem de Mensagem (como MPI, PVMe, MPL), Ambiente Operacional Paralelo (POE - Parallel Operating Environment) e ferramentas como Depuradores Paralelos e ferramentas de visualização.

- LoadLeveler, software responsável pelo gerenciamento, escalonamento de jobs e pelo balanceamento de carga nos nós de processamento.

Esta seção apresenta uma breve discussão sobre os softwares disponíveis no SP2.

\section{Sistema Operacional AIX/6000}

O sistema operacional AIX é uma versão IBM do sistema UNIX System $V$, da AT\&T e 4.3 BSD (Berkeley Software Distribuition). Este sistema operacional é um sistema multi-usuário e multi-tarefa. Isto significa que vários usuários podem utilizar a mesma máquina ao mesmo tempo e que várias tarefas podem ser executadas concorrentemente (quando há um único processador) ou em paralelo (quando há vários processadores) [AIX95] .

Além disso, o IBM AIX fornece um ambiente operacional comum à uma grande área de sistema RISC/6000, incluindo estações de trabalho com processadores da tecnologia RISC, multiprocessadores e plataformas IBM SP (Scalable POWER). 


\section{Ambiente Paralelo (PE)}

O Ambiente Paralelo (PE) do SP2, desenvolvido pela IBM, é um sistema de passagem de mensagem de memória distribuída, que é executado em plataformas RISC System/6000 usando o sistema operacional AIX. Este ambiente consiste de componentes e ferramentas para o desenvolvimento e execução de aplicações paralelas, incluindo aplicações paralelas que utilizam a plataforma IBM MPI. Um dos componentes principais deste ambiente é o Ambiente Operacional Paralelo (POE - Parallel Operating Environment) que gerencia o desenvolvimento e a execução de aplicações paralelas. $\mathrm{O}$ POE é utilizado para compilar, executar, monitorar e depurar programas paralelos, sendo também responsável pela carregamento do código executável nos nós de processamento e gerenciamento de operações de E/S [MPI95].

O principal objetivo do desenvolvimento do POE foi otimizar a utilização do switch de alto desempenho, sendo portanto um ambiente implementado com o propósito de fornecer alto desempenho nas comunicações entre os processos paralelos de uma aplicação.

O POE utiliza a estrutura de daemon (denominada de pmd) [POE95]. O pmd é iniciado em cada nó de processamento pelo nó home (processador aonde o POE é executado), servindo como um ponto de contato entre o nó home e as tarefas do usuário. $\mathrm{O} \mathrm{POE}$ roteia as operações de $\mathrm{E} / \mathrm{S}$ entre o nó home e as tarefas do usuário via daemon $(p m d)$, utilizando o protocolo TCP/IP. A conexão é estabelecida no momento em que os daemons são iniciados nos nós de processamento, permitindo que o nó home transmita mensagens de controle a fim de sincronizar, sinalizar e finalizar as tarefas paralelas do usuário.

A estrutura do ambiente paralelo (PE) do SP2 é ilustrada na figura 5.9 [POE95]. Quando uma aplicação paralela é executada, o POE inicia seu gerenciador de partição (partition manager), que se responsabiliza em alocar os nós de processamento e iniciar o ambiente local. Dependendo do hardware e da configuração, o gerenciador de partição pode usar tanto um arquivo compreendendo uma lista de hosts (lista de todos os nós 
disponíveis) como o gerenciador de recursos do sistema SP, ou mesmo utilizar ambos para alocar os nós. O gerenciador de recursos aloca os nós através de um ou mais pools de processadores ${ }^{1}$, de acordo com sua disponibilidade.

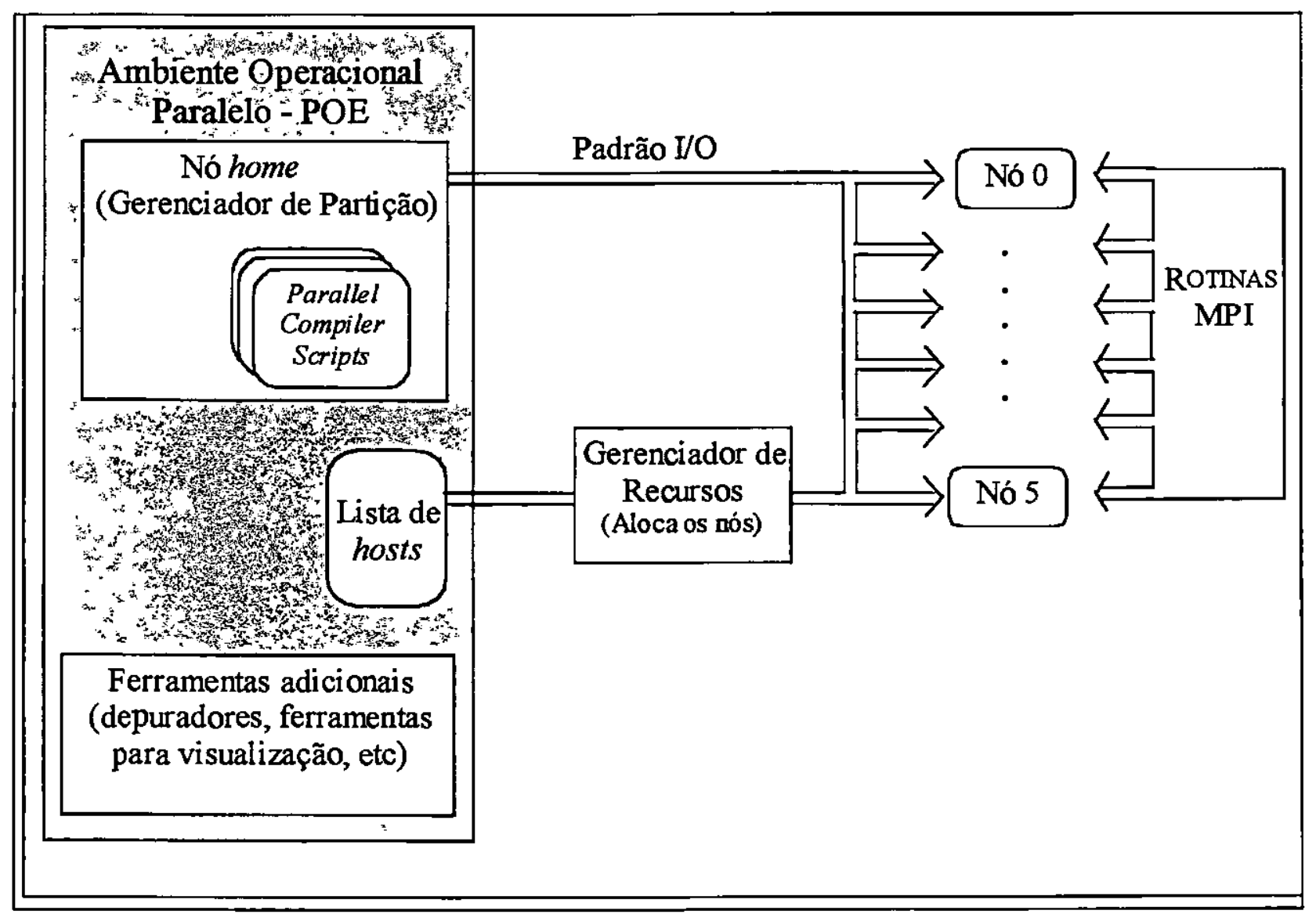

Figura 5.9 - Ambiente Paralelo IBM AIX

O gerenciador de partição também é responsável em direcionar as operações de $\mathrm{E} / \mathrm{S}$, de acordo com uma estratégia especificada. Se algum dos processos paralelos de uma aplicação encerra sua execução ou falha durante a execução, a aplicação é completamente finalizada e o gerenciador de partição retorna todos os recursos requisitados ao gerenciador de recursos antes de terminar sua execução.

\footnotetext{
${ }^{1}$ Um pool de processadores é uma coleção de nós de processamento que são configurados aparte pelo administrador do sistema (pode-se ter pools interativos e pools em batch, por exemplo).
} 


\section{LoadLeveler}

LoadLeveler é um sistema de gerenciamento de jobs desenvolvido pela IBM para máquinas SP2 e clusters RISC/6000. O LoadLeveler serve como um escalonador de processos e fornece facilidades como: construir jobs, submetê-los e processá-los rapidamente em um ambiente dinâmico [LOA95]. Além disso, o LoadLeveler faz o balanceamento de carga e distribui os jobs entre os processadores de forma eficiente, evitando-se que determinados nós fiquem mais sobrecarregados e que recursos, como o switch, sejam melhor compartilhados entre os usuários do SP2 [IBM95].

Para executar aplicações no SP2 é necessário que estes programas sejam submetidos a alguma fila do ambiente. Para isso, é necessário criar um arquivo de comandos do LoadLeveler, também chamados de jobs. Os comandos são necessários para indicar o programa a ser submetido, a fila em que o job será submetido, os recursos necessários para a execução do programa, entre outros. Este arquivo pode ser editado em qualquer editor de texto, como vi ou pico [LOA95]. O LoadLeveler requisita o gerenciador de recursos do ambiente paralelo do SP2 para que possa alocar todos os recursos solicitados pelo usuário.

\section{Plataformas de portabilidade}

Neste trabalho, as plataformas de portabilidade utilizadas na máquina paralela SP2 foram as implementação IBM PVMe e IBM MPI.

Embora, o SP2 também tenha disponível o PVM versão 3.3.10, não foi interessante adotá-lo neste trabalho, devido ao fato do PVM estar configurado para ser executado sobre a biblioteca do IBM MPI, prejudicando desta forma, o desempenho do PVM. Além disso, a utilização da plataforma IBM PVMe tornou-se mais viável, visto que sua implementação foi totalmente voltada para ser usada no SP2, possibilitando alcançar melhores desempenhos do que a plataforma PVM. A implementação das duas plataformas utilizadas serão descritas a seguir. 


\section{IBM PVMe}

A plataforma de portabilidade PVMe é um pacote proprietário da IBM e otimizado para o IBM SP. O PVMe é compatível com o PVM de domínio público (PVM versão 3.3.10), porém sua estrutura interna é totalmente diferente, devido ao fato do PVMe ser construído para executar em plataformas homogêneas (IBM SP e cluster de estações RISC System/6000) juntamente com o switch de alto desempenho [PVMe95]. O PVM de domínio público foi desenvolvido para permitir que um conjunto de computadores interconectados, possivelmente de diferentes arquiteturas, cooperassem entre si para formar uma máquina paralela virtual. Devido a implementação do PVMe ser feita exclusivamente para ambientes homogêneos, não é possivel que seu código fonte seja transportado para outras arquiteturas, perdendo a portabilidade da plataforma. É importante salientar que a portabilidade da aplicação continua a existir.

O objetivo principal do desenvolvimento do PVMe foi oferecer alto desempenho às aplicações paralelas. Um esquema de memória melhorada do PVMe permite explorar os recursos de memória de forma mais eficiente, principalmente em aplicaçð̃es de larga escala, ou seja, aplicaçð̃es que envolvem maior quantidade de processamento. As aplicações paralelas PVMe podem ser escritas em linguagem $\mathrm{C}, \mathrm{C}++$ e Fortran.

Assim como o PVM de domínio público, o PVMe possui dois componentes principais: o daemon (pvmd3e) e a biblioteca de comunicação.

O daemon manipula todo o controle de processos, sincronização e gerenciamento de hosts e grupos de tarefas. No PVMe o daemon é executado em apenas um nó de processamento, ao invés de ser executado em todos os nós como é feito no PVM público. Isto permite simplificar o gerenciamento de tarefas e em muitos casos agilizá-lo.

A biblioteca contém um conjunto de primitivas que são ativadas pela aplicação do usuário para efetuar troca de mensagens, gerar processos e coordenar tarefas (sincronização). Um processo mestre lida tanto com rotinas básicas (comunicação de dados e gerenciamento de processos) quanto o gerenciamento de grupos dinâmicos, ao 
contrário do PVM público, onde o gerenciamento de grupos fica em uma biblioteca separada.

A comunicação no IBM PVMe sempre ocorre entre os processos paralelos, sem a participação do daemon. O software de comunicação utilizado é o Message Passing Client Interface (MPC), a qual é executado sobre o switch de alto desempenho. Existem duas implementações do MPCI, sendo uma delas executando com o protocolo de comunicação IP (Internet Protocol) e outra implementação utilizando-se do protocolo US (User Space).

O protocolo US foi projetado exclusivamente para o switch de alto desempenho e para os adaptadores de comunicação utilizados pelo switch. Ele permite que as tarefas de uma aplicação tenham uso exclusivo do switch de alto desempenho e deve ser utilizado sempre quando se deseja obter alto desempenho nas comunicações entre processos paralelos. Entretanto, este protocolo não pode ser utilizado por mais de um processo por nó, restringindo a execução de uma aplicação paralela por vez. A vantagem de se utilizar o protocolo US é que a comunicação é feita de maneira bastante rápida, oferecendo portanto mais eficiência e desempenho às aplicações paralelas.

O protocolo IP não oferece tanto desempenho quanto o protocolo US, porem suporta múltiplos processos por nó, permitindo que várias aplicações de diferentes usuários executem simultaneamente. Ele é muito utilizado durante as fases de testes e desenvolvimento das aplicações.

As aplicações PVMe são executadas através do arquivo de comandos do LoadLeveler, que é escrito pelo próprio programador. Neste arquivo de comandos deve ser especificado o nome do código executável, a quantidade de nós desejados, o protocolo de comunicação a ser adotado (US ou IP), dentre muitas outras rotinas oferecidas pelo LoadLeveler [LOA95]. Deste modo, o LoadLeveler aloca todos os recursos solicitados no arquivo de comandos e o PVMe, por sua vez, inicia o daemon (pvmd3e) em um dos nós alocado e carrega os códigos executáveis nos nós de processamento. 
Ao contrário do PVM, onde o programador deve especificar as máquinas componentes da máquina paralela virtual, no PVMe apenas é necessário que se especifique o número de nós desejados e o software LoadLeveler, fica com a responsabilidade de determinar quais nós serão alocados às tarefas paralelas.

O PVMe permite que apenas uma tarefa esteja executando em um nó de processamento em um determinado instante, visto que esta limitação é imposta pelo próprio ambiente SP2. Com o PVM de domínio publico esta situação não ocorre, podendo-se ter múltiplas tarefas executando no mesmo processador ao mesmo tempo.

\section{IBM MPI}

IBM MPI é uma implementação da IBM e que foi otimizado para o IBM SP e clusters RISC System/6000. Esta plataforma é a biblioteca nativa para passagem de mensagens no sistema SP2, sendo disponível como parte integrante do ambiente paralelo (PE - Parallel Environment) da máquina SP2 [MPI95].

O Ambiente Operacional Paralelo (POE) que é executado com a plataforma IBM MPI, fornece alto desempenho nas comunicações entre os processos paralelos de uma aplicação, devido ao fato do POE ser implementado com o principal objetivo de otimizar a utilização do switch de alto desempenho e agilizar a comunicação entre os processos paralelos. Por este motivo, as aplicações paralelas que utilizam a plataforma IBM MPI apresentam alto desempenho em suas execuções. Entretanto, assim como PVMe, o IBM MPI só pode ser executado na máquina paralela SP2 e em máquinas RISC/6000, não sendo portanto um ambiente portátil para outras arquiteturas diferentes.

Uma aplicação IBM MPI é executada na máquina paralela SP2 por meio do arquivo de comandos do LoadLeveler. Quando este arquivo de comandos é executado, o LoadLeveler executa o ambiente operacional paralelo (POE) para que este compile e execute a aplicação paralela. $\mathrm{O}$ gerenciador de partição (partition manager) do POE se responsabiliza em alocar os nós de processamento requisitados pelo programador (através 
do gerenciador de recursos), carregar o código executável nos nós, controlar a execução da aplicação e gerenciar as operações de E/S.

O IBM MPI implementa todas as rotinas da especificação MPI versão 1.1, fornecendo, assim como a implementação MPICH, uma variedade de rotinas para comunicação ponto-a-ponto e coletiva (algumas das rotinas foram apresentadas no capítulo 2, seção 2.6.2).

Outra característica semelhante ao MPICH é que a implementação IBM MPI não suporta a estrutura de daemons, não impondo portanto a sobrecarga gerada pelo daemon, especialmente nas transmissões de dados.

Os grupos de processos são projetados para serem estáticos, ou seja, todos os processos de uma aplicação derivam de um grupo inicial. Isto não permite que novos processos sejam gerados durante a execução da aplicação paralela. Além disso, da mesma forma que o PVMe, apenas um processo pode ser executado em um nó em um determinado momento.

O IBM MPI possui dois protocolos de comunicação internos para realizar a comunicação ponto-a-ponto: o protocolo eager e o protocolo rendezvous [FRA95] [SHE95].

O protocolo eager é utilizado para transmissão de mensagens curtas, onde o envio de uma mensagem ocorre sempre quando o transmissor desejar, sem ter que requisitar isso ao receptor. Se o receptor não estiver pronto para recebe-la, esta será temporariamente bufferizada. Isso tem como desvantagem a possibilidade de problemas de memória se os dados transmitidos ultrapassarem a capacidade do buffer de recepção.

O protocolo rendezvous é usado para transmissão de mensagens longas. Com este protocolo, quando o transmissor deseja enviar uma mensagem, ele deve solicitar uma requisição de envio ao receptor, para que este então envie uma mensagem de confirmação. Somente após o transmissor receber a confirmação é que estará apto para enviar sua mensagem. Enquanto o transmissor aguarda uma confirmação, outras 
transmissões podem ser realizadas. Embora as mensagens não precisem ser bufferizadas temporariamente (as mensagens enviadas são transferidas para uma fila de transmissões e distribuídas), o protocolo rendezvous gasta tempos extras na transmissão de dados, ocasionada pelas requisições e confirmações. Entretanto, este overhead não é tão significativo para mensagens longas.

A transição entre os protocolos ocorre no tamanho de mensagem determinado pelo ambiente (através da função do sistema MP_EAGER_LIMIT). Este tamanho varia de acordo com a quantidade de processos utilizados em uma aplicação.

A comunicação entre os processos paralelos ocorre através do switch de alto desempenho, e é realizada utilizando-se o software de comunicação Message Passing Client Interface (MPCI), da mesma forma que o PVMe. Desta forma, o usuário pode optar entre os dois protocolos suportados pelo MPCI, ou seja, o protocolo US (User Space) e o protocolo IP (Internet Protocol) [MPI95].

\subsection{Considerações Finais}

Os últimos anos têm apresentado um grande avanço tecnológico, o qual tem possibilitado tanto o desenvolvimento de arquiteturas com maior poder computacional bem como de novas tecnologias de redes de comunicação. Como conseqüência ocorreu um grande aumento na aceitação e adoção do processamento paralelo para diversos fins.

As plataformas de portabilidade têm-se mostrado abordagens eficientes para a implementação de programas paralelos utilizando troca de mensagens. A possibilidade de transportar programas diretamente entre ambientes heterogêneos, incluindo arquiteturas paralelas e sistemas distribuídos, tornam a utilização dessas plataformas atraente. Atualmente, diversas implementações de bibliotecas de passagem de mensagens estão disponíveis, fornecendo ao usuário uma variedade de opções.

Neste capitulo, foram apresentados as arquiteturas adotadas neste trabalho (o sistema distribuído e a máquina paralela SP2) e também as plataformas de portabilidade 
PVM, IBM PVMe, MPICH e IBM MPI, a fim de possibilitar uma visão geral das plataformas de portabilidade e dos ambientes computacionais utilizados.

É importante compreender as características de cada arquitetura e de cada plataforma de portabilidade, visto que são essenciais para uma melhor conclusão sobre a análise de desempenho dos algoritmos paralelos. No próximo capítulo, serão descritas as implementações dos algoritmos paralelos de ordenação. 


\section{Capítulo 6}

\section{Implementações}

Este capítulo apresenta as implementações dos algoritmos paralelos de ordenação, a qual foram desenvolvidos utilizando as plataformas de portabilidade PVM e MPI e executados tanto no sistema distribuído como na máquina paralela SP2.

\subsection{Introdução}

O desenvolvimento de algoritmos paralelos de ordenação é um item de grande importância na computação paralela [HWA87], que tem sido alvo de intenso estudo desde que Batcher [BAT68] propôs o algoritmo de ordenação bitonic projetado para máquinas paralelas. No entanto, pesquisas para o projeto de algoritmos paralelos de ordenação surgiram realmente no fim da década de 1980, quando a disponibilidade de multiprocessadores tornou-se considerável [HUI94].

Atualmente, ao se tratar de algoritmos paralelos de ordenação, percebe-se uma abrangente literatura enfocando as mais diversas arquiteturas e ambientes de processamento paralelo, tanto em sistemas distribuídos como em arquiteturas paralelas.

A ordenação é uma das atividades mais conhecida nos sistemas de programação. Em geral, um conjunto de itens é ordenado com o intuito de simplificar o acesso aos dados, bem como tornar estes acessos mais eficientes. Muitos métodos de ordenação seqüenciais, incluindo o quicksort (classificação por troca de partị̧ão), merge sort (classificação por intercalação), entre outros, tem sido utilizados na implementação de algoritmos paralelos. O principal objetivo de se desenvolver algoritmos paralelos de ordenação é a diminuição do tempo de execução e do número de passos necessários para classificar um conjunto de dados, através da execução de várias comparações e trocas de elementos simultaneamente [MOD88]. 
Os algoritmos paralelos de ordenação foram implementados utilizando-se as plataformas de portabilidade e executados em um sistema distribuído e na máquina paralela SP2, a fim de comparar o desempenho do PVM e do MPI para cada tipo de arquitetura e para cada algoritmo implementado.

\subsection{Implementações dos Algoritmos Paralelos}

A maioria dos algoritmos paralelos de ordenação implementados encontram-se descritos no capítulo 4, sendo eles: o algoritmo QuickSort Paralelo 1, QuickSort Paralelo 2, QuickSort Paralelo 2.1 (uma variação do algoritmo QuickSort Paralelo 2), Merge Paralelo, Odd-even Merging e Merging Distribuido. A escolha por estes algoritmos deve-se ao fato de todos eles se adaptarem aos ambientes computacionais propostos (o sistema distribuído e a máquina paralela SP2) e explorarem uma granulação mais grossa, exceto o algoritmo merging distribuído que envolve grande quantidade de comunicação. Este último algoritmo foi implementado, pois tornou-se interessante avaliar o comportamento das plataformas de portabilidade em face de aplicações que envolvem muitas comunicações entre os processos paralelos.

Os algoritmos utilizam dois métodos de ordenação seqüencial (ou pelo menos um dos métodos) muito conhecidos na literatura, sendo eles o quicksort e o merge sort. $\mathrm{O}$ quicksort (ou classificação por partição) ordena um determinado vetor através da escolha de um elemento localizado em uma posição específica do vetor. Deste modo, o vetor é dividido em 2 partes, ou seja, os elementos menores que o elemento selecionado são colocados nas posições anteriores à ele e os maiores são posicionados após o elemento escolhido. Este elemento então, é marcado como classificado. Este processo se repete recursivamente até que todos os elementos estejam marcados como classificados. No método merge sort (ou classificação por intercalação), dois ou mais vetores são intercalados em um terceiro vetor ordenado. Observa-se portanto, que tanto o quicksort 
como o merge sort envolvem a divisão de um vetor em partes, a classificação destas partes separadamente e a posterior união das partes classificadas [LAN96].

Todos algoritmos paralelos de ordenação foram executados em três processadores, visto que é o número de nós de processamento disponível na máquina paralela SP2. Além disso, no sistema distribuído também foi utilizado três processadores, com 0 intuito de executar os algoritmos na mesma quantidade de processadores que o SP2.

A linguagem de programação escolhida para implementar os algoritmos foi a linguagem $\mathrm{C}$, devido ao fato de ser uma das linguagens mais utilizadas atualmente e por ser uma das linguagens suportadas pelas plataformas de portabilidade PVM e MPI.

Nos próximos tópicos serão apresentados os algoritmos paralelos de ordenação desenvolvidos neste trabalho.

\subsubsection{Algoritmo QuickSort Paralelo 1}

Este algoritmo foi implementado da forma descrita no capítulo 4, onde cada processador é responsável pela ordenação de N/P elementos (onde $\mathrm{N}$ é o tamanho do vetor a ser ordenado e $\mathrm{P}$ é o número de processadores) [GRE91]. Neste método, a aplicação manipula três processos, sendo um deles o processo mestre e os demais são os escravos.

Cada processo executa em um processador distinto. O processo mestre gerencia a execução dos processos escravos e distribui um subvetor (com N/P elementos) a ser ordenado para cada um deles, sendo que um dos subvetores fica com o próprio mestre.

Após a distribuição ser realizada, cada processo executa o algoritmo quicksort seqüencial para ordenar seus respectivos subvetores, para que então os escravos enviem seus subvetores ordenados para o mestre. O vetor final ordenado é obtido no processo mestre, através da intercalação (algoritmo merge seqüencial) de todos os subvetores ordenados. 


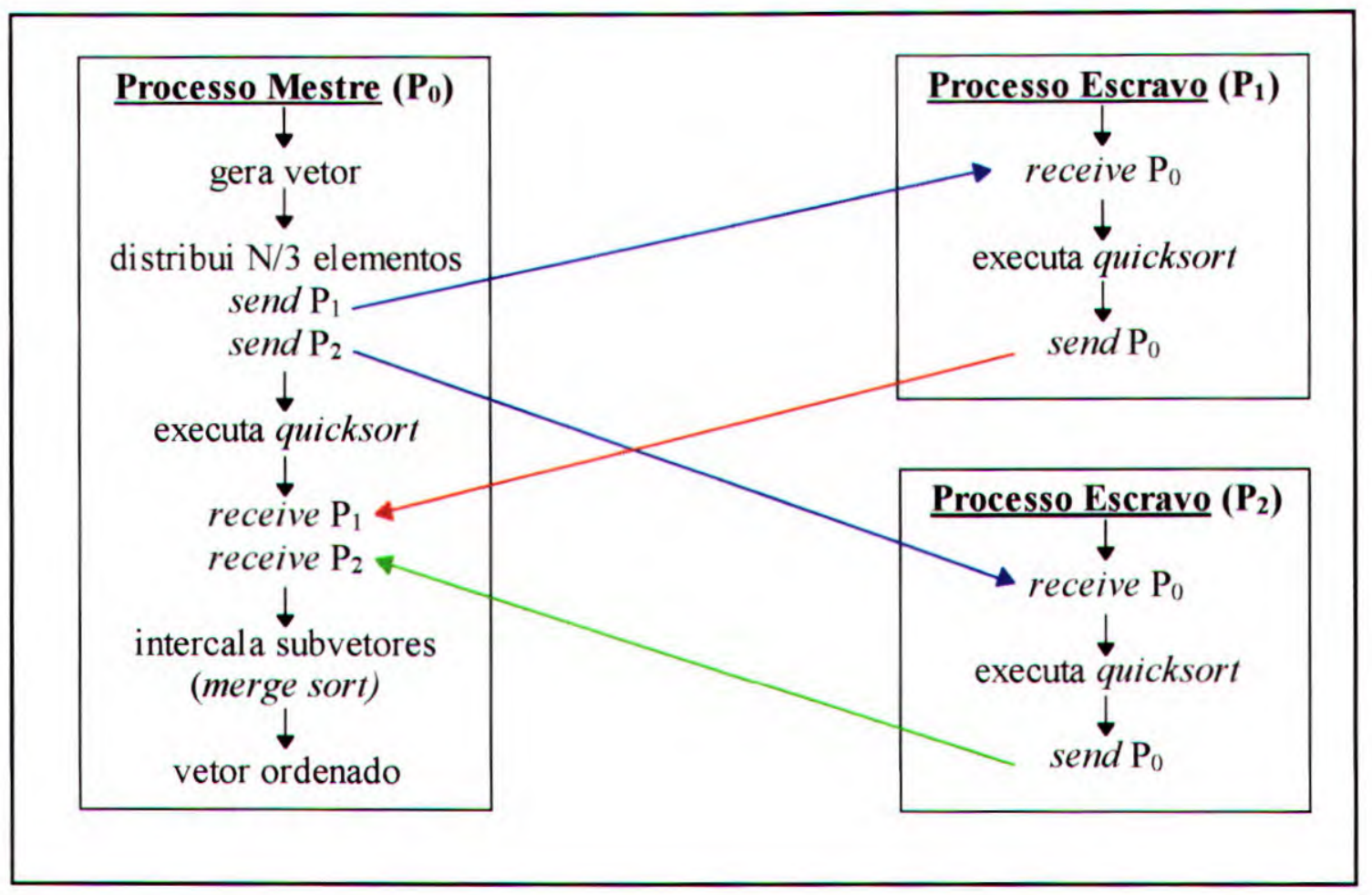

Figura 6.1 - Comunicações envolvidas no Algoritmo Quicksort Paralelo 1

Como pode ser observado na figura 6.1, este algoritmo envolve poucas comunicações, sendo necessário realizar quatro chamadas às rotinas send/receive bloqueantes durante a execução, ou seja, duas relacionadas à distribuição dos subvetores aos escravos e outras duas para o envio dos subvetores ordenados ao processo mestre.

Além disso, este algoritmo tem como vantagem o balanceamento de carga entre os processadores, uma vez todos eles recebem do processador mestre a mesma quantidade de elementos para serem ordenados, principalmente em casos de se utilizar um sistema homogêneo.

Outra vantagem deste algoritmo é a simplicidade de sua implementação, não impondo maiores dificuldades em seu desenvolvimento, visto que ele utiliza dois métodos de ordenação (o quicksort e o merge ) muito conhecidos na literatura. 


\subsubsection{Algoritmo QuickSort Paralelo 2}

Neste método, como no anterior, um dos processadores é definido como mestre (onde é executado o processo mestre) e os outros como escravos [DUA96]. Porém, diferente do algoritmo quicksort paralelo 1 , neste método os elementos do vetor são distribuídos entre os processadores de maneira não balanceada, sendo que cada processador receberá uma subvetor gerado a partir de alguns pivôs.

O mestre é responsável em gerar aleatoriamente um vetor de $\mathrm{N}$ elementos a ser ordenado nos processadores, em definir um vetor com P-1 elementos pivôs (onde P é o número de processadores utilizados) e em distribuir os subvetores aos escravos.

O processo de escolha dos elementos pivôs é feito de maneira aleatória, ocasionando desta forma uma distribuição não balanceada dos subvetores, ou seja, cada um dos processadores receberá diferentes quantidades de elementos. Os subvetores são distribuídos para os processadores escravos, de forma que o processador mestre retenha consigo os elementos menores ou iguais ao pivô 1, o processador escravol receba todos os elementos maiores que o pivôl, porém menores ou iguais ao pivô 2 , e o processador escravo 2 receba todos os elementos maiores que o pivô2.

Desta forma, todos subvetores são ordenados através do algoritmo quicksort seqüencial, e então enviados ao processo mestre. O vetor final ordenado é gerado pelo mestre, sendo apenas necessário realizar a concatenação de todos os subvetores, respeitando a ordem determinada pelo vetor de pivôs, ou seja, concatenando-se o subvetor do mestre, seguido dos subvetores ordenados do escravol e do escravo2.

Este algoritmo, como o anterior, envolve poucas comunicações, sendo necessários executar quatro vezes as rotinas send/receive bloqueantes (duas para a distribuição dos subvetores e outras duas para o envio dos subvetores ordenados ao processo mestre), como é ilustrado na figura 6.2. 


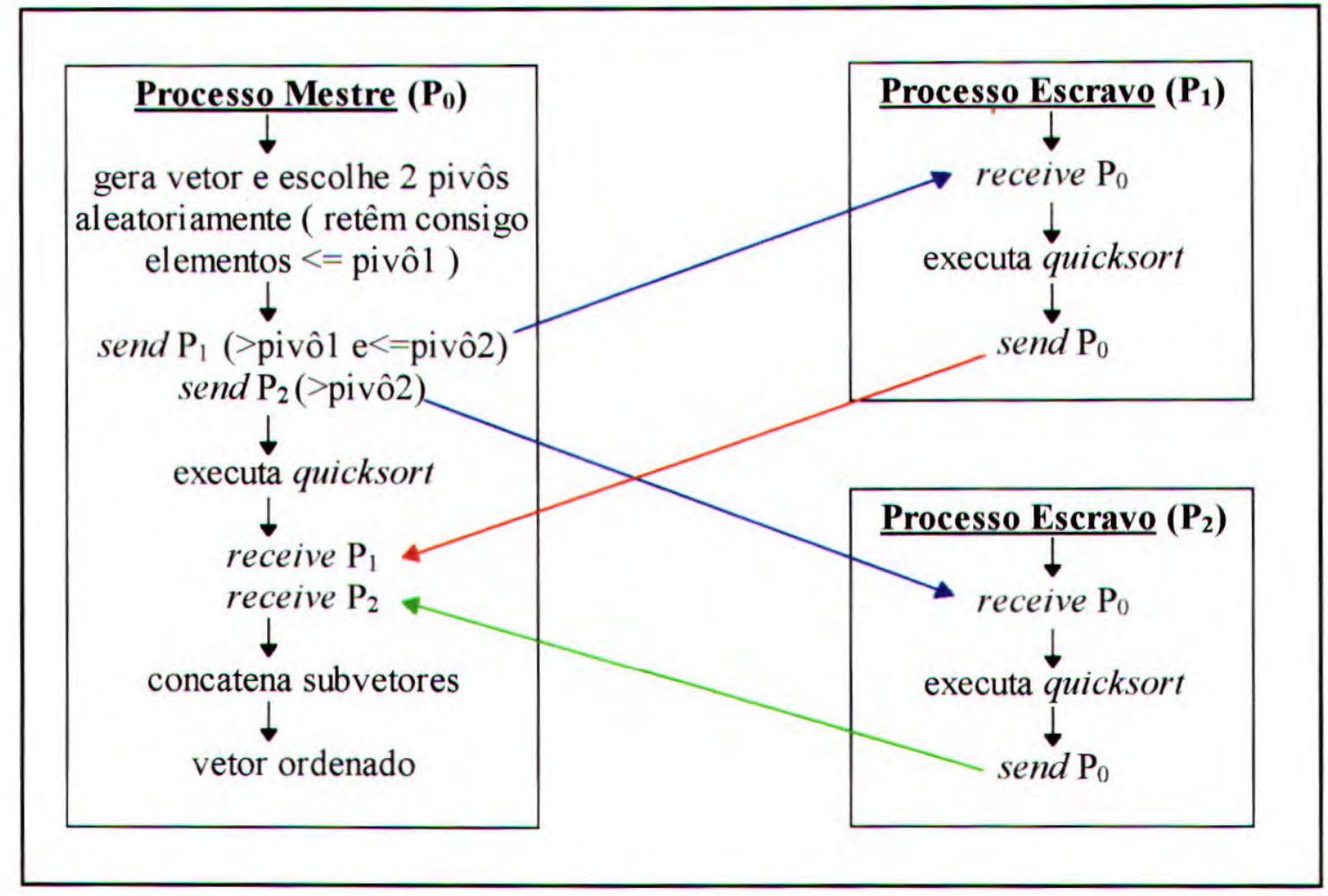

Figura 6.2 - Comunicações envolvidas no Algoritmo Quicksort Paralelo 2

A vantagem deste algoritmo em relação ao anterior é que a geração do vetor final ordenado é feita apenas com a concatenação dos subvetores ordenados, não necessitando portanto executar o algoritmo merge seqüencial para intercalá-los, tornando o processo mais rápido que no anterior. Porém, uma desvantagem deste algoritmo é que não há nenhum balanceamento de carga, visto que com a escolha aleatória dos pivôs, os elementos dos subvetores não são igualmente distribuídos para cada processador.

Esta situação pode tornar o algoritmo ineficiente, quando executado em um ambiente homogêneo (como a máquina paralela SP2), visto que os processadores podem ficar ociosos, aguardando o término de execução de processadores que possuem maior quantidade de elementos a serem ordenados. Porém, esta situação se inverte em um sistema heterogêneo, onde os subvetores com maiores quantidades de elementos podem ser transferidos para processadores com maior capacidade computacional e os subvetores com menor número de elementos distribuídos aos processadores menos velozes. 


\subsubsection{Algoritmo QuickSort Paralelo 2.1}

Como apresentado na seção 6.2.2, o algoritmo quicksort paralelo 2 não distribui igualmente os elementos entre os processadores, podendo degradar o desempenho do algoritmo paralelo, principalmente em sistemas homogêneos. Visando alcançar melhores desempenhos, decidiu-se fazer algumas modificações no algoritmo quicksort paralelo 2, gerando assim uma outra versão, a qual denominamos quicksort paralelo 2.1.

A modificação realizada é no processo de escolha dos pivôs, que é feita de maneira com que os elementos a serem distribuídos aos processadores seja mais balanceada possível. Neste caso, após a geração do vetor a ser ordenado, o algoritmo pesquisa qual é o maior e o menor elemento do vetor para encontrar os valores máximo e mínimo. Com isso, os pivôs recebem os seguintes valores:

$$
\begin{aligned}
& \text { pivô } 1=\frac{(\text { máximo }+ \text { mínimo })}{\mathbf{P}}+\text { mínimo } \\
& \text { pivô } 2=2 \times\left(\frac{(\text { máximo }+ \text { mínimo })}{\mathrm{P}}+\text { mínimo }\right)
\end{aligned}
$$

onde $\mathbf{P}$ é o número de processadores utilizados.

Com esta alteração na escolha dos elementos pivôs, os subvetores são distribuídos de maneira mais balanceada aos processadores. É importante ressaltar que esta nova versão do algoritmo quicksort paralelo 2 pode apresentar melhores resultados do que a versão anterior quando executado em uma arquitetura homogênea, como é o caso da máquina paralela SP2.

Este algoritmo realiza os mesmos passos de ordenação que o algoritmo quicksort paralelo 2, ou seja, após a distribuição, cada processador executa o algoritmo quicksort seqüencial e os resultados enviados ao processador mestre para que este realize a concatenação dos subvetores, gerando assim, o vetor final ordenado. 
Desta forma, o algoritmo quicksort paralelo 2.1 mantém o mesmo número de comunicações envolvidas entre os processos paralelos, sendo um total de quatro chamadas às rotinas send/receive bloqueantes, relacionadas à distribuição dos subvetores aos escravos e ao envio destes subvetores ordenados ao mestre (como mostrado na figura 6.2).

\subsubsection{Algoritmo Merge Paralelo}

Neste algoritmo, $\mathrm{N}$ elementos são ordenados em $\mathrm{P}$ processadores (como apresentado no capítulo 4). O processador mestre (aonde é executado o processo mestre) divide o vetor original em relação à quantidade de processadores que serão utilizados $($ subvetor $=\mathrm{N} / \mathrm{P})$. Desta forma, o mestre é responsável pela distribuição dos subvetores aos processadores escravos, retendo um dos subvetores consigo.

Para que esses subvetores sejam classificados, cada processo executa em paralelo o algoritmo merge sort seqüencial, para que então todos eles façam uma nova divisão dos seus subvetores em relação ao número de processadores utilizados (subvetor/P). Com isso, os processadores iniciam, em paralelo, a troca de elementos entre si, envolvendo a transferência de N/9 elementos (como foi mostrado no capítulo 4 - figura 4.7), ou seja:

- As primeiras partes dos subvetores dos escravos são transferidas ao mestre;

- A segunda e a terceira parte do subvetor do mestre são transferidas ao escravol e escravo2 respectivamente;

- escravol transfere a terceira parte de seu subvetor para o escravo2, e

- escravo2 transfere a segunda parte de seu subvetor ao escravol.

Pode-se observar portanto, que o objetivo desta troca de elementos é manter todas as primeiras partes dos subvetores com o mestre, as segundas partes com o escravol e as terceiras partes de todos os subvetores com o processo escravo2. 


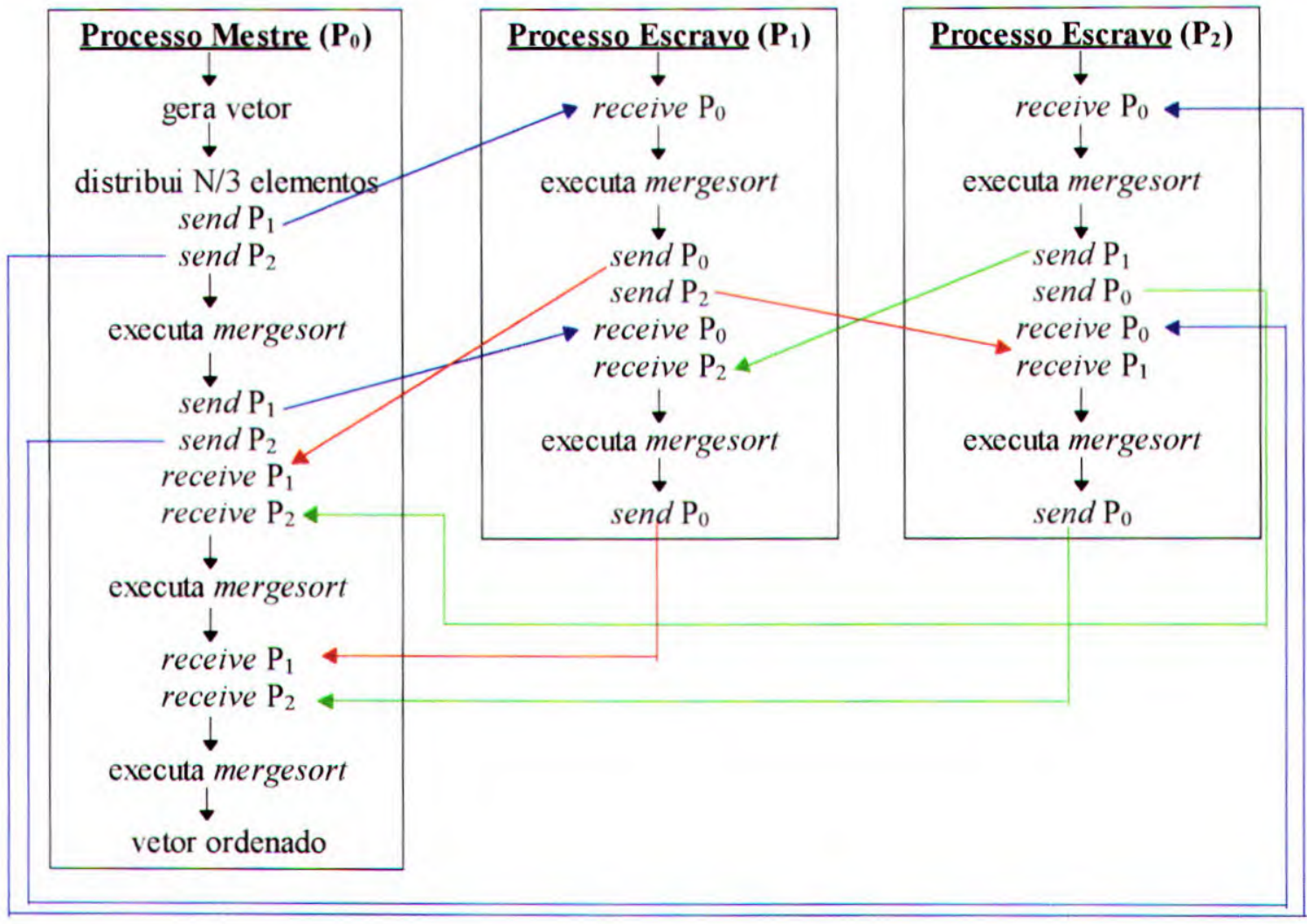

Figura 6.3 - Comunicações envolvidas no Algoritmo Merge Paralelo

Com a troca de elementos entre os processos, é necessário então que cada processador execute novamente o algoritmo merge sort seqüencial para ordenar seus subvetores. Desta forma, os subvetores ordenados dos escravos (com N/3 elementos) são enviados ao processo mestre, para que este gere o vetor final ordenado, através da intercalação de todos subvetores (merge sort).

Diferente dos algoritmos paralelos de ordenação anteriores, neste método é envolvido mais processamento tanto por parte dos escravos como do mestre, pois precisam executar várias vezes o algoritmo de intercalação para ordenarem seus subvetores. Além disso, como mostra a figura 6.3, neste algoritmo há necessidade de um maior número de comunicações entre os processos paralelos, onde as rotinas send/receive bloqueantes são executadas dez vezes durante a execução, ou seja, duas para a distribuição dos subvetores a serem ordenados pelos escravos, seis para as trocas de 
elementos dos subvetores entre os processos e mais duas para o envio dos subvetores ordenados dos escravos para o mestre.

\subsubsection{Algoritmo Odd-even Merging}

Conforme descrito no capítulo 4, neste algoritmo $\mathrm{N}$ elementos são distribuídos igualmente em P processadores [UML94] [NAR96], assim como no algoritmo quicksort paralelo 1 e no merge paralelo. Os processadores são numerados de 0 (mestre) a $\mathrm{P}-1$ (escravos), sendo o processador mestre $\left(\mathrm{P}_{0}\right)$ responsável pela criação do vetor a ser ordenado e pela distribuição dos subvetores aos processadores escravos $\left(\mathrm{P}_{1}\right.$ e $\left.\mathrm{P}_{2}\right)$.

Com a distribuição dos subvetores, cada processador é responsável pela ordenação de seu respectivo subvetor, através da execução do algoritmo quicksort seqüencial. Feita a ordenação, inicia-se o processo de intercalação, ou seja, o processador com índice impar $\mathrm{P}_{1}$ (escravol) recebe uma cópia do subvetor ordenado do seu sucessor $\mathrm{P}_{2}$ (escravo2) e intercala os subvetores (através do algoritmo merge sort), gerando um único vetor ordenado. Este vetor é então dividido em duas partes, sendo que a parte com os menores elementos permanecem em $\mathrm{P}_{1}$ e a outra parte é transferida para $\mathrm{P}_{2}$. O próximo estágio, é realizado o passo par, que é semelhante ao anterior, onde os elementos do processador com índice par $\mathrm{P}_{0}$ (mestre) são intercalados com o do seu sucessor $\mathrm{P}_{1}$ (escravol), sendo que os maiores elementos são enviados ao processador $\mathrm{P}_{1}$ e os menores são retidos em $\mathrm{P}_{0}$.

Os passos (ímpar e par) são executados até que todos os elementos do processador $P_{0}$ sejam menores ou iguais aos elementos de $P_{1}$ e os elementos de $P_{1}$, por sua vez, sejam menores ou iguais aos elementos de $\mathrm{P}_{2}$. Como são utilizados apenas três processadores (tanto no sistema distribuído como na máquina paralela SP2), são necessários três passos (ímpar, par e ímpar) para que se tenha todos os elementos ordenados. $O$ vetor final ordenado é obtido através da concatenação dos subvetores dos processadores $\mathrm{P}_{0}, \mathrm{P}_{1}$ e $\mathrm{P}_{2}$, nesta ordem (a qual é realizada pelo processo mestre). 


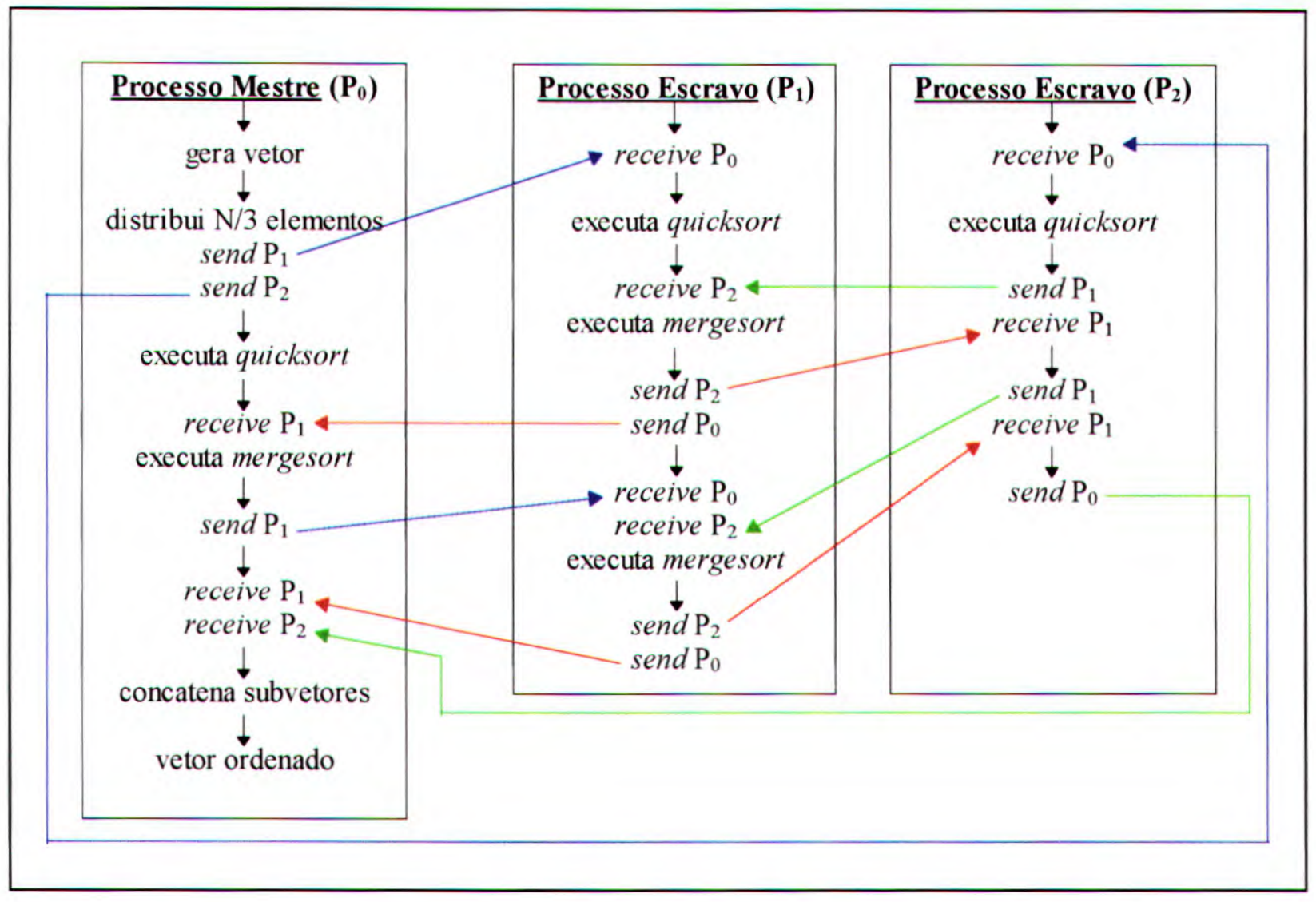

Figura 6.4 - Comunicações envolvidas no Algoritmo Odd-even Merging

Este algoritmo, como o anterior, envolve maior quantidade de comunicações do que os algoritmos quicksort paralelol, quicksort paralelo 2 e quicksort paralelo 2.1, sendo necessários executar dez chamadas às rotinas sendreceive bloqueantes durante a execução (duas para a distribuição dos subvetores, seis durante as etapas de intercalação entre os processos e mais duas para o envio dos subvetores ordenados para o mestre). A figura 6.4 ilustra a comunicação envolvida na execução do algoritmo odd-even merging.

\subsubsection{Algoritmo Merging Distribuído}

O algoritmo merging distribuído [KLE86] foi implementado de maneira muito semelhante ao descrito na capítulo 4, entretanto foram feitas algumas alterações. Este algoritmo consiste em intercalar P-1 subvetores ordenados, contendo cada um N/(P-1) elementos, onde $\mathrm{N}$ é o número de elementos do vetor a ser ordenado e $\mathrm{P}$ é a quantidade 
de processadores utilizados. Um dos processadores, o mestre, é designado para armazenar o vetor final ordenado, enquanto os outros, os escravos, possuem cada um dos subvetores a serem ordenados.

O processador mestre, após gerar aleatoriamente o vetor a ser ordenado, distribui N/2 (N/P-1) elementos aos escravos. Desta forma, os escravos ordenam seus subvetores através do algoritmo merge sort seqüencial.

Com os subvetores ordenados, cada processador escravo difunde pela rede seu valor corrente (menor elemento do subvetor), de modo que o processador escravol receba o valor corrente do escravo2, este por sua vez receba o valor corrente do escravol e o processador mestre receba os valores que estão na rede de ambos processadores escravos.

Com isso, o processador mestre verifica quais dos valores é o menor e o armazena em um vetor (que será o vetor final ordenado). Cada processador escravo verifica também se seu valor corrente é menor ou igual que o valor corrente do outro processador, se for, no ciclo seguinte será difundido pela rede o próximo elemento do seu subvetor, caso contrário, difundirá o valor corrente atual. Para se difundir os valores correntes pela rede de comunicação é utilizada a rotina broadcasting (comunicação coletiva).

Esse processo se repete até que um dos subvetores dos processadores escravos esteja vazio. O processador que possuir o subvetor não vazio, simplesmente transfere os elementos restantes de seu subvetor ao processador mestre, para que este os adicione ao vetor final ordenado.

Este algoritmo, diferente dos outros algoritmos paralelos de ordenação implementados, envolve uma grande quantidade de comunicações, como mostra a figura 6.5. Por este motivo, requer que os processadores estejam conectados através de uma rede de interconexão de alto desempenho, visto que a taxa de comunicação entre os processos paralelos para gerar o vetor final ordenado é muito intensa. 
O principal motivo de se implementar um algoritmo que possua muitas comunicações foi o interesse de realizar uma melhor análise comparativa entre as plataformas utilizadas em cada tipo de arquitetura. Entretanto, com a sobrecarga ocasionada pelas comunicações, o algoritmo paralelo pode tornar-se menos eficiente que sua versão seqüencial.

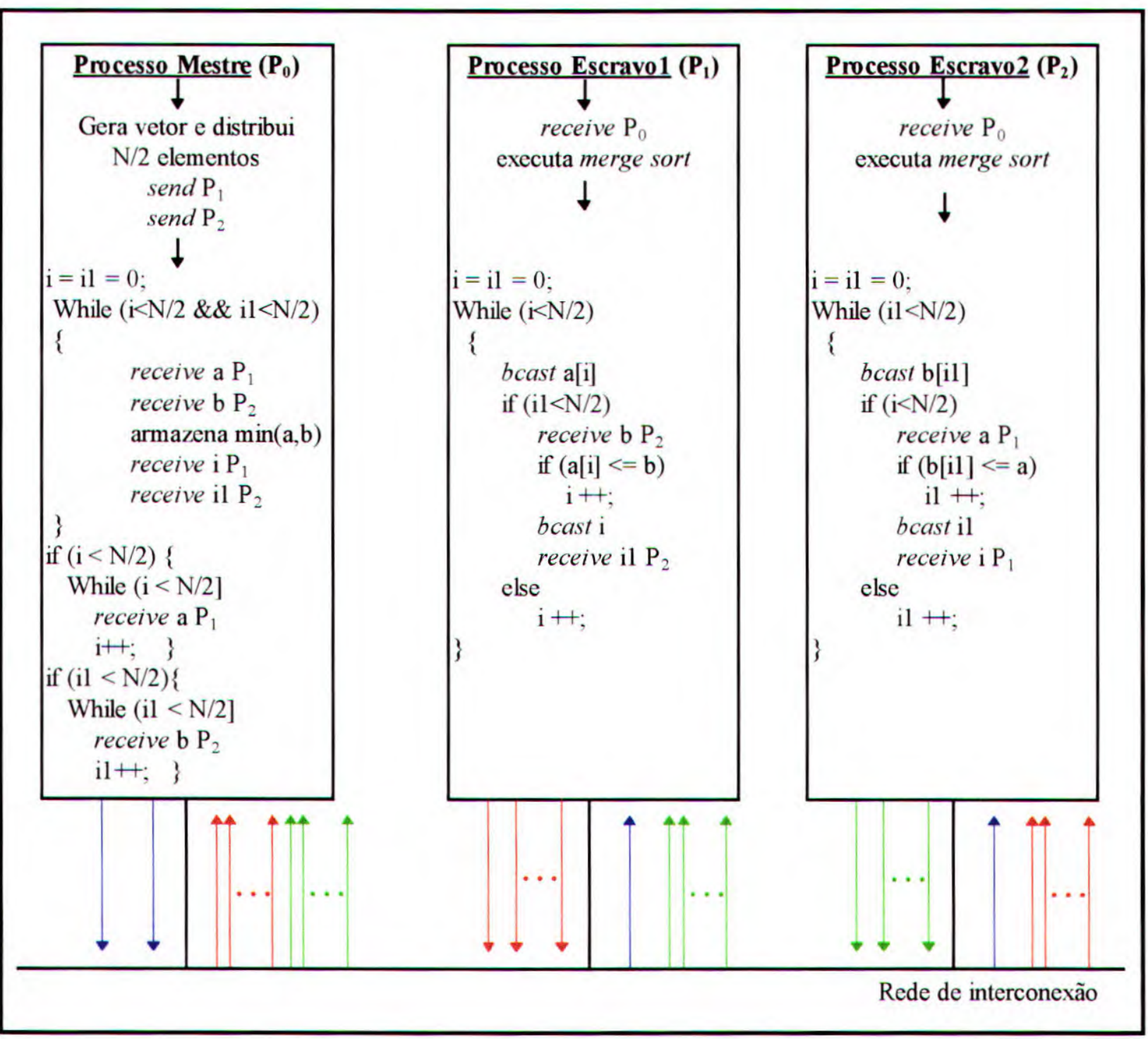

Figura 6.5 - Comunicações envolvidas no Algoritmo Merging Distribuído

Porem, espera-se conseguir melhores resultados com este algoritmo utilizando as plataformas utilizadas no SP2 (IBM MPI e IBM PVMe), pois como comentado anteriormente (no capítulo 5) sua rede de interconexão apresenta alto desempenho em relação à rede Ethernet (10 Mbits) utilizada no sistema distribuído. 


\subsection{Modelo de Programação}

Um modelo de programação refere-se ao modo em que o programador implementa uma determina aplicação. Cada aplicação deve ser dividida em um conjunto de tarefas para serem executadas em paralelo. Existem dois tipos de modelos de programação de aplicações paralelas, o modelo SPMD (Single Program, Multiple Data) e o modelo MPMD (Multiple Program, Multiple Data). A diferença entre os modelos de programação, é que com o modelo MPMD, têm-se códigos distintos executando nos processadores e manipulando diferentes dados. Por outro lado, no modelo SPMD os processadores executam o mesmo código fonte, mas assim como o MPMD, processam sobre dados distintos.

Todos os algoritmos paralelos de ordenação foram implementados adotando o modelo de programação MPMD quando utilizaram-se das plataformas de portabilidade PVM e IBM PVMe. Exceto o algoritmo merging distribuído que utilizou o modelo SPMD, sendo o mais adequado para esta aplicação, visto que o algoritmo foi implementado utilizando o conceito de grupos dinâmicos de tarefas (sendo necessário para realizar as comunicações coletivas no PVM). Entretanto, os algoritmos desenvolvidos com as implementações MPICH e IBM MPI, seguiram o modelo de programação SPMD, devido ao fato de ser o modelo de programação mais utilizado por essas plataformas para o desenvolvimento de aplicações paralelas.

\subsection{Considerações Finais}

O desempenho de um algoritmo paralelo de ordenação é determinado pelo custo de comunicação e o grau de balanceamento de carga [HU194]. Muitas comunicações requerem uma rede de interconexão que tenha uma alta taxa de transmissão de dados, caso contrário o algoritmo paralelo pode tornar-se menos eficiente que $o$ algoritmo 
seqüencial correspondente, ocasionado pela sobrecarga gerada pela comunicação entre os processos paralelos.

Além disso, o balanceamento de carga é um fator de extrema importância, pois em um sistema heterogêneo (como o sistema distribuído) a distribuição do trabalho entre os processadores deve ser feita de maneira que os processadores com maior poder computacional não fiquem ociosos a espera do término de processamento de processadores menos velozes. Em um sistema homogêneo (como o SP2), esta carga não balanceada pode tornar o algoritmo ineficiente, sendo que alguns processadores podem ficar aguardando o término de execução de outros processadores que possuem maior quantidade de elementos a serem ordenados.

Os algoritmos paralelos de ordenação implementados neste trabalho, foram executados tanto no sistema distribuído como na máquina paralela SP2. Através da utilização das plataformas de portabilidade PVM e MPI, foi possivel transportar os algoritmos paralelos de ordenação diretamente entre as diferentes arquiteturas, necessitando apenas de alguns ajustes nos algoritmos (como na função spawn da plataforma PVM, visto que no sistema distribuído deve-se especificar em quais máquinas os processos escravos serão executados, enquanto que no SP2 essa especificação não é necessária, em virtude do LoadLeveler responsabilizar-se em determinar quais nós serão alocados às tarefas paralelas) e serem recompilados para cada plataforma de portabilidade utilizada.

No próximo capítulo serão apresentados os resultados obtidos com a execução destes algoritmos, mostrando uma análise comparativa das plataformas de portabilidade PVM e MPI executadas em cada arquitetura. 


\section{Capítulo 7}

\section{Análise dos Resultados}

Este capitulo apresenta os resultados obtidos com a execução dos algoritmos paralelos de ordenação, a análise de desempenho das plataformas de portabilidade, o estudo do speedup alcançado em cada algoritmo paralelo e as conclusões obtidas desses resultados.

\subsection{Introdução}

O PVM e o MPI, têm sido as plataformas de portabilidade mais utilizadas na computação paralela. Porem muitas discussões entre os programadores abordam uma dúvida: se suas aplicações paralelas devem ser desenvolvidas utilizando-se PVM ou MPI.

O PVM surgiu em 1989, através de um projeto desenvolvido por Vaidy Sunderam e Al Geist [GEI96] [GEI96a] [GEI94](Oak Ridge National Laboratory) com objetivo de realizar pesquisas na área de computação distribuída, e em 1991 o PVM tornou-se publicamente disponivel. A utilização do PVM cresceu significativamente nos últimos anos, e atualmente já envolve diversos institutos de pesquisas e universidades.

Diferente do PVM, a especificação MPI surgiu por um comitê de 40 profissionais experientes após diversos encontros realizados em 1993 a 1994. O objetivo do desenvolvimento da especificação MPI foi criar uma padronização de uma interface de passagem de mensagens para aplicações que utilizam arquiteturas paralelas de memória distribuída ou sistemas distribuídos [DON95].

Várias implementações MPI estão disponíveis para diversas plataformas. Muitas dessas implementações foram desenvolvidas especificamente para determinadas arquiteturas (como o IBM MPI para o SP2) a fim de proporcionar alto desempenho às aplicações paralelas [GEI96a]. Porém, nem todas as implementações MPI são 
necessariamente eficientes, uma vez que a especificação do MPI não define detalhes de implementação de suas rotinas [DON95].

Segundo alguns autores [BOD96] [GEI96] [GEI96a], o MPI implementado em máquinas paralelas apresenta melhor desempenho do que em sistemas distribuídos, enquanto que o PVM é melhor utilizado em computação distribuída, visto que ele não foi projetado para sistemas paralelos fortemente acoplados.

Neste capítulo serão apresentados os resultados das execuções dos algoritmos paralelos de ordenação e a análise comparativa entre as plataformas PVM e MPI executadas na máquina paralela SP2 e em um sistema distribuido, a fim de avaliar os desempenhos das plataforma de portabilidade em cada tipo de arquitetura e para cada algoritmo paralelo implementado.

As primeiras três seções deste capítulo (7.2, 7.3 e 7.4) apresentam alguns fatores essenciais para a análise dos resultados obtidos, como a configuração de hardware utilizada em cada ambiente computacional, a medida utilizada para a realização da avaliação de desempenho, como também uma apresentação dos tempos consumidos nas comunicações ponto-a-ponto (ping-pong) e nas comunicações coletivas (broadcasting) para diferentes quantidades de dados em cada plataforma de portabilidade.

Na seção 7.5 são discutidos os resultados obtidos com as execuções dos algoritmos paralelos utilizando-se das plataformas de portabilidade (IBM MPI, IBM PVMe, MPICH e PVM). Finalmente, na seção 7.6 são apresentadas algumas comparações entre os algoritmos, analisando-se números das mensagens, tempo de execução, etc.

\subsection{Configuração de Hardware}

Nesta seção serão descritas as características de hardware dos ambientes computacionais utilizados neste trabalho. 
As máquinas componentes do sistema distribuído utilizado para a execução dos algoritmos paralelos possui a seguinte configuração de hardware:

- 1 PC Pentium / 100 MegaHertz;

- 1 PC Pentium / 160 MegaHertz;

- 1 PC Pentium / 200 MegaHertz;

A não existência de três máquinas idênticas no laboratório de Sistemas Distribuídos e Programação Concorrente, levou a opção por três máquinas PC's de diferentes capacidades computacionais, possibilitando a análise do comportamento das plataformas de portabilidade executadas em um ambiente heterogêneo. Esta escolha possibilita ainda comparar as plataformas de portabilidade quando executadas em ambientes computacionais totalmente distintos, ou seja, em um sistema heterogêneo (sistema distribuído) e um ambiente homogêneo (máquina paralela SP2). Em relação ao número de processadores para executar as aplicações no sistema distribuído, optou-se em utilizar a mesma quantidade disponível na máquina paralela SP2 (que são três nós de processamento).

Para a utilização da plataforma de portabilidade PVM é necessário criar uma máquina paralela virtual. Desta forma foi especificada a configuração da figura 7.1.

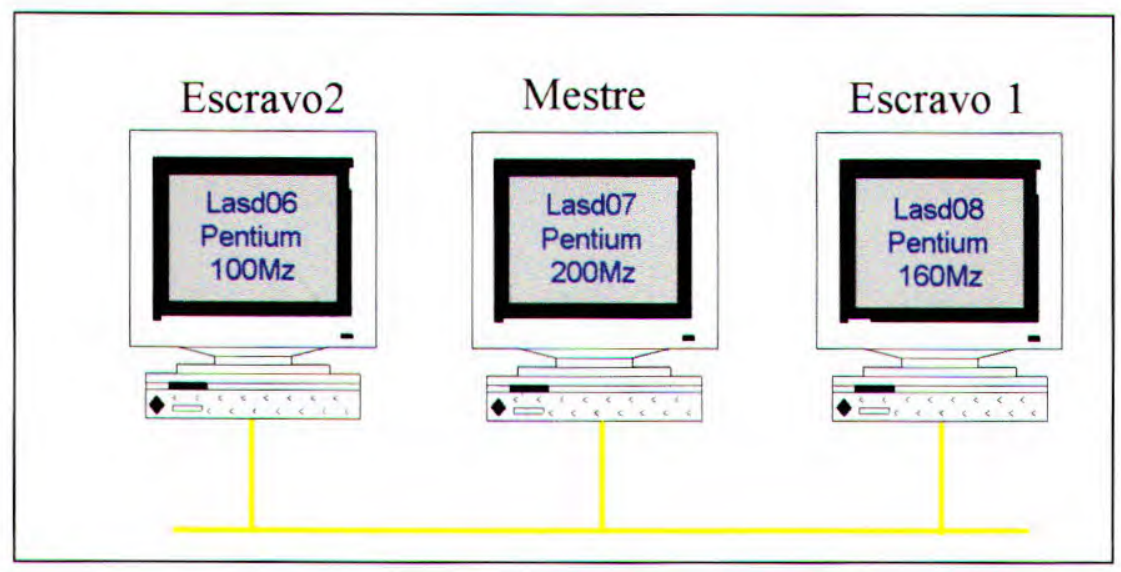

Figura 7.1 - Configuração da máquina paralela virtual

Esta configuração foi utilizada por todos os algoritmos implementados, exceto o algoritmo quicksort paralelo 2 e algoritmo odd-even merging. Para o algoritmo 
quicksort paralelo 2, a máquina paralela virtual foi configurada de acordo com as quantidades de elementos que são distribuídas aos processadores, de modo que os subvetores com maiores quantidades de elementos a serem ordenados sejam transferidos para os processadores com maiores capacidades computacionais (lasd07 e lasd08). A necessidade de se utilizar uma nova configuração é devido ao fato dos elementos serem distribuídos aos processadores de forma não balanceada, podendo acarretar que algum processador menos veloz receba maior quantidade de elementos, degradando assim o desempenho da aplicação. Para o algoritmo odd-even merging, a máquina paralela virtual foi configurada de modo que o processo escravol executasse na máquina mais veloz (lasd07), por ser o processo que possui uma maior sobrecarga de processamento (veja descrição do algoritmo no capítulo 6).

$\mathrm{Na}$ implementação MPICH, os processadores são configurados a partir de um arquivo que contem uma lista de processadores disponíveis. Esse arquivo deve ser criado pelo próprio usuário e é utilizado pelo comando de execução de programas $\mathrm{MPICH}$, o mpirun, que responsabiliza-se em configurar o ambiente de execução. Desta forma, para a utilização do MPICH foi necessário apenas criar esse arquivo com as máquinas utilizadas (lasd07, lasd08 e lasd06).

$\mathrm{Na}$ implementação IBM PVMe, que é executada na máquina paralela SP2, a máquina paralela virtual é formada a partir de um pool de processadores (contendo os nós de processamento do SP2 - apresentados no capítulo 5), que é configurado pelo próprio administrador do sistema. Portanto, somente foi preciso especificar o número de nós desejados (no arquivo de comandos LoadLeveler, como descrito no capitulo anterior) e através do pool de processadores foi formada a máquina paralela virtual. Do mesmo modo, na implementação IBM MPI a configuração do ambiente de execução é feita através desse pool de processadores.

Para a execução dos algoritmos seqüenciais no sistema distribuído foi utilizado um PC de $200 \mathrm{MHz}$, visto que é necessária a execução desses algoritmos em uma máquina veloz parạ que o estudo do speedup obtido com a execução dos algoritmos paralelos 
correspondentes seja feita com maior exatidão. Na máquina paralela SP2 os algoritmos seriais foram executados em um dos nós de processamento, selecionado pelo próprio sistema (através do pool de processadores).

\subsection{Medida de Avaliação de Desempenho}

Todos os algoritmos implementados utilizam a rotina gettimeofday0, que retorna o tempo corrente do sistema. Com esta rotina é possível coletar o tempo total decorrido (em segundos) durante a execução do algoritmo. Este tempo total representa o tempo de ordenação mais o tempo de comunicação entre os processos paralelos, desconsiderando o tempo de geração do vetor aleatório a ser ordenado e o tempo de ativação dos processos (no algoritmo quicksort Paralelo 2 foi também desconsiderado o tempo decorrido no processo de escolha dos elementos pivôs).

O tempo consumido com o processamento (ordenação) e comunicação entre os processos paralelos estão diretamente ligados à quantidade de elementos manipulada pela aplicação paralela. Desta forma, foram testadas as quantidades entre 9.000 e 540.000 dados (do tipo inteiro, que é representado por 4 bytes no sistema LINUX e AIX), a fim de se avaliar os resultados para diferentes tamanhos de vetores envolvidos na ordenação e na comunicação.

O tamanho das mensagens utilizadas é um aspecto muito importante a ser considerado na análise do tempo de comunicação. Mensagens de tamanhos diferentes podem apresentar diferenças em termos de desempenho. Assim, é importante separar as mensagens em grupos de mensagens grandes, médias e pequenas. Neste trabalho são consideradas pequenas as mensagens cujos valores encontram-se na faixa entre 0 a 36.000 bytes (de 0 a 9.000 elementos) e são consideradas mensagens grandes àquelas com tamanho a partir de 120.000 bytes (de 30.000 elementos em diante). As mensagens que manipulam quantidades de dados em um tamanho intermediário, ou seja, entre valores acima de 36.000 bytes (maiores que 9.000 elementos) e inferiores a 120.000 bytes 
(menores que 30.000 elementos), são consideradas mensagens médias. É importante ressaltar que estes valores foram escolhidos de maneira a facilitar a análise dos resultados, não sendo desta forma valores baseados em nenhum outro trabalho da área.

Os algoritmos foram executados várias vezes (acima de 50 testes) para cada quantidade de elementos e para cada plataforma de portabilidade, considerando como resultado final o tempo médio.

\subsection{Comunicação ponto-a-ponto e coletiva}

A maioria dos algoritmos paralelos de ordenação implementados, apresentados no capítulo 6, utilizam comunicação ponto-a-ponto entre os processos paralelos. Apenas o algoritmo merging distribuído que faz utilização de comunicação coletiva (broadcast).

As rotinas de comunicação ponto-a-ponto são responsáveis pela ação básica de uma biblioteca de troca de mensagens, que é a transferência de uma mensagem. Cada transferência ponto-a-ponto envolve exatamente dois processos, um que transmite a mensagem (denominado transmissor) e um que a recebe (denominado receptor). Estas operações são feitas pela utilização de duas rotinas: send() que é responsável pela transmissão e receive() que é responsável pela recepção de uma mensagem.

Uma maneira de se analisar o tempo consumido em uma comunicação ponto-aponto é através de benchmarks que calculam o tempo de transmissão de uma mensagem. Esses benchmarks implementam a troca de mensagem entre dois processos (P1 e P2), de maneira que se colete o tempo gasto em uma transmissão da mensagem em uma única direção (modelo de comunicação ping, apresentado na figura 7.2(a)) e em uma transmissão bidirecional (ping-pong, ilustrado na figura 7.2(b)) .

As comunicações coletivas caracterizam-se pela participação de dois ou mais processos em cada operação de comunicação. Estas funções podem ser construidas a partir de rotinas de comunicação ponto-a-ponto. Existem três operações coletivas mais 
comuns, que são: broadcast(), rotinas aritméticas globais e rotinas de sincronização. Na rotina broadcast() uma mensagem é distribuída, a partir de um processo raiz, para todos os processos participantes de uma determinada aplicação (esta função encontra-se descrita no capítulo 2).

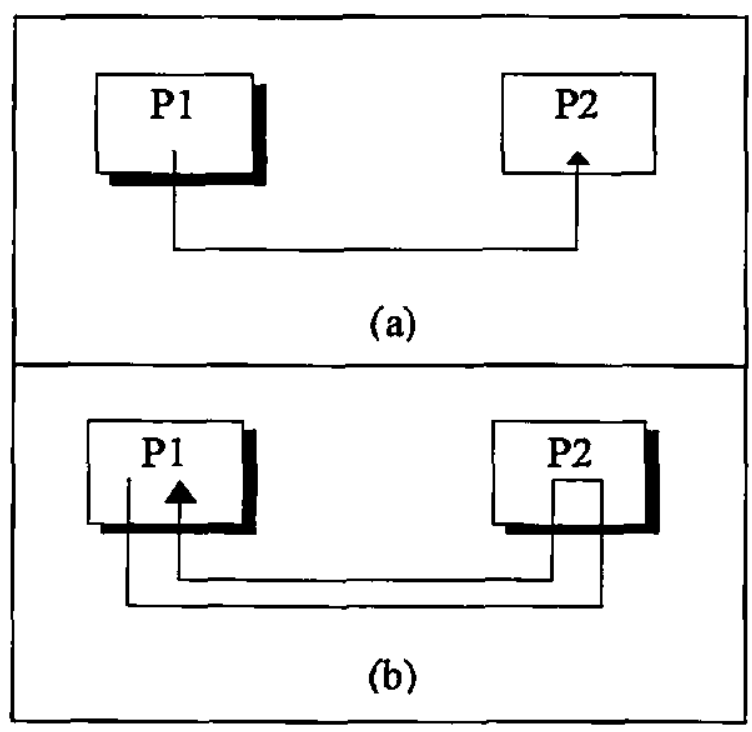

Figura 7.2 - Modelos de comunicação: a) Ping. b) Ping-pong.

Como citado na seção anterior, o tempo de comunicação entre os processos paralelos é fator muito importante quando se deseja analisar o desempenho de uma aplicação paralela. Desta forma, tornou-se interessante coletar dados referentes aos tempos consumidos em uma comunicação ponto-a-ponto e coletiva para cada uma das plataformas de portabilidade (IBM MPI, IBM PVMe, MPICH e PVM), a fim de realizar uma melhor análise dessas plataformas e dos resultados obtidos nos algoritmos paralelos para ordenação.

Nesta análise foi utilizado o modo de comunicação ponto-a-ponto padrão bloqueante (MPI_Send/MPI_Recv) das implementações MPICH e IBM MPI, como também os modos bloqueantes assíncronos (pvm_send/pvm_recv) das plataformas PVM e IBM PVMe (apresentados no capítulo 2). Esses modos de comunicação foram escolhidos, pois os algoritmos paralelos de ordenação implementados utilizaram estas formas de comunicações ponto-a-ponto. 
Vários testes de comunicação ponto-a-ponto foram executados (benchmark pingpong) para diferentes quantidades de dados, considerado como tempo final a média de todos os tempos coletados. A tabela 7.1 ilustra o tempo (em segundos) envolvidos em uma comunicação ponto-a-ponto para diferentes quantidade de dados.

Analisando-se os resultados, observa-se que a plataforma IBM MPI é a que apresenta menores tempos de comunicações entre os processos paralelos. Isso ocorre devido ao fato do MPI ser executado juntamente com o Ambiente Operacional Paralelo (POE) do SP2 que otimiza a utilização do switch de alto desempenho, fornecendo alto desempenho nas comunicações entre os processos paralelos de uma aplicação, como discutido no capítulo anterior.

\begin{tabular}{|c|c|c|c|c|c|}
\hline Quantidade & Em bytes & IBM MPI & IBM PVMe & MPICH & PVM \\
\hline $\mathbf{1 0}$ & $\mathbf{4 0}$ & 0,00070 & 0,26368 & 0,00189 & 0,01311 \\
\hline $\mathbf{1 0 0}$ & $\mathbf{4 0 0}$ & 0,00087 & 0,27079 & 0,00310 & 0,01397 \\
\hline $\mathbf{1 . 0 0 0}$ & $\mathbf{4 . 0 0 0}$ & 0,00143 & 0,27739 & 0,01244 & 0,02192 \\
\hline $\mathbf{3 . 0 0 0}$ & $\mathbf{1 2 . 0 0 0}$ & 0,00354 & 0,28389 & 0,03691 & 0,05015 \\
\hline $\mathbf{9 . 0 0 0}$ & $\mathbf{3 6 . 0 0 0}$ & 0,00768 & 0,29401 & 0,10882 & 0,11680 \\
\hline $\mathbf{1 8 . 0 0 0}$ & $\mathbf{7 2 . 0 0 0}$ & 0,01323 & 0,30388 & 0,20133 & 0,22260 \\
\hline $\mathbf{3 0 . 0 0 0}$ & $\mathbf{1 2 0 . 0 0 0}$ & 0,02135 & 0,31045 & 0,37410 & 0,36920 \\
\hline $\mathbf{3 6 . 0 0 0}$ & $\mathbf{1 4 4 . 0 0 0}$ & 0,02464 & 0,31532 & 0,54937 & 0,44420 \\
\hline $\mathbf{5 4 . 0 0 0}$ & $\mathbf{2 1 6 . 0 0 0}$ & 0,03618 & 0,32310 & 0,83695 & 0,80810 \\
\hline $\mathbf{6 0 . 0 0 0}$ & $\mathbf{2 4 0 . 0 0 0}$ & 0,03855 & 0,33370 & 0,91597 & 0,86139 \\
\hline $\mathbf{9 0 . 0 0 0}$ & $\mathbf{3 6 0 . 0 0 0}$ & 0,05924 & 0,35068 & 1,27793 & 1,11530 \\
\hline $\mathbf{1 8 0 . 0 0 0}$ & $\mathbf{7 2 0 . 0 0 0}$ & 0,11412 & 0,36638 & 2,29390 & 2,21540 \\
\hline $\mathbf{2 4 0 . 0 0 0}$ & $\mathbf{9 6 0 . 0 0 0}$ & 0,15542 & 0,37396 & 2,96461 & 2,73840 \\
\hline
\end{tabular}

Tabela 7.1 - Tempo de comunicação ping-pong

A plataforma IBM PVMe apresenta um tempo de comunicação muito maior do que as outras plataformas para mensagens de tamanhos pequenos e médios. Entretanto essa situação se inverte em uma comunicação que envolva mensagens de tamanhos maiores (na tabela 7.1 - no tamanho de 120 Kbytes). 
Isso acontece, pois o tempo de transmissão de mensagens pequenas normalmente é dominado pela sobrecarga inicial da biblioteca de comunicação, ou seja, o tempo consumido para se processar uma mensagem (como acrescentar cabeçalhos, calcular checksums, entre outras tarefas), enquanto que, para mensagens grandes, essa influência diminui e tem-se maior influência do tempo de transmissão da mensagem (onde devem ser consideradas as sobrecargas geradas pelo protocolo de comunicação) [NUP94].

Desta forma, o IBM PVMe, por executar sobre um switch de alto desempenho e utilizar o protocolo User Space que apresenta maior eficiência em relação ao protocolo IP, possibilita alcançar melhores resultados nas transmissões de mensagens grandes quando comparado às plataformas executadas no sistema distribuído.

Na implementação MPICH percebe-se que o tempo de comunicação ponto-a-ponto é menor do que a plataforma PVM para transmissão de mensagens pequenas e médias. Por outro lado, para mensagens grandes (na tabela 7.1 no tamanho de 120 Kbytes) a plataforma de portabilidade PVM alcança melhores tempos de transmissð̃es que o MPICH, assim como o IBM PVMe.

A comunicação entre os processos paralelos na implementação MPICH, é realizada diretamente entre os processos (via protocolo TCP/IP), visto que não é utilizada a estrutura de daemons. Para tanto, a cada transmissão de dados deve-se estabelecer uma conexão TCP com a máquina receptora.

No PVM, a comunicação entre as tarefas paralelas ocorre com a participação dos daemons, onde uma tarefa transmissora deve conectar-se ao daemon (via TCP/IP) para que este estabeleça uma conexão UDP com o daemon do host remoto. A tarefa receptora será então notificada pelo daemon sobre a mensagem transmitida. Este processo provoca maior sobrecarga no tempo de comunicação. Entretanto a partir de uma determinada quantidade de dados (120 Kbytes), esse overhead não é tão significativo, ou seja, a sobrecarga gerada com o tempo gasto para efetuar a conexão entre a tarefa e o daemon é minimizada, sendo que o tempo de transmissão da mensagem pela rede tem maior influência no tempo total de comunicação. Desta forma, pode-se afirmar que a plataforma 
PVM é mais adequada para transmissão de mensagens grandes, enquanto que o MPICH apresenta melhor desempenho para comunicações que envolvem mensagens pequenas e médias.

Além dos testes ping-pong foram coletados os tempos envolvidos em uma comunicação coletiva através da utilização da rotina broadcast(), para cada plataforma de portabilidade. Os resultados são apresentados na tabela 7.2.

Da mesma forma que a análise anterior, os resultados mostram que para qualquer quantidade de dados, na máquina paralela SP2 a implementação IBM MPI apresenta menor tempo de transmissão da mensagem em relação à plataforma IBM PVMe, visto que ela fornece um ambiente de execução altamente eficiente às aplicações paralelas (como apresentado no estudo das comunicações ponto-a-ponto).

\begin{tabular}{|c|c|c|c|c|c|}
\hline Quantidade & Em bytes & IBM MPI & IBM PVMe & MPICH & PVM \\
\hline $\mathbf{1}$ & $\mathbf{4}$ & 0,00004 & 0,00006 & 0,00033 & 0,00230 \\
\hline $\mathbf{1 0}$ & $\mathbf{4 0}$ & $\mathbf{0 , 0 0 0 0 4}$ & 0,00006 & 0,00038 & $\mathbf{0}, 00232$ \\
\hline $\mathbf{1 0 0}$ & $\mathbf{4 0 0}$ & 0,00011 & 0,00019 & 0,00056 & 0,00240 \\
\hline $\mathbf{1 . 0 0 0}$ & $\mathbf{4 . 0 0 0}$ & 0,00025 & 0,00030 & 0,00214 & 0,00408 \\
\hline $\mathbf{3 . 0 0 0}$ & $\mathbf{1 2 . 0 0 0}$ & 0,00053 & 0,00089 & 0,00445 & 0,00671 \\
\hline $\mathbf{9 . 0 0 0}$ & $\mathbf{3 6 . 0 0 0}$ & 0,00187 & 0,00231 & 0,00616 & 0,01448 \\
\hline $\mathbf{1 8 . 0 0 0}$ & $\mathbf{7 2 . 0 0 0}$ & 0,00357 & 0,00487 & 0,03129 & 0,02558 \\
\hline $\mathbf{3 6 . 0 0 0}$ & $\mathbf{1 4 4 . 0 0 0}$ & 0,00681 & 0,00928 & 0,08984 & 0,04981 \\
\hline $\mathbf{5 4 . 0 0 0}$ & $\mathbf{2 1 6 . 0 0 0}$ & 0,01001 & 0,01755 & 0,15644 & 0,07440 \\
\hline $\mathbf{9 0 . 0 0 0}$ & $\mathbf{3 6 0 . 0 0 0}$ & 0,01617 & 0,02972 & 0,28110 & 0,13178 \\
\hline $\mathbf{1 8 0 . 0 0 0}$ & $\mathbf{7 2 0 . 0 0 0}$ & 0,03207 & 0,04943 & 0,58978 & 0,23074 \\
\hline $\mathbf{2 4 0 . 0 0 0}$ & $\mathbf{9 6 0 . 0 0 0}$ & 0,04213 & 0,05908 & 0,78838 & 0,34024 \\
\hline
\end{tabular}

Tabela 7.2 - Tempo de comunicação coletiva (broadcast)

No sistema distribuído, as mensagens de tamanhos menores (entre 4 e 36.000 bytes) são transmitidas de forma mais rápida com o uso da implementação MPICH comparando-se à utilização do PVM. Mas, assim como nas comunicações ponto-a-ponto, para mensagens maiores o PVM torna-se mais eficiente que o MPICH, visto que o PVM é mais adequado para comunicações que envolvam maior quantidade de dados. 
Esse estudo dos tempos de comunicação ponto-a-ponto e coletiva é importante neste trabalho, visto que serão utilizados e referenciados na análise dos resultados dos algoritmos paralelos de ordenação.

\subsection{Resultados Obtidos}

Nesta seção serão apresentados os resultados obtidos com as execuções dos algoritmos paralelos de ordenação (cujas implementações encontram-se descritas no capitulo 6) utilizando as plataformas de portabilidade executadas no sistema distribuído (MPICH e PVM) e na máquina paralela SP2 (IBM MPI e IBM PVMe).

Além disso, serão apresentados os resultados das execuções dos algoritmos seqüenciais, fazendo-se uma análise comparativa dos tempos de execuções obtidos com as duas implementações dos algoritmos (seriais e paralelos). Com o resultado da execução paralela e seqüencial é possível calcular a avaliação de velocidade de processamento obtido através da utilização do paralelismo, ou seja, o speedup (discutido no capítulo 2), que também será apresentado.

\subsubsection{QuickSort Paralelo 1}

O algoritmo quicksort paralelo 1 (implementação descrita no capítulo 6) caracteriza-se pela distribuição balanceada dos elementos aos processadores (1/3 do vetor) e pela pouca comunicação envolvida entre os processos paralelos (um total de 4 chamadas as rotinas send()/receive()). Nesse algoritmo, são utilizados dois métodos de ordenação seqüencial, o quicksort (por todos os processos) e o merge sort (apenas pelo mestre) durante a execução.

Os resultados obtidos com a execução desse algoritmo para cada plataforma de portabilidade são apresentados na tabela 7.3 e gráfico 7.1. 
Analisando-se os resultados, observa-se que a implementação IBM MPI executada na máquina paralela SP2 apresenta melhor desempenho para todas as quantidades de elementos analisadas quando comparada ao IBM PVMe, como também em relação às plataformas executadas no sistema distribuído PVM e MPICH. Este desempenho alcançado, como foi exposto na seção anterior, está relacionado ao fato de que as aplicações que utilizam o IBM MPI executarem sobre o controle do ambiente operacional paralelo (POE) do SP2, que fornece suporte às aplicações paralelas de modo a otimizar a utilização do switch de alto desempenho, tornando assim, a comunicação entre os processos paralelos mais rápida e eficiente.

\begin{tabular}{|c|c|c|c|c|c|c|c|c|}
\hline Plataformas & $\mathbf{9 . 0 0 0}$ & $\mathbf{1 8 . 0 0 0}$ & $\mathbf{3 6 . 0 0 0}$ & $\mathbf{5 4 . 0 0 0}$ & $\mathbf{9 0 . 0 0 0}$ & $\mathbf{1 8 0 . 0 0 0}$ & $\mathbf{3 6 0 . 0 0 0}$ & $\mathbf{5 4 0 . 0 0 0}$ \\
\hline MPI IBM & 0,0193 & 0,0357 & 0,0723 & 0,1119 & 0,1820 & 0,3033 & 0,7121 & 1,1399 \\
\hline IBM PVMe & 0,3048 & 0,322 & 0,3643 & 0,4213 & 0,5150 & 0,7465 & 1,0319 & 1,6265 \\
\hline MPICH & 0,0739 & 0,1301 & 0,2047 & 0,3855 & 0,8994 & 1,9041 & 4,3802 & 5,9062 \\
\hline PVM & 0,0857 & 0,1439 & 0,2729 & 0,4175 & 0,8533 & 1,6360 & 3,0512 & 4,4880 \\
\hline
\end{tabular}

Tabela 7.3 - Tempos das execuções do algoritmo quicksort paralelo 1

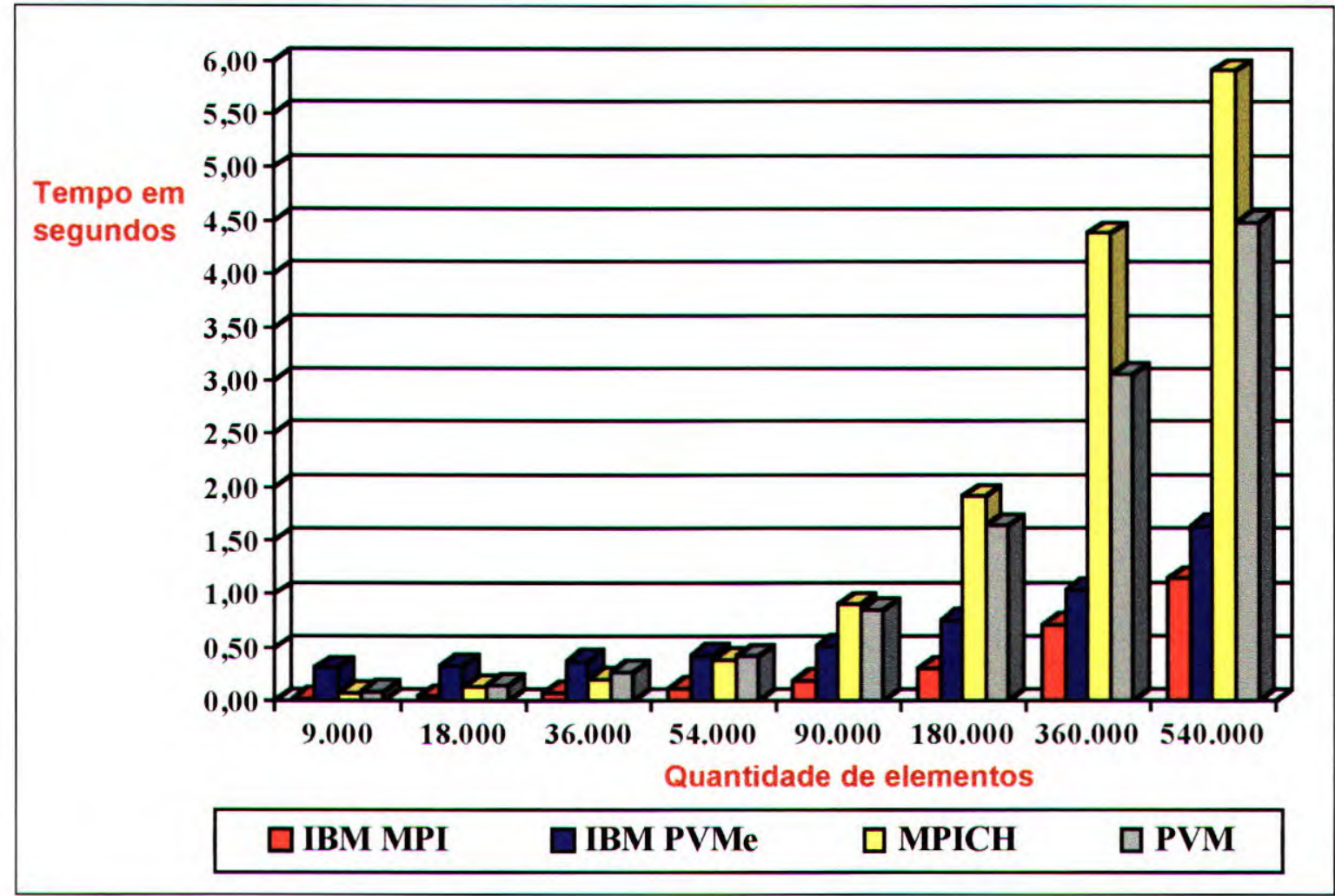

Gráfico 7.1 - Tempos das execuções do algoritmo quicksort paralelo 1 
A implementação IBM PVMe apresenta melhores resultados comparando-se às plataformas de portabilidade PVM e MPICH, para maiores quantidades de elementos, sendo portanto mais adequada para aplicações que manipulam grandes quantidades de dados e efetuam transmissão de mensagens grandes (a partir de 90.000 elementos, onde o tamanho das mensagens é de $120 \mathrm{Kbytes,} \mathrm{ou} \mathrm{seja,} 30.000$ elementos). Isso é comprovado com a execução do benchmark ping-pong (seção 7.4), onde a partir dessa quantidade de dados as comunicações apresentam maior eficiência em relação ao MPICH e PVM.

No sistema distribuído os resultados obtidos mostram que os tempos das execuções do algoritmo paralelo utilizando a implementação MPICH são mais satisfatórios para menores quantidades de dados. Porém essa situação se inverte para quantidades maiores de elementos, onde o PVM passa a apresentar melhores desempenhos. Como mostrado na seção anterior, o PVM fornece maior eficiência nas transmissões de mensagens grandes, o que se explica tais resultados.

Os tempos das execuções obtidos com a versão sequencial do algoritmo quicksort paralelo 1 são apresentados na tabela 7.4 e no gráfico 7.2 .

Os resultados mostram que o algoritmo quicksort paralelo 1 utilizando a plataforma IBM MPI apresenta menores tempos de execuções para todas as quantidades de elementos testadas em relação ao algoritmo seqüencial. Entretanto com a utilização da plataforma IBM PVMe, o algoritmo paralelo é mais eficiência quando a aplicação manipula grande quantidade de dados (a partir de 360.000 elementos).

\begin{tabular}{|c|c|c|c|c|c|c|c|c|}
\hline Plataformas & $\mathbf{9 . 0 0 0}$ & $\mathbf{1 8 . 0 0 0}$ & $\mathbf{3 6 . 0 0 0}$ & $\mathbf{5 4 . 0 0 0}$ & $\mathbf{9 0 . 0 0 0}$ & $\mathbf{1 8 0 . 0 0 0}$ & $\mathbf{3 6 0 . 0 0 0}$ & $\mathbf{5 4 0 . 0 0 0}$ \\
\hline IBM MPI & 0,0193 & 0,0357 & 0,0723 & 0,1119 & 0,1820 & 0,3033 & 0,7121 & 1,1399 \\
\hline IBM PVMe & 0,3048 & 0,322 & 0,3643 & 0,4213 & 0,5150 & 0,7465 & 1,0319 & 1,6265 \\
\hline Serial - SP2 & 0,0259 & 0,0551 & 0,1145 & 0,1829 & 0,3161 & 0,6318 & 1,3886 & 2,3437 \\
\hline MPICH & 0,0739 & 0,1301 & 0,2047 & 0,3855 & 0,8994 & 1,9041 & 4,3802 & 5,9062 \\
\hline PVM & 0,0857 & 0,1439 & 0,2729 & 0,4175 & 0,8533 & 1,6360 & 3,0512 & 4,488 \\
\hline Serial - S.D. & 0,0415 & 0,0866 & 0,1803 & 0,2787 & 0,4921 & 1,0066 & 2,1342 & 3,2702 \\
\hline
\end{tabular}

Tabela 7.4 - Tempos das execuções do algoritmo quicksort 1 serial e paralelo 


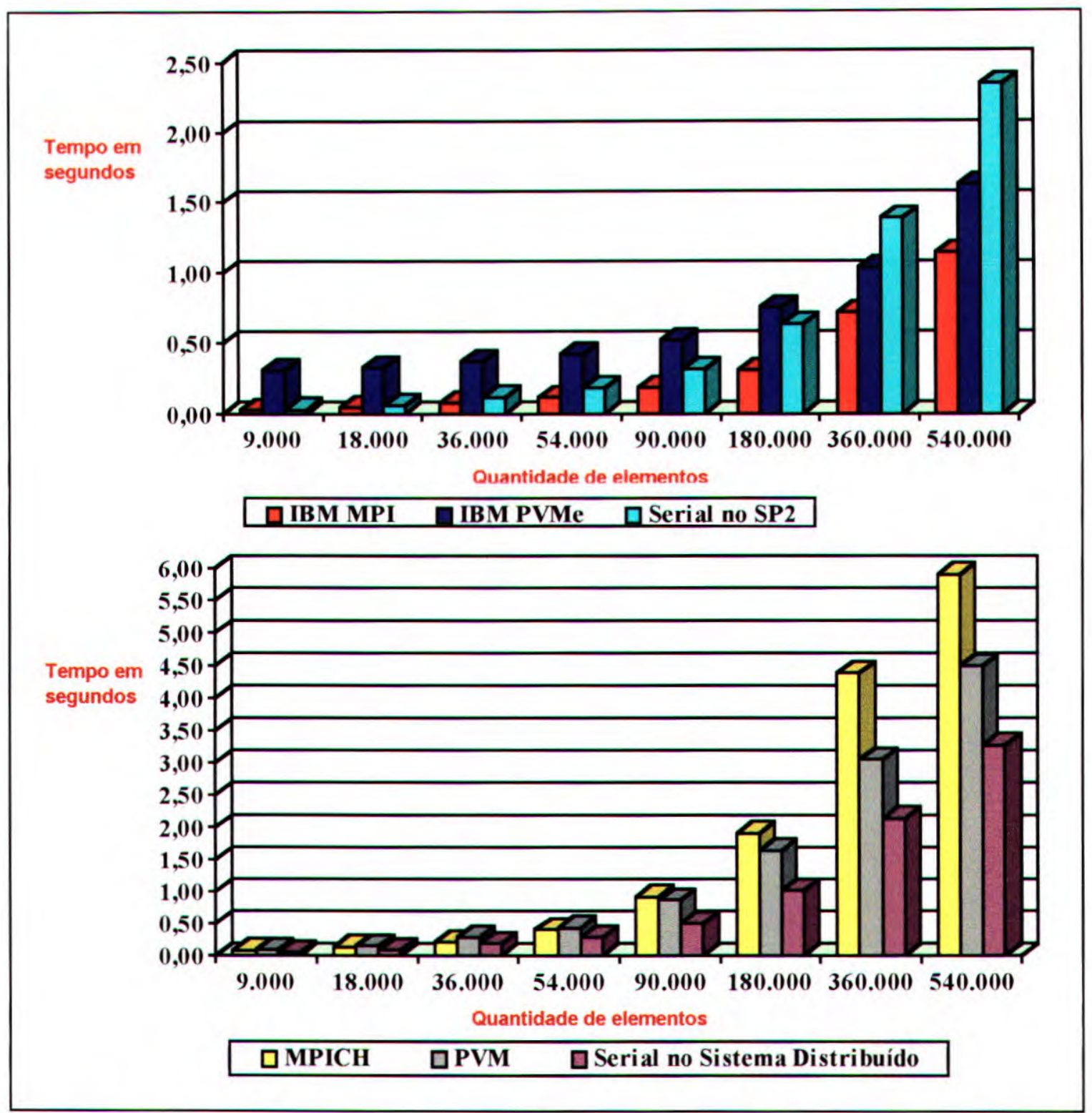

Gráfico 7.2 - Tempos das execuções do algoritmo quicksort 1 serial e paralelo

No sistema distribuído, o algoritmo paralelo utilizando as plataformas de portabilidade PVM e MPICH, apresenta maiores tempos de execuções do que o algoritmo seqüencial. Os fatores principais que degradaram o desempenho do algoritmo paralelo relacionam-se com: 
- a sobrecarga de comunicação, visto que a rede do sistema distribuído, Ethernet de 10 Mbits, não forneceu o desempenho necessário para efetuar as transmissões de dados entre os processos; e

- a dificuldade de balanceamento da carga de trabalho entre os processadores de diferentes capacidades computacionais, devido aos elementos serem igualmente distribuídos entre os mesmos.

A partir dos resultados das execuções do algoritmo paralelo e seqüencial têm-se os speedups apresentados na tabela 7.5 e gráfico 7.3 .

\begin{tabular}{|c|c|c|c|c|c|c|c|c|}
\hline Plataformas & $\mathbf{9 . 0 0 0}$ & $\mathbf{1 8 . 0 0 0}$ & $\mathbf{3 6 . 0 0 0}$ & $\mathbf{5 4 . 0 0 0}$ & $\mathbf{9 0 . 0 0 0}$ & $\mathbf{1 8 0 . 0 0 0}$ & $\mathbf{3 6 0 . 0 0 0}$ & $\mathbf{5 4 0 . 0 0 0}$ \\
\hline IBM MPI & 1,34 & 1,54 & 1,58 & 1,63 & 1,74 & 2,08 & 1,95 & 2,06 \\
\hline IBM PVMe & 0,08 & 0,17 & 0,31 & 0,43 & 0,61 & 0,85 & 1,35 & 1,44 \\
\hline MPICH & 0,56 & 0,67 & 0,88 & 0,72 & 0,55 & 0,53 & 0,49 & 0,55 \\
\hline PVM & 0,48 & 0,60 & 0,66 & 0,67 & 0,58 & 0,62 & 0,70 & 0,73 \\
\hline
\end{tabular}

Tabela 7.5 - Speedup das execuções do algoritmo quicksort paralelo 1

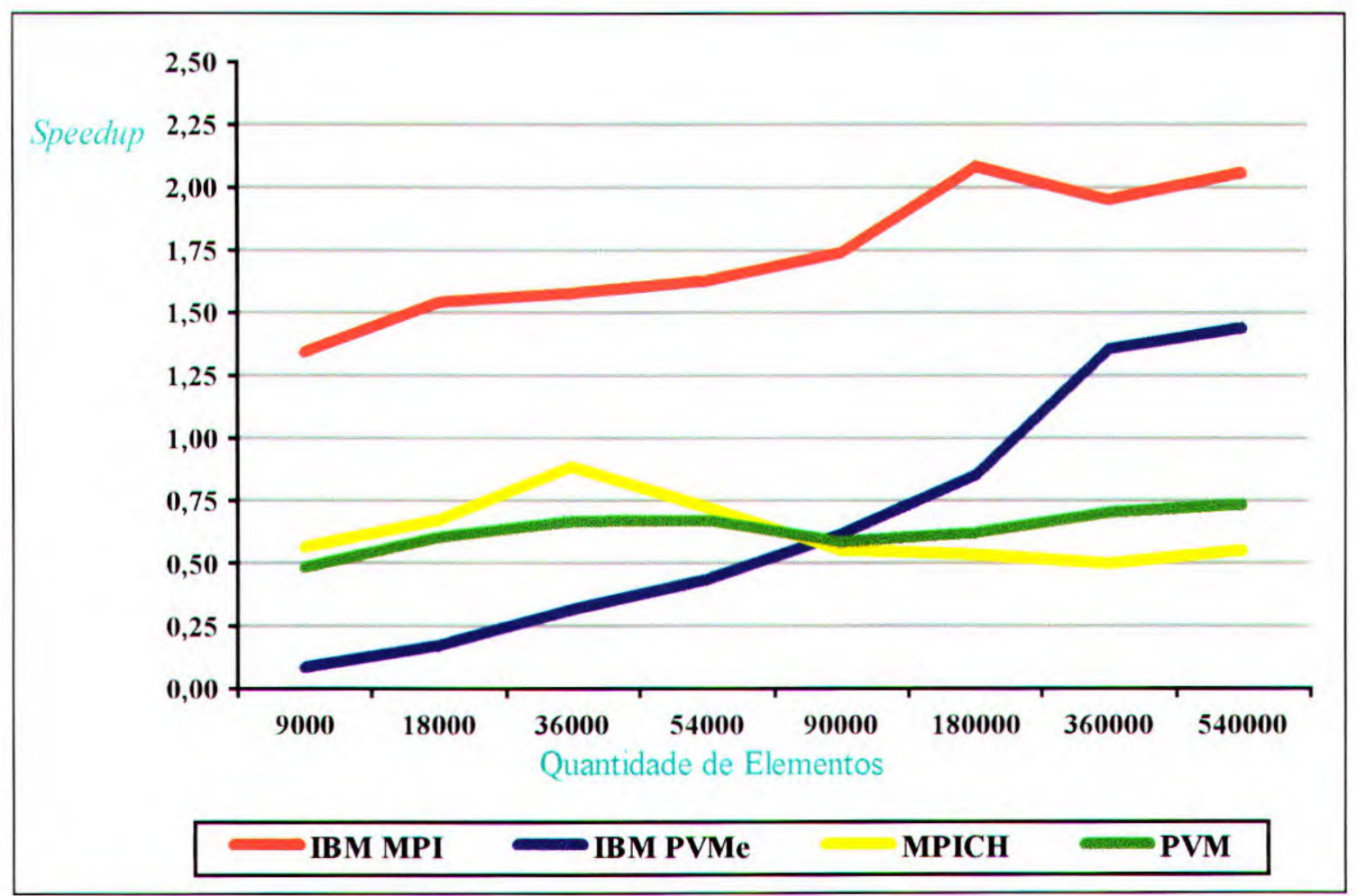

Gráfico 7.3 - Speedups das execuções do algoritmo quicksort paralelo 1 
A implementação IBM MPI apresenta bons speedups para todas as quantidades de dados. Nota-se também que nas quantidades de 180.000 e 540.000 elementos têm-se speedups mais altos, havendo uma queda em uma quantidade intermediária (ou seja, $360.000)$.

Essa queda do speedup quando vetores de 360.000 elementos são considerados, acontece pois se for calculado o tempo necessário para se transmitir um elemento para cada tempo de comunicação ping-pong apresentado na seção 7.4, percebe-se que 60.000 elementos corresponde à transmissão de um elemento a cada $3,2 \times 10^{-7}$ segundos em uma única direção (ping), 90.000 corresponde a $3,3 \times 10^{-7}$ segundos e na quantidade de $180.000,3,2 \times 10^{-7}$ segundos. Portanto, há um pequeno aumento de tempo de transmissão em uma quantidade situada entre 180.000 e 540.000 (onde são transferidos respectivamente 60.000 e 180.000 elementos), o que de certa forma provoca uma diminuição no speedup.

Com a plataforma IBM PVMe obtêm-se speedups quando a aplicação manipula grande quantidades de dados, acima de 180.000 elementos, sendo que o melhor speedup é alcançado para a maior quantidade de elementos, ou seja, 540.000. Essa situação ocorre visto que a medida que aumenta-se a quantidade de dados manipulada pela aplicação maior é o speedup.

Entretanto, com a utilização do PVM e MPICH, não obteve-se speedups, visto que o algoritmo quicksort paralelo $l$ foi menos eficiente que a versão serial, devido principalmente ao tempo consumido na comunicação entre os processos paralelos, como exposto anteriormente.

\subsubsection{QuickSort Paralelo 2}

Este algoritmo, ao contrário do algoritmo quicksort paralelo 1 , tem como característica a distribuição não balanceada dos elementos aos processadores e a utilização de apenas um método de ordenação seqüencial, o quicksort (executado por 
todos processos paralelos). Porem, da mesma forma que o algoritmo anterior, são realizadas poucas comunicações entre os processos (4 chamadas send()/receive()).

Devido à distribuição dos elementos não ser feita de maneira balanceada, foi necessário realizar uma nova configuração da máquina paralela virtual (para uma utilização mais adequada da plataforma de portabilidade PVM no sistema distribuído), de modo que os processadores mais velozes (lasd07 e lasd08) ficassem encarregados em ordenar os subvetores com maiores quantidades de elementos (como descrito na seção 7.2). Assim, para cada quantidade de elementos, os tamanhos dos subvetores foram analisados, possibilitando que a distribuição dos subvetores com maiores quantidades de elementos fossem transferidos aos processadores com maior capacidade computacional.

\begin{tabular}{|c|c|c|c|c|c|c|c|c|}
\hline Plataformas & $\mathbf{9 . 0 0 0}$ & $\mathbf{1 8 . 0 0 0}$ & $\mathbf{3 6 . 0 0 0}$ & $\mathbf{5 4 . 0 0 0}$ & $\mathbf{9 0 . 0 0 0}$ & $\mathbf{1 8 0 . 0 0 0}$ & $\mathbf{3 6 0 . 0 0 0}$ & $\mathbf{5 4 0 . 0 0 0}$ \\
\hline MPI IBM & 0,0198 & 0,0423 & 0,0745 & 0,1479 & 0,2329 & 0,3115 & 0,7659 & 1,1737 \\
\hline IBM PVMe & 0,3162 & 0,3373 & 0,4762 & 0,5401 & 0,7272 & 0,8263 & 1,1439 & 1,7283 \\
\hline MPICH & 0,0688 & 0,0881 & 0,1664 & 0,2595 & 0,7983 & 1,5417 & 2,5762 & 3,3019 \\
\hline PVM & 0,0696 & 0,1194 & 0,1692 & 0,2656 & 0,7424 & 1,4924 & 2,4171 & 3,1242 \\
\hline
\end{tabular}

Tabela 7.6 - Tempos das execuções do algoritmo quicksort paralelo 2

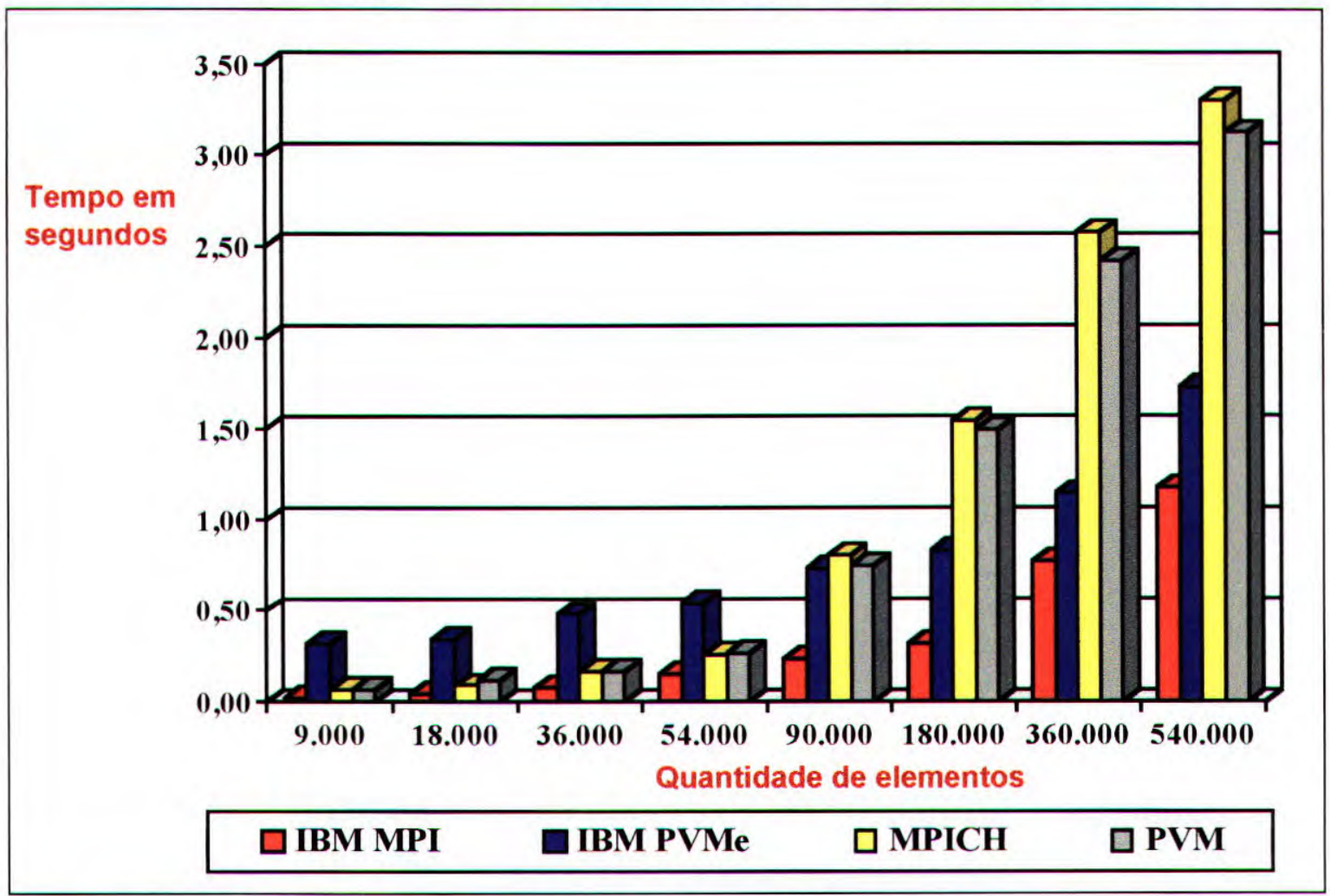

Gráfico 7.4 - Tempos das execuções do algoritmo quicksort paralelo 2 
Os resultados obtidos, apresentados na tabela 7.6 e gráfico 7.4, semelhante aos resultados do algoritmo anterior, apresentam melhores desempenhos com a utilização da plataforma IBM MPI executada no SP2, devido a sua alta eficiência para este tipo de arquitetura. Enquanto que, a plataforma IBM PVMe se destaca em termos de desempenho a partir de 90.000 elementos em relação às plataformas utilizadas no sistema distribuído (PVM e MPICH). Isso acontece, pois a partir dessa quantidade de dados, as transmissões das mensagens tornam-se mais eficientes (acima de $120 \mathrm{Kbytes}$ ), como foi verificado na seção 7.4.

Nota-se porem, que neste algoritmo tanto o IBM MPI como o IBM PVMe mostram-se menos eficientes que no anterior, devido à distribuição não balanceada dos elementos entre os nós de processamento, refletindo numa perda de desempenho.

Analisando o comportamento das plataformas executadas no sistema distribuído, a implementação MPICH é mais adequada quando o algoritmo paralelo executa sobre poucas quantidades de elementos e realizam transmissões de mensagens pequenas e médias. Entretanto, o PVM apresenta melhor desempenho a medida que aumenta-se a quantidade de dados. Essa situação é exatamente a mesma apresentada no algoritmo anterior.

Com a execução deste algoritmo, percebe-se que as plataformas de portabilidade MPICH e PVM, apresentam melhores tempos de execuções do que o algoritmo quicksort paralelo 1. Um dos principais motivos é que neste algoritmo, a distribuição de diferentes quantidades de dados entre os processadores possibilita a transferência dos maiores subvetores aos processadores mais velozes, como também não há a necessidade de se executar o algoritmo merge sort para intercalar os subvetores ordenados, sendo apenas preciso concatená-los. Porem, como discutido acima, esta situação se inverte na máquina paralela SP2, devido ao fato de ser uma plataforma homogênea.

Os resultados das execuções do algoritmo seqüencial correspondente no sistema distribuído e na máquina paralela SP2 são apresentados na tabela 7.7 e no gráfico 7.5. 


\begin{tabular}{|c|c|c|c|c|c|c|c|c|}
\hline Plataformas & $\mathbf{9 . 0 0 0}$ & $\mathbf{1 8 . 0 0 0}$ & $\mathbf{3 6 . 0 0 0}$ & $\mathbf{5 4 . 0 0 0}$ & $\mathbf{9 0 . 0 0 0}$ & $\mathbf{1 8 0 . 0 0 0}$ & $\mathbf{3 6 0 . 0 0 0}$ & $\mathbf{5 4 0 . 0 0 0}$ \\
\hline IBM MPI & 0,0198 & 0,0423 & 0,0745 & 0,1479 & 0,2329 & 0,3115 & 0,7659 & 1,1737 \\
\hline IBM PVMe & 0,3162 & 0,3373 & 0,4762 & 0,5401 & 0,7272 & 0,8263 & 1,1439 & 1,7283 \\
\hline Serial - SP2 & 0,0223 & 0,0491 & 0,0948 & 0,1873 & 0,2977 & 0,5589 & 1,3125 & 2,0854 \\
\hline MPICH & 0,0688 & 0,0881 & 0,1664 & 0,2595 & 0,7983 & 1,5417 & 2,5762 & 3,3019 \\
\hline PVM & 0,0696 & 0,1194 & 0,1692 & 0,2656 & 0,7424 & 1,4924 & 2,4171 & 3,1242 \\
\hline Serial - S.D. & 0,0312 & 0,0667 & 0,1417 & 0,2153 & 0,3902 & 0,8086 & 1,7188 & 2,7552 \\
\hline
\end{tabular}

Tabela 7.7 - Tempos das execuções do algoritmo quicksort 2 serial e paralelo

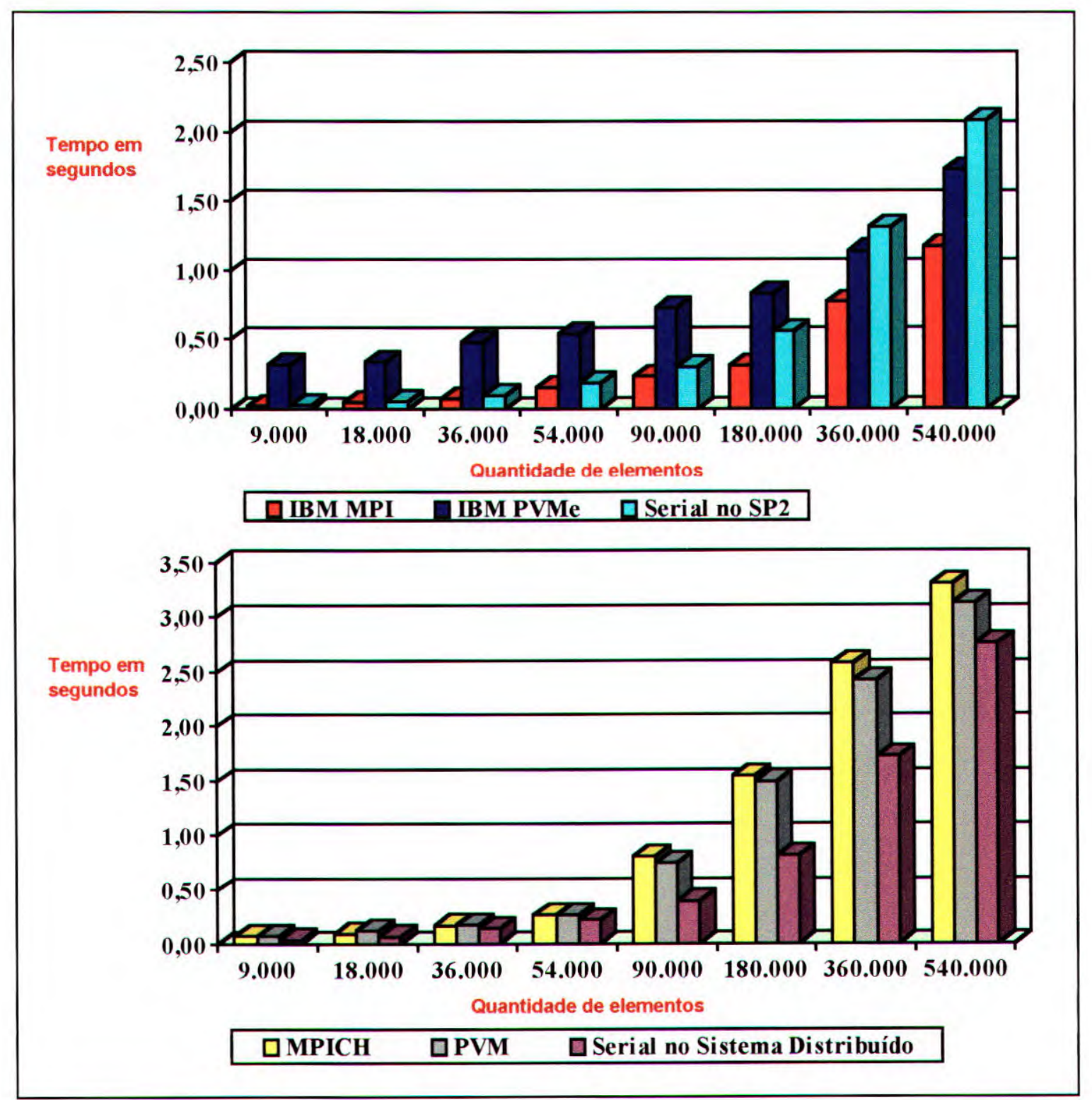

Gráfico 7.5 - Tempos das execuções do algoritmo quicksort 1 serial e paralelo 
Fazendo-se uma análise comparativa entre o algoritmo paralelo e serial, percebe-se que os resultados obtidos foram semelhantes ao algoritmo anterior. A plataforma IBM MPI apresenta melhores tempos de execução em relação às outras plataformas, se destacando novamente em termos de eficiência e desempenho. Já com a plataforma IBM PVMe, obtêm-se melhores desempenhos do algoritmo paralelo para as maiores quantidades de elementos testadas (360.000 e 540.000).

No ambiente computacional distribuído, mesmo com a distribuição dos elementos serem realizadas de maneira mais balanceada entre os processadores, 0 algoritmo seqüencial apresenta menores tempos de execuções do que o algoritmo paralelo utilizando as plataformas de portabilidade PVM e MPICH. Essa situação deve-se principalmente à sobrecarga ocasionada pela comunicação entre os processos paralelos (como discutido na análise do algoritmo anterior).

O estudo do speedup (apresentados na tabela 7.8 e gráfico 7.6), mostra que a implementação IBM MPI apresenta speedups para todas as quantidades de dados analisadas, sendo que os mais altos speedups são obtidos quando o algoritmo paralelo classifica uma quantidade de dados em tomo de 180.000 e 540.000 elementos, visto que para essas quantidades, as transmissões se tornam mais eficientes como foi comentado no estudo do speedup do algoritmo quicksort paralelo 1.

O algoritmo paralelo utilizando a plataforma IBM PVMe, alcança speedups para quantidades de dados acima de 180.000 , sendo que para a maior quantidade de elementos obtêm-se o mais alto speedup.

Por outro lado, com a execução do algoritmo paralelo no sistema distribuído não há ganhos em termos de speedup, visto que o algoritmo paralelo torna-se menos eficiente que sua versão seqüencial, devido à alta latência ocasionada pelas transmissões de dados. 


\begin{tabular}{|c|c|c|c|c|c|c|c|c|}
\hline Plataformas & $\mathbf{9 . 0 0 0}$ & $\mathbf{1 8 . 0 0 0}$ & $\mathbf{3 6 . 0 0 0}$ & $\mathbf{5 4 . 0 0 0}$ & $\mathbf{9 0 . 0 0 0}$ & $\mathbf{1 8 0 . 0 0 0}$ & $\mathbf{3 6 0 . 0 0 0}$ & $\mathbf{5 4 0 . 0 0 0}$ \\
\hline IBM MPI & 1,13 & 1,16 & 1,27 & 1,27 & 1,28 & 1,79 & 1,71 & 1,78 \\
\hline IBM PVMe & 0,07 & 0,15 & 0,20 & 0,35 & 0,41 & 0,68 & 1,15 & 1,21 \\
\hline MPICH & 0,45 & 0,76 & 0,85 & 0,83 & 0,49 & 0,52 & 0,67 & 0,83 \\
\hline PVM & 0,45 & 0,56 & 0,84 & 0,81 & 0,53 & 0,54 & 0,71 & 0,88 \\
\hline
\end{tabular}

Tabela 7.8 - Speedup das execuções do algoritmo quicksort paralelo 2

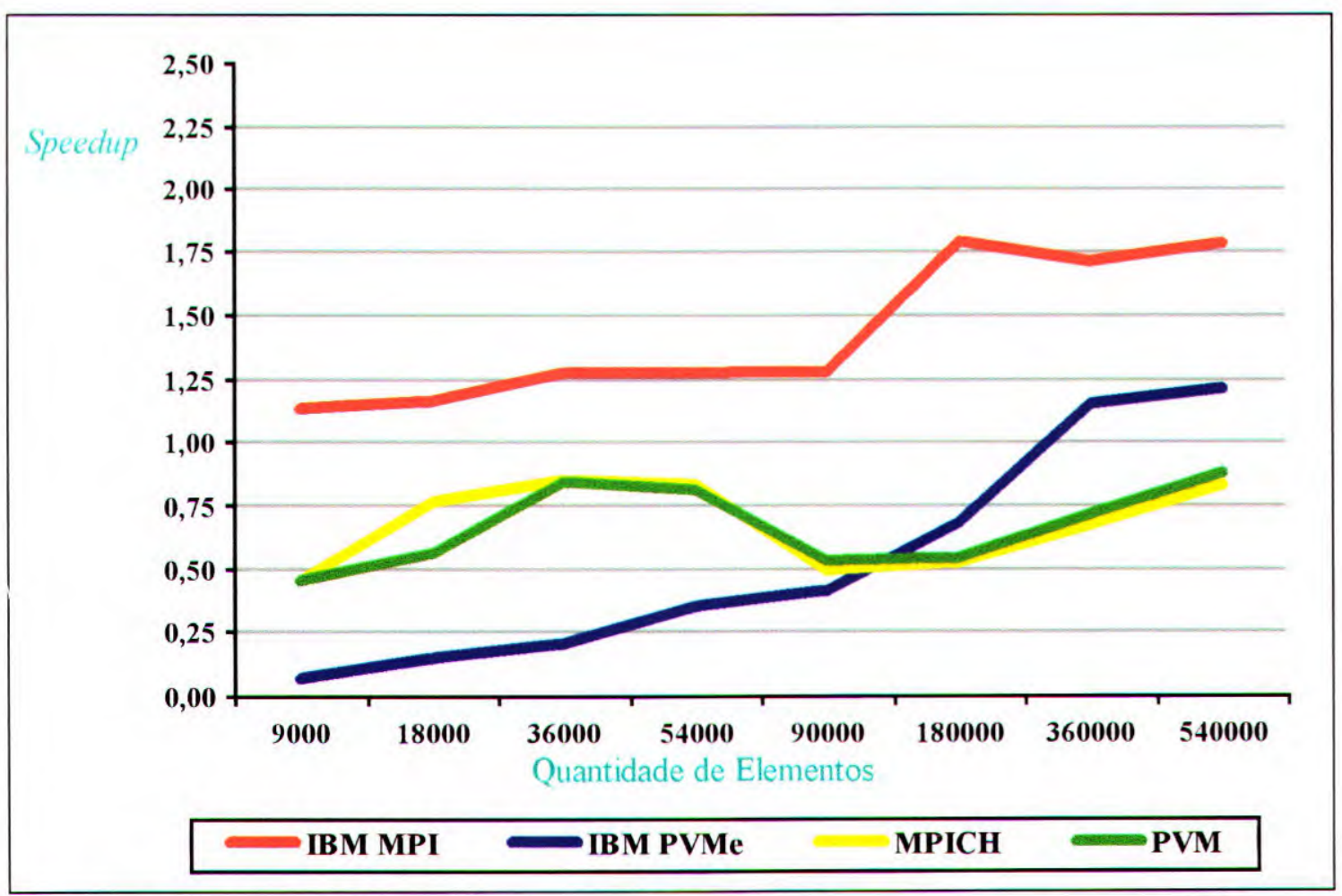

Gráfico 7.6 - Speedup das execuções do algoritmo quicksort paralelo 2

\subsubsection{QuickSort Paralelo 2.1}

Este algoritmo tem como objetivo solucionar o problema apresentado com o algoritmo quicksort paralelo 2, ou seja, a distribuição não balanceada dos elementos aos processadores (como apresentado no capítulo 6). Da mesma forma que o algoritmo anterior, ele utiliza apenas um método de ordenação seqüencial (quicksort) e envolve poucas comunicações entre os processos paralelos (4 chamadas send()/receive( )). Os resultados das execuções são apresentadas na tabela 7.9 e gráfico 7.7 . 


\begin{tabular}{|c|c|c|c|c|c|c|c|c|}
\hline Plataformas & $\mathbf{9 . 0 0 0}$ & $\mathbf{1 8 . 0 0 0}$ & $\mathbf{3 6 . 0 0 0}$ & $\mathbf{5 4 . 0 0 0}$ & $\mathbf{9 0 . 0 0 0}$ & $\mathbf{1 8 0 . 0 0 0}$ & $\mathbf{3 6 0 . 0 0 0}$ & $\mathbf{5 4 0 . 0 0 0}$ \\
\hline MPI IBM & 0,0137 & 0,0245 & 0,052 & 0,0753 & 0,1369 & 0,2684 & 0,4942 & 0,7891 \\
\hline IBM PVMe & 0,2781 & 0,3074 & 0,3559 & 0,4096 & 0,5087 & 0,7175 & 0,8354 & 1,0849 \\
\hline MPICH & 0,0746 & 0,1361 & 0,2674 & 0,3898 & 0,8016 & 1,6659 & 3,0232 & 4,8162 \\
\hline PVM & 0,0896 & 0,1545 & 0,2881 & 0,3992 & 0,7834 & 1,5907 & 2,7004 & 3,7776 \\
\hline
\end{tabular}

Tabela 7.9 - Tempos das execuções do algoritmo quicksort paralelo 2.1

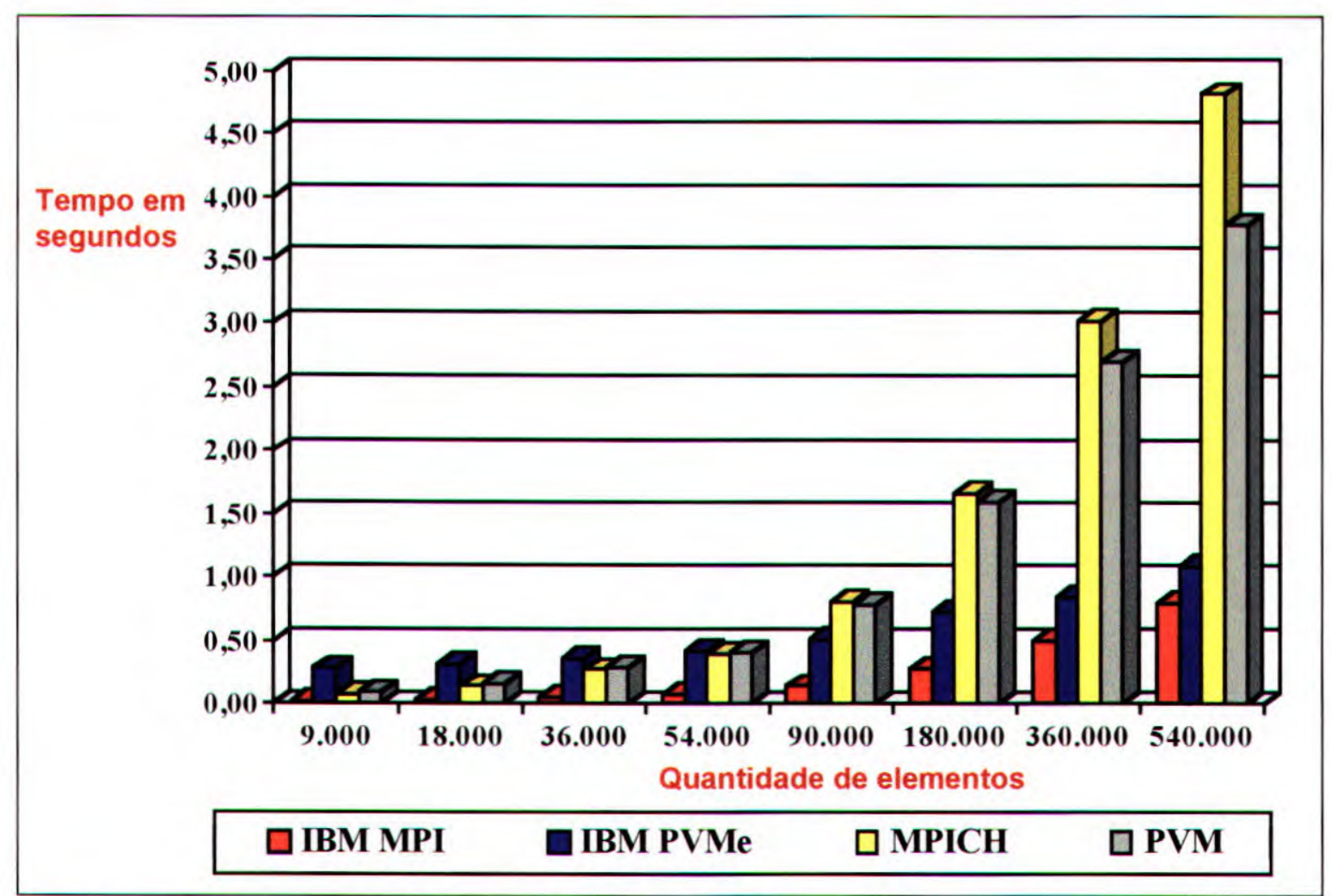

Gráfico 7.7 - Tempos das execuções do algoritmo quicksort paralelo 2.1

Analisando-se os resultados obtidos com o algoritmo quicksort paralelo 2.1, percebe-se uma grande melhora nos tempos de execuções com a utilização das plataformas IBM MPI e IBM PVMe, quando comparado ao algoritmo quicksort paralelo 2 e quicksort paralelo 1. Porém isto não ocorre para as plataformas MPICH e PVM, como já era previsto, visto que são executados em uma plataforma heterogênea.

Entretanto, a análise comparativa de desempenho entre as plataformas utilizadas continua semelhante à anterior, sendo que o IBM MPI é o mais eficiente. A plataforma IBM PVMe apresenta menores tempos de execuções apenas quando comparada ao PVM 
e ao MPICH a partir de 90.000 elementos (visto que o IBM PVMe fornece maior desempenho para transmissões de mensagens grandes).

No sistema distribuído, a implementação MPICH apresenta melhor desempenho que a plataforma PVM para as mesmas quantidades de elementos obtidas nos algoritmos anteriores, ou seja, para menores quantidades de dados. Porem, essa situação se inverte quando o algoritmo classifica um conjunto grande de elementos (acima de 54.000 elementos), obtendo-se melhor desempenho com a utilização da plataforma de portabilidade PVM. Com já argumentado, isso se comprova com a execução do benchmark ping-pong apresentado na seção 7.4.

Os resultados das execuções do algoritmo serial são apresentados na tabela $7.10 \mathrm{e}$ no gráfico 7.8. Os tempos obtidos com a execução do algoritmo sequencial na máquina paralela SP2, são superiores aos tempos obtidos com o algoritmo paralelo utilizando a plataforma IBM MPI, como também maiores do que sua versão paralela utilizando a plataforma IBM PVMe, em face de grandes quantidades de dados.

Por outro lado, no sistema distribuído, o algoritmo quicksort paralelo 2.1 utilizando as plataformas MPICH e PVM não apresenta melhores tempos de execuções do que o algoritmo seqüencial. Esse comportamento deve-se a dois motivos principais (comentados na análise do algoritmo quicksort paralelo l), sendo eles: a sobrecarga imposta pelas transmissões de dados em uma rede Ethernet de $10 \mathrm{Mbits}$ (incluindo-se as sobrecargas do próprio protocolo de comunicação) e a distribuição balanceada dos elementos, provocando uma sobrecarga nos processadores com menores capacidades computacionais.

\begin{tabular}{|c|c|c|c|c|c|c|c|c|}
\hline Plataformas & $\mathbf{9 . 0 0 0}$ & $\mathbf{1 8 . 0 0 0}$ & $\mathbf{3 6 . 0 0 0}$ & $\mathbf{5 4 . 0 0 0}$ & $\mathbf{9 0 . 0 0 0}$ & $\mathbf{1 8 0 . 0 0 0}$ & $\mathbf{3 6 0 . 0 0 0}$ & $\mathbf{5 4 0 . 0 0 0}$ \\
\hline IBM MPI & 0,0137 & 0,0245 & 0,052 & 0,0753 & 0,1369 & 0,2684 & 0,4942 & 0,7891 \\
\hline IBM PVMe & 0,2781 & 0,3074 & 0,3559 & 0,4096 & 0,5087 & 0,7175 & 0,8354 & 1,0849 \\
\hline Serial - SP2 & 0,021 & 0,0427 & 0,0915 & 0,1514 & 0,2768 & 0,5465 & 1,0027 & 1,6148 \\
\hline MPICH & 0,0746 & 0,1361 & 0,2674 & 0,3898 & 0,8016 & 1,6659 & 3,0232 & 4,8162 \\
\hline PVM & 0,0896 & 0,1545 & 0,2881 & 0,3992 & 0,7834 & 1,5907 & 2,7004 & 3,7776 \\
\hline Serial - S.D. & 0,0298 & 0,0627 & 0,1383 & 0,2001 & 0,3469 & 0,7452 & 1,5225 & 2,4451 \\
\hline
\end{tabular}

Tabela 7.10 - Tempos das execuções do algoritmo quicksort 2.1 serial e paralelo 


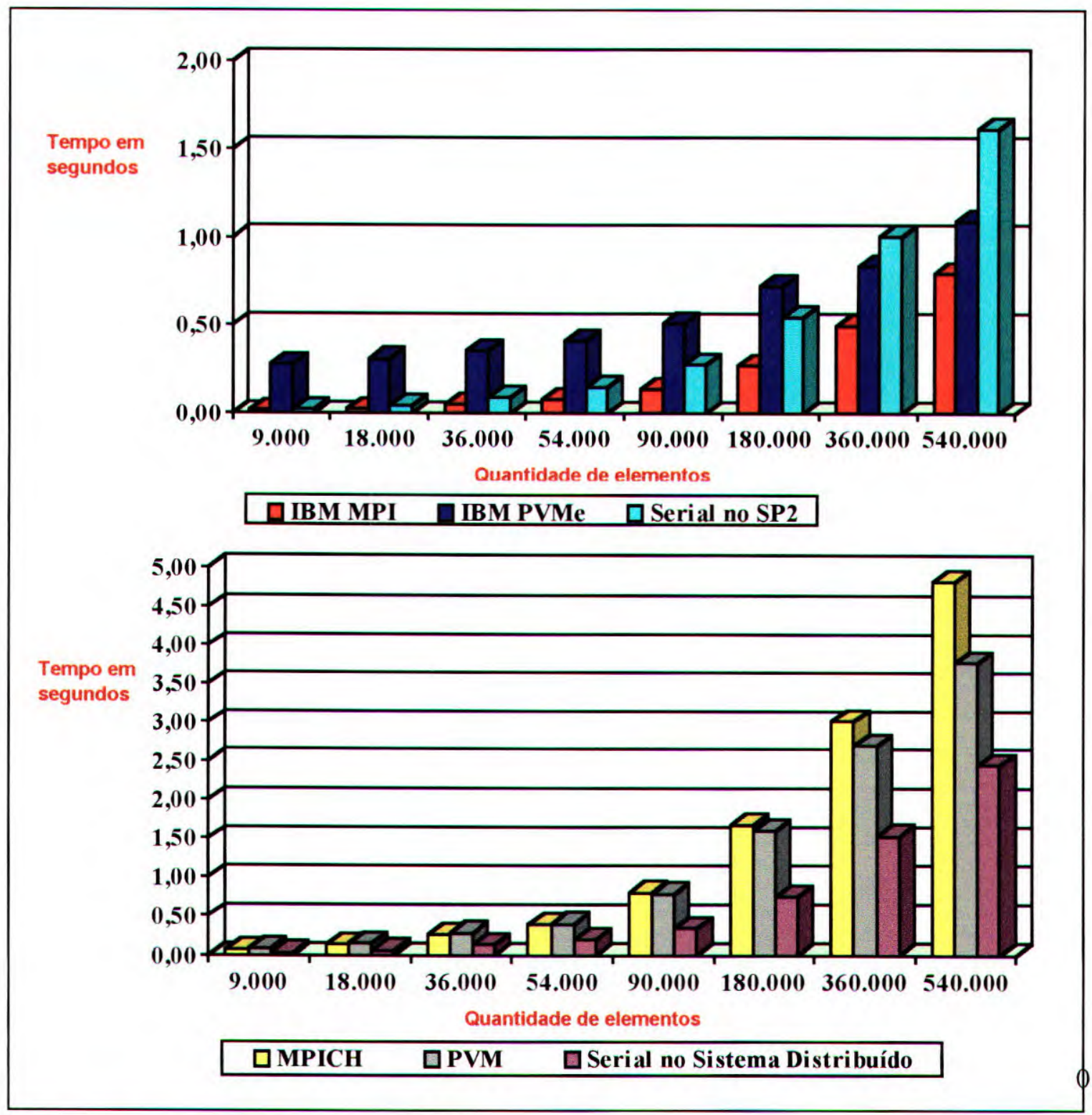

Gráfico 7.8 - Tempos das execuções do algoritmo quicksort 2.1 serial e paralelo

Desta forma, o estudo do speedup (apresentado na tabela 7.11 e gráfico 7.9) obtido através da execução do algoritmo quicksort paralelo 2.1 continua equivalente aos obtidos com os outros algoritmos paralelos. 


\begin{tabular}{|c|c|c|c|c|c|c|c|c|}
\hline Plataformas & $\mathbf{9 . 0 0 0}$ & $\mathbf{1 8 . 0 0 0}$ & $\mathbf{3 6 . 0 0 0}$ & $\mathbf{5 4 . 0 0 0}$ & $\mathbf{9 0 . 0 0 0}$ & $\mathbf{1 8 0 . 0 0 0}$ & $\mathbf{3 6 0 . 0 0 0}$ & $\mathbf{5 4 0 . 0 0 0}$ \\
\hline IBM MPI & 1,53 & 1,74 & 1,76 & 2,01 & 2,02 & 2,04 & 2,03 & 2,05 \\
\hline IBM PVMe & 0,08 & 0,14 & 0,26 & 0,37 & 0,54 & 0,76 & 1,20 & 1,49 \\
\hline MPICH & 0,40 & 0,46 & 0,52 & 0,51 & 0,43 & 0,45 & 0,50 & 0,51 \\
\hline PVM & 0,33 & 0,41 & 0,48 & 0,50 & 0,44 & 0,47 & 0,56 & 0,65 \\
\hline
\end{tabular}

Tabela 7.11 - Speedup das execuções do algoritmo quicksort paralelo 2.1

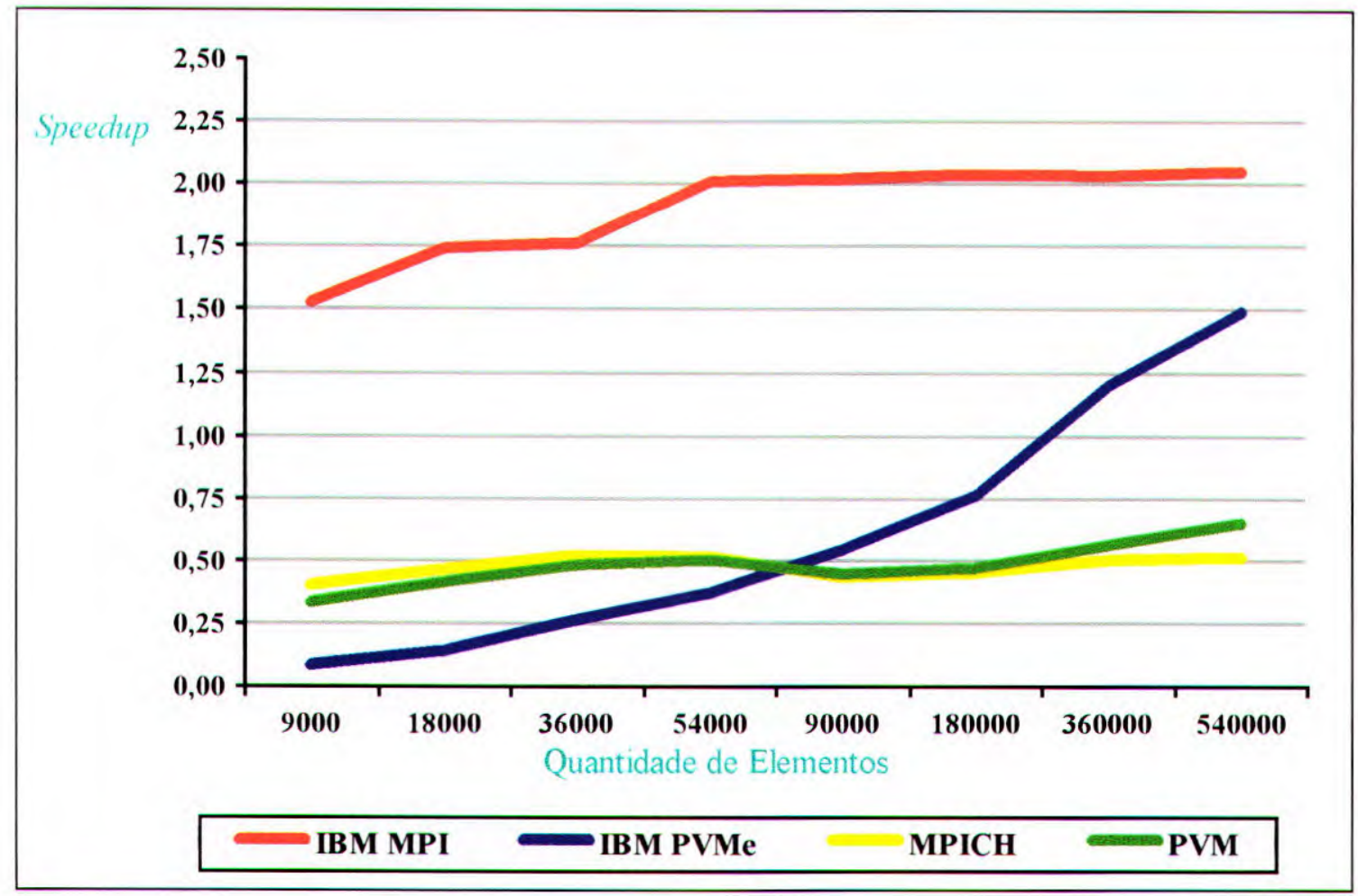

Gráfico 7.9 - Speedup das execuções do algoritmo quicksort paralelo 2.1

$\mathrm{Na}$ máquina paralela SP2 têm-se bons speedups quando utilizando-se da implementação IBM MPI, obtendo-se o mais alto speedup na quantidade de 540.000 elementos (devido às transmissões ocorrerem de maneira mais rápida). Com a utilização da plataforma IBM PVMe, por outro lado, os speedups são alcançados apenas quando o algoritmo manipula maior quantidade de dados (acima de 180.000 elementos).

Quanto ao sistema distribuído, praticamente não obtêm-se speedups com a execução do algoritmo paralelo utilizando as plataformas MPICH e PVM, devido ao fato do algoritmo ser afetado pela sobrecarga relacionada às operações de comunicações e 
pela distribuição relativamente balanceada ( aproximadamente as mesmas quantidades) dos elementos entre os processadores heterogêneos.

\subsubsection{Merge Paralelo}

Este algoritmo, assim como o quicksort paralelo 1, distribui a mesma quantidade de elementos aos processadores, entretanto tanto o processamento como o número de comunicações envolvidas (10 chamadas às rotinas send( )/receive( ), onde são transmitidos $1 / 3$ e um $1 / 9$ do vetor) entre os processos paralelos é bem maior. $O$ método de ordenação seqüencial utilizado é o merge sort, sendo executado num total de 7 vezes ( 3 executadas pelo processo mestre e mais 4 pelos escravos)

Os resultados obtidos com a execução deste algoritmo, ilustrados na tabela $7.12 \mathrm{e}$ gráfico 7.10, mostram que a plataforma IBM MPI é a que mais se destaca em termos de desempenho entre todas as plataformas analisadas, visto que ela fornece alto desempenho nas comunicações entre os processos paralelos, não apenas por executar sobre um switch de alto desempenho, mas também por executar juntamente com o ambiente operacional paralelo do SP2.

Nota-se porem, que os resultados obtidos com a plataforma IBM PVMe são mais eficientes em relação ao MPICH e PVM a partir de 36.000 elementos, ao invés de 90.000 como foi obtido nos algoritmos anteriores. Os motivos que contribuíram a esses resultados, é que neste algoritmo tanto o número de comunicações como a quantidade de processamento é bem maior do que nos algoritmos anteriores. Em virtude do IBM PVMe possuir mecanismos que permitam uma utilização mais eficiente dos recursos de memória e por executar em um ambiente composto por um switch de alto desempenho, as comunicações e o processamento são executadas de maneira mais rápida do que no sistema distribuído. 


\begin{tabular}{|c|c|c|c|c|c|c|c|c|}
\hline Plataformas & $\mathbf{9 . 0 0 0}$ & $\mathbf{1 8 . 0 0 0}$ & $\mathbf{3 6 . 0 0 0}$ & $\mathbf{5 4 . 0 0 0}$ & $\mathbf{9 0 . 0 0 0}$ & $\mathbf{1 8 0 . 0 0 0}$ & $\mathbf{3 6 0 . 0 0 0}$ & $\mathbf{5 4 0 . 0 0 0}$ \\
\hline MPI IBM & 0,0261 & 0,0491 & 0,0981 & 0,1444 & 0,2422 & 0,4795 & 0,9740 & 1,4854 \\
\hline IBM PVMe & 0,2957 & 0,3156 & 0,3501 & 0,4012 & 0,4872 & 0,6852 & 1,1588 & 1,5739 \\
\hline MPICH & 0,1338 & 0,2494 & 0,4986 & 0,7223 & 1,2819 & 2,9741 & 5,6731 & 8,3033 \\
\hline PVM & 0,1450 & 0,2586 & 0,5101 & 0,7342 & 1,2835 & 2,6317 & 5,2056 & 7,2192 \\
\hline
\end{tabular}

Tabela 7.12 - Tempos das execuções do algoritmo merge paralelo

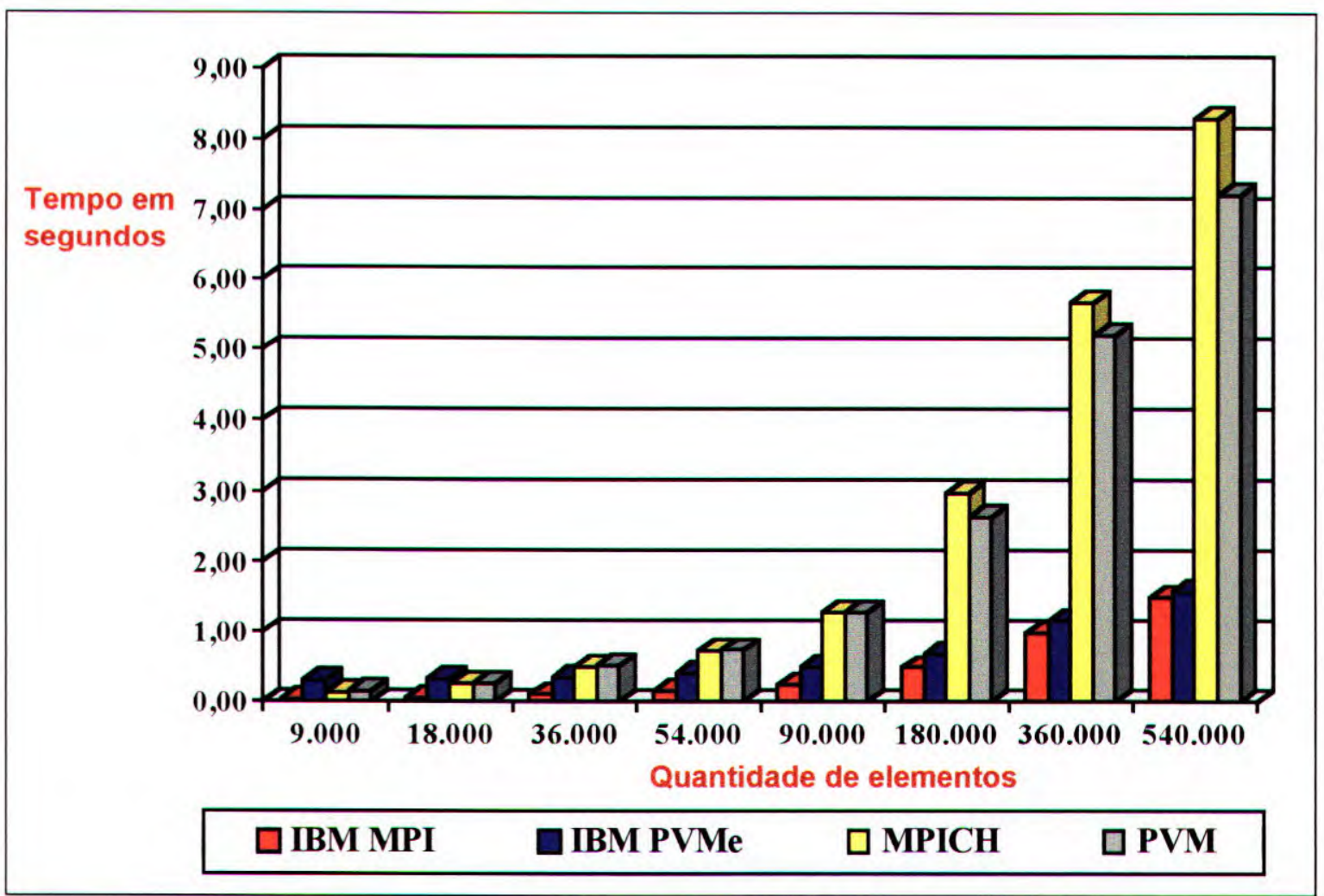

Gráfico 7.10 - Tempos das execuções do algoritmo merge paralelo

Quanto ao sistema distribuído, a plataforma PVM apresenta melhor desempenho que o MPICH para quantidades de elementos superiores a 90.000 elementos. Isso ocorre pois neste algoritmo são transmitidas mensagens contendo 1/3 (envolvidos com a distribuição dos elementos aos escravos e com o envio dos mesmos ao mestre) e 1/9 do vetor (durante a troca de elementos entre os processos), ou seja, na quantidade de 180.000 elementos são transferidas mensagens de 240 Kbytes (60.000 elementos) e 80 Kbytes (20.000 elementos), que foram considerados mais eficientes com a utilização do PVM (seção 7.4). 
Os resultados obtidos com o algoritmo seqüencial são apresentados na tabela 7.13 e gráfico 7.11.

\begin{tabular}{|c|c|c|c|c|c|c|c|c|}
\hline Plataformas & $\mathbf{9 . 0 0 0}$ & $\mathbf{1 8 . 0 0 0}$ & $\mathbf{3 6 . 0 0 0}$ & $\mathbf{5 4 . 0 0 0}$ & $\mathbf{9 0 . 0 0 0}$ & $\mathbf{1 8 0 . 0 0 0}$ & $\mathbf{3 6 0 . 0 0 0}$ & $\mathbf{5 4 0 . 0 0 0}$ \\
\hline IBM MPI & 0,0261 & 0,0491 & 0,0981 & 0,1444 & 0,2422 & 0,4795 & 0,9740 & 1,4854 \\
\hline IBM PVMe & 0,2957 & 0,3156 & 0,3501 & 0,4012 & 0,4872 & 0,6852 & 1,1588 & 1,5739 \\
\hline Serial - SP2 & 0,0337 & 0,0709 & 0,1516 & 0,2504 & 0,4216 & 0,8816 & 1,7856 & 2,7632 \\
\hline MPICH & 0,1338 & 0,2494 & 0,4986 & 0,7223 & 1,2819 & 2,9741 & 5,6731 & 8,3033 \\
\hline PVM & 0,1450 & 0,2586 & 0,5101 & 0,7342 & 1,2835 & 2,6317 & 5,2056 & 7,2192 \\
\hline Serial - S.D. & 0,0799 & 0,1765 & 0,3709 & 0,5659 & 0,9833 & 1,8715 & 3,4128 & 5,7255 \\
\hline
\end{tabular}

Tabela 7.13 - Tempos das execuções do algoritmo merge serial e paralelo

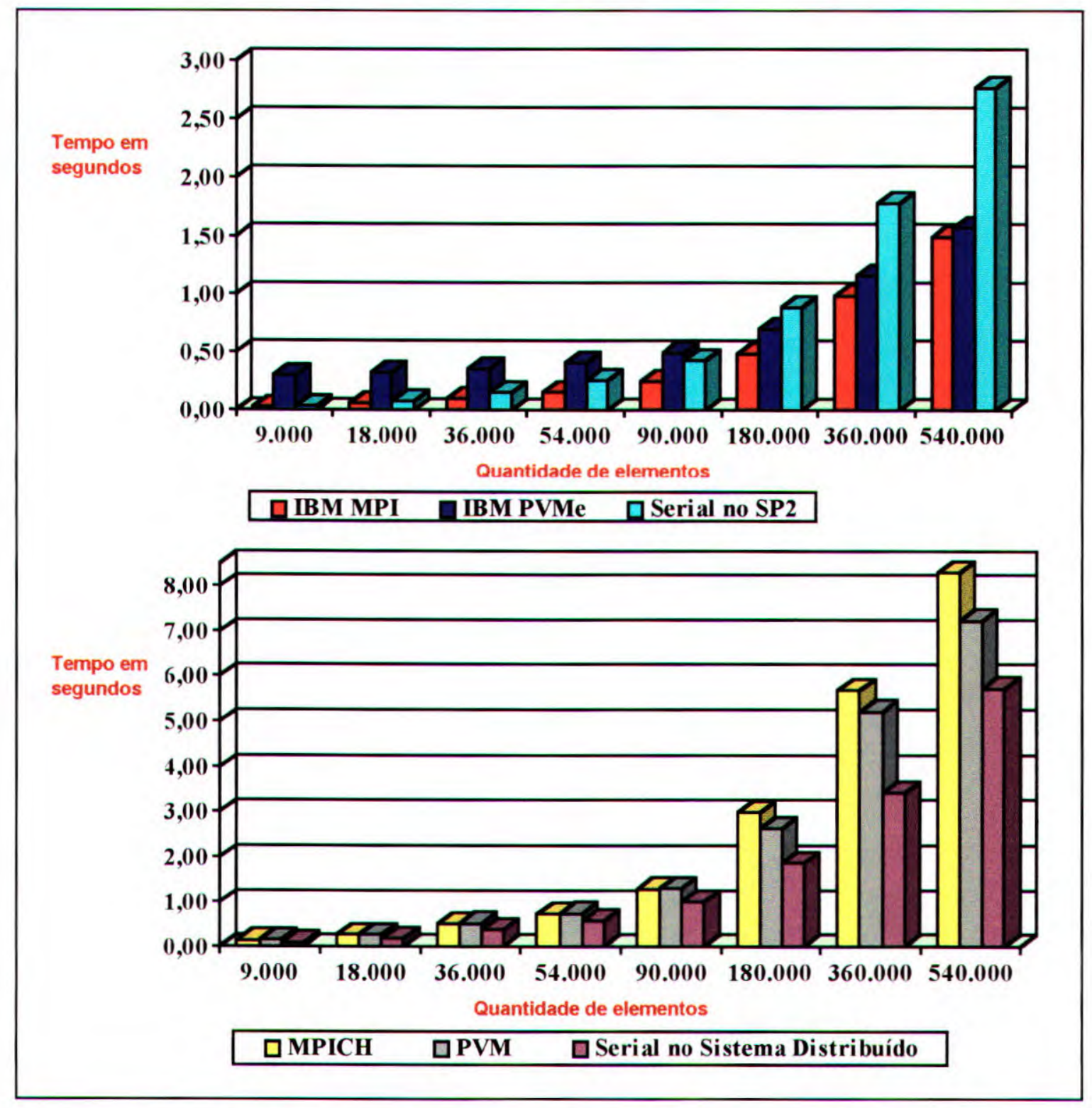

Gráfico 7.11 - Tempos das execuções do algoritmo merge serial e paralelo 
A execução do algoritmo paralelo na máquina paralela SP2, quando utilizando a plataforma IBM MPI apresenta melhores resultados do que sua implementação seqüencial para todas as quantidades de elementos analisadas. Entretanto, este algoritmo paralelo utilizando a plataforma IBM PVMe, diferente dos outros algoritmos apresentados, é mais eficiente que o serial a partir de 180.000 elementos (ao invés de 360.000 elementos).

Pode-se observar que o IBM PVMe se comporta melhor quando a aplicação requer muitas comunicações e maior quantidade de processamento, visto que os algoritmos anteriores envolvem pouquíssima comunicação entre os processos e não atingiram tais resultados.

No sistema distribuído, os resultados foram semelhantes aos anteriores, visto que 0 algoritmo paralelo utilizando as plataformas de portabilidade PVM e MPICH apresenta pior desempenho que o seqüencial. É importante lembrar que em uma rede Ethernet de 10 Mbits a comunicação entre os processos paralelos não é realizada com a mesma eficácia de um switch, sendo que a sobrecarga gerada pelas operações de comunicações afetam diretamente o desempenho do algoritmo paralelo.

A partir desses resultados, a tabela 7.14 e o gráfico 7.12 apresentam os speedups obtidos nas execuções do algoritmo paralelo nos dois tipos de arquiteturas. No SP2, a implementação IBM MPI apresenta bons speedups para todas as quantidades de dados (alcançando melhores resultados para quantidades de 180.000 e 540.000). Com a utilização do IBM PVMe obtêm-se speedups quando o algoritmo paralelo executa sobre quantidades superiores a 90.000 elementos (no gráfico 7.12, a partir de 180.000 elementos), apresentando melhores resultados a medida que aumenta-se o tamanho do vetor a ser ordenado.

Porem, com o uso das plataformas MPICH e PVM os resultados não são muito satisfatórios, não apresentando speedup em qualquer quantidade de dados executada, em virtude do algoritmo paralelo ser menos eficiente que sua versão seqüencial. 


\begin{tabular}{|c|c|c|c|c|c|c|c|c|}
\hline Plataformas & $\mathbf{9 . 0 0 0}$ & $\mathbf{1 8 . 0 0 0}$ & $\mathbf{3 6 . 0 0 0}$ & $\mathbf{5 4 . 0 0 0}$ & $\mathbf{9 0 . 0 0 0}$ & $\mathbf{1 8 0 . 0 0 0}$ & $\mathbf{3 6 0 . 0 0 0}$ & $\mathbf{5 4 0 . 0 0 0}$ \\
\hline IBM MPI & 1,29 & 1,44 & 1,55 & 1,73 & 1,74 & 1,84 & 1,83 & 1,86 \\
\hline IBM PVMe & 0,11 & 0,22 & 0,43 & 0,62 & 0,87 & 1,29 & 1,54 & 1,76 \\
\hline MPICH & 0,60 & 0,71 & 0,74 & 0,78 & 0,77 & 0,63 & 0,60 & 0,69 \\
\hline PVM & 0,55 & 0,68 & 0,73 & 0,77 & 0,77 & 0,71 & 0,66 & 0,79 \\
\hline
\end{tabular}

Tabela 7.14 - Speedup das execuções do algoritmo merge paralelo

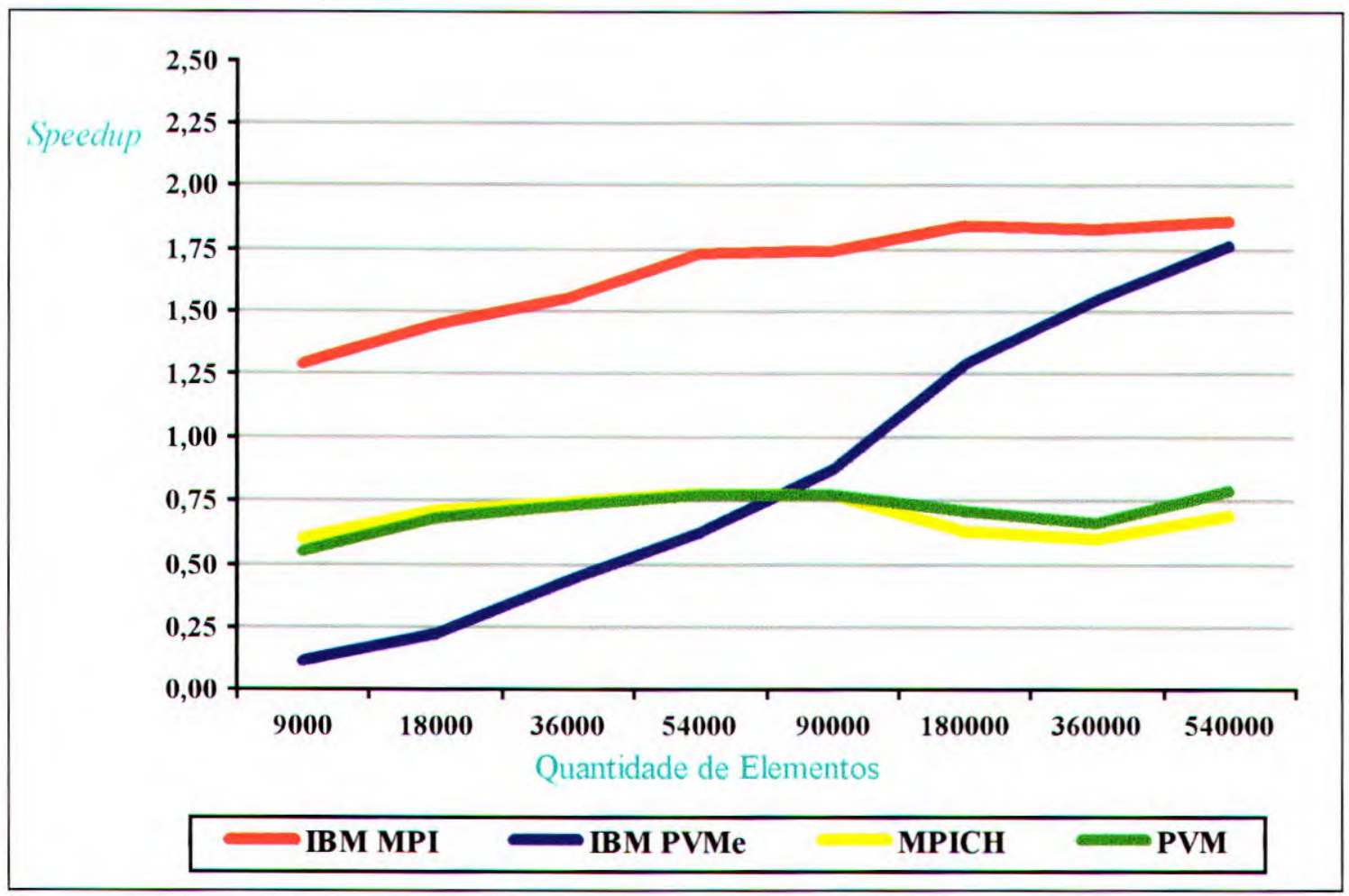

Gráfico 7.12 - Speedup das execuções do algoritmo merge paralelo

\subsubsection{Odd-even Merging}

O algoritmo odd-even merging (cuja implementação encontra-se descrita no capítulo 6) caracteriza-se em distribuir igualmente os elementos entre os processadores (assim como o quicksort paralelo 1 e merge paralelo) e por efetuar maior quantidade de comunicações (um total de 10 chamadas send/receive, onde são transmitidos 1/3 do vetor). São utilizados dois métodos de ordenação seqüencial, sendo eles o quicksort 
(realizado por todos os processos) e o merge sort (executado 1 vez pelo mestre e duas pelo escravol).

Como exposto na seção 7.2, para a execução deste algoritmo houve a necessidade de se realizar uma nova configuração da máquina paralela virtual (da plataforma PVM), de modo que o processo escravol executasse na máquina mais veloz (lasd07), por ser o processo que possui uma maior sobrecarga de processamento. Desta forma utilizou-se a seguinte configuração:

- mestre - lasd08 (Pentium $160 \mathrm{MHz}$ )

- escravo 1 - lasd07 (Pentium $200 \mathrm{MHz}$ )

- escravo 2 - lasd06 (Pentium $100 \mathrm{MHz}$ )

Os resultados das execuções desse algoritmo são apresentados na tabela $7.15 \mathrm{e}$ gráfico 7.13. Semelhante aos resultados anteriores, o algoritmo paralelo é mais eficiente com a utilização do IBM MPI. É importante ressaltar que para todos os algoritmos apresentados (que realizam comunicação ponto-a-ponto ), o IBM MPI é o que mais se destaca.

Como o número de comunicações envolvidas durante a execução do algoritmo é maior do que nos três primeiros algoritmos apresentados (semelhante ao algoritmo merge paralelo), a plataforma IBM PVMe apresenta melhores tempos de execuções em relação as plataformas de portabilidade MPICH e PVM, para a maioria das quantidades de dados analisadas. Como comentado na análise do algoritmo anterior, o IBM PVMe mostra-se bastante eficiente para aplicações que manipulam muitas comunicações, visto que a rede de interconexão do SP2 e o protocolo de comunicação utilizado (User Space) fornecem alto desempenho nas transmissões dos dados.

No sistema distribuído, nota-se que o MPICH é mais adequado quando o algoritmo executa sobre poucos dados e efetua transmissões de mensagens pequenas e médias. $O$ PVM porem, apresenta mais desempenho e eficiência para tamanhos maiores de dados. Este comportamento foi idêntico em todos os resultados já apresentados, tanto com a 
execução dos algoritmos paralelos como do estudo das comunicações ponto-a-ponto realizada através do benchmark ping-pong.

\begin{tabular}{|c|c|c|c|c|c|c|c|c|}
\hline Plataformas & $\mathbf{9 . 0 0 0}$ & $\mathbf{1 8 . 0 0 0}$ & $\mathbf{3 6 . 0 0 0}$ & $\mathbf{5 4 . 0 0 0}$ & $\mathbf{9 0 . 0 0 0}$ & $\mathbf{1 8 0 . 0 0 0}$ & $\mathbf{3 6 0 . 0 0 0}$ & $\mathbf{5 4 0 . 0 0 0}$ \\
\hline MPI IBM & 0,0342 & 0,0604 & 0,1178 & 0,1771 & 0,2864 & 0,5595 & 1,1410 & 1,7007 \\
\hline IBM PVMe & 0,3064 & 0,3261 & 0,3676 & 0,4245 & 0,5051 & 0,7304 & 1,2224 & 1,7297 \\
\hline MPICH & 0,1842 & 0,3645 & 0,6963 & 1,0371 & 1,9278 & 3,8747 & 7,0867 & 9,9980 \\
\hline PVM & 0,1938 & 0,3723 & 0,7248 & 1,1123 & 1,8917 & 3,6927 & 6,2061 & 8,5884 \\
\hline
\end{tabular}

Tabela 7.15 - Tempos das execuções do algoritmo odd-even merging

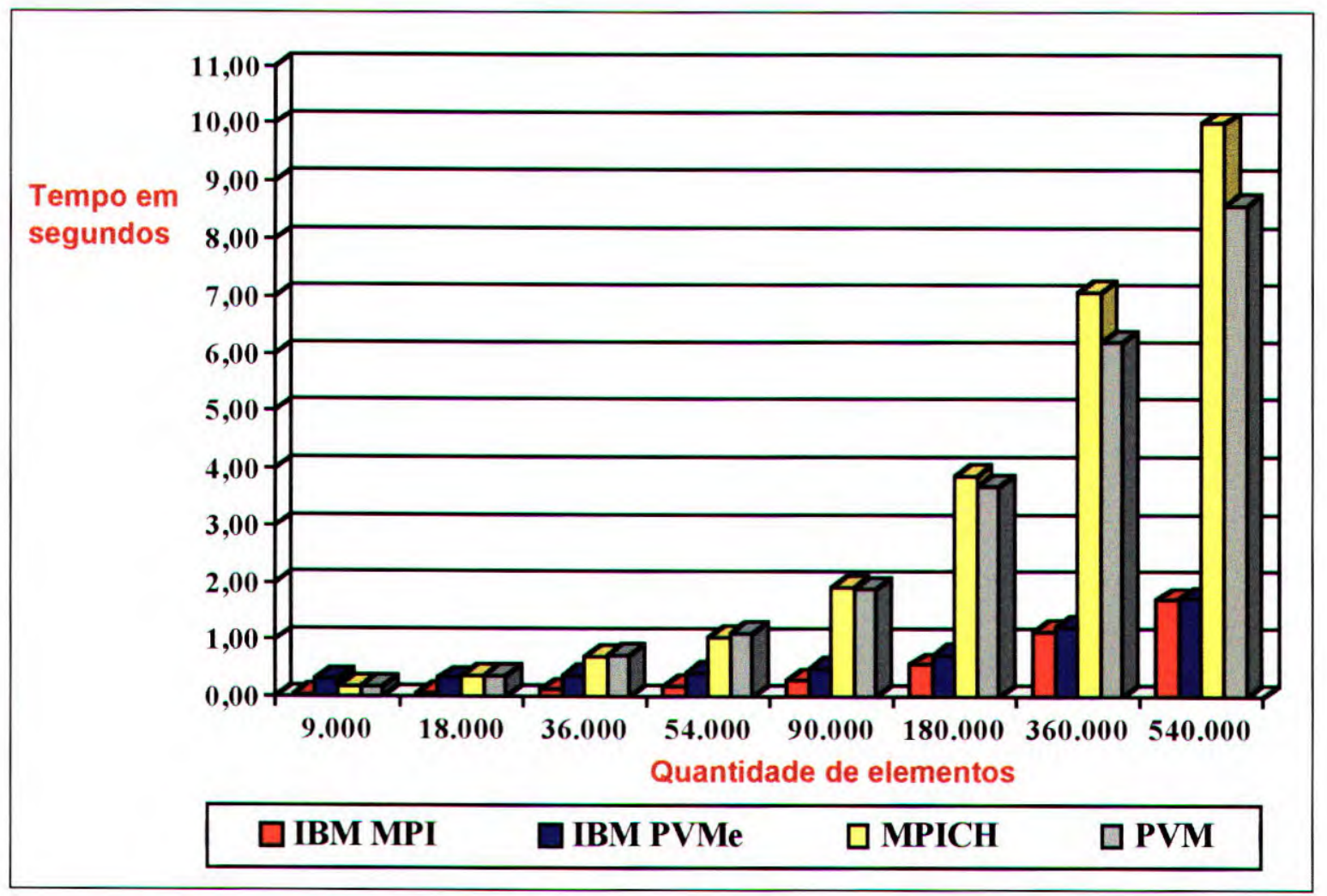

Gráfico 7.13 - Tempos das execuções do algoritmo odd-even merging

Quanto à análise comparativa entre o algoritmo paralelo e serial, apresentados na tabela 7.16 e gráfico 7.14 , os resultados mostram que com a utilização da plataforma IBM MPI, os tempos das execuções do algoritmo paralelo são menores que os tempos obtidos com o algoritmo seqüencial. Assim como a plataforma IBM MPI se destaca em relação às outras plataformas utilizadas, quando comparada aos algoritmos paralelos implementados, ela também possibilita que as aplicações paralelas sejam mais eficientes do que as versões seqüenciais correspondentes. 


\begin{tabular}{|c|c|c|c|c|c|c|c|c|}
\hline Plataformas & $\mathbf{9 . 0 0 0}$ & $\mathbf{1 8 . 0 0 0}$ & $\mathbf{3 6 . 0 0 0}$ & $\mathbf{5 4 . 0 0 0}$ & $\mathbf{9 0 . 0 0 0}$ & $\mathbf{1 8 0 . 0 0 0}$ & $\mathbf{3 6 0 . 0 0 0}$ & $\mathbf{5 4 0 . 0 0 0}$ \\
\hline IBM MPI & 0,0342 & 0,0604 & 0,1178 & 0,1771 & 0,2864 & 0,5595 & 1,1410 & 1,7007 \\
\hline IBM PVMe & 0,3064 & 0,3261 & 0,3676 & 0,4245 & 0,5051 & 0,7304 & 1,2224 & 1,7297 \\
\hline Serial - SP2 & 0,0352 & 0,0724 & 0,1634 & 0,2638 & 0,4381 & 0,8987 & 1,8225 & 2,8031 \\
\hline MPICH & 0,1842 & 0,3645 & 0,6963 & 1,0371 & 1,9278 & 3,8747 & 7,0867 & 9,9980 \\
\hline PVM & 0,1938 & 0,3723 & 0,7248 & 1,1123 & 1,8917 & 3,6927 & 6,2061 & 8,5884 \\
\hline Serial - S.D. & 0,0891 & 0,1858 & 0,3968 & 0,5911 & 1,0073 & 1,8732 & 3,4852 & 5,6974 \\
\hline
\end{tabular}

Tabela 7.16 - Tempos das execuções do algoritmo odd-even merging serial e paralelo

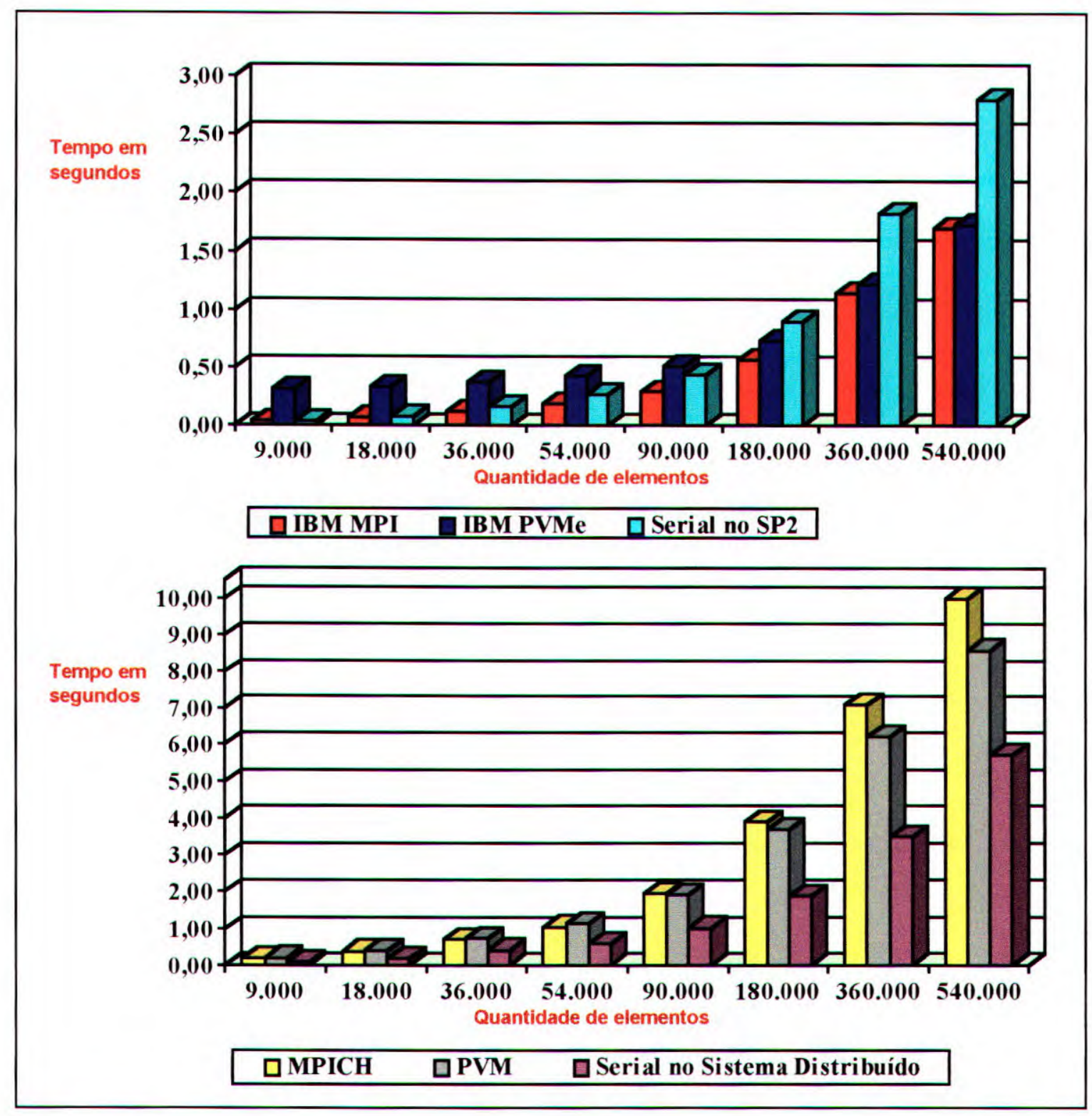

Gráfico 7.14 - Tempos das execuções do algoritmo oddeven merging serial e paralelo 
Com a utilização da plataforma IBM PVMe, o algoritmo paralelo apresenta melhor desempenho que o serial para maiores quantidades de elementos. Pode-se observar que esta plataforma é mais adequada para aplicações de larga escala (que envolvem mais processamento e maior número de comunicações), pois tanto o algoritmo merge paralelo como o algoritmo odd-even merging foram mais eficientes quando comparado às plataformas MPICH e PVM, como também em relação às versões seqüenciais.

$\mathrm{O}$ algoritmo odd-even merging executado no sistema distribuido, utilizando-se as plataformas PVM e MPICH, apresenta maiores tempos de execuções do que o algoritmo seqüencial, como aconteceu em todos os algoritmos paralelos devido ao tempo consumido com as comunicações entre os processos.

É importante ressaltar que deve-se levar em consideração a arquitetura utilizada para cada plataforma, visto que na máquina paralela SP2 é utilizado um switch de alto desempenho, possibilitando alta eficiência nas comunicações entre os processos paralelos. Entretanto, no sistema distribuído têm-se disponível uma rede Ethernet de 10 Mbits, à qual apresenta uma diferença muito grande em relação ao switch em termos de desempenho.

A partir desses resultados, a tabela 7.17 e o gráfico 7.15 apresentam o speedup obtido com a execução do algoritmo paralelo para cada plataforma de portabilidade.

Com a execução do algoritmo paralelo na máquina paralela SP2, obtêm-se speedups tanto com a utilização da implementação IBM MPI quanto com a plataforma IBM PVMe. Percebe-se também que o mais alto speedup é atingido para a maior quantidade de dados (540.000 elementos).

Entretanto, o IBM MPI se destaca apresentando resultados mais satisfatórios (apresentando speedups para todos tamanhos de dados analisados), enquanto que o IBM PVMe, os speedups são alcançados apenas quando o algoritmo manipula maiores quantidades de elementos ( a partir de 180.000 elementos, semelhante ao algoritmo anterior). 


\begin{tabular}{|c|c|c|c|c|c|c|c|c|}
\hline Plataformas & $\mathbf{9 . 0 0 0}$ & $\mathbf{1 8 . 0 0 0}$ & $\mathbf{3 6 . 0 0 0}$ & $\mathbf{5 4 . 0 0 0}$ & $\mathbf{9 0 . 0 0 0}$ & $\mathbf{1 8 0 . 0 0 0}$ & $\mathbf{3 6 0 . 0 0 0}$ & $\mathbf{5 4 0 . 0 0 0}$ \\
\hline IBM MPI & 1,03 & 1,20 & 1,39 & 1,49 & 1,53 & 1,61 & 1,60 & 1,65 \\
\hline IBM PVMe & 0,11 & 0,22 & 0,44 & 0,62 & 0,87 & 1,23 & 1,49 & 1,62 \\
\hline MPICH & 0,48 & 0,51 & 0,57 & 0,57 & 0,52 & 0,48 & 0,49 & 0,57 \\
\hline PVM & 0,46 & 0,50 & 0,55 & 0,53 & 0,53 & 0,51 & 0,56 & 0,66 \\
\hline
\end{tabular}

Tabela 7.17 - Speedup das execuções do algoritmo odd-even merging

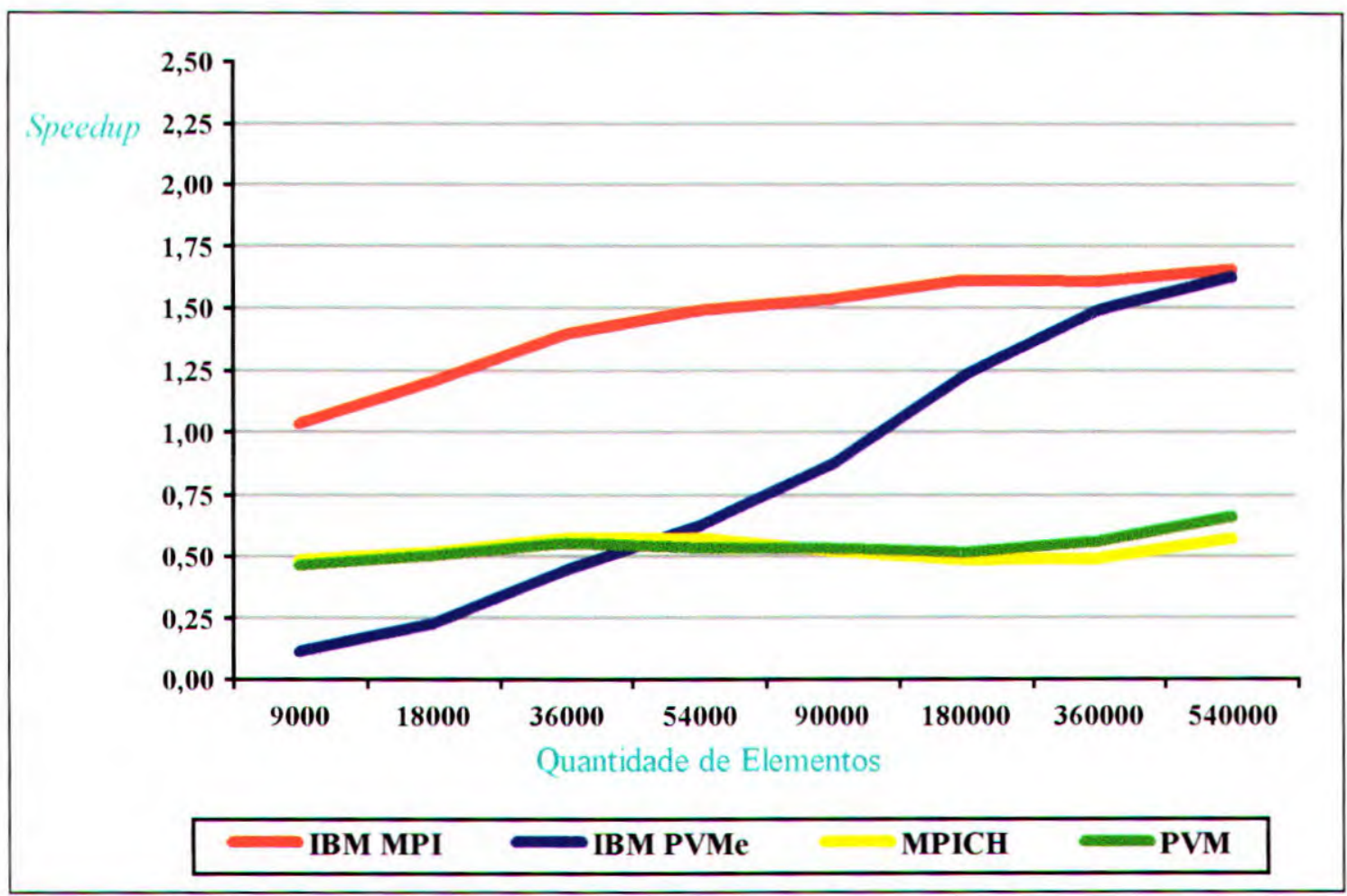

Gráfico 7.15 - Speedup das execuções do algoritmo odd-even merging

No sistema distribuído, visto que o algoritmo paralelo apresenta piores resultados que sua versão seqüencial, não é possível que se tenha ganhos em termos de speedup mesmo para grandes quantidades de elementos.

\subsubsection{Merging Distribuído}

Este algoritmo é o único que envolve comunicação coletiva entre os processos paralelos (através da rotina broadcast()). Uma característica principal desse algoritmo é 
que o número de comunicações realizadas durante a execução é muito intensa (onde em cada comunicação são transferidos um elemento, ou seja, 4 bytes). Como foi discutido no capítulo 6, o objetivo de sua implementação relaciona-se com o interesse de analisar um algoritmo que apresente uma granulą̧ão mais fina em relação aos anteriores, a fim de melhor avaliar o comportamento das plataformas de portabilidade em cada tipo de arquitetura utilizada. Os resultados das execuções (tempos em minutos) desse algoritmo são ilustrados na tabela 7.18 e no gráfico 7.16 (devido aos tempos serem relativamente altos, o gráfico ilustra apenas os resultados para as quantidades de 9.000 a 180.000 elementos).

Analisando-se os resultados, nota-se novamente que a plataforma IBM MPI apresenta melhores resultados do que o IBM PVMe (como também em relação às outras plataformas). De acordo com a análise dos tempos de comunicações coletivas (seção 7.4), o IBM MPI apresenta mais eficiência nas transmissões, possibilitando assim, alcançar melhores resultados.

Entretanto, a plataforma IBM PVMe apresenta maior desempenho quando comparada às plataformas executadas no sistema distribuído (MPICH e PVM) para todas as quantidades de dados. Isso ocorre pois o número de comunicações entre os processos paralelos é tão intensa, que os tempos das execuções deste algoritmo tornam-se menores quando executado na máquina paralela SP2. Além disso, as comunicações envolvem transmissões de mensagens pequenas ( 4 bytes, ou seja, um elemento) e como verificado no estudo das comunicą̧ões coletivas, o IBM PVMe realiza as transmissões de maneira mais rápida do que as plataformas MPICH e PVM.

\begin{tabular}{|c|c|c|c|c|c|c|c|c|}
\hline Plataformas & $\mathbf{9 . 0 0 0}$ & $\mathbf{1 8 . 0 0 0}$ & $\mathbf{3 6 . 0 0 0}$ & $\mathbf{5 4 . 0 0 0}$ & $\mathbf{9 0 . 0 0 0}$ & $\mathbf{1 8 0 . 0 0 0}$ & $\mathbf{3 6 0 . 0 0 0}$ & $\mathbf{5 4 0 . 0 0 0}$ \\
\hline MPI IBM & 0,1338 & 0,2666 & 0,5166 & 0,7413 & 1,2153 & 2,4573 & 4,7544 & 7,2262 \\
\hline BBM PVMe & 0,1709 & 0,3216 & 0,6113 & 0,8981 & 1,4655 & 2,8689 & 5,64482 & 8,4258 \\
\hline MPICH & 0,6303 & 1,2629 & 2,348 & 3,4779 & 5,7759 & 11,2162 & 22,112 & 40,3903 \\
\hline PVM & 0,9498 & 1,8671 & 3,5099 & 5,1199 & 8,1195 & 15,9394 & 31,2653 & 47,3030 \\
\hline
\end{tabular}

Tabela 7.18 - Tempos das execuções do algoritmo merging distribuido 


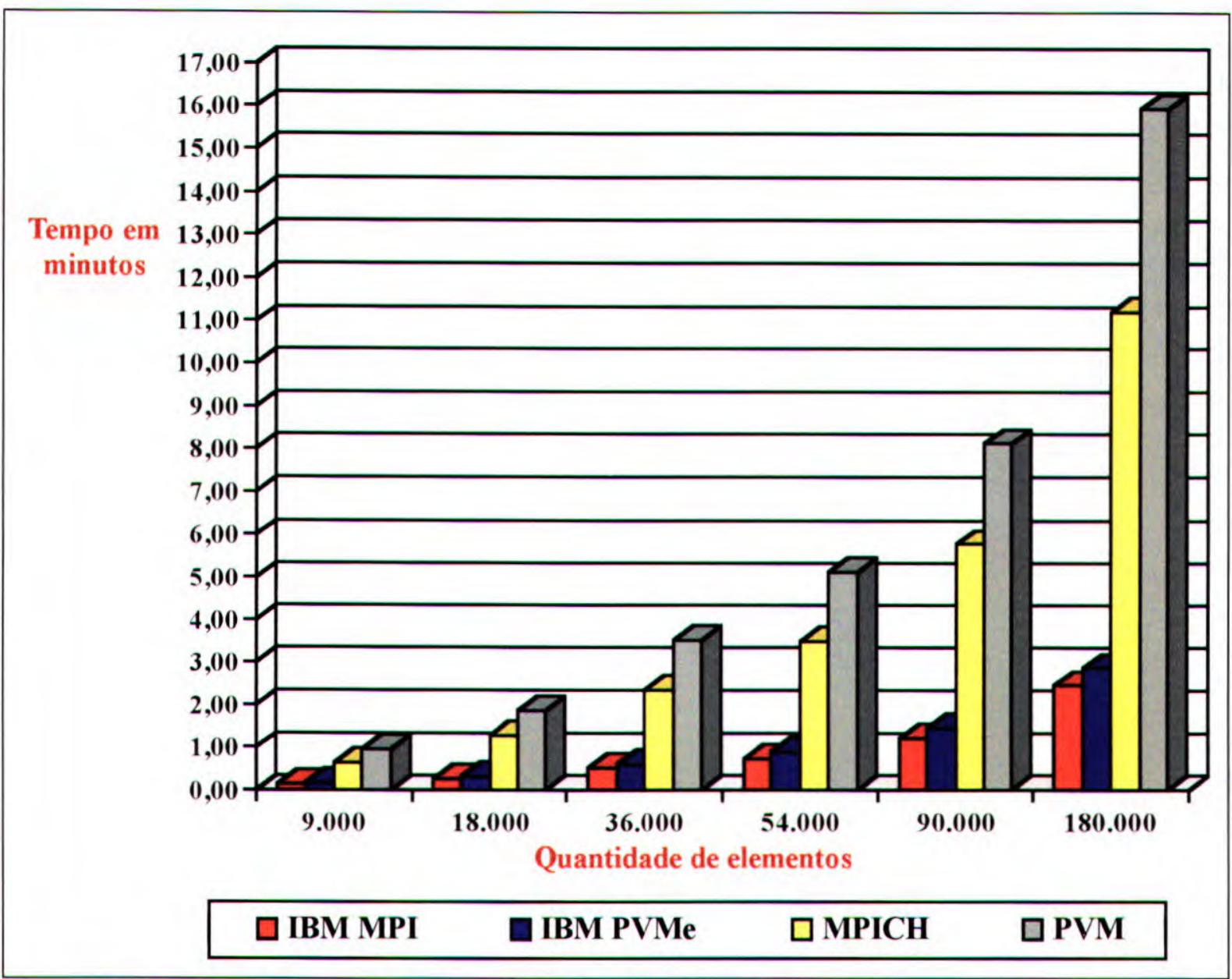

Gráfico 7.16 - Tempos das execuções do algoritmo merging distribuído

Quanto ao sistema distribuído, o MPICH da mesma forma que analisado na seção 7.4, apresenta tempos inferiores para a transmissão de mensagens pequenas. Desta forma, este algoritmo paralelo utilizando-se a implementação MPICH apresenta melhores resultados quando comparado ao PVM. Porem, pode-se observar que os tempos de execuções são bastante altos, visto que são necessárias muitas transmissões de dados durante o processo de ordenação.

Os tempos das execuções do algoritmo seqüencial correspondente encontram-se descritos na tabela 7.19 e gráfico 7.17. Os resultados mostram, que o algoritmo paralelo executado na máquina paralela SP2 apresenta tempos superiores, tanto com a utilização da plataforma IBM MPI como do IBM PVMe. Apesar do SP2 disponibilizar de um switch de alto desempenho, não foi suficiente para que este algoritmo alcançasse melhores resultados que sua versão serial, em virtude do excesso de comunicações realizadas. 


\begin{tabular}{|c|c|c|c|c|c|c|c|c|}
\hline Plataformas & $\mathbf{9 . 0 0 0}$ & $\mathbf{1 8 . 0 0 0}$ & $\mathbf{3 6 . 0 0 0}$ & $\mathbf{5 4 . 0 0 0}$ & $\mathbf{9 0 . 0 0 0}$ & $\mathbf{1 8 0 . 0 0 0}$ & $\mathbf{3 6 0 . 0 0 0}$ & $\mathbf{5 4 0 . 0 0 0}$ \\
\hline IBM MPI & 0,1338 & 0,2666 & 0,5166 & 0,7413 & 1,2153 & 2,4573 & 4,7544 & 7,2262 \\
\hline IBM PVMe & 0,1709 & 0,3216 & 0,6113 & 0,8981 & 1,4655 & 2,8689 & 5,64482 & 8,4258 \\
\hline Serial - SP2 & 0,0008 & 0,0016 & 0,0037 & 0,0065 & 0,0079 & 0,0133 & 0,0411 & 0,0558 \\
\hline MPICH & 0,6303 & 1,2629 & 2,348 & 3,4779 & 5,7759 & 11,2162 & 22,112 & 40,3903 \\
\hline PVM & 0,9498 & 1,8671 & 3,5099 & 5,1199 & 8,1195 & 15,9394 & 31,2653 & 47,3030 \\
\hline Serial - S.D. & 0,0010 & 0,0023 & 0,0050 & 0,0072 & 0,0137 & 0,0289 & 0,0528 & 0,0867 \\
\hline
\end{tabular}

Tabela 7.19 - Tempos das execuções do merging distribuído serial e paralelo

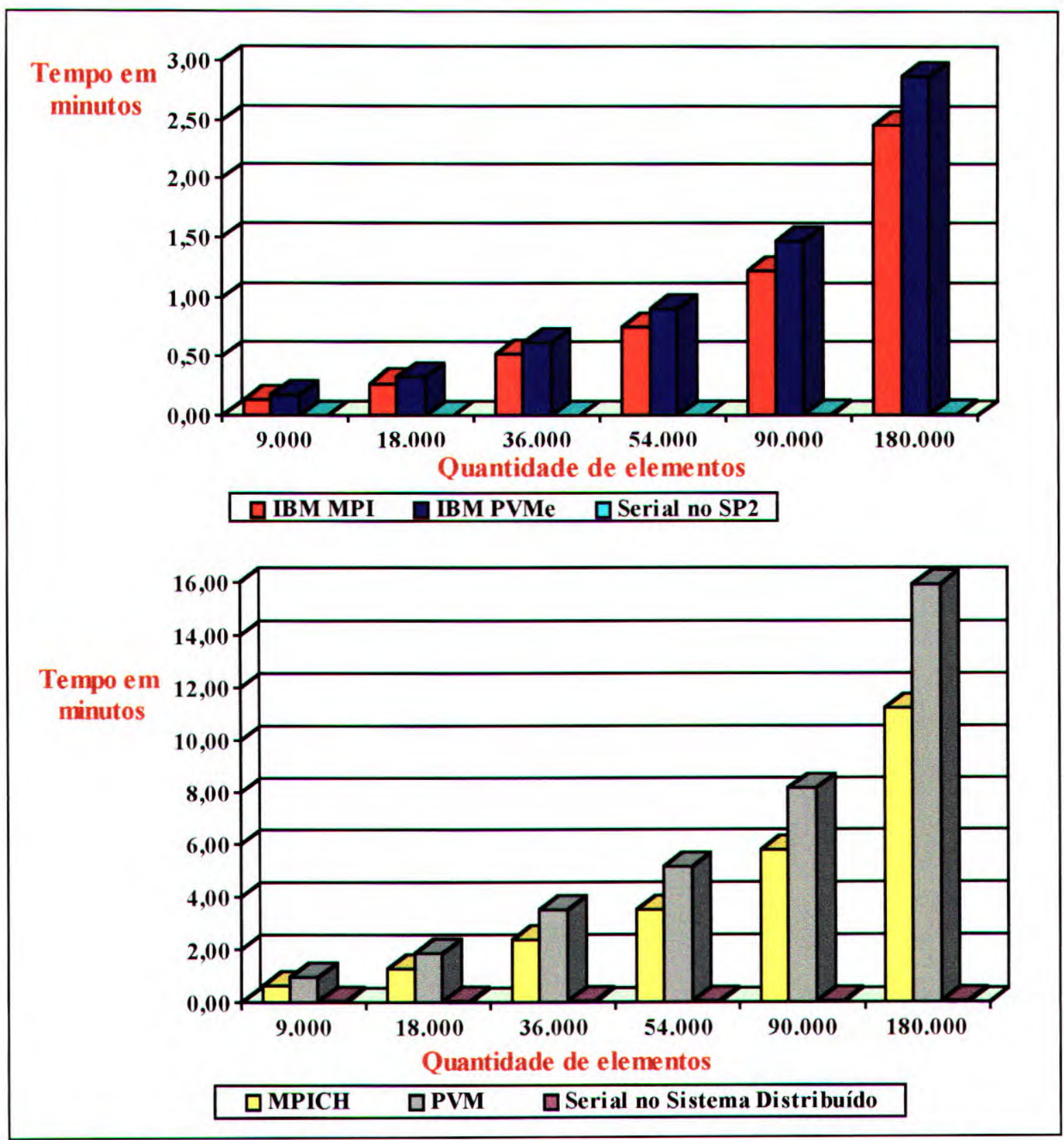

Gráfico 7.17 - Tempos das execuções do merging distribuido serial e paralelo 
Essa mesma situação é obtida com a execução do algoritmo no sistema distribuído, apresentando resultados extremamente inferiores quando comparado às execuções seqüenciais, pois como citado no parágrafo anterior este algoritmo apresenta piores resultados devido a grande quantidade de comunicações envolvidas durante sua execução.

A quantidade de comunicação é um aspecto importante na construção de um algoritmo eficiente, visto que operações de comunicação geram uma sobrecarga que pode degradar o desempenho, tornando o algoritmo menos eficiente que o seqüencial. Além disso, a arquitetura na qual se executará o algoritmo, também deve ser considerada, visto que a sua eficiência pode variar de acordo com o tipo de arquitetura.

Visto a baixa eficiência deste algoritmo paralelo, pode-se afirmar que os tipos de arquiteturas utilizados neste trabalho não são adequadas à sua execução, não obtendo-se speedups tanto quando executado na máquina paralela SP2 como no sistema distribuído (como apresentado na tabela 7.20 e no gráfico 7.18 ).

É importante ressaltar que este algoritmo foi implementado com o principal objetivo de verificar seu comportamento nos ambientes computacionais utilizados, de modo a possibilitar uma melhor avaliação de desempenho entre diferentes tipos de algoritmos paralelos de ordenação (com diferentes granulações - de poucas a muitas comunicações).

\begin{tabular}{|c|c|c|c|c|c|c|c|c|}
\hline Plataformas & $\mathbf{9 . 0 0 0}$ & $\mathbf{1 8 . 0 0 0}$ & $\mathbf{3 6 . 0 0 0}$ & $\mathbf{5 4 . 0 0 0}$ & $\mathbf{9 0 . 0 0 0}$ & $\mathbf{1 8 0 . 0 0 0}$ & $\mathbf{3 6 0 . 0 0 0}$ & $\mathbf{5 4 0 . 0 0 0}$ \\
\hline IBM MPI & 0,0058 & 0,0060 & 0,0071 & 0,0088 & 0,0065 & 0,0054 & 0,0086 & 0,0077 \\
\hline BBM PVMe & 0,0045 & 0,0050 & 0,0060 & 0,0073 & 0,0054 & 0,0046 & 0,0073 & 0,0066 \\
\hline MPICH & 0,0017 & 0,0019 & 0,0021 & 0,0021 & 0,0021 & 0,0026 & 0,0024 & 0,0021 \\
\hline PVM & 0,0012 & 0,0013 & 0,0014 & 0,0014 & 0,0015 & 0,0018 & 0,0017 & 0,0018 \\
\hline
\end{tabular}

Tabela 7.20 - Speedup das execuções do algoritmo merging distribuído 


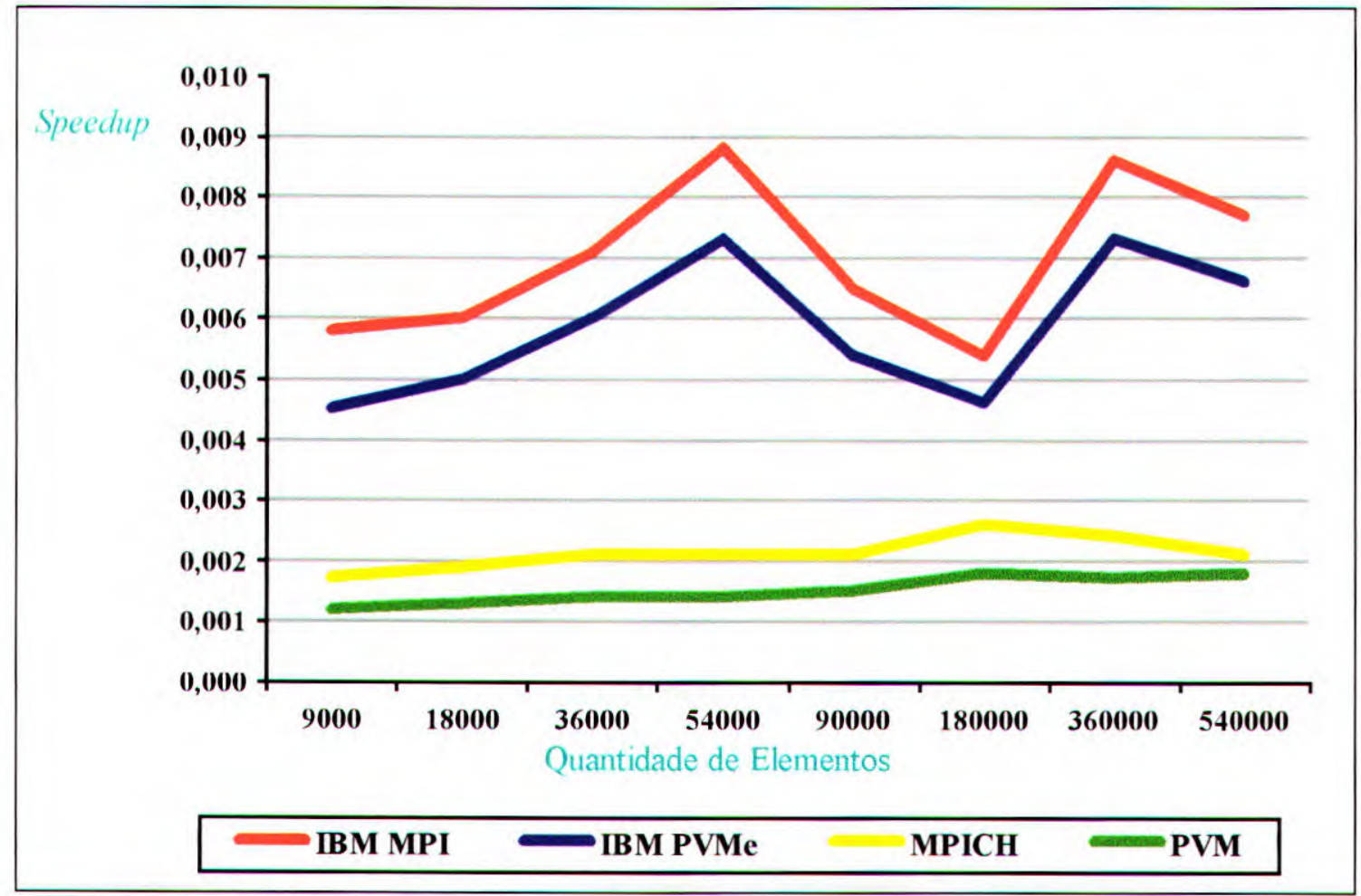

Gráfico 7.18 - Speedup das execuções do algoritmo merging distribuído

\subsection{Considerações Finais}

Neste capítulo, foram apresentados os resultados da análise de desempenho dos algoritmos paralelos de ordenação utilizando as plataformas de portabilidade. Com esses resultados, é importante apresentar uma análise geral e resumida de algumas conclusões obtidas neste trabalho.

Algoritmos Paralelos de Ordenacão: Relacionando-se todos os algoritmos paralelos apresentados no capítulo 6 , e discutindo-se suas características relacionadas à eficiência obtida de sua utilização, tem-se:

- QuickSort Paralelo 1: caracteriza-se em distribuir os elementos aos processadores de maneira balanceada, envolver poucas comunicações entre os processos e utilizar dois métodos de ordenação seqüencial, o quicksort (executado uma vez pelos 3 processos) e o merge sort (executado uma vez pelo mestre). Este algoritmo mostrou-se mais eficiente 
quando executado na máquina paralela SP2, apresentando speedups para todas as quantidades de dados analisadas. No sistema distribuído, os resultados obtidos não foram muito satisfatórios, de modo que não houve praticamente speedups com a execução deste algoritmo paralelo.

- QuickSort Paralelo 2: diferente do algoritmo quicksort paralelo 1, a distribuição dos elementos é realizada de forma não balanceada e é utilizado apenas o método quicksort (executado uma única vez por todos os processos), entretanto, também executa poucas operações de comunicação. Em virtude da distribuição desbalanceada e por executar somente um método de ordenação seqüencial, este algoritmo tornou-se mais eficiente no sistema distribuído do que o algoritmo anterior, porem não foi possivel obter speedups, visto que a velocidade da rede não foi suficiente para suprir a sobrecarga gerada pelas transmissões de dados. Ao contrário, quando executado no SP2 apresentou piores resultados em relação ao quicksort paralelo 1 , devido aos elementos não serem igualmente distribuídos, embora, foi a arquitetura que melhor desempenho ofereceu, obtendo-se speedups para todas as quantidades de dados.

- QuickSort Paralelo 2.1: tem como característica a distribuição mais balanceada (aproximadamente a mesma quantidade) dos elementos, poucas comunicações entre os processos paralelos e a utilização de um método de ordenação, o quicksort (executado uma vez pelos três processos). Este algoritmo apresentou maior eficiência que os anteriores quando executado na máquina paralela SP2, apresentando melhores speedups, em virtude da distribuição dos elementos ser relativamente mais balanceada e da utilização de apenas um modelo de ordenação. Porem, no sistema distribuído não obteve-se o mesmo comportamento, de modo que o algoritmo serial apresentou melhores resultados, tornando o algoritmo paralelo menos eficiente.

- Merge Paralelo: da mesma forma que o algoritmo quicksort paralelo 1, realiza uma distribuição balanceada dos elementos aos processadores. Neste algoritmo, é utilizado apenas um modelo de ordenação seqüencial, o merge sort (sendo executado 7 vezes, 3 pelo mestre e 2 vezes cada processo escravo). Diferente dos algoritmos anteriores, neste 
algoritmo é envolvido um maior número de comunicações entre os processos paralelos (10 chamadas send()/receive(), ao invés de 4 como é realizada pelos outros algoritmos apresentados acima). Na máquina paralela SP2, este algoritmo apresentou desempenhos superiores quando comparado ao sistema distribuído, visto a necessidade de se realizar uma maior quantidade de comunicações e de processamento.

- Odd-even Merging: assim como o algoritmo merge paralelo, caracteriza-se pela distribuição balanceada e por envolver maior quantidade de comunicações durante sua execução. Porem, são utilizados dois métodos de ordenação, o quicksort (executado uma vez por todos os processos) e o merge sort (executado uma vez pelo mestre e 2 vezes pelo processo escravo 1). Este algoritmo também tomou-se mais eficiente (obtendo-se bons speedups) para a máquina paralela SP2, pois como exposto acima, as sobrecargas geradas pelas comunicações degradaram o desempenho do algoritmo quando executado no sistema distribuído.

- Merging Distribuído: utiliza-se do modelo de ordenação merge sort (executado uma vez pelos processos escravos) e é o único algoritmo implementado que possui uma granulação mais fina, onde a taxa de transmissões de dados entre os processos é muito intensa. Em virtude da grande quantidade de comunicações, este algoritmo tornou-se totalmente inadequado às arquiteturas utilizadas, tanto quando executado no SP2 como no sistema distribuído, não obtendo-se em nenhum dos casos ganhos em termos de speedups.

Nota-se portanto, que todos os algoritmos paralelos de ordenação não apresentaram speedups quando executados no sistema distribuído, visto que a rede de interconexão disponível (Ethernet de 10 Mbits) não forneceu a velocidade de transmissão de dados necessária para a obtenção-de melhores resultados. Porem, é importante acrescentar que esses resultados serão muito úteis com a substituição da rede utilizada para uma Ethernet de 100 Mbits (esta otimização será brevemente realizada no laboratório de Sistemas Distribuídos), visto que poderão ser comparados com a execução dos mesmos algoritmos paralelos-nesta-nova rede de interconexão. 
Para melhor visualizar os comentários apresentados neste item, os gráficos 7.19 e 7.20 mostram uma comparação de desempenho dos algoritmos para cada plataforma. $\mathrm{O}$ algoritmo merging distribuido foi desconsiderado em virtude de apresentar desempenho muito baixo e dificultar a visualização dos outros resultados.

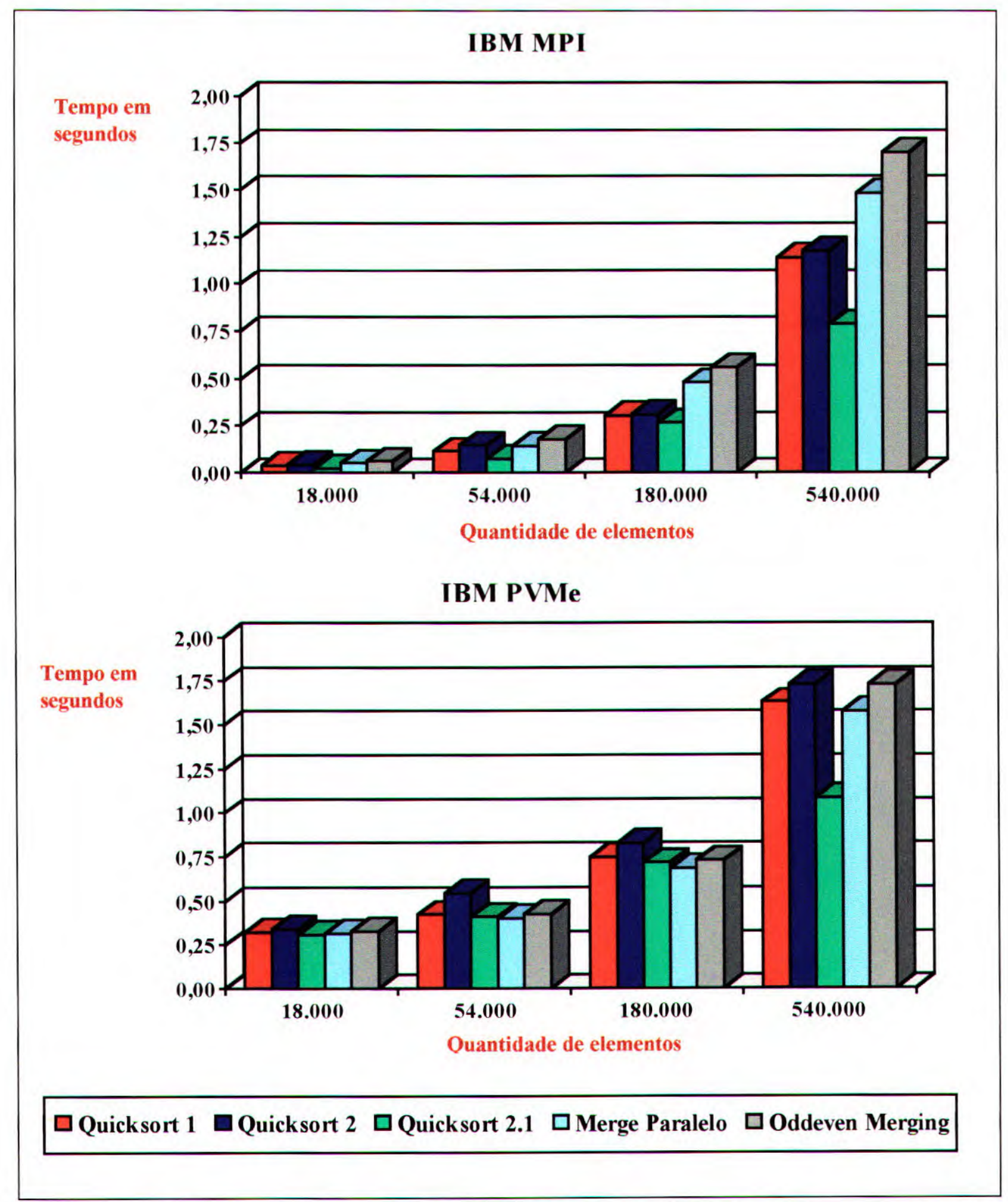

Gráfico 7.19 - Tempo das execuções dos algoritmos utilizando as plataformas do SP2 


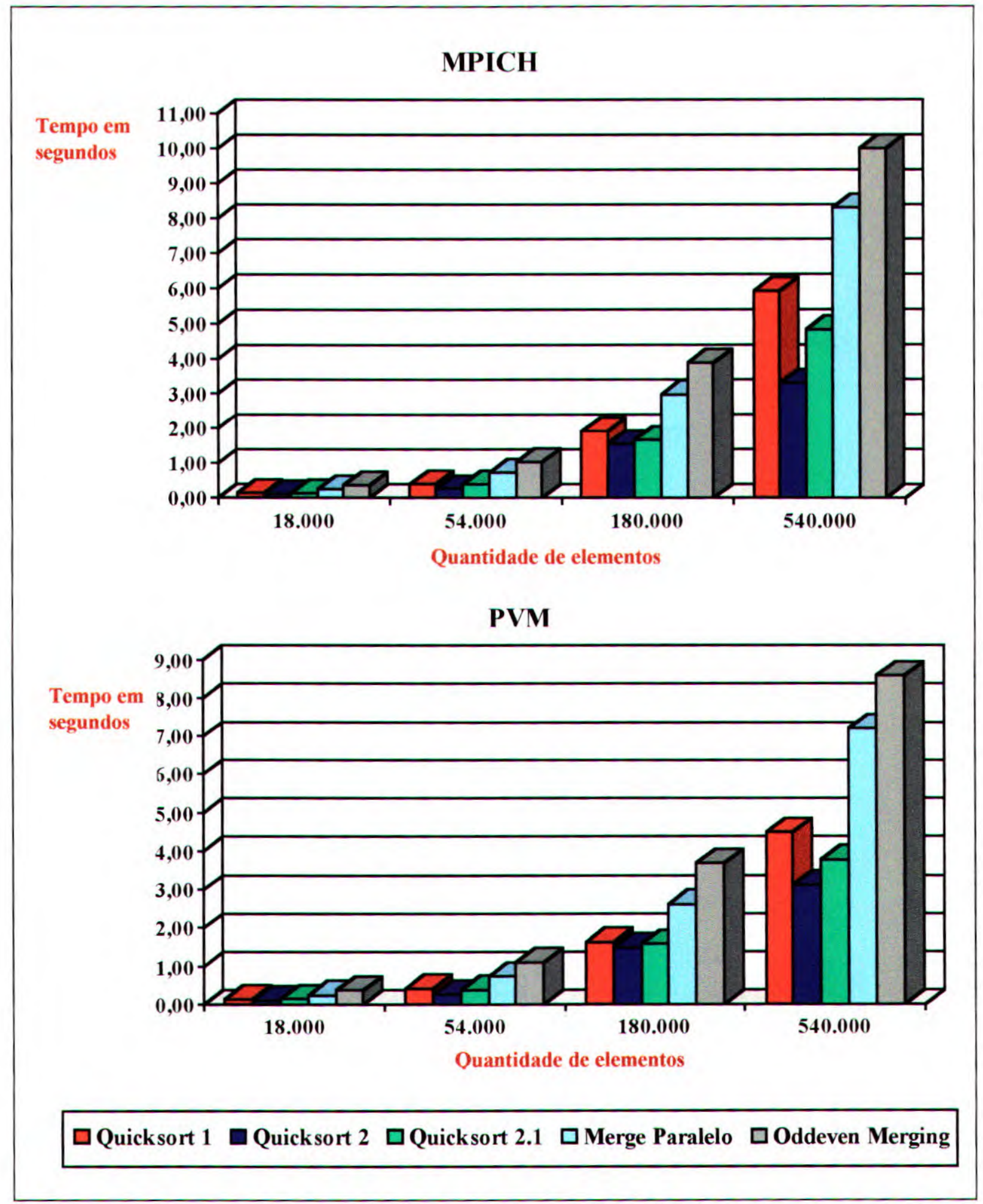

Gráfico 7.20 - Tempo das execuções dos algoritmos utilizando as plataformas do S.D.

Como pode-se observar com a utilização das plataformas executadas no sistema distribuído, o algoritmo quicksort paralelo 2 apresentou melhores resultados em relação 
aos outros algoritmos, em virtude de não distribuir a mesma quantidade de dados aos processadores, o que possibilitou um balanceamento de carga mais adequado. No entanto, no SP2 apresentou piores resultados em relação aos algoritmos quicksort paralelo 1 e 2.1 , ocasionado pela distribuição desbalanceada dos elementos aos processadores.

O algoritmo quicksort paralelo 2.I, que realiza uma distribuição mais balanceada, alcançou os melhores resultados quando executado na máquina paralela SP2. O algoritmo merge paralelo também apresentou bastante eficiência quando utilizando-se do IBM PVMe, pois como comentado na seção 7.5.4, o IBM PVMe apresenta um bom comportamento para aplicações que manipulam maior quantidade de processamento e muitas comunicações, em virtude de possuir mecanismos de otimização de memória e por executar em um ambiente que disponha de uma a rede de interconexão de alto desempenho.

\section{Plataformas de Portabilidade utilizadas na máquina paralela SP2: Com os} resultados obtidos é importante apresentar uma análise comparativa entre as plataformas de portabilidade:

- O IBM MPI, uma implementação da IBM e otimizado para o IBM SP e clusters RISC System/6000, apresentou melhor desempenho que o IBM PVMe (como também em relação as plataformas do sistema distribuído). Este alto desempenho se deve a dois motivos principais: por ser a biblioteca de passagem de mensagens nativa do SP2 e por fazer parte integrante do Ambiente Paralelo (PE - Parallel Environment) do sistema, que tem como principal função otimizar a utilização do switch de alto desempenho. Desta forma, a rapidez com que as operações de comunicações são realizadas faz com que as aplicações paralelas sejam altamente eficientes.

- O IBM PVMe, pacote proprietário da IBM e otimizado para o IBM SP, apresentou um desempenho superior em relação às plataformas executadas no sistema distribuído, para aplicações que manipulam grandes quantidades de dados e muitas comunicações (principalmente em transmissões de mensagens grandes). É importante destacar que a plataforma IBM PVMe possui um esquema de memória melhorada que permite explorar 
os recursos de memória de forma mais eficiente, principalmente em aplicações de larga escala. Entretanto, mesmo sendo uma implementação otimizada para o uso do SP2, o PVMe não alcançou os desempenhos obtidos com o IBM MPI.

Plataformas de Portabilidade utilizadas no sistema distribuído: Fazendo-se uma análise comparativa entre as plataformas de portabilidade, quando executadas sobre 0 sistema operacional LINUX, tem-se:

- O MPICH, uma das implementações da especificação MPI, ofereceu um bom desempenho para aplicações que manipulam poucas quantidades de dados e as transmissões das mensagens envolvidas entre os processos paralelos compreendam tamanhos considerado de pequeno a médio. Porém, apresentou pior desempenho que 0 PVM (com exceção do algoritmo merging distribuído que envolve transmissões de mensagens pequenas).

- O PVM, considerado por alguns autores um padrão de fato para plataformas de portabilidade, mostrou mais eficiência para aplicações que executam sobre grande quantidade de dados e para transmissões de mensagens grandes. Considerando-se que um algoritmo paralelo é desenvolvido para resolver problemas que requerem muito processamento e envolvem grande quantidade de dados de forma mais rápida do que resolvê-lo seqüencialmente, conclui-se que no sistema distribuído o PVM é o que apresenta melhor desempenho.

A partir dessas colocações, pode-se concluir que na máquina paralela SP2 o IBM MPI é implementação que apresenta maior desempenho, enquanto que no sistema distribuído, o melhor desempenho é obtido com a utilização da plataforma PVM. Desta forma, comprova-se as afirmações discutidas por alguns autores [BOD96][GEI96] (comentadas na introdução deste trabalho), que consideram o MPI mais adequado para arquiteturas paralelas e o PVM mais adaptado para sistemas distribuídos. 


\section{Capítulo 8 \\ Conclusões}

Este capítulo apresenta uma avaliação final do trabalho desenvolvido, as principais conclusões, incluindo análise da revisão bibliográfica, principais dificuldades e trabalhos futuros.

\subsection{Considerações iniciais}

Nesse trabalho foi apresentado um estudo relacionado ao desempenho das plataformas de portabilidade PVM e MPI quando executadas em tipos arquiteturais distintos, através da implementação de diferentes algoritmos paralelos de ordenação. $O$ principal objetivo foi analisar e comparar o desempenho do PVM e do MPI, implementados tanto em sistemas distribuídos como em máquinas paralelas.

Adicionalmente, foi realizada uma comparação com os algoritmos seqüenciais correspondentes, analisando desta forma a eficiência obtida através da utilização do paralelismo em cada ambiente computacional.

Neste capítulo será apresentada uma análise bibliográfica abordando os pontos mais relevantes encontrados na literatura e que foram tratados nessa dissertação (seção 8.2), as conclusões obtidas (seção 8.3), as contribuições oferecidas (seção 8.4), as principais dificuldades encontradas durante o desenvolvimento desse trabalho (seção 8.5) e algumas sugestões para trabalhos futuros (seção 8.6).

\subsection{Análise da Bibliografia}

A computação paralela tem como motivação principal o aumento de desempenho em aplicações específicas, através do uso de um conjunto de elementos de 
processamento, que cooperam e comunicam-se entre si para solucionarem grandes problemas [ALM94].

$\mathrm{Na}$ busca por esses sistemas foram criados novos elementos de hardware e de software, os quais fornecem o suporte necessário para as técnicas impostas pela computação paralela. No que diz respeito ao hardware, várias arquiteturas foram propostas sendo agrupadas nas classificações de Flynn [FLY72] e Duncan [DUN90]. Dentre as arquiteturas paralelas em geral, destacam-se as arquiteturas MIMD de memória distribuída, devido a sua flexibilidade e potencialidade para a execução de algoritmos paralelos de granulação grossa e média [BLE94].

Em relação ao software, vários métodos foram propostos para a ativação $\mathrm{e}$ coordenação de processos paralelos, e várias abordagens para o desenvolvimento de algoritmos paralelos foram definidas [QUI87]. Os métodos de ativação de processos paralelos diferenciam-se basicamente pelos itens flexibilidade e estruturação, de maneira que métodos fork/join oferece um mecanismo flexível porém desestruturado, enquanto cobegin/coend e doall apresentam maior estruturação e menor flexibilidade [QUI87] [ALM94].

Os métodos para coordenação (comunicação e sincronismo) dos vários processos paralelos, são definidos de acordo com a organização de memória da arquitetura onde se executam os processos. Nas arquiteturas com memória compartilhada, utilizam-se variáveis compartilhadas (busy-waiting, semáforos e monitores), e em arquiteturas com memória distribuída, utiliza-se troca de mensagens (comunicação ponto-a-ponto, rendezvouz e RPC) [QUI87] [NAV89] [ALM94].

Uma tendência atual dentro da computação paralela trata-se do uso de sistemas distribuídos como ambientes para execução de programas paralelos. Sistemas distribuídos apresentam uma alternativa de grande versatilidade, reaproveitamento de hardware (minimizando custo) e fácil instalação em relação às arquiteturas paralelas, possibilitando o uso do processamento paralelo para uma comunidade maior de usuários [ZAL91] [ALM94] [SUN94] [MCB94]. 
Para viabilizar essa idéia foram desenvolvidas ambientes de passagem de mensagens portáteis. Um ambiente de passagem de mensagem consiste basicamente de uma biblioteca de comunicação (atuando como uma extensão das linguagens seqüenciais), que possibilita o desenvolvimento de aplicações paralelas.

Atualmente, os ambientes de passagem de mensagens portáteis mais adotados e que mais se destacam dentro da comunidade acadêmica são: PVM [GEI94] [SUN94] e MPI [MCB94] [DON95] [SNI96].

O PVM, considerado um padrão para plataformas de portabilidade, nasceu com o objetivo de permitir que um grupo de computadores interconectados, possivelmente com diferentes arquiteturas, trabalhasse cooperativamente formando uma máquina paralela virtual [GEI94]. Segundo alguns autores [BOD96][GEI96], o PVM apresenta melhor desempenho quando implementado em sistemas distribuídos.

O MPI, uma tentativa de padronização de interface de passagem de mensagens para aplicações que utilizam computadores MIMD com memória distribuida, foi desenvolvido com o principal objetivo de garantir eficiência em qualquer plataforma paralela (arquiteturas paralelas ou sistemas distribuídos). Porem, ao contrário do PVM, o MPI é considerado mais adequado para arquiteturas paralelas do que para sistemas distribuídos [GEI96].

Através da utilização do PVM e do MPI, torna-se possivel transportar os algoritmos paralelos diretamente entre as diferentes arquiteturas, o que de certa forma torna a adoção dessas plataformas bastante atrativa.

O desenvolvimento de algoritmos paralelos é um item de grande importância na computação paralela [HWA87]. Ao se tratar de algoritmos paralelos de ordenação, percebe-se uma abrangente literatura enfocando as mais diversas arquiteturas e ambientes de processamento paralelo, tanto em sistemas distribuídos como em arquiteturas paralelas (alguns desses algoritmos paralelos foram descritos nesta dissertação, visto que são de extrema importância nesse trabalho). 


\subsection{Conclusões Obtidas}

A partir dos resultados obtidos neste trabalho destacam-se as seguintes conclusões:

- De acordo com a análise dos resultados, a melhor plataforma executada em uma máquina paralela SP2 é o IBM MPI, em virtude de oferecer maior desempenho às aplicações paralelas quando comparado ao IBM PVMe, enquanto que em um sistema distribuído, o melhor desempenho é fornecido pela plataforma de portabilidade PVM, visto que as execuções dos algoritmos paralelos foram mais eficientes do que com a utilização do MPICH.

- Segundo a comparação dos tempos de comunicações ponto-a-ponto, o IBM PVMe (executado no SP2) e o PVM (executado no sistema distribuído) apresentam melhor desempenho para transmissões de mensagens grandes, tendo portanto um comportamento similar. Entretanto as diferentes implementações do MPI fornecem comportamentos diferentes, sendo que o IBM MPI apresenta alta eficiência e velocidade nas transmissões das mensagens (envolvendo desde poucos a muitos dados), enquanto que o MPICH mostra-se mais adequado para transmissões de mensagens pequenas e médias;

- Os algoritmos paralelos apresentaram melhores speedups quando executados na máquina paralela SP2, em virtude de disponibilizar de um switch de alto desempenho (altamente adequado para efetuar as comunicações entre os processos paralelos), enquanto que no sistema distribuído não obteve-se praticamente speedups com a execução dos algoritmos paralelos (visto que uma rede Ethernet $10 \mathrm{Mbits}$ oferece pior desempenho em relação ao switch). Portanto, o ambiente computacional distribuído a ser utilizado para a execução das aplicações paralelas deve oferecer uma rede de interconexão de alto desempenho, visto que é um fator de extrema importância para a obtenção de algoritmos mais eficientes;

- Quando se deseja desenvolver um algoritmo paralelo, deve-se considerar o tipo de arquitetura utilizada, escolhendo a aplicação mais adequada (considerando a quantidade 
de comunicações envolvidas no algoritmo) de forma a obter melhores desempenhos. $\underline{O}$ quantidade exçessiva de comunicações pode ser um problema crítico mesmo com a utilização de um switch de alto desempenho (principalmente ao se tratar de algoritmos paralelos de ordenação);

- Além da comunicação, outro fator que influi no desempenho de um algoritmo paralelo é o grau de balanceamento de carga (como foi observado com a execução do algoritmo quicksort paralelo 2, que envolve uma distribuição desbalanceada dos dados entre os processadores e portanto mais adequado ao sistema distribuido e quicksort paralelo 2.l, que distribui os dados aos processadores de maneira mais balanceada, apresentando melhores resultados no SP2). Para tanto, deve-se distribuir as tarefas entre os processadores de acordo com suas capacidades computacionais, não permitindo assim, que processadores fiquem ociosos a espera do término de processamento de algum processador menos veloz ou com maior sobrecarga de trabalho;

- As plataformas executadas no SP2 (IBM MPI e IBM PVMe) oferecem altos desempenhos (principalmente a implementação IBM MPI), entretanto por serem projetadas para ambientes homogêneos, não é possível que seu código fonte seja transportado para outras arquiteturas, perdendo assim sua portabilidade. Porem essa situação não acontece com as plataformas PVM e MPICH, que apesar de oferecerem desempenhos mais modestos em relação as plataformas executadas no SP2, tem como principal vantagem serem ambientes portáteis para diversas arquiteturas diferentes. Portanto, a escolha da plataforma de portabilidade deve ser feita considerando-se as reais necessidades (desempenho $\mathrm{X}$ portabilidade) do usuário.

\subsection{Contribuições deste Trabalho}

Algumas contribuições oferecidas por este trabalho devem ser ressaltadas: 
- Apresenta resultados práticos da utilização das plataformas de portabilidade PVM e MPI quando executadas em uma máquina paralela SP2 e em um sistema distribuído, comparando-se os pontos fracos e fortes de cada ambiente ;

- Constata a veracidade das afirmações discutidas por alguns autores [BOD96][GEI96] que consideram o PVM mais adequado para sistemas distribuídos, enquanto que o MPI melhor se adapta em arquiteturas paralelas;

- O usuário possui informações com as quais pode escolher uma das plataformas de portabilidade analisadas e desenvolver suas aplicações de acordo com seus objetivos;

- Analisa o desempenho das plataformas de portabilidade mais adotadas e que mais se destacam atualmente dentro da comunidade acadêmica;

- Possibilita que os algoritmos paralelos de ordenação implementados neste trabalho sejam executados em um sistema distribuído composto por uma rede de alta velocidade, permitindo a realização de uma análise comparativa entre os resultados obtidos.

\subsection{Dificuldades Encontradas}

Durante o desenvolvimento desse trabalho algumas dificuldades foram encontradas, principalmente relacionadas ao fato de se utilizar ambientes computacionais distintos e de se implementar vários algoritmos paralelos. Podem ser destacadas as seguintes dificuldades encontradas no decorrer desse trabalho:

- A instalação do Sistema Operacional LINUX em algumas máquinas do sistema distribuído, devido de incompatibilidade de hardware (principalmente ao fato do sistema não reconhecer a placa de rede);

- A execução dos algoritmos paralelos na máquina paralela SP2, em virtude de ser utilizada por vários usuários, muitos deles executando programas seriais, que ocasionou na divisão do seu uso em intervalos semanais (entre usuários que executam aplicações 
paralelas e seriais), não possibilitando assim, que as execuções dos algoritmos fossem realizada continuamente;

- A implementação dos algoritmos paralelos, visto que são passiveis de erros e algumas vezes de difíceis diagnósticos. Além disso, por surgirem alguns problemas de compilação e execução quando estes eram transportados do sistema distribuído para a máquina paralela e vice-versa;

- O envolvimento de grande quantidade de números relacionados aos tempos de execuções, que necessitavam ser organizados de modo que se pudesse melhor analisálos (o que implicou na adoção de muitas tabelas e gráficos para serem analisados);

- Poucas documentações referentes às plataformas de portabilidade utilizadas na máquina paralela SP2, o que de certa forma dificultou estudá-las mais profundamente.

\subsection{Sugestões para Trabalhos Futuros}

Alguns trabalhos podem dar continuidade ao desenvolvimento deste trabalho:

- Estudar o comportamento das plataformas de portabilidade PVM e MPI em ambiente Windows 95 (existe uma implementação do PVM desenvolvida pelo grupo de sistemas distribuídos e programação concorrente [SAN96][SOU95]);

- Implementar os algoritmos paralelos de ordenação utilizando outras plataformas, como LINDA, PARMACS, EXPRESS, entre outras;

- Implementar e analisar os algoritmos paralelos em ambientes que possuam grande quantidade de processadores, fazendo-se uma comparação com os resultados obtidos neste trabalho;

- Analisar os resultados obtidos com a execução dos algoritmos paralelos utilizando as plataformas de portabilidade PVM e MPI em arquiteturas diferentes (como em uma 
máquina CRAY e em redes de workstations Sun), verificando a semelhança entre as conclusões;

- Analisar as rotinas de comunicação da implementação IBM MPI, verificando o motivo das variações dos tempos de transmissão de dados (conforme comentado na seção 7.5.1, ocorre um pequeno aumento do tempo de transmissão para quantidades entre $180.000 \mathrm{e}$ $540.000)$

- Avaliar o desempenho dos algoritmos paralelos de ordenação implementados neste trabalho, quando executados em um ambiente distribuído que disponha de uma rede mais eficaz, onde ofereça altas velocidades de transmissões (como uma Ethernet de 100 Mbits);

- Executar os algoritmos paralelos em um ambiente computacional distribuído homogêneo, fazendo-se uma análise comparativa entre os resultados obtidos.

- Desenvolver algoritmos paralelos numéricos para executá-los nos ambientes computacionais utilizados neste trabalho. 


\section{Referências Bibliográficas}

[AIX95] IBM Corporation, "IBM AIX Version 4.1 Technical References", 1995.

[AKL85] AKL, S. G., "Parallel Sorting Algorithms", Academic Press, Orlando, 1985.

[ALM94] ALMASI, G. S.; Gottlieb A., "Highly Parallel Computing", 2". ed., The Benjamin Cummings Publishing Company, Inc., 1994.

[BAT68] BATCHER, K., "Sorting networks and their applications", In Proc. Of the AFIPS Spring Joint Computer Conference, volume 32, pp. 307-314. 1968.

[BIR84] BIRREL, A., B. J. Nelson, "Implementing Remote Procedure Calls", ACM Transactions on Computer Systems, Vol. 2, No. 1, Fevereiro, 1984.

[BLE94] BLECH, R. A., “An overview of parallel processing”, slides, Parallel Computing with PVM Workshop, Nasa Lewis Research Center, 1994.

[BOD96] BODE, A.; DONGARRA, J.; LUDWIG T.; SUNDERAM, V. (Eds.), "Parallel Virtual Machine - EuroPVM'96", Lecture Notes in Computer Science, vol. 1156, Munich, Outubro, 1996.

[BUT94] BUTLER, R. M., Lusk, E. L., "Monitors, messages and clusters: The p4 parallel programming system", Parallel Computing, vol. 20, pp. 547-564, 1994.

[CAR89] CARRIERO, N.; GELERNTER, D., "How to write Parallel Programs: A Guide to the Perplexed", ACM Computing Surveys, vol.21, número 3, September 1989.

[COU88] COULOURIS, G.; DOLLIMORE, J., "Distributed Systems Concepts and Design”, Addison-Wesley Publishing Company, 1988.

[COU94] COULOURIS, G.; DOLLIMORE, J.; KINDBERG, T., "Distributed Systems Concepts and Design", 2. ed., Addison-Wesley Publishing Company, 1994.

[DON95] DONGARRA, J. J., et al, "An introduction to the MPI standard", University of Tennessee Technical Report CS-95-274, http://www.netlib.org/utk/papers/intro-mpi/intro-mpi.html,1995.

[DUA96] DUARTE, M., “Algoritmos Paralelos de Ordenação em Ambientes Heterogêneos", Dissertação de Mestrado, Instituto de Ciências Matemáticas de São Carlos (ICMSC), Universidade de São Paulo, São Paulo (USP), Junho, 1996. 
[DUN90] DUNCAN, R., “A Survey of Parallel Computer Architectures”, IEEE Computer, pp.5-16, Fevereiro, 1990.

[FLY72] FLYNN, M. J., "Some Computer Organizations and Their Effectiveness", IEEE Transactions on Computers, v. C-21, pp.948-960, 1972.

[FLY96] FLYNN, M. J.; RUDD K. W., "Parallel Architectures"; ACM Computing Surveys, vol.28, $\mathrm{n}^{\circ} 1$, pp. 67-70; março de 1996.

[FOS95] FOSTER, Y., "Designing and Bulding Parallel Programs: Concepts and Tools for Parallel Software Engineering", Addison-Wesley Publishing Company Inc., 1995.

[FRA95] FRANKE, H.; WU C. E.; RIVIERE M.; PATTNAIK P.; SNIR M., "MPI programming Environment for IBM SP1/SP2", 15th International Conference on Distributed Computing Systems, Vancouver, British Columbia, Canada, 1995.

[GEI94] GEIST, A.; BEGUELIN, A.; DONGORRA, J.; JIANG, W.; MANCHECK, R.; SUNDERAN, V., "PVM: Parallel Virtual Machine - A User's Guide and Tutorial for Networked Parallel Computing", The MIT Press, 1994.

[GEI96] GEIST, Al, “Advanced PVM Programming Tutorial", Slides, http://www.epm.ornl.gov/pvm/tutorials/euroPVM96, EuroPVM'96, Munich, Outubro, 1996.

[GEI96a] GEIST, Al; KOHL J. A.; PAPADOPOULOS P. M., "PVM and MPI: a Comparison of Features", Calculateurs Paralleles, vol. 8, Maio, 1996.

[GRE91] GREGORY, R. A., "Paradigmas Fr Process Interaction in Distributed Programs", ACM Computing Surveys, vol. 23, numero 1, March 1991.

[GRO98] GROPP, W., Lusk, E., “User's guide for MPICH, a portable implementation of MPI", Argonne National Laboratory, July 6, 1998.

[GRO96] GROPP, W., et al, "A high-performance, portable implementation of the MPI Message Passing Interface standard",

http://www.mcs.anl.gov/mpi/mpich.html, 1996.

[HUA90] HUANG, J.; KLEINROCK, L., "Distributed Selectsort Sorting Algorithms on Broadcast Communication Networks", Parallel Computing, vol. 16, pp. 183 - 190, 1990.

[HU194] LF, HUI; SEVCIK, K. C., "Parallel Sorting by Overpartitioning", Computer -Systems Research Institute, University of Toronto, Canada, 1994. 
[HWA84] HWANG, K.; BRIGGS, F. A., “ Computer Architecture and Parallel Processing", McGraw-Hill, 1984.

[HWA87] HWANG, K., "Advanced Parallel Processing with Supercomputer Architectures", Proceedings of thr IEEE, New York, 1987.

[IBM94] IBM Journal of Researh and Development, "POWER2 e POWERPC Architecture e Implementation", volume 38, número 5, Setembro, 1994.

[IBM95] IBM Corporation, "POWER2: Next Generation of RISC System/6000", página HTML (http://ibm.tc.cornell.edu/ibm/pps/power /power2/index.html), 1995.

[IBM97] IBM Corporation, "RS/6000 SP System", página HTML (http://www.rs6000.ibm.com/hardware/largescale/index.html), 1997.

[KIR89] KIRNER, Cláudio; "Sistemas Operacionais para Ambientes Paralelos", IX Congresso da Sociedade Brasileira de Computação. VIII Jornada de Atualização em Informática. 1989.

[KIR91] KIRNER, C., "Arquiteturas de sistemas avançados de computação", Anais da Jornada EPUSP/IEEE em Sistemas de Computação de Alto Desempenho, pp. 307-353, 1991.

[KIT95] KITAJINA, J.P.F.W., "Programação paralela utilizando mensagens", $X V$ Congresso da Sociedade Brasileira de Computação, XIV Jornada de Atualização em Informática, 1995.

[KLE86] KLEINROCK, L.; DECHTER, R., "Broadcast Communications and Distributed Algorithms", IEEE Transactions on Computers, vol. c-35, numero 3, March 1986.

[LAN96] LANGSAM, Y.; AUGENSTEIN, M. J.; TENENBAUM, A. M., "Data Structure Using C and C+", Second Edition, Prentice-Hall, 1996.

[LOA95] IBM Corporation, “LoadLeveler User's Guide”, Release 2.1, $3^{\circ}$ edição, Agosto, 1995.

[LOO92] LOOTS, W.; SMITH, T.H.C., “A parallel Three Phase Sorting Procedure for a K-dimensional Hypercube and a Transputer Implementation", Parallel Computing, vol. 18, pp. $335-344,1992$.

[MAL96] MALARDM, J., "MPI: A Message Passing Interface Standard. History, Overview and Current Status", página HTML (http://www.epcc.ed.ac.uk/epcc- 
tec/documents/techwatch-mpi/mpi-tw.book_l.html), Edinburgh Parallel Computing Center, Universidade de Edinburgo, 1996.

[MCB94] MCBRYAN, O. A., “An overview of message passing environments", Parallel Computing, v. 20, pp. 417-444, 1994.

[MEY94] MEYER, J., "Message-passing interface for Microsoft Windows 3.1", Msc.

Thesis, Department of Computer Science, University of Nebraska, 1994.

[MOD88] MODI, J. J., "Parallel Algorithms and Matrix Computation", University of Cambridge, february 1988.

[MPI96] MPICH Home Page, http://www.mcs.anl.gov/mpi/mpich.html, 1996.

[MPI95] IBM Coporation, "IBM Parallel Environment for AIX: MPI Programing and Subrotine Reference", 1995.

[MÜL93] MÜLLENDER, S. (ed.), “Distributed Systems", 2a ed., ACM PRESS Frontier Series, Addison-Wesley, 1993.

[NAR96] NARASIMHAN, V. L.; ARMSTRONG J., "Performance Modelling of Three Parallel Sorting Algorithms on a Pipelined Transputer Network", Concurrency: Practice and Experience, vol. 8, pp. 335 - 355, June 1996.

[NAV89] NAVAUX, P. O. A., "Introdução ao processamento paralelo", RBCRevista Brasileira de Computação, v. 5, nํ2, pp.31-43, Outubro, 1989.

[NUP94] NUPAIROJ, N., Ni, L. M., "Performance evaluation of some MPI implementations on workstations clusters", Proceedings of the 1994 Scalable Parallel Libraries Conference, SPLC94, pp. 98-105, 1994.

[POE95] IBM Corporation, "IBM Parallel Environment for AIX: Operation and use", 1995.

[PVMe95] IBM Coporation, "IBM PVMe for AIX User's Guide and Subrotine Reference", 1995.

[QUE94] QUEALY, A, “An introduction to Message Passing”, slides, NASA Lewis Research Center, http://www.lerc.nasa.gov/Other_Groups /IFMD/2620/tutorialPP.html, 1994.

[QUI87] QUINN, M.J., "Designing Efficient Algorithms for Parallel Computers", McGraw Hill, 1987. 
[SAN96] SANTANA, M.J.; SOUZA, Paulo S. L.; SANTANA, R.C.; SOUZA, S.S., "Parallel Virtual Machine for Windows95", Lecture Notes in Computer Science 1156, Springer, 1996.

[SHE95] SHEN X.; ZOLLWEG J., "Notes on the transition from MPI-F to IBM MPI", Cornell Theory Center, http://www.tc.cornell.edu/Smart/Newsletters /MPI.series/transition.html, 1995.

[SKJ94] SKJELLUM, A., et al, "Extending the Message Passing Interface (MPI)", Proceedings of the 1994 Scalable Parallel Libraries Conference, IEEE Computer Society Press, 1994.

[SMI93] SMITH, B., Gropp, W., “Chameleon parallel programming tools users manual”, Technical Report ANL-93/23, Argonne National Laboratory, 1992.

[SMI94] SMITH, S. G., et al, "The design and evolution of Zipcode", Parallel Computing, vol. 20, pp. 565-596, 1994.

[SNI96] SNIR M.; OTTO S.; HUSS-LEDERMAN S.; WALKER D.; DONGARRA J., "MPI: The complete Reference", the MIT Press, London, England, 1996.

[SNO92] SNOW, C.R., "Concurrent Programming", Cambridge University Press, 1992.

[SOU95] SOUZA, P.S. L. de, "Máquina Paralela Virtual no Ambiente Windows", Dissertação de Mestrado, Instituto de Ciências Matemáticas de São Carlos (ICMSC), Universidade de São Paulo, São Paulo (USP), Junho, 1995.

[SOU96] SOUZA, M.A. de, "Avaliação das Rotinas de Comunicação Ponto-a-Ponto do MPI", Dissertação de Mestrado, Instituto de Ciências Matemáticas de São Carlos (ICMSC), Universidade de São Paulo, São Paulo (USP), Dezembro, 1996.

[SUN94] SUNDERAM, V. S.; GEIST, G.A.; DONGARRA, J.; MANCHEK, R., "The $P V M$ concurrent computing system: evolution, experiences and trends", Parallel Computing, v. 20, pp. 531-545, 1994.

[STE90] STEVENS, W. R., "UNIX Network Programming”, Prentice Hall,1990.

[TAN88] TANENBAUM, A. S., “Computer Networks", 2" ed., Prentice Hall International Inc., 1988.

[TAN92] TANENBAUM, A. S., "Modern Operating Systems", 2". ed., Prentice Hall International Inc., 1992. 
[TAN95] TANENBAUM, A. S., "Distributed Operating Systems". · Prentice Hall International Inc., 1995.

[UML94] UMLAND, T., "Parallel Sorting Revisited", Parallel Cómputing, vol. 20,.pp. 115 - 124, 1994.

[WAL94] WALKER, D. W., "The design of a standard message passing interface for distributed memory concurrent computers", Parallel Computing, vol. 20, pp. 657-673, 1994.

[WAL95] WALKER, D.W., "MPI: From fundamentals to applications", Oak Ridge National Laboratory, http://www.epm.ornl.gov/ walker/mpi /SLIDES/mpitutorial.html, 1995.

[WEL95] WELSH, M., "Linux Installation and Getting Started", 1995.

[WEN96] WEN Z., "Multiway Merging in Parallel", IEEE Transactions on Parallel and Distributed System, vol. 7, número 1, January 1996.

[WIL87] WILBUR, S., Bacarisse B., "Building Distributed Systems with Remote Procedure Call”, Software Engineering Journal, Setembro, 1987.

[ZAL91] ZALUSKA E. J., "Research lines in distributed computing systems and concurrent computation", Anais do Workshop em Programação Concorrente, Sistemas Distribuídos e Engenharia de Software, pp. 132-155, 1991. 